UNIVERSIDADE DE SÃO PAULO

ESCOLA DE COMUNICAÇÕES E ARTES

CLARISSA RIBEIRO PEREIRA DE ALMEIDA

Instantes de Metamorfose:

o coletivo como processo; o processo como sistema 



\title{
Instantes de Metamorfose: \\ o coletivo como processo; o processo como sistema
}

\author{
versão corrigida
}

(original se encontra disponível na Unidade que aloja o programa)

\begin{abstract}
Tese apresentada à Escola de Comunicações e Artes da Universidade de São Paulo para obtenção do título de Doutor em Artes Visuais.

Área de Concentração: Poéticas Visuais

Orientador: Prof. Dr. Gilberto dos

Santos Prado
\end{abstract}

São Paulo

2011 
Autorizo a reprodução e divulgação total ou parcial deste trabalho, por qualquer meio convencional ou eletrônico, para fins de estudo e pesquisa desde que citada a fonte.

\section{Catalogação na publicação Serviço de Biblioteca e Documentação \\ Escola de Comunicações e Artes da Universidade de São Paulo}

Almeida, Clarissa Ribeiro Pereira de

Instantes de metamorfose : o coletivo como processo ; o processo como sistema / Clarissa Ribeiro Pereira de Almeida - São Paulo : C. R. P. Almeida, 2011

$240 p+i l$

Tese (Doutorado) - Escola de Comunicações e Artes / Universidade de São Paulo.

Orientador: Prof. Dr. Gilberto dos Santos Prado

1. Arte digital 2. Criação artística 3. Sistemas complexos adaptativos. I. Prado, Gilberto dos Santos II. Título.

CDD 21.ed. - 709.0408 
NOME: ALMEIDA, Clarissa Ribeiro Pereira de

TíTULO: Instantes de metamorfose: o coletivo como processo; o processo como sistema

Tese apresentada à Escola de

Comunicações e Artes da Universidade de

São Paulo para obtenção do título de

Doutor em Artes Visuais.

Aprovado em:

\section{Banca Examinadora}

Prof. Dr. Instituição:

Julgamento: Assinatura:

Prof. Dr. Instituição:

Julgamento: Assinatura:

Prof. Dr. Instituição:

Julgamento: Assinatura:

Prof. Dr. Instituição: Julgamento: Assinatura:

Prof. Dr. Instituição: Julgamento: Assinatura: 

Ao acaso. 


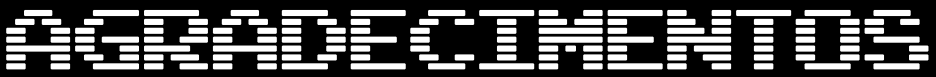

Nesses anos em que se desenvolveu a pesquisa, muitas pessoas, dentro e fora dos círculos acadêmicos, foram importantes. Essas pessoas participaram de um processo que implicou, para além da pesquisa, a transformação daquele que observa e que vai tecendo, nessas relações, redes invisíveis de significado.

Ao professor Gilbertto Prado, agradeço pela maneira com que transformou conversas informais em momentos de aprendizado e orientação. Agradeço por saber compartilhar, nessas conversas randômicas, um intenso envolvimento com o processo criativo em artes digitais, desvelando uma vasta rede de conexões para além desses domínios.

Aos colegas do grupo Poéticas Digitais, com os quais trabalhei durante os três anos de pesquisa em que estivemos juntos, pelas trocas, pelo apoio, e pela amizade. Em especial aos amigos Luis Bueno, Maurício Taveira, Tatiana Travisani, e às professoras Silvia Laurentiz e Tânia Fraga. 
Ao professor Roy Ascott, orientador da pesquisa no exterior, agradeço pela serenidade e inteligência com que influenciou e participou dos processos de aprendizado no Planetary Collegium. Agradeço ainda por traduzir em tutoriais e momentos informais de trocas, um universo de saberes que conecta todos os saberes, todos os tempos, atravessando sujeitos e realidades.

Aos colegas do CAiiA-Hub e do Milano Node do Planetary Collegium, com os quais compartilhei os dias de imersão nas sessões compostas, por se envolverem intensamente, permitindo um entrelaçamento entre as pesquisas individuais. Agradeço por saberem ver além, e estarem abertos à construção de olhares em conjunto. Em especial, agradeço aos amigos Amos Bianchi, Jennifer Kanary Nikolov(a), e ao professor Pier Luigi Capucci. 
À CAPES - Coordenação de Aperfeiçoamento de Pessoal de Nível Superior, pelo apoio financeiro à pesquisa, através da concessão da bolsa de Demanda Social, via Programa de Pós-Graduação em Artes Visuais da Escola de Comunicações e Artes da Universidade de São Paulo, e da bolsa do Programa de Doutorado no País com Estágio no Exterior.

À artista e pesquisadora Luisa Paraguai Donati, agradeço pela amizade, pelo carinho e por ajudar a construir uma rede de conexões entre artistas, pesquisadores, realidades, descobrindo afinidades, novos espaços e novos amigos com os quais dialogar.

Ao artista e pesquisador Guto Nóbrega, por compartilhar uma visão transcendente de pesquisa em artes visuais, que ajudou a entender as várias camadas de significado e referências nos processos criativos. Agradeço ainda, pelo acolhimento na chegada à Plymouth pela amizade e a energia que traduzem uma grande afinidade.

Aos professores e colegas do Transtechnology Research, em especial ao Professor Michael Punt e aos colegas Claudy Op Den Kamp, Hannah Drayson, Joanna Griffin, John Vines e Amanda Egbe, agradeço pela abertura e interesse em discutir a presente pesquisa, incentivando a integração e participação ativa nas dinâmicas do grupo. Agradeço, sobretudo, pela amizade no convívio em nosso ambiente de trabalho no laboratório i-DAT.

Aos queridos Anas Sattar, Claudy Op Den Kamp, Jacques Chueke, João Gomes, Robin Read, e Fernanda e Marcelo Gimenes, pelas trocas que vão além dos universos individuais de pesquisa, fazendo dialogar a robótica e as neurociências, a música, o cinema, a biomedicina, a linguística, o design e as artes visuais. Agradeço, sobretudo, pela amizade nos dias que compartilhamos em Plymouth.

À profa Anja Pratschke, pela abertura à interlocução e por compartilhar experiências impressões, vivências, sempre estimulando a buscar novas entradas, novos caminhos. Agradeço por incentivar a construção de pontes entre as pesquisas que orienta, aproximando pesquisadoras como Renata La Rocca e Graziele Lautenschlaeger, com as quais pude dialogar no processo de desenvolvimento dos primeiros trabalhos do coletivo O Duplo.

Ao professor Nelson Fiedler-Ferrara do Instituto de Física da USP, agradeço pelas orientações em conversas informais e pela abertura e interesse em contribuir. Agradeço, sobretudo, por 
ter ajudado a construir uma visão transdisciplinar para os processos criativos a partir da complexidade.

À Renata La Rocca, agradeço a amizade incondicional e a parceria em todos os momentos, que foram instantes de metamorfose - momentos de descoberta, de aprendizado, de sonhos compartilhados.

À Graziele Lautenschlaeger, pela amizade e pelas trocas que ajudaram a materializar ideias, a entender processos em que os sujeitos se transformam nas e pelas ideias.

Ao Norberto, à Conceição e à Candice e Luiza, pelo incentivo e carinho incondicionais que desconstroem as distâncias.

Aos queridos amigos Fábio Abreu, Ralf Flores e Isabella Flores, pelo apoio, incentivo e carinho incondicionais.

Aos alunos, que se tornaram amigos, em especial a Ana Carolina Ramos, Danilo Ricardo da Silva, Leandro Barroso, Moacyr Marangoni, Nayara Laurindo e Philipe Guedes, por construírem em conjunto, um mundo de experiências compartilhadas que podem caber, coloridas, em muros nas ruas das cidades, em conversas online, numa música da Lady Gaga.

Aos colegas, funcionários e diretores da Faculdade de Administração e Artes de Limeira, pelo incentivo e amizade durante os anos em que trabalhamos juntos. Em especial, ao Professor Sebastião Orlando da Silva, in memoriam.

Ao Bartolomeu Júnior, pela amizade, pela confidência e carinho em nossas intermináveis conversas online.

Aos meus caros amigos de Londres, Eduardo Cançado, Sharon Bagge e, em especial, ao Luis Felipe Carvalho, por me acolherem. Agradeço por compartilharem fantásticas aventuras em uma cidade que existe através de espelhos com molduras Vitorianas, além da imaginação de Alexander McQueen.

São Paulo, Janeiro de 2011 


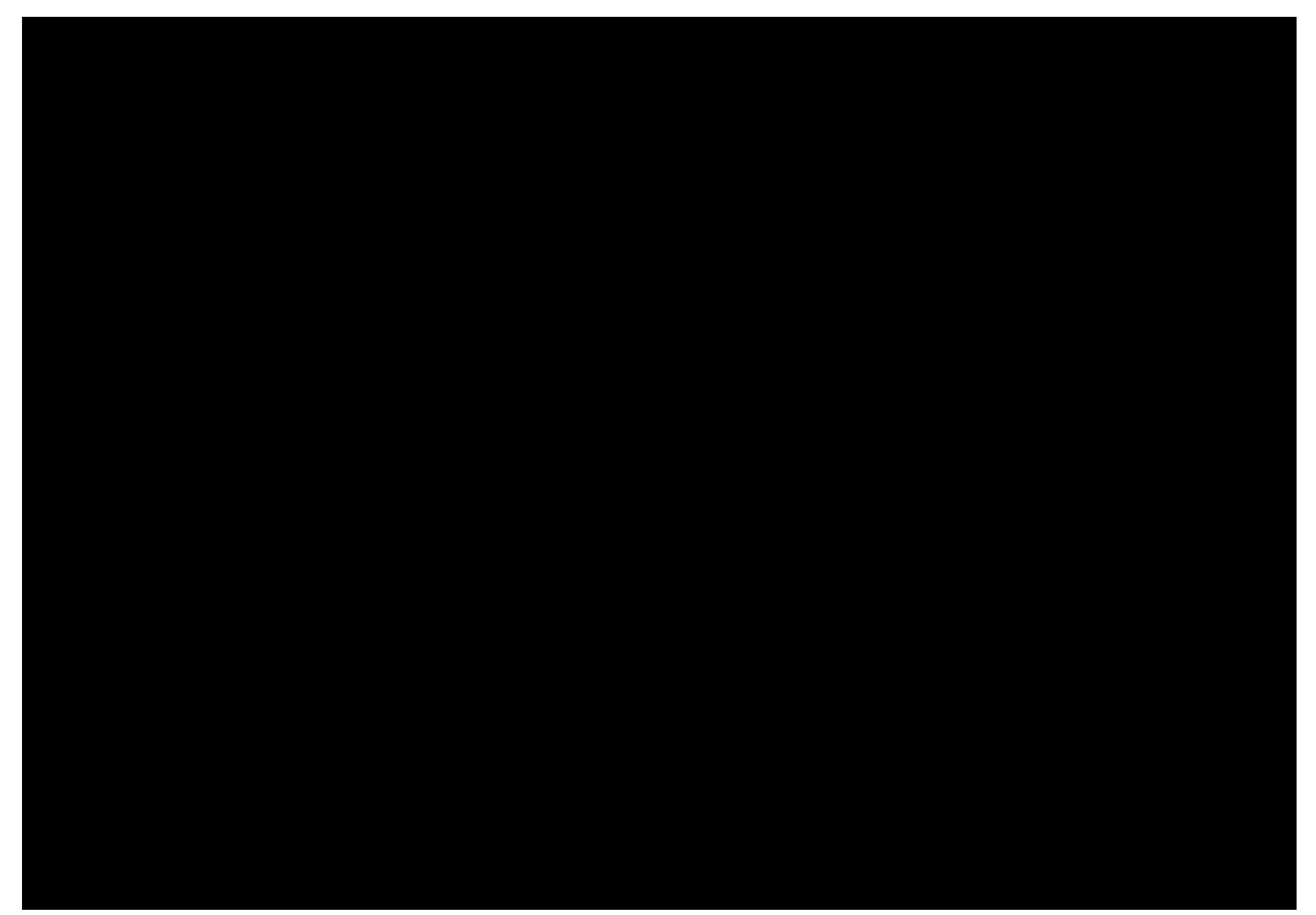


Fixo instantes súbitos que trazem em si a própria morte e outros nascem - fixo os instantes de metamorfose e é de terrível beleza a sua seqüência e concomitância.

Clarice Lispector, Água Viva, p.13 


\section{Resumo}

O trabalho coletivo em artes digitais define uma prática que implica a interação de diversos atores em processos de criação que podem ter características generativas. Na presente tese, propomos a construção de um olhar a partir da complexidade para estudar esses processos como sistemas complexos adaptativos. A especificidade está relacionada ao conceito de espaços estoricizados - artifício para desenhar uma rede de significados emergentes, a partir das inter-relações entre os elementos do sistema. A adoção dessa perspectiva implica a integração da auto-observação ao sistema, dando ao complexo auto-organizado, visibilidade de si - partindo do fluxo de informações para a construção de memórias e imagens transitórias, no limiar entre impressão e imaginação.

Palavras-chave: Processo criativo coletivo em artes digitais. Sistemas complexos adaptativos. Espaços estoricizados. Auto-organização. Emergência. 


\begin{abstract}
Collective work in digital arts defines a practice, which entails an interaction of various actors in creative processes, which may have generative features. In the current theses, we propose the construction of a point of view from complexity to study these processes as complex adaptive systems. The specificity in this work is related to the concept of storied spaces - an artifice to design a network of emergent meanings from the inter-relations amongst elements of the system. The adoption of this standpoint implies integrating self-observation into the system, granting visibility of itself to the selforganizing complex - from the flow of information to the construction of memories and transitory images on the threshold between impression and imagination.
\end{abstract}

Key words: Collective creative processes in digital arts. Complex adaptive systems. Storied spaces. Self-organization. Emergence. 


\section{Sumário}

\section{Introdução | 18}

A prática coletiva em artes digitais | 22

O olhar a partir da complexidade | 25

\section{Capítulo 01: Espaços Estoricizados | 28}

1.1. Arte e complexidade: reestruturando processos | 31

1.2. Espaços Estoricizados | 35

1.3. Informação e significado: a dinâmica do complexo organizado | 39

\section{Capítulo 02: O que é tecido em conjunto $\mid 44$}

2.1. A complexidade como artifício 47

2.2. Do objeto ao sistema $\mid 50$

2.3. Sistemas de Sistemas $\mid 51$

2.4. Ordem-desordem-organização| 53

2.5. Os fenômenos emergentes $\mid 59$

2.6. Entrelaçamento quântico e Decoerência | 66

2.7. Nos domínios da Interação Quântica | 75

2.8. Sistemas de Sistemas ou o Complexo Adaptativo | 79

\section{Capítulo 03: O Processo Criativo como Sistema | 82}

3.1. O método da complexidade; a complexidade como método | 86

3.2. Fios e tessitura | 91

3.3. O complexo generativo: informação e morfogênese | 92

3.4. Da Impressão à imaginação | 99

3.5. Níveis de Percepção e Realidade | 107

3.6. Colecionando narrativas: testando a dinâmica | 112

Capítulo 04: Um olhar sistêmico para o processo criativo em artes digitais | 118

4.1. O boom telemático: Entrelaçados, Hibridizados, Múltiplos | 121

4.2. Sistemas de Sistemas: a dinâmica da datapoo/ | 123

4.3. O olhar para o complexo: Estudo de Caso - O Coletivo Transmute | 124 
4.4. Grounded Light (2003) | 127

4.5. Shifting Intimacies (2006) | 130

4.6. Coletivo Transmute: o coletivo como processo; o processo como sistema | 135

4.6.1. Liquid Gold (2001) | 136

4.6.2. Transact (Flesh/Skin/Bone) (2002) | 137

4.6.3. Intimate Transactions: primeira versão | 139

4.6.4. Intimate Transactions: versão multiusuário | 147

4.7. O Modelo Úmido | 157

4.8. Transmute: complexidade e organização | 160

Capítulo 05: Instantes de Metamorfose: participação em práticas artísticas | 162 5.1. Poéticas Digitais | 166

5.1.1. Vídeo-poema Incógnito | 166

5.1.2. Pedralumen | 168

5.1.3. Des/uz | 170

5.2. Série Instantes de Metamorfose: a construção de um metapontodevista | 173

5.2.1. Coletivo O Dup/o: Formação Inicial | 174

5.3. Instantes de Metamorfose: desenvolvimentos iniciais | 175

5.4. Série Instantes de Metamorfose: versão $01 \mid 182$

5.5. Instantes de Metamorfose: Espaços Estoricizados | 190

5.6. Série Instantes de Metamorfose: versão O2 | 194

5.7. Série Instantes de Metamorfose: complexidade e organização | 199

\section{Considerações Finais | 202}

Espaços Estoricizados | 204

Transcendendo as fronteiras disciplinares: da ordem a partir do ruído, ao entrelaçamento quântico | 206

O Modelo Úmido | 208

A construção do Metapontodevista | 209

Desdobramentos Futuros | 211

Referências | 212

Iconografia | 229

Anexos | 232 


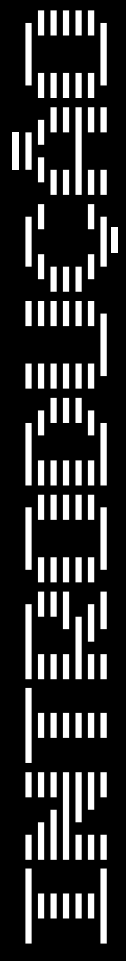




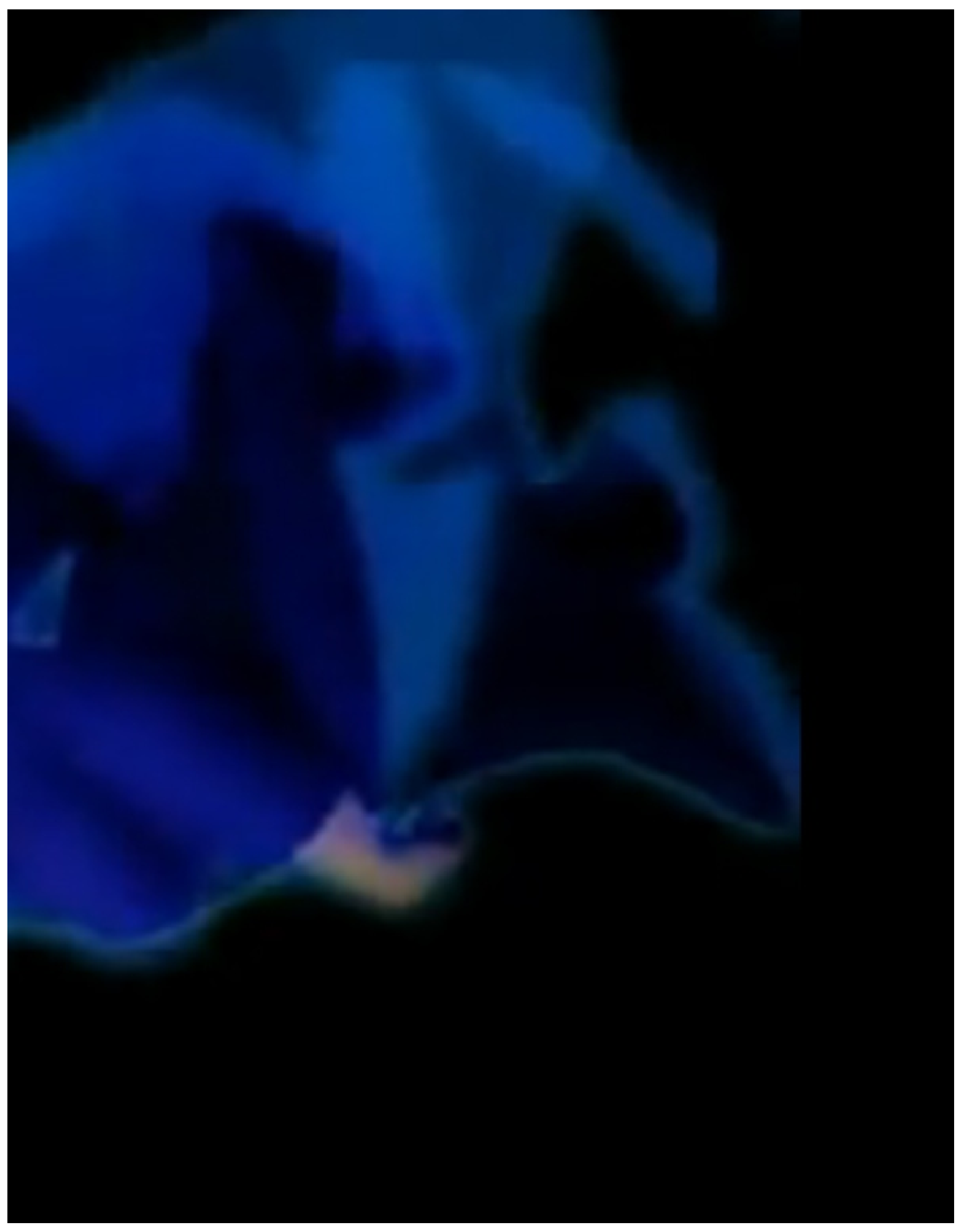


Partimos da compreensão de que não há, a partir de uma perspectiva das ciências da complexidade, e de um pensar complexo, como produzir conhecimento inovador, sem re-integrar a auto-observação ao sistema. Na presente Tese, a observação é concebida como parte do próprio processo, no nosso caso, o processo criativo coletivo em artes digitais. É dessa forma que o processo de pesquisa traz a aceitação da circularidade e da complexidade na aproximação ao objeto de estudo.

Na construção deste que é um metapontodevista, o observador se transforma na e com a observação - observador-sistema de um complexo de sistemas de sistemas. A observação se transforma em realidades, em poéticas, nos sujeitos e seus múltiplos Eus, no Nós e nos Outros. É essa a beleza sutil de um balé morfogenético. 
Discutir o que alguém está fazendo, mais que o trabalho artístico resultante, tentar desvendar os loops da atividade criativa, é, em muitos aspectos, um problema comportamental. A fusão de arte, ciência e personalidade está envolvida. Isso leva a uma consideração de nosso relacionamento total com um trabalho artístico, no qual movimentos físicos podem levar a movimentos conceituais, no qual Comportamento se relaciona à ideia... Um organismo é mais eficiente quando ele conhece a sua própria ordem interna."

Roy Ascott $^{2}, 1964$

A partir dessa perspectiva inclusiva, a complexidade se apresenta como artifício para conectar conhecimentos das ciências - nomeadamente a biologia, a físico-química, a física quântica -, a conhecimentos no âmbito das ciências sociais, da filosofia e da metafísica. A partir dessas diversas áreas, as referências se combinam em uma teia tecida no e pelo pensamento e prática em artes visuais, onde os trabalhos artísticos podem ser considerados como produtos das inter-relações entre os sujeitos, entre os sujeitos e o todo sistêmico, e desses com o ambiente.

\footnotetext{
Do original em inglês: "To discuss what one is doing rather than the artwork which results, to attempt to unrave the loops of creative activity, is, in many ways, a behavioural problem. The fusion of art, science and personality is involved. It leads to a consideration of our total relationship to a work of art, in which physical moves may lead to conceptual moves, in which Behaviour relates to idea... 'An organism is most efficient when it knows its own internal order.' " (ASCOTT 1964 apud LIPPARD 1997, p.1)

${ }^{2}$ ASCOTT, Roy. The construction of change. Cambridge Opinion, 37, jan. 1964.
} 


\section{A prática coletiva em artes digitais}

Apesar de ser observável na prática em artes digitais desde os primórdios, na década de 1980, é cada vez mais comum ver obras criadas coletivamente denominadas como partes de uma série - 001, 002, versão 1, versão 2, etc.. Um exemplo pioneiro é a série Points of View de Jeffrey Shaw, produzida entre 1983 e 1984. Os três trabalhos da série constituíam uma espécie de teatro de signos (SHAW, 2011a, tradução nossa) onde o palco e os protagonistas eram gerados por computação gráfica e projetados sobre uma grande tela em frente à audiência. Na ação controlada utilizando joysticks especiais, um membro qualquer da audiência poderia mover-se interativamente no ambiente virtual projetado $-360^{\circ}$ (trezentos e sessenta graus) ao redor do palco, 90 (noventa graus) para cima e para baixo, indo do térreo à vista aérea. No primeiro trabalho da série, Points of View l: Computergraphic installation, de 1983, a representação dos atores no palco foi derivada do antigo alfabeto Egípcio, onde cada figura era um caractere hieróglifo. Como explica Shaw, "essa constelação de signos foi utilizada para articular um modelo de mundo com uma subjacente relação de relacionamentos físico e conceitual." (SHAW, 2011a, tradução nossa)

O segundo trabalho da série, Points of View II - Babel, também desenvolvido em 1983, incorpora questões relacionadas à Guerra das Malvinas - conflito entre Argentina e Reino Unido, no ano de 1982. Como explica Shaw, o trabalho "[...] implementou estruturas funcionais e iconográficas que eram similares a Points of View I. Os hieróglifos egípcios foram usados para articular ambas, uma arquitetura visual e psicológica - um edifício hierárquico definido para identificar a patologia essencial do poder e sua inevitável predisposição para opressão e guerra." (SHAW, 2011b, tradução nossa)

Nessa segunda emergência da série, o som constituía um aspecto integral da instalação. Um total de 13 (treze) textos falados, extraídos do Congresso de Psicologia Militar, realizado em Viena no ano de 1983, foram ligados interativamente à imagem através do mesmo joystick que controlava o movimento virtual do usuário. Funcionando com um

\footnotetext{
${ }^{3}$ Do original em inglês: "This constellation of signs was used to articulate a world model with an underlying set of physical and conceptual relationships." (SHAW, 2011a)

${ }^{4}$ Do original em inglês: "[...] It implemented functional and iconographic structures that were similar to Points of View I. Egyptian hieroglyphs were used to articulate both a visual and psychological architecture - a hierarchical edifice that set out to identify the essential pathology of power and its inevitable predisposition to oppression and warfare." (SHAW, 2011b)
} 
misturador de áudio, esse joystick modulava as várias vozes, em função de diferentes posições espaciais do usuário, em relação ao ambiente virtual. Dessa forma, cada pessoa que interagia, tinha a oportunidade de criar uma jornada audiovisual pessoal. Nas considerações de Shaw, a mudança das faixas de som, gerando um confronto espontâneo de informação falada, "[...] em conjunção com o movimento visual em torno da imagem, expôs as relações significantes dessa zigurate hieroglífica." ${ }^{5}$ (SHAW, 2011b, tradução nossa)

O terceiro trabalho da série, Points of View III - A Three Dimensional Story, explorava a ideia de uma obra capaz de estimular a audiência a participar ativamente na construção final do trabalho artístico, convidando 16 (dezesseis) pessoas a fazer contribuições narrativas. Essas contribuições eram interativamente ligadas à cenografia visual na qual essa audiência poderia navegar entre estórias paralelas. Participaram do processo coletivo de desenvolvimento dos três trabalhos da série Points of View, Larry Abel, responsável pelos desenvolvimentos relativos a software, e Tat Van Vark e Charly Jungbauer, responsáveis pelas questões relacionadas a hardware. Em uma reconstrução de Points of View I, em 1999, Torsten Ziegler foi o responsável pelos desenvolvimentos relativos a software e Armin Steinke a hardware.

A consideração de trabalhos de arte digital, realizados coletivamente, como parte de uma série, evidencia a intenção de assumir a prática como um processo. De um modo geral, as séries mostram de que forma o dominar uma tecnologia específica, combinado à adoção de uma moldura conceitual particular, evolui em um processo de trabalho de base coletiva. Esse processo se estrutura a partir de uma intensa troca de informações, que liga os diversos níveis organizacionais de um todo que pode ter características complexas. Um exemplo contemporâneo que pode ser referido é a série de Camille Utterback, External Measures (2003). A série começou a partir da tentativa de criar pinturas interativas, e evoluiu na medida em que a artista, trabalhando coletivamente, "[...] experimenta com as possibilidades de articular sistemas computacionais com movimentos humanos." ${ }^{6}$ (UTTERBACK, 2010, tradução nossa)

\footnotetext{
${ }^{5}$ Do original em inglês: "[...] in conjunction with the visual movement around the image exposed the signifying relationships of this hieroglyphic ziggurat." (SHAW, 2011b)

${ }^{6}$ Do original em inglês: "[...] experiments with the possibilities for hinging computational systems to human movement." (UTTERBACK, 2010)
} 
Outro exemplo é o trabalho Intimate Transactions do coletivo Transmute. O Coletivo, que se estabeleceu em 1998, começou a desenvolver Intimate Transactions em 2001. Existem dois projetos-piloto iniciais que fixaram as bases para futuros desenvolvimentos relacionados diretamente a essa obra - Liquid Gold (2001) e Transact (Flesh/Skin/Bone) (2002). De acordo com o diretor artístico Keith Armstrong, o coletivo "[...] decidiu que o núcleo de seu projeto interativo, computacional, seria inspirado pelos fluxos energéticos dentro de ecologias descritas cientificamente (por exemplo, os fluxos de energia que se originam do sol/fotossíntese e que são intercambiados via consumo e decomposição)."” (ARMSTRONG, 2006, p.16, tradução nossa)

Na proposta do coletivo, emergindo do conceito de uma imagem de campo total relacional, a colaboração e a ação coletiva se tornam elementos chave de uma práxis ecosófica. Com esse objetivo, foram adotadas abordagens capazes de dar à audiência a oportunidade de uma experiência compartilhada, interação social e discussão em torno de questões ecológicas prementes.

Ao longo de quatro anos de trabalho coletivo, Intimate Transactions evoluiu a partir de uma instalação local e não baseada em rede, para um trabalho artístico multi-local, articulado por um servidor, projetado para dois ou mais participantes em rede. Foi dessa forma que, segundo o diretor artístico Keith Armstrong (ARMSTRONG, 2006, p.33), a interatividade da audiência, o engajamento ecológico e a colaboração, foram estendidos para produzir uma complexa experiência relacional.

As experiências aqui referidas nos dão um ponto de partida para discutir a perspectiva que propomos no presente trabalho - a de estudar o processo criativo coletivo em artes digitais a partir da complexidade, da adoção de uma perspectiva sistêmica.

\footnotetext{
7 Do original em inglês: "[...] decided that the core of their interactive, computational design would be inspired by the energetic flows within scientifically described ecologies (for example the flows of energy that originate from the sun/photosynthesis and are subsequently exchanged via consumption and decomposition)." (ARMSTRONG, 2006, p.16)
} 


\section{O olhar a partir da complexidade}

As questões abordadas pelas ciências da complexidade se desenvolveram e estruturaram a partir de pesquisas em diversos campos disciplinares. Entre estes, são de importância central, os trabalhos em cibernética nos anos 1940. Esses trabalhos foram basilares para as pesquisas em Teoria Geral dos Sistemas na década de 1950, para os trabalhos envolvendo Caos e a Teoria da Catástrofe nas décadas de 1960 e 1970, e para as investigações contemporâneas sobre Sistemas Complexos Adaptativos ${ }^{8}$, lideradas por grupos de pesquisa como o Santa Fe Institute ${ }^{9}$.

Nesse contexto, que estimula uma espécie de miscigenação disciplinar, consideramos pertinente perguntar, a exemplo de Barbara Bolt, se seria possível postular uma teoria da prática capaz de contribuir para entender processos criativos coletivos em artes digitais como processos generativos. Bolt (2004) acredita que, para discutir o caráter generativo de qualquer prática artística, devemos, antes de tudo, compreender as implicações do que chama de uma lógica gerativa. Para além desse exercício de compreensão, acreditamos ser relevante o esforço de elaboração de perspectivas que ajudem a observar, teorizar, a construir em conjunto projetos e experiências artísticas. É essa intenção que moveu a pesquisa realizada nesses quatro anos em que estruturamos um olhar a partir da complexidade, para os processos criativos coletivos em artes digitais.

Articulando as questões aqui apresentadas, em torno do objetivo central da pesquisa, a presente Tese se estrutura nos seguintes capítulos:

\section{Capítulo 01: Espaços Estoricizados}

A abordagem do presente capítulo traz a ideia de espaços gerados por ações, pelo fluxo de informações de um nível para outro, em estruturas multi-nível como os sistemas complexos. Partimos dessa perspectiva, para refletir sobre os espaços como construções a partir de ações de entidades vivas, em processos de percepção, memória, imaginação,

${ }^{8}$ Do termo em inglês: CAS - Complex Adaptive Systems

${ }^{9}$ O Santa Fe Institute é um centro privado de educação e pesquisa estruturado como uma organização

independente e sem fins lucrativos. Foi fundado em 1984 para colaboração multidisciplinar nas ciências físicas, biológicas, computacionais e sociais, considerando a compreensão dos sistemas complexos adaptativos como fundamental para confrontar os desafios ambientais, tecnológicos, biológicos, económicos, e políticos. (SANTA FE INSTITUTE, 2011) 
até manifestarem-se como estruturas estoricizadas. O objetivo é contribuir para um estudo da lógica generativa dos processos criativos coletivos em artes digitais.

\section{Capítulo 02: O que é tecido em conjunto}

Neste capítulo, apresentamos ideias que ultrapassam os domínios específicos de suas áreas de conhecimento originais, como as noções de ordem a partir do ruído, autopoiese, emergência e entrelaçamento quântico. O objetivo é construir uma perspectiva a partir da qual seja possível estudar o processo criativo coletivo em artes digitais como fenômeno emergente, em um diálogo que transcende as fronteiras disciplinares.

\section{Capítulo 03: O Processo Criativo como Sistema}

Neste capítulo, nos dedicamos à construção de um modelo, a partir das referências conceituais das ciências da complexidade, como forma de dar ao sistema visibilidade de si. A proposta incorpora a dinâmica de colecionar e inter-relacionar espaços estoricizados, gerados no e pelo processo de auto-organização sistêmico. O objetivo é contribuir para visualizar o sistema, que é o processo criativo coletivo em artes digitais, como estrutura dinâmica, mutante, metamórfica.

\section{Capítulo 04: Um olhar sistêmico para o processo criativo em artes digitais}

Nesse capítulo, trazemos a perspectiva do modelo proposto no capítulo anterior, para discutir o processo criativo coletivo em artes digitais, como sistema complexo adaptativo. Essa perspectiva é considerada como entrada para discutir a complexidade e a organização no estudo de caso, onde analisamos o trabalho do coletivo Transmute.

\section{Capítulo 05: Instantes de Metamorfose: participação em práticas artísticas}

Esse capítulo se estrutura como um relato do envolvimento da autora em práticas artísticas coletivas. Desde o envolvimento em trabalhos desenvolvidos pelo grupo Poéticas Digitais, até a participação no coletivo O Duplo, a necessidade de envolvimento com a prática artística, está implícita na pesquisa como forma de integrar a autoobservação ao sistema. Esse esforço implica a construção de um ponto de vista, que permita observar o conjunto constituído pelo observador e sua observação. 


\section{Considerações Finais}

As considerações finais constituem uma reflexão sobre as potencialidades trazidas por um pensar complexo, nos exercícios de teorizar e integrar práticas artísticas coletivas em artes digitais. Estas reflexões podem se apresentar como lentes para observar essas práticas. Simultaneamente, elas podem permitir aos sujeitos envolvidos em processos criativos, entenderem-se como elementos ativos em complexos organizacionais. Dessa forma, articulamos nessas considerações, algumas ideias centrais que atravessam todas as instâncias da pesquisa realizada, e que convergiram na abordagem da presente tese.

Em todos os capítulos que compõem a tese, a motivação foi a da construção de um olhar a partir da complexidade para os processos criativos coletivos em artes digitais. Essa perspectiva convida a ir além, discutindo o caráter generativo das práticas artísticas coletivas, e as potencialidades trazidas por um pensar complexo, nos exercícios de teorizar e integrar essas práticas. 


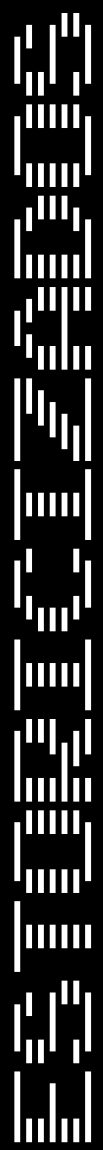

$\mid$

IIIIIII

$\left.\right|_{I^{I I I}} ^{\mid}$

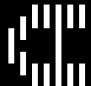

1111

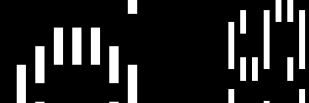

IIIIIIIII 


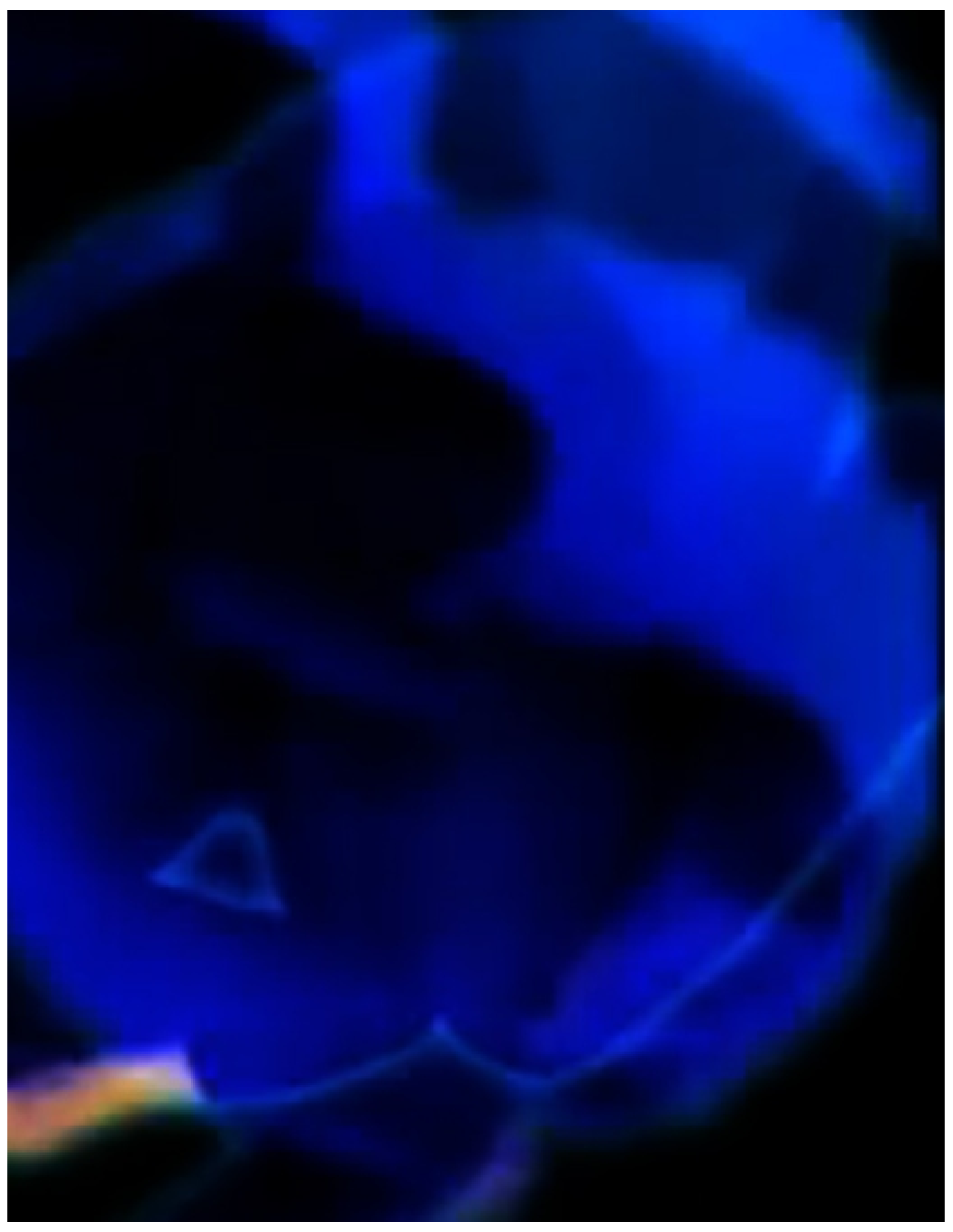


A abordagem do presente capítulo traz a ideia de espaços gerados por ações, pelo fluxo de informações de um nível para outro, em estruturas multi-nível como os sistemas complexos. É dessa perspectiva que partimos para refletir sobre os espaços como construções, a partir de ações de entidades vivas, em processos de percepção, memória, imaginação, até manifestarem-se como estruturas estoricizadas. O objetivo é contribuir para um estudo dos processos criativos coletivos em artes digitais. Esses processos envolvem a interação de sujeitos em dinâmicas que podem ter características generativas. 
Se o objeto singular deve ser ambos utópico e destrutivo, orientado ao futuro e refinadamente representativo do presente, ele será um objeto particular de fato. Esse modelo não será nem arquitetura nem filosofia separadamente, como praticado tradicionalmente, mas um produtivo desdobramento de um no outro - um evento mais que um objeto, uma operação de construção em que cada discurso interpreta outro mas, no entanto, produz uma coisa nova, irredutível, singular: essa coisa peculiar que chamamos de teoria.

Michael Hays, 2002, p.VIII

\subsection{Arte e complexidade: reestruturando processos}

A perspectiva sistêmica, assim como o universo conceitual da cibernética e da teoria da informação, está na gênese de uma arte conceitual que floresce na década de 1960, e ganha força e visibilidade internacional nas duas décadas seguintes. Se referindo à arte conceitual das décadas de 1960 e 1970, Lucy Lippard afirma que, "[...] para artistas procurando reestruturar a percepção e o relacionamento processo/produto da arte, informação e sistemas substituíram as tradicionais preocupações formais de composição, cor, técnica, e presença física."2 (LIPPARD, 1997, p.XV, tradução nossa).

${ }^{1}$ Do original em inglês: "If the singular object is to be both utopian and destructive, future directed and exquisitely representative of the present, it will be a particular object indeed. Its model will be neither architecture nor philosophy freestanding, as traditionally practiced, but a productive enfolding of one into the other - an event more than an object, a constructional operation in which each discourse interprets the other but nevertheless produces a new, irreducible, singular thing: that peculiar thing we call theory." (HAYS, 2002, p.VIII)

${ }^{2}$ Do original em inglês: "For artists looking to restructure perception and process/product relationship of art, information and systems replaced traditional formal concerns of composition, colour, technique, and physical presence." (LIPPARD 1997, p.xv) 
A arte se torna sistêmica, informacional, processual. O objeto da arte se desmaterializa ${ }^{3}$. Em arquitetura, como afirma Bernard Tschumi,

\begin{abstract}
A renovada importância dada ao valor de objetivos conceituais [...] tornou-se rapidamente estabelecida. Os meios utilizados para a comunicação de conceitos se tornaram arquitetura, informação era arquitetura, atitude era arquitetura, o programa escrito ou o brief era arquitetura, fofoca era arquitetura, produção era arquitetura, e inevitavelmente, o arquiteto era arquitetura. Libertando-se dos compromissos ideológicos da construção, o arquiteto pode, finalmente, alcançar a satisfação sensual que a confecção de objetos materiais não mais proporcionava. ${ }^{4}$ (TSCHUMI, 1975, p.138, tradução nossa)
\end{abstract}

As colocações de Tschumi ilustram um panorama em que, noções cada vez mais abstratas de espaço são discutidas. Nesse contexto, como coloca Henri Lefebvre (LEFEBVRE, 2009, p.2), os matemáticos emergiram como proprietários de uma ciência autossuficiente e um clamor por status científico, claramente separado da filosofia, apropriando-se do espaço e do tempo como parte de seus domínios. Nas palavras de Lefebvre, "eles inventaram espaços - uma 'indefinidade', por assim dizer, de espaços: espaços não-Euclidianos, espaços curvos, espaços $x$-dimensionais (mesmo os espaços com uma infinidade de dimensões), espaços de configuração, espaços abstratos, espaços definidos por deformação ou transformação, através de uma topologia, e assim por diante" ${ }^{5}$ (LEFEBVRE, 2009, p.2, tradução nossa).

O trabalho de Douglas Huebler, "dematerialized" place (or space), ilustra esse contexto. Como observa Lucy Lippard, as várias peças mapa produzidas pelo artista,“[...] em uma maneira quintessencialmente 'Conceitual' ignoravam as limitações de tempo e espaço

\footnotetext{
${ }^{3}$ Uma referência ao livro de Lucy Lippard, publicado em 1973, Six Years: The dematerialization of the art object from 1966 to 1972: a cross-reference book of information on some esthetic boundaries: consisting of a bibliography into which are inserted a fragment text, art works, documents, interviews, and symposia, arranged chronologically and focused on so-called conceptual or information or idea art with mentions of such vaguely designated areas as minimal, anti-form, systems, earth, or process art, occurring now in the Americas, Europe, England, Australia, and Asia (with occasional political overtones), edited and annotated by Lucy R. Lippard. (LIPPARD, 1997, p. XV) ${ }^{4}$ Do original em inglês: "The renewed importance given to the value of conceptual aims [...] became quickly established. The media used for the communication of concepts became architecture, information was architecture, the attitude was architecture, the written programme or brief was architecture, gossip was architecture, production was architecture, and inevitably, the architect was architecture. Escaping the predictable ideological compromises of building, the architect could finally achieve the sensual satisfaction that the making of material objects no longer provided." (TSCHUMI, 1975, p.138)

${ }^{5}$ Do original em inglês: "They invented spaces - an 'indefinity', so to speak, of spaces: non-Euclidian spaces, curved spaces, $x$-dimensional spaces (even spaces with an infinity of dimensions), spaces of configuration, abstract spaces, spaces defined by deformation or transformation, by a topology, and so on." (LEFEBVRE, 2009 , p.2)
} 
[....." (LIPPARD, 1997, p.XXI, tradução nossa) Isso se torna evidente, por exemplo, em trabalhos como um de 1970, que consistia em uma linha reta vertical desenhada em uma folha de papel onde se lê, abaixo da imagem, em um texto alinhado horizontalmente: "a linha acima está rotacionando em torno de seu eixo a uma velocidade de uma revolução por dia." (Figura 1.01)

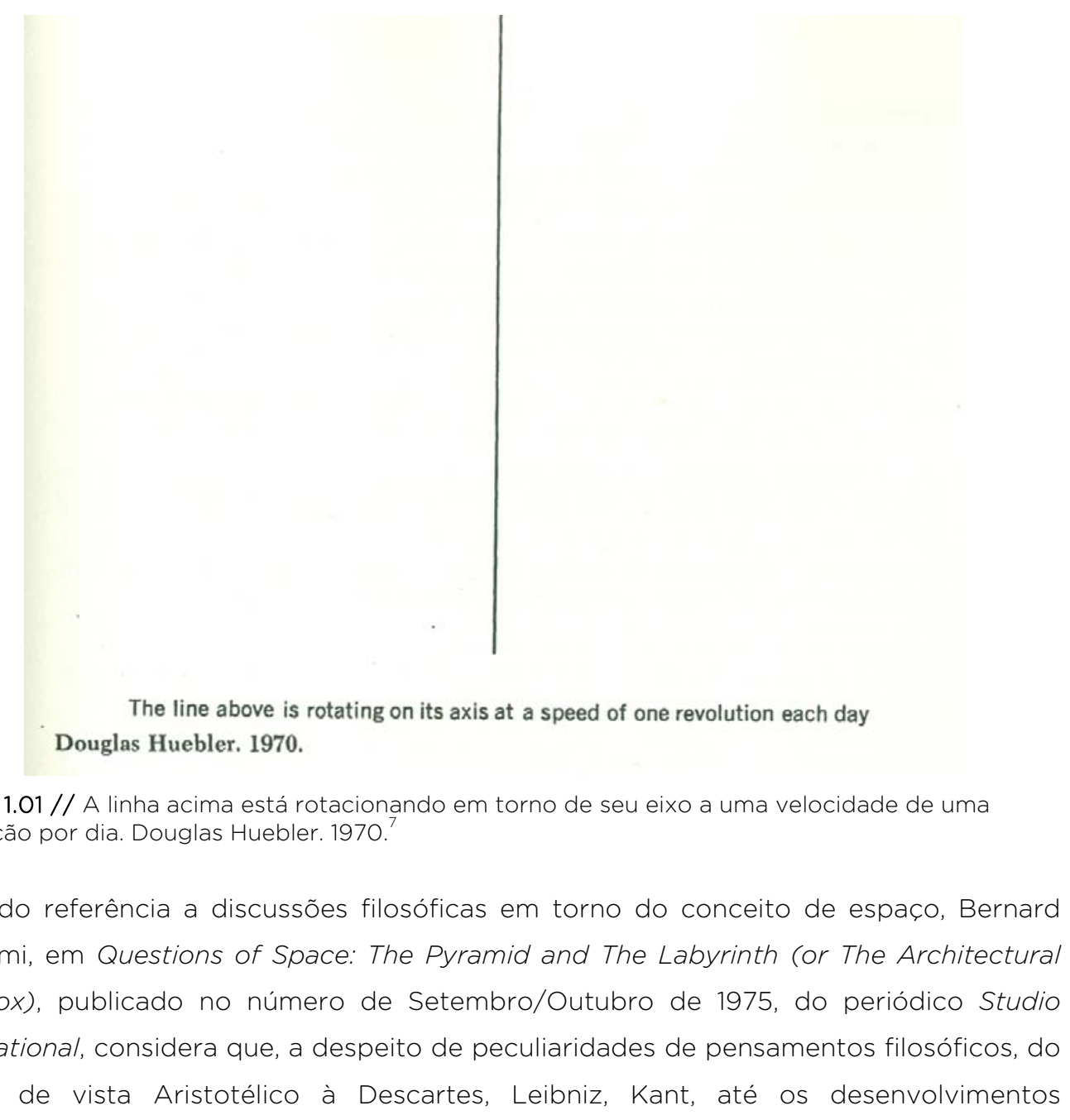

${ }^{6}$ Do original em inglês: "[...] in a quintessentially 'Conceptual' manner disregarded time and space limitations [...]."(LIPPARD, 1997, p.XXI)

${ }^{7}$ Do original em inglês: "The line above is rotating on its axis at a speed of one revolution each day. Douglas Huebler. 1970." (LIPPARD, 1997, p.167) 
matemáticos concernentes a espaços não-Euclidianos, "o espaço foi geralmente aceito como cosa mentale, uma 'coisa mental', uma espécie de conjunto abrangente com seu subconjunto, como o espaço literário, espaço ideológico e o espaço psicanalítico." ${ }^{8}$ (TSCHUMI, 1975, p.137, tradução nossa) É nessa mesma década que Henri Lefebvre discute em seu The Production of Space, publicado pela primeira vez em 1974, a necessidade de uma teoria sobre o espaço que unisse todas a teorias, uma teoria que poderia ser chamada de uma teoria unitária, que teria como objetivo, segundo o autor,

[...] descobrir ou construir uma unidade teórica entre 'campos' que são apreendidos separadamente, tal como as forças molecular, eletromagnética e gravitacional são na física. Os campos com os quais estamos preocupados são, em primeiro lugar, o físico - a natureza, o Cosmos; em segundo lugar, o mental, incluindo abstrações lógicas e formais; e, em terceiro, o social. Em outras palavras, estamos preocupados com o espaço lógico-epistemológico, o espaço da prática social, o espaço ocupado por fenômenos sensoriais, incluindo produtos da imaginação, como projetos e projeções, símbolos e utopias. ${ }^{9}$ (LEFEBVRE, 2009, p.11-12, tradução nossa)

Os argumentos de Lefebvre fazem sentido, se considerarmos, como ele mesmo coloca (LEFEBVRE, 2009, p.12), que nosso conhecimento do mundo material é baseado em uma série de conceitos definidos em termos de ampla generalidade e grande abstração científica. Segundo o autor, "Mesmo que as conexões entre esses conceitos e as realidades físicas às quais eles correspondem, nem sempre sejam claramente estabelecidas, sabemos que essas conexões existem, e que o conceito ou teorias que implicam - energia, espaço, tempo - não podem ser nem confundidas nem separadas uma da outra."10 (LEFEBVRE, 2009, p.12, tradução nossa)

Considerando a possibilidade de uma teoria unitária, as considerações de Bernard Tschumi acerca da teoria arquitetônica, são pertinentes. Na perspectiva do arquiteto, "a

\footnotetext{
${ }^{8}$ Do original em inglês: "[...] space was generally accepted as a 'cosa mentale', a mental thing, a sort of allembracing set with its subset, such as literary space, ideological space and psychoanalytical space." (TSCHUMI, 1975, p.137)

${ }^{9}$ Da tradução para o inglês a partir do original em francês: "[...] to discover or construct a theoretical unit between 'fields' which are apprehended separately, just as molecular, electromagnetic and gravitational forces are in physics. The fields we are concerned with are, first, the physical - nature, the Cosmos; secondly, the mental, including logical and formal abstractions; and, thirdly, the social. In other words, we are concerned with logicalepistemological space, the space of social practice, the space occupied by sensory phenomena, including products of the imagination such as projects and projections, symbols and utopias."(LEFEBVRE, 2009, p.11-12)

${ }^{10}$ Da tradução em inglês a partir do original em francês: "Even if the links between these concepts and the physical realities to which they correspond are not always clearly established, we do know that such links exist, and that the concept or theories they imply - energy, space, time - can be neither conflated nor separated from one another." (Levebvre 2009, p.12),
} 
teoria arquitetônica compartilha com a teoria artística uma característica peculiar: ela é prescritiva." "11 (TSCHUMI, 1975, p.139, tradução nossa). É de certa forma, adotando uma postura prescritiva, que a abordagem da presente tese se constrói, em domínios-entre, articulando-se em uma rede tecida por conhecimentos das ciências, das artes, e de tantas outras áreas que contemplam a criatividade e a produção do conhecimento humano. O sentido da presente abordagem é se estruturar como um olhar que perpassa essas várias áreas, podendo ser relevante, simultaneamente, enquanto perspectiva e enquanto projeção. Perspectiva pra imaginar, e para integrar a imaginação, no sentido evidenciado por Mel Bochner. Segundo o artista,

\begin{abstract}
A raiz 'imagem' não precisa ser usada apenas para significar representação (no sentido de uma coisa se referindo a algo distinto de si mesmo). Re-presentar pode ser definido como a mudança nos quadros referenciais do espectador a partir do espaço de eventos para o espaço de declarações, ou vice-versa. Imaginando (em oposição à imagem) não é uma preocupação pictórica. Imaginação é uma projeção, a exteriorização de ideias sobre a natureza das coisas visíveis. Ela re-produz o que é inicialmente sem produto. ${ }^{2}$ (BOCHNER apud LIPPARD, 1997, p.XV, tradução nossa)
\end{abstract}

Essa compreensão da ideia de imaginação é importante quando nossa abordagem se coloca em um lugar onde falamos de espaços não-dimensionais, gerados por ações, pelo fluxo de informações de um nível para outro numa estrutura multinível, como a de um sistema complexo. Espaço que não é, como coloca Lefebvre, "[...] nem um 'sujeito', nem um 'objeto', mas sim uma realidade social - isto é, um conjunto de relações e formas." ${ }^{13}$ (LEFEBVRE, 2009, p.116, tradução nossa)

\title{
1.2. Espaços Estoricizados
}

A partir da sociologia do espaço, uma subdisciplina da sociologia, é possível refletir sobre os espaços como construções a partir da ação de entidades vivas, em diálogo com tecnologia, mídia, constituídas em processos de percepção, memória, reflexão,

\footnotetext{
"Do original em inglês: "Architectural theory shares with art theory a peculiar characteristic: it is prescriptive." (Tschumi 1975, p.139)

${ }^{12}$ Do original em inglês: "The root 'image' need not be used only to mean representation (in the sense of one thing referring to something other than itself). To re-present can be defined as the shift in referential frames of the viewer from the space of events to the space of statements or vice versa. Imagining (as opposed to imaging) is not a pictorial preoccupation. Imagination is a projection, the exteriorizing of ideas about nature of things seen. It re-produces that which is initially without product." (BOCHNER apud LIPPARD, 1997, p.XV)

${ }^{13}$ Do original em inglês: "[...] neither a 'subject' nor an 'object' but rather a social reality - that is to say , a set of relations and forms." (LEFEBVRE, 2009, p.116)
} 
imaginação, até manifestarem-se como estruturas estoricizadas. Esta linha de pensamento tem alguns aspectos em comum com abordagens que incorporam a lógica hermenêutica, a partir de uma perspectiva da complexidade. Abordagens que se articulam em torno do objetivo de observar a emergência de significado e consciência em processos de leitura, uma espécie de hermenêutica radical (RASMUSSEN, 2002). Na hermenêutica, o significado é entendido como algo que é construído como uma fronteira entre o atual e o possível sendo, nem uma coisa nem outra, mas, "[...] a relação entre o atual e o possível. O significado é uma certa maneira de se comportar onde atenção é dirigida a uma possibilidade entre muitas, onde o atual recebe/é investido de significado em um horizonte de possibilidade." ${ }^{14}$ (RASMUSSEN, 2002, p.7, tradução nossa, grifo do autor)

Considerando essa perspectiva, a noção de espaços estoricizados explorada por Ken Baskin ${ }^{15}$ no artigo intitulado Storied Spaces: The Human Equivalent of Complex Adaptive Systems (2008), publicado pelo Emergence: Complexity \& Organization - An International Transdisciplinary Journal of Complex Social Systems, em 2008, é interessante como um ponto de partida entender espaços como emergências, construções a partir de coleções de narrativas, produto das interações, das transações de sujeitos envolvidos em processos criativos. Segundo Baskin (BASKIN, 2008), espaços estoricizados podem ser descritos como uma coleção de estórias, construídas a partir da experiência, na dinâmica de interpretar o contexto para agir. Na construção do pesquisador, a dinâmica desses espaços estoricizados se dá a partir da interação de dois tipos de estórias que refletem a teoria de Gell-Mann (1994) sobre como os sistemas complexos adaptativos aprendem - as narrativas e as antenarrativas, numa referência à abordagem de David Boje ${ }^{16}$.

\footnotetext{
${ }^{14}$ Do original em inglês: "[...] the relation between the actual and the possible. Meaning is a certain way of behaving where attention is direct at one possibility among many, where the actual receives/is invested with meaning on a horizon of possibility." (RASMUSSEN, 2002)

${ }^{15}$ Ken Baskin é membro do "Institute for the Study of Coherence and Emergence (ISCE)" nos Estados Unidos, tendo vários projetos de pesquisa financiados por essa instituição. Foi co-editor, com David Boje da New Mexico State University, do número especial "Complexity and Storytelling" do periódico E:CO - Emergence:

Coherence\&Organization. Suas pesquisas buscam uma integração entre pensamento complexo e a narratologia em estudos dos sistemas sociais humanos como 'espaços estoricizados', ou que chama de 'o equivalente humano dos sistemas complexos adaptativos'. Ver: Baskin, K., 2008. Storied Spaces: The Human Equivalent of Complex Adaptive Systems. E:CO, 10(2), p. 1-12. Disponível em:

<http://business.nmsu.edu/ dboje/655/articles_655/Baskin_Storied_spaces_pdf.pdf>. Acesso em: 23 dez. 2010.

${ }^{16}$ David Boje emergiu como um dos principais pensadores pós-modernos em teoria da gestão e ciência da organização. Atualizando e revisando a teoria narrativa para a condição pós-moderna, Boje reconstrói os conceitos e métodos de contar estórias, na medida em que subverte os princípios dominantes da teoria da
} 
No livro Narrative Methods for Organizational and Communication Research, BOJE (2001) apresenta 8 (oito) opções de análises de antenarrativas como forma de lidar com a prevalência de narrativas fragmentadas e polifônicas em organizações complexas, dando exemplos de como esses métodos podem ser aplicáveis em estudos sobre organização. O autor considera que as estórias, de um modo geral, no que se refere à organização, são "[...] auto-deconstrutíveis, fluentes, emergentes e em rede, e, de modo nenhum, estáticas."17 (BOJE, 2001, p.3, tradução nossa) Dentro dessa perspectiva, a ideia de antenarrativa, se coloca como artifício para lidar com a fragmentação e a polifonia das narrativas em organizações complexas. As antenarrativas são caracteristicamente narrativas fragmentadas, não-lineares, incoerentes, coletivas, sem enredo e impróprias. Boje apresenta a seguinte definição para o conceito:

Dou à 'antenarrativa' um duplo significado: como sendo antes e como uma aposta. Em primeiro lugar, estória é 'ante' em relação à narrativa, é 'antenarrativa'. A 'narrativa' é algo que é narrado, ou seja, 'estória'. A estória é um relato de incidentes ou eventos, mas a narrativa vem depois e acrescenta 'enredo' e 'coerência' à estória. A estória é, portanto, 'ante' à estória e a narrativa é pós-estória. A estória é um 'ante' estado de coisas existindo anteriormente à narrativa; está em vantagem em relação à narrativa. Usado como advérbio, 'ante' combinado com 'narrativa' significa anterior à narrativa. ${ }^{18}$ (BOJE, 2001, p.1, tradução nossa)

O autor fala de 5 (cinco) dimensões de antenarrativas. A primeira, antenarrando, é ambos, anterior à narratologia como método, e suplementar à teoria. A dimensão antenarrando, enquadra e se impõe sobre a estória, e é frequentemente o requerimento para um começo, meio e fim, completado com uma moral e um enredo acordado. Essas noções se apresentam em contraposição à ideia de narrativa propriamente dita essencialmente pós, uma espécie de "[...] explanação retrospectiva de uma apreciação especulativa do narrar,"19 (BOJE, 2001, p.3, tradução nossa)

organização modernista. Ver: BOJE, David. Narrative Methods for Organizational and Communication Research. London: Sage, 2001.

${ }^{17}$ Do original em inglês: "[...] self-deconstructing, flowing, emerging and networking, not at all static." (BOJE, 2001, p.3)

${ }^{8}$ Do original em inglês: "I give 'antenarrative' a double meaning: as being before and as a bet. First, story is 'ante to narrative; it is 'antenarrative'. A 'narrative' is something that is narrated, i.e. 'story'. Story is an account of incidents or events, but narrative comes after and adds 'plot' and 'coherence' to the story line. Story is therefore 'ante' to story and narrative is post-story. Story is an 'ante' state of affairs existing previously to narrative; it is in advance of narrative. Used as an adverb, 'ante' combined with 'narrative' means earlier than narrative." (BOJE, 2001, p.1)

${ }^{19}$ Do original em inglês: "[...] retrospective explanation of storytelling's speculative appreciations." (BOJE, 2001, p.3) 
A segunda dimensão do conceito de antenarrativa se atém ao especulativo, à ambiguidade do fazer sentido e adivinhar o que está acontecendo no fluxo da experiência, respondendo à questão o que está acontecendo aqui? Em uma terceira dimensão, a ideia de antenarrativa dirige nossa atenção analítica para o fluxo do narrar como um dar sentido à experiência vivida antes dos requerimentos da narrativa de começos, meios e fins. Segundo Boje, "a teoria narrativa é uma experiência das consequências do narrar uma vez que a coerência é processada, enquanto a antenarrativa é uma experiência do narrar a vida com abreviadas e interrompidas performances da estória que rendem plurivocalidade." ${ }^{20}$ (BOJE, 2001 apud BOJE, 1995, tradução nossa)

Em uma quarta dimensão, a ideia de antenarrativa diz respeito ao que Boje se refere como o Tamara do narrar. (BOJE, 2001 apud BOJE, 1995) Em Tamara, a mais longa peça de Los Angeles, 12 (doze) atores, encenam estórias em frente a uma audiência que está caminhando ou, algumas vezes, correndo. É um exercício de tentar encontrar quem fez isso? A audiência se fragmenta, em certo momento, em pequenos grupos, seguindo os personagens de um cômodo (um cenário) para outro. Como observa BOJE (2001), se existem 12 (doze) palcos e 12 (doze) narradores, o número de versões da estória que uma plateia poderia acompanhar, seria 12 (doze) fatorial.

Em uma quinta dimensão, antenarrativa é memória coletiva antes de se tornar reificada em estória na narrativa consensual, como se fosse a narrativa em estado de vir-a-ser, em evolução, transformação. Sob uma perspectiva mais ampla, englobando as cinco dimensões as quais referimos aqui, a noção de desconstrução, enquanto fenômeno e análise, para Boje, resume o que é a antenarrativa:

Desconstrução é antenarrativa em ação. Cada estória exclui. Cada estória legitima um ponto de vista central, uma visão de mundo, ou uma ideologia em outras alternativas. Nenhuma estória é ideologicamente neutra; estória flutua na sopa caótica de 'bits' e pedaços de fragmentos de estórias. A estória nunca está sozinha; ela vive e respira seu significado numa rede de outras estórias. E, cada estória, desde que esteja inserida em contextos de mudança de

\footnotetext{
${ }^{20}$ Do original em inglês: "Narrative theory is an experience of the after-effects of storytelling once coherence is rendered, while antenarrative is an experience of the storytelling life with abbreviated and interrupted story performances that yield plurivocality." (BOJE, 2001 apud BOJE, 1995).
} 
significado de múltiplas estórias e produção coletiva de estórias, se 'autodesconstrói' com cada contar. ${ }^{21}$ (BOJE, 2001, p.18, tradução nossa)

É referindo-se à abordagem de Derrida (DERRIDA, 1999), que Boje fala de desconstrução como estratégia, e não como método. Desconstrução como algo que delineia o micropoder nos processos textuais, expondo aspectos centralizadores e não revelados, tornando menos visíveis aspectos mais aparentes. No contexto da presente pesquisa, o conceito de antenarrativa é utilizado como parte da construção do olhar que desvenda a arquitetura do nosso sistema, integrando espaços estoricizados vinculados aos sujeitos que se inter-relacionam como partes de complexos organizados.

\subsection{Informação e significado: a dinâmica do complexo organizado}

A perspectiva que adotaremos para estudar macrocomportamentos observáveis nos sistemas que nos propomos a estudar, os espaços estoricizados, combinam em sua gênese, ambas, narrativas e antenarrativas. Nas palavras de Baskin, "no espaço estoricizado, a antenarrativa fornece feedback flexível às pessoas acerca de acontecimentos recentes que podem exigir comportamentos um pouco diferentes daqueles conduzidos pelas narrativas dos seus espaços estoricizados."22 (BASKIN, 2008, p.6. tradução nossa)

Falando sobre estórias e as narrativas relacionadas e, levando em conta uma perspectiva complexa, as considerações de Stephen Denning são interessantes. Segundo o autor, "O fato de as narrativas não serem matematicamente precisas e, na verdade, serem cheias de relações qualitativas fuzzy ${ }^{23}$, parece ser uma chave para o seu sucesso em nos permitir cooperar com a complexidade." ${ }^{24}$ (DENNING, 2000, p.113, tradução nossa, grifo nosso)

\footnotetext{
${ }^{21}$ Do original em inglês: "Deconstruction is antenarrative in action. Every story excludes. Every story legitimates a centered point of view, a worldview, or an ideology among alternatives. No story is ideologically neutral; story floats in the chaotic soup of bits and pieces of story fragments. Story is never alone; it lives and breathes its meaning in a web of other stories. And, every story since it is embedded in changing meaning contexts of multiple stories and collective story making, 'self-deconstructs' with each telling." (BOJE, 2001, p.18)

${ }^{22}$ Do original em inglês: "In storied space, antenarrative provides flexible feedback to people about recent happenings that may call for behaviors quite different from those driven by their storied space's narratives." (BASKIN, 2008, p.6)

${ }^{23}$ Expressão que remete à lógica fuzzy ou lógica difusa, que é uma extensão da lógica booleana que admite valores lógicos intermediários entre o FALSO (O) e O VERDADEIRO (1).

${ }^{24}$ Do original em inglês: "The fact that narratives are not mathematically precise, and in fact are full of fuzzy qualitative relationships, seems to be a key to their success in enabling us to cope with complexity." (DENNING, 2000, p.113)
} 
Segundo Baskin, Gell-Mann sugere que "[...] sistemas complexos adaptativos aprendem através da forma como processam informação. Eles aprendem na medida em que as condições, o contexto, mudam."25 (GELL-MANN, 1994 apud BASKIN, 2008, p.5, tradução nossa) Essas mudanças são possíveis em um contexto onde o fluxo de informação é constante entre, através e além do sistema. Retomando aqui a perspectiva de uma hermenêutica radical, Rasmussen (2002) menciona que Gadamer concebe o círculo hermenêutico como "[...] um processo através do qual o intérprete se move para trás e para frente entre a descrição empírica/material e conceitos teóricos/analíticos." ${ }^{26}$ (RASMUSSEN, 2002, p.4, tradução nossa) Essa noção de um círculo hermenêutico como um circuito generativo - implicando a interação contínua entre sujeitos-sistema-ambiente em um complexo auto-organizado, é interessante para ajudar a compreender a natureza do significado, sua relação com as ações realizadas, e sua consequente importância na constituição do sistema.

Para Cohen (2003), a habilidade de criar significados aparentemente contraditórios a partir da mesma realidade é uma qualidade central dos sistemas complexos. Para Niklas Luhmann, "[...] significado é uma representação da complexidade. Significado não é uma imagem ou um modelo da complexidade utilizado por sistemas conscientes ou sociais, não simplesmente uma nova e poderosa forma de cooperar com a complexidade sob uma inevitável condição de seletividade imposta."27 (LUHMANN, 1990, p.84, tradução nossa)

Em seu livro Social systems, Luhmann trata de informação no sentido de novidade, recorrendo à definição de Gregory Bateson onde '[...] um 'bit' de 'informação' é definível como uma diferença que faz uma diferença." ${ }^{28}$ (BATESON, 1972, p. 315, tradução nossa) A mensagem é informação, na medida em que ela produz efeito seletivo no sistema, quando escolhas podem acontecer a partir de diferenças. Luhmann fala da autopoiese (a

\footnotetext{
${ }^{25}$ Do original em inglês: "[...] complex adaptive systems learn through the way they process information. They learn as the conditions, the context, change." (GELL-MANN, 1994 apud BASKIN, 2008, p.5)

${ }^{26}$ Do original em inglês: "[...] a process whereby the interpreter moves back and forth between empirical/material description and theoretical/analytical concepts." (RASMUSSEN, 2002, p.4)

${ }^{27}$ Do original em inglês: "[...] meaning is a representation of complexity. Meaning is not an image or a model of complexity used by conscious or social systems, not simply a new and powerful form of coping with complexity under the unavoidable condition of enforced selectivity." (LUHMANN, 1990, p.84)

${ }^{28}$ Do original em inglês: "A 'bit' of 'information' is definable as a difference which makes a difference". (BATESON, 1972, p.315)
} 
partir de Humberto Maturana e Francisco Varela) como característica dos sistemas sociais - sistemas auto-organizados em que a ação se dá a partir de um self construído pelo imaginário inconsciente, de um ambiente que the fornece os elementos para agir, que the fornece informações.

Segundo Luhmann, sistemas autopoiéticos "[...] são soberanos com respeito à constituição de identidades e diferenças. Eles não criam um mundo material próprio. Eles pressupõem outros níveis de realidade." ${ }^{29}$ (LUHMANN, 1986, p.3, tradução nossa) Sistemas sociais utilizam a comunicação como seu modo particular de reprodução autopoiética sendo, seus elementos "[...] comunicações que são recursivamente produzidas e reproduzidas por uma rede de comunicações as quais não podem existir fora dessa rede."30 (LUHMANN, 1986, p.3, tradução nossa)

Para Luhmann, a teoria da autopoiese oferece uma vantagem importante em relação à visão estruturalista, que considera a comunicação como produto da linguagem. Na autopoiese, é a rede de eventos que se autoproduz. Humberto Maturana e Francisco Varela, falando da comunicação em sistemas sociais, e de macrocomportamentos observáveis a partir da dinâmica organizacional, colocam que, "toda vez que há um fenômeno social há uma acoplamento estrutural entre indivíduos. Portanto, como observadores podemos descrever uma conduta de coordenação recíproca entre eles." (MATURANA; VARELLA, 2007, p.214)

Os biólogos acreditam que, "[...] o peculiar da comunicação não é que ela resulte de um mecanismo distinto dos demais comportamentos, mas sim que ocorra no domínio do acoplamento social." (MATURANA; VARELLA, 2007, p.214-215) Luhmann acredita que, para uma teoria dos sistemas autopoiéticos, "[...] apenas a comunicação é um sério candidato à posição de unidade elementar do básico processo auto-referencial dos sistemas sociais" ${ }^{31}$ (LUHMANN, 1986, p.6, tradução nossa), afirmando a importância de uma discussão conceitual que trate da relação entre ação e comunicação e dessa relação

\footnotetext{
${ }^{29}$ Do orginal em inglês: [...] are sovereign with respect to the constitution of identities and differences. They do not create a material world of their own. They presuppose other levels of reality."(LUHMANN, 1986, p.3)

${ }^{30}$ Do original em inglês: "[...] communications which are recursively produced and reproduced by a network of communications and which cannot exist outside of such a network." (LUHMANN, 1986, p.3)

${ }^{31}$ Do original em inglês: "[...] only communication is a serious candidate for the position of the elementary unit of the basic self-referential process of social systems."(LUHMANN, 1986 p.6)
} 
como a base para a emergência, seja de consciência ou de sistemas sociais. Luhmann (1986) propõe considerar o processo de significado como operação autopoiética dos sistemas social e psicológico, onde a linguagem humana permite a construção e troca de modelos, utilizando metáforas que nos permitem comunicar significado. Segundo Maturana (2000), quando as expectativas são trocadas, o desenvolvimento de uma dinâmica não-linear pode emergir pelo processo de troca de informações. Esse processo de troca de informações é a base da estrutura sistêmica.

Como coloca Luhmann (LUHMANN, 1986), as interações devem levar em conta a comunicação ambiental e reconhecer o fato de que, as pessoas que participam na interação, têm outros papéis e outras obrigações dentro de sistemas que não podem ser controlados naquele momento. As interações podem ser descritas ainda como sistemas fechados, no sentido em que sua própria comunicação pode ser motivada e entendida apenas no contexto do sistema. Como exemplifica Luhmann, "[...] se alguém se aproxima do espaço interacional e começa a participar, ele tem que ser introduzido e os tópicos da conversa eventualmente têm de ser adaptados para a nova situação." 32 (LUHMANN, 1986 p.5, tradução nossa) Para o pesquisador, as interações não podem implicar comunicação ready-made do ambiente. Os sistemas, em função de decidirem reproduzir ou não, seus próprios elementos, continuam ou descontinuam sua autopoiese como sistemas vivos que são.

Quando consideramos essa perspectiva, fica evidente que a própria estrutura sistêmica é essencial para a reprodução de eventos a partir dos próprios eventos. A estrutura sistêmica, com seus nós, que são seus elementos, e as interconexões entre eles, as relações, permite ter visibilidade da dinâmica sistêmica e entender seus processos organizacionais e sua complexidade. Diante da intenção de dar ao sistema visibilidade de si, um mapeamento da estrutura torna-se essencial. Segundo Luhmann, o mapeamento das estórias envolve a apresentação da arquitetura social, ou seja, de que forma uma estória está intertextualmente ligada a outras estórias, em um sociograma em rede - um mapa de nós e os links que interconectam estórias. Na concepção de Luhmann, em análise de redes de estórias, os nós, podem ser pessoas, grupos, organizações,

${ }^{32}$ Do original em inglês: "[...] if somebody approaches the interactional space and begins to participate, he has to be introduced and the topics of conversation eventually have to be adapted to the new situation." (LUHMANN, 1986 p.5) 
categorias, e até mesmo as próprias estórias. Os links podem ser analíticos ou virtuais. Para Luhmann “[...] um 'nó' é um container-de-categoria para várias ideias, códigos, conceitos e atributos selecionados para sua análise." ${ }^{33}$ (LUHMANN, 1986, p. 64, tradução nossa)

O estudo de sistemas sociais é uma vertente das ciências comportamentais que tenta entender as arquiteturas complexas que emergem de sistemas estruturados a partir de laços fortes e fracos entre os elementos. Nesse contexto, na visão de Luhmann, a abordagem do estudo de sistemas sociais a partir da noção de antenarrativa pode ser aplicada de três formas distintas e complementares. Em uma primeira instância, essa abordagem pode focalizar o entendimento da complexa dinâmica de contar estórias entre as pessoas, através de suas redes sociais.

Esse exercício é o que permite criar o modelo que pode dar ao sistema visibilidade de si, como um mapa do território antenarrado. Em uma segunda instância, os aspectos intertextuais das estórias podem ser explorados em relação às relações de intercâmbio conectivo. Em uma instância mais ampla, ferramentas computacionais podem ser adicionadas nos processos de análise, focalizando a visualização de dados e a construção de mapas interorganizacionais de simulação de combinações de redes de estórias, por exemplo.

De um modo geral, a partir da abordagem do presente capítulo, é possível entender de que forma a análise de redes de estórias, pode ser a base para a criação de um modelo que dê ao sistema visibilidade de si. Um modelo construído a partir de um complexo virtual de hiper-ligações, para re-enatar a interconectividade de uma rede de narrativas e antenarrativas - rede onde os espaços estoricizados estão vinculados aos sujeitos que os produzem coletivamente, que integram os sistemas como seus elementos. Assim, agrupar narrativas e antenarrativas em espaços estoricizados, constitui importante artifício para dar visibilidade à arquitetura dinâmica dos sistemas que nos propomos estudar, importante na proposição de um possível modelo para o estudo dos processos criativos coletivos em artes digitais como sistemas complexos adaptativos.

\footnotetext{
${ }^{33}$ Do original em inglês: A 'node' is a category-container for various ideas, codes, concepts and attributes selected for your analysis." (LUHMANN, 1986, p.64) 


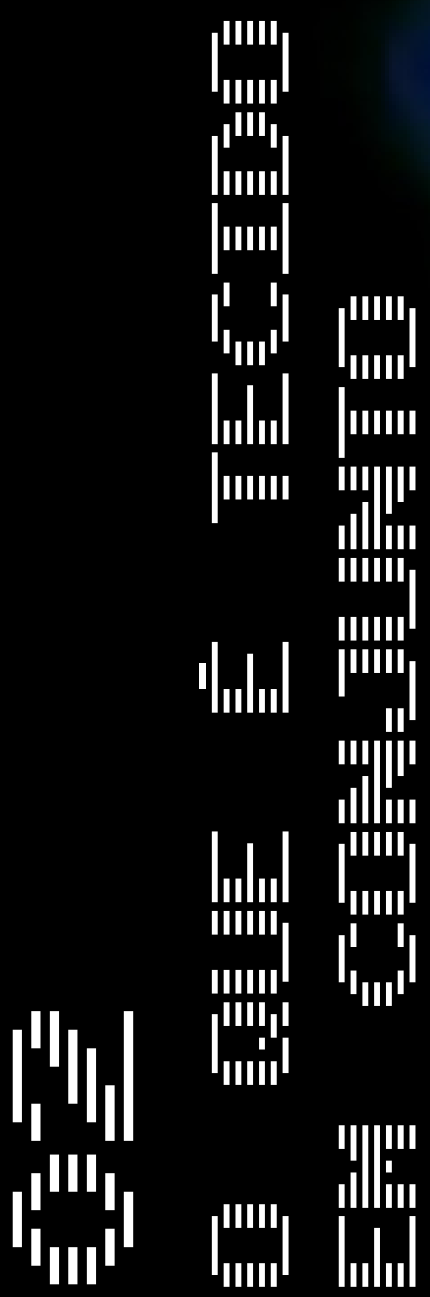




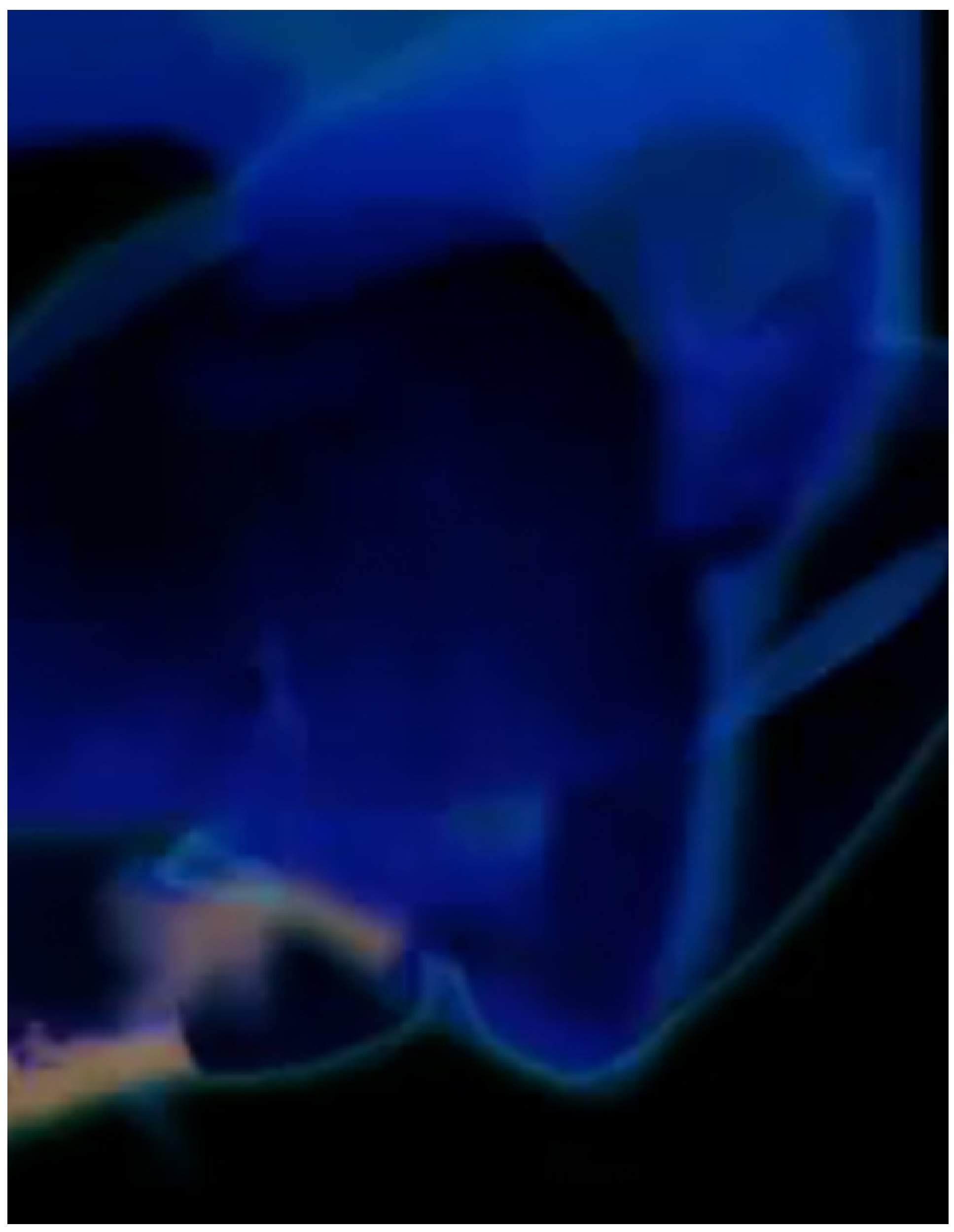


豆

Neste capítulo apresentamos ideias que ultrapassam os domínios específicos de suas áreas de conhecimento originais, como as noções de ordem a partir do ruído, autopoiese, emergência e entrelaçamento quântico. O objetivo é construir uma perspectiva a partir da qual, seja possível estudar o processo criativo coletivo em artes digitais como fenômeno emergente, em um diálogo que transcende as fronteiras disciplinares. 
O pensamento complexo incorpora a incerteza e é capaz de conceber a organização.

Edgar Morin, 1996, p.14

\subsection{A complexidade como artifício}

A partir dos desenvolvimentos científicos do século passado, torna-se evidente nas ciências contemporâneas, que grandes progressos são obtidos quando o observador é reintegrado à observação, seja das dimensões física, microfísica ou cosmofísica. Além, esse que observa, que pensa, que cria, não pode ser descolado de suas dimensões sociológica e biológica e ser unicamente considerado em sua dimensão individual, unitária. Não há apenas a unidade, há a perspectiva da rede, do sistema, com seus elementos interconectados.

'Do original em inglês: "Complex thought incorporates uncertainty and is capable of conceiving organization." (MORIN, 1996, p.14). 
Sendo um dos pilares do pensamento complexo, a noção de organização, "[...] introduz uma dimensão física radical na organização viva e na organização antropossocial, que podem e devem ser consideradas como desenvolvimentos transformadores da organização física." (MORIN, 2003, p.23). Dentro dessa ótica, se consideramos o ser humano como observador primeiro, esse que cria, que pensa, vemos que ele é indissociável de sua cultura e de sua sociedade. Assim, como afirma Morin, "[...] a realidade antropossocial se projeta e se inscreve no próprio âmago da ciência física." (MORIN, 2003, p. 24, grifo do autor).

Essa integração, e a consideração dessa perspectiva multidimensional na prática, quer em física, biologia, em filosofia, torna-se um desafio que produz uma desarticulação na própria base da produção de conhecimento. Confrontando um saber desarticulando em essência, o pesquisador vê-se diante de um fragmento do todo, cuja visão geral escapa não a si, mas a todos. Considerando a interdependência entre os saberes, o conhecimento produzido por áreas convencionalmente distintas, gera uma incerteza que desemboca na impossibilidade de um conhecimento do próprio objeto de estudo.

A circularidade se coloca como essencial para que as contradições sejam mantidas e se evite a simplificação e a disjunção do próprio saber, para se considerar a complexidade e perceber o objeto de estudo como um complexo plurifacetado, pluridimensional. A circularidade está no cerne de um conhecimento auto-reflexivo. Para Morin (MORIN 2003, p.32), conservar a circularidade, implica manter a associação entre duas proposições reconhecidas isoladamente como verdadeiras e que, quando confrontadas, se negam mutuamente. A conservação da circularidade implica abrir a possibilidade de conceber essas duas verdades como duas faces de uma verdade complexa, revelando a realidade principal, que é a relação de interdependência entre noções que a disjunção isola ou opõe.

É a partir dessa perspectiva inclusiva que, na presente pesquisa, a complexidade se apresenta como artifício para conectar conhecimentos das ciências - nomeadamente a biologia, físico-química, a física quântica -, a conhecimentos no âmbito das ciências sociais, da filosofia e da metafísica, em uma teia tecida no e pelo pensamento e prática em artes visuais. Perspectiva em que o espaço alcança a dimensão conceitual e pode ser 
produto das inter-relações entre os sujeitos, entre os sujeitos e o todo sistêmico e desses com o ambiente.

O conhecimento só é possível diante de um entrelaçamento de conhecimentos de áreas que originalmente produzem e são produzidas pelo próprio conhecimento que produzem e disseminam e compartilham; Processo de pesquisa que traz em si a aceitação da circularidade e da complexidade no próprio processo de aproximação do objeto de estudo.

Assim, a visão a partir da complexidade para os processos criativos coletivos que estruturamos aqui, não vem exclusivamente de uma articulação e contaminação primária entre desenvolvimentos da cibernética, da teoria geral dos sistemas e teoria da informação e comunicação ${ }^{2}$. A perspectiva que construímos procura ir além de uma articulação que evidencia a ligação e a origem compartilhada de uma ciência que bebeu ao longo dos séculos, em fontes como a Arte da Memória ${ }^{3}$. Nesse palco, temos atores como Ramon Llull e suas rodas da memória, trazendo movimento à arte da memória clássica, Leibniz e seu calculus ratiocinator. Ideias que convergem em um diálogo que se torna cada vez mais intenso a partir dos anos 1940.

No livro Cibernética; ou contrôle e comunicação no animal e na máquina, Norbert Wiener evidencia essas conexões e contaminações argumentando que, "[...] assim como o cálculo da aritmética presta-se a uma mecanização que vai do ábaco e da máquina de calcular de mesa às ultrarrápidas máquinas de computar de nossos dias, do mesmo modo o calculus ratiocinator de Leibniz contém os germes da machina ratiocinatrix, a máquina de raciocinar." (WIENER, 1970, p.37).

Esse diálogo evidenciado por Wiener, que se traduz nas próprias ciências da complexidade e em um chamado pensar complexo, se amplia e ganha maior pervasividade com, uma cada vez maior, facilidade de comunicação e deslocamento,

${ }^{2}$ Ver: ALMEIDA, Clarissa Ribeiro Pereira de. Entre e Através: Complexidade e Processos de Design em Arquitetura. 2006. 268 f. Dissertação (Mestrado em Arquitetura) Escola de Engenharia de São Carlos da Universidade de São Paulo, São Carlos, 2006.

${ }^{3}$ Ver: YATES, F. A. The Art of Memory. Chicago: The University of Chicago Press, 1984. (Orig. 1966) 
viabilizados por mídias e tecnologias - Extensões do homem ${ }^{4}$ que permitem ver, experimentar e imaginar além. Extensões que permitem explorar o universo estrangeiro das fendas abissais nos oceanos e seus seres e suas densidades, cores e texturas ${ }^{5}$. Desvendar os domínios além do planeta, encontrando evidências do nascimento e morte de estrelas, e do próprio cosmos. Extensões que permitem buscar e compartilhar online, desvendadas, além da espiral via láctea, bolhas de energia ${ }^{6}$ que ultrapassam a compreensão e fruição pelos sentidos naturais em nossa instância biológica. Artifícios para ir ao nano, ao intra, ao infra-thin ${ }^{7}$ no universo microscópico e, além, no experimental domínio da quântica.

\subsection{Do objeto ao sistema}

É através de nossa percepção e de nossa representação que conhecemos e nos sentimos parte do universo físico - a matéria em seus vários estados e formas, as forças que atuam sobre essa matéria. É nesse diálogo entre o nosso universo perceptivo e o mundo dos fenômenos, que a ciência clássica fundou suas bases sob o signo da objetividade, reinando em um universo constituído por objetos isolados, em espaços neutros, submetidos a leis universais. Esses objetos existem de maneira positiva, ou seja, sem a interferência do observador em sua construção. Essa construção diz respeito à sua situação no espaço (a posição e a velocidade), às suas qualidades físicas e químicas como massa, energia, além das forças que nele atuam como a gravidade, por exemplo.

É assim que, no final do século XIX, O método de decomposição e medição da ciência clássica, triunfava como artifício para conhecer e definir a realidade. Nas colocações de Edgar Morin, esse objeto é, então, "[...] uma entidade fechada e distinta que se define

\footnotetext{
${ }^{4}$ Numa referência a Marshall McLuhan: MCLUHAN, M. Os meios de comunicação como extensões do homem Tradução de Décio Pignatari, São Paulo: Editora Cultrix, 1964. (copyright 1964)

${ }^{5}$ A exposição Deep Sea na Waterhouse Gallery do Natural History Museum, em Londres, de 28 de maio a 5 September 2010, construiu um abrangente e fascinante panorama da história da exploração das profundezas oceânicas. A oportunidade de visitar a exposição durante o período de estágio PDEE no Reino Unido (2009-2010) foi importante como momento de refletir sobre como os avanços científico-tecnológicos em cada uma das fases dessa exploração influenciaram, viabilizaram, definiram visões de mundo, construções de realidades. Disponível em: < http://www.nhm.ac.uk/visit-us/whats-on/thedeep/>. Acesso em: 08 jan. 2011.

${ }^{6}$ Numa referência à descoberta recente de bolhas de raios-gama (gamma-ray bubbles) que se estendem por 50000 anos luz, de ponta a ponta na via láctea. Ver: SU, Meng; SLATYER, Tracy R.; FINKBEINER, Douglas P. Giant gamma-ray bubbles from fermi -lat: agn activity or bipolar galactic wind? Disponivel em: <http://arxiv.org/PS_cache/arxiv/pdf/1005/1005.5480v3.pdf >. Acesso em: 20 jan. 2011.

Infra-thin é um neologismo criado por Marcel Duchamp para medir as margens quase imperceptíveis de diferença entre dois itens aparentemente idênticos.
} 
isoladamente de seu ambiente. Quanto mais o isolamos experimentalmente, melhor determinamos sua realidade 'objetiva'." (MORIN, 2003, p.124).

Dessa forma, podendo o objeto ser descrito e definido a partir de leis gerais e de unidades elementares, a objetividade das ciências clássicas, exclui todas as referências ao observador, ao ambiente e, em última instância, à organização desse objeto. A biologia estudou as diferentes espécies de animais e plantas extraindo-as de ambiente e contexto - isolou o indivíduo, o organismo, depois a célula, até chegar à molécula. A física isolou o átomo, depois as partículas subatômicas. Mas é no cerne mesmo desse método, que nasce a possibilidade da mudança, no início do século XX. Se o átomo não é mais a unidade elementar (noção que vem desde Demócrito) e, como descrito no Modelo Planetário de Niels Bohr, era uma estrutura instável, onde os elétrons com carga negativa orbitavam ao redor de um núcleo com carga positiva formado por prótons, se instaura uma crise de ordem, de unidade e, em última instância, de identidade.

A matéria pode ser onda e pode ser partícula - ora ela é considerada como um sistema composto de quarks, ora como um campo de interações específicas. No contexto dessas transformações, a partícula que era elementar, enquanto objeto, "[...] perdeu toda substância, toda clareza, toda distinção e às vezes, até mesmo, toda realidade; ela se converteu em nó górdio de interações e trocas." (MORIN, 2003, p.126). O objeto se revela sistêmico. O que seria a unidade constituinte do universo físico - metais, gases, líquidos, os animais e as plantas -, não tem mais consistência, solidez, está em fluxo, em desequilíbrio, enquanto sistemas em processo organizacionais. Para além da noção de sistema, existe apenas a dispersão particular.

\subsection{Sistemas de Sistemas}

Dentro da lógica sistêmica, a realidade física é constituída por um complexo de sistemas dentro de sistemas. Nessa lógica, segundo Stéphane Lupasco, a noção de sistema unitário, isolado do todo sistêmico, não faz sentido, "[...] o simples sistema sendo apenas uma abstração didática." (LUPASCO, 1962, p.186, apud MORIN, 2003, p.129). Desde definições mais básicas como a de Leibniz para quem o "sistema é um conjunto de partes" (LEIBNIZ, 1666, apud MORIN, 2003, p.131) até as considerações do biólogo Ludwig Von Bertanlanffy em sua General Systems Theory, onde "Um sistema pode ser 
definido como um complexo de elementos em interação" (BERTALANFFY, 1977, p.84), a ideia de sistema pressupõe duas premissas essenciais que são, a inter-relação entre os elementos, e o fato de o todo sistêmico ser constituído pelos elementos em inter-relação, ou seja, um aspecto de totalidade ou globalidade e um aspecto relacional.

A ideia de organização é a ponte que liga totalidade e inter-relação e torna as três noções indissociáveis, podendo-se conceber uma definição de sistema como "[...] uma unidade global organizada de inter-relações entre elementos, ações ou indivíduos." (MORIN, 2003, p.132). Essa é a definição que adotaremos na presente abordagem para estudar processos criativos coletivos em artes digitais como sistemas complexos adaptativos.

Segundo M. Mitchell Waldrop, no livro Complexity: The Emerging Science at the Edge of Order and Chaos (1992), a complexidade é a ciência de compreender como agentes interagem uns com os outros para se influenciarem mutuamente e ao todo que integram. Os organismos, por exemplo, se adaptam constantemente ao longo de um processo dito evolutivo, se organizando em um sistema ecológico ajustado em função dessa dinâmica. Segundo o pesquisador, esses sistemas auto-organizados são adaptativos, ou seja, sua lógica organizacional trabalha no sentido de tirar vantagem de todos os acontecimentos. É essa lógica dos sistemas complexos, a adaptação, os saltos à beira do caos. É essa lógica que, segundo Waldrop, fez florescer o Santa Fe Institute e as ciências do século $X X I$, numa perspectiva mais ampla.

Assim, do estudo dos sistemas computacionais, das redes, à dinâmica de grandes corporações, e a sistemas sociais das mais diversas ordens, a lógica dos sistemas complexos adaptativos tem ajudado a descrever e compreender a fenomenologia da complexidade. Estudando sistemas sociais a partir dessa ótica, John Miller e Scott Page, no livro Complex Adaptive Systems, publicado em 2007, mostram que os chamados Sistemas Sociais Complexos Adaptativos ${ }^{8}$ demonstram algumas características-chave dos CAS. Para eles, "as características inatas de muitos sistemas sociais tendem a produzir complexidade. Agentes sociais, sejam eles abelhas ou pessoas ou robôs, veemse enredados em uma teia de conexões uns com os outros e, através de uma variedade

\footnotetext{
${ }^{8}$ Traduzido a partir do termo em inglês: Complex Adaptive Social Systems. (MILLER; PAGE, 2007)
} 
de processos adaptativos, devem navegar com sucesso através de seu mundo." (MILLER; PAGE, 2007, p.10, tradução nossa). ${ }^{9}$

Com o objetivo de explorar a modelagem da complexidade sistêmica, Miller e Page consideram o que chamam de um mundo simples, composto por duas cidades, cada uma delas com 3 (três) cidadãos. Segundo Miller e Page, o experimento evidencia características de CAS na medida em que, em primeiro lugar, tem-se "[...] uma rede de conexões que, nesse caso, resulta das ligações dos cidadãos uns aos outros por serem residentes em uma dada cidade"10 e, em segundo lugar, observa-se "[.... mudança induzida por escolhas feitas por todos os diferentes tipos de agentes no sistema." 11 (MILLER; PAGE, 2007, p.20, tradução nossa).

O experimento demonstra, por exemplo, que a introdução de ruido, ou de diferentes regras de comportamento, pode interferir na organização dos sistemas sociais. O modelo dos pesquisadores incorpora temas centrais, relacionados aos sistemas sociais complexos adaptativos, como equilíbrio, dinâmica, adaptação, e o papel central das interações não-centralizadas na organização do sistema.

\subsection{Ordem-desordem-organização}

Estudando o processo criativo coletivo como fenômeno complexo, consideramos uma série de conceitos que emergiram nas mais diversas áreas do conhecimento científico e que funcionam aqui, como diferentes lentes para orientar e, ao mesmo tempo, construir o nosso olhar. De um modo geral, essas diferentes ideias, combinadas e em diálogo, ajudam a entender a organização do nosso sistema, a relação entre partes, a natureza das conexões que estabelecem um diálogo entre elas, as emergências. Noções que permitem visualizar nosso sistema enquanto complexo organizado.

\footnotetext{
${ }^{9}$ Do original em inglês: "The innate features of many social systems tend to produce complexity. Social agents, whether they are bees or people or robots, find themselves enmeshed in a web of connections with one another and, through a variety of adaptive processes, they must successfully navigate through their world." (MILLER; PAGE, 2007, p.10)

${ }^{10}$ Do original em inglês: "[...] a web of connections that, in this case, results from citizens linking to one another by being resident in a given town," (MILLER; PAGE, 2007, p.20)

"Do original em inglês: "[...] change induced by choices made by all of the different types of agents in the system." (MILLER; PAGE, 2007, p.20)
} 
A partir de Henri Atlan, vemos que na física, desordem corresponde à imagem que fazemos de uma distribuição totalmente aleatória de objetos, ou seja, onde não está presente um princípio organizador. A ordem, por sua vez, corresponderia a uma heterogeneidade "[...] medida por probabilidades desiguais: por exemplo a probabilidade de se encontrar uma intensa concentração de moléculas seria mais elevada em alguns pontos do espaço do que em outros."(ATLAN, 1992, p.30).

Outra característica da desordem em física é o fato de sua definição ser estatística, parecendo desconsiderar as preocupações com a significação dos objetos constitutivos do sistema observado. Isso fica evidente, segundo Atlan (1992), quando nos referimos à entropia como um caso particular da informação, no sentido da Teoria da Informação, de Claude Shannon que, utilizando a probabilidade, resulta formalmente numa expressão matemática que se aproxima da de Boltzmann para a entropia. A utilização que Shannon fez das probabilidades para medir a informação sem significação foi, segundo Atlan (1992), a mesma que Boltzmann utilizou para medir a entropia.

Assim, na visão da organização proposta por Henri Atlan, medir a desordem na natureza tomando a grandeza entropia como sua medida, implica uma visão puramente probabilística da ordem onde, assim como na teoria de Shannon, no que se refere à transmissão de mensagens, o significado está ausente, reduzido ou uniformizado. Essas definições são de natureza operacional, e funcionam em situações, em contextos, em que é possível abstrair as significações. No entanto, como alerta o biólogo, por mais que possa ser abstraída, ignorada, uniformizada, a significação está implícita, sempre - "Uma ordem observada na natureza só aparece como tal aos olhos do observador que nela projeta significações conhecidas ou supostas." (ATLAN, 1992, p.34).

Na formulação de sua Teoria da Organização a Partir do Ruido, Atlan resgata, em um primeiro momento, as conexões entre biologia e cibernética, se referindo à obra de Norbert Wiener (1948). O cientista fala de um momento em que os organismos vivos foram considerados como máquinas de um tipo particular - as máquinas naturais. Essa atitude não deve ser confundida com a atitude mecanicista dos séculos XIX e XX. As máquinas da cibernética eram produtos de uma ciência aberta que se construiu em 
amplo diálogo com a biologia - do estudo do organismo para a máquina, dos estudos e do desenvolvimento da máquina para o organismo.

Entre as principais características inerentes às máquinas naturais, consideradas como as que as diferenciam das artificiais, está a aptidão para integrar o ruído. Isso, antes mesmo de se considerar fenômenos como a auto-organização e a auto-reprodução. Segundo Atlan, "os organismos, com sua faculdade de 'engolir' o ruído, não podiam ser concebidos como máquinas apenas um pouco mais fidedignas do que as artificiais conhecidas, mas como sistemas cuja confiabilidade só podia ser explicada por princípios de organização qualitativamente diferentes." (ATLAN, 1992, p.38).

Alguns estudos foram basilares, em diferentes momentos, para construir uma compreensão contemporânea do papel organizador do ruído. Entre estes, o Princípio da Ordem a Partir do Ruido, de Heinz Von Foerster, partindo da consideração da insuficiência do Princípio da Ordem a Partir da Ordem, inaugurado pelo ensaio seminal What is life? (1944) de Erwin Schrödinger, um dos fundadores da mecânica quântica. Para Foerster, os sistemas auto-organizados se alimentam não só de ordem, mas também do ruído.

Levando a considerações nessa mesma direção, como lembra Atlan, uma série de trabalhos desenvolvidos pelo ciberneticista William Ross Ashby, ajudaram a estabelecer sua Lei da Variedade Indispensável, importante para compreender de que forma, a partir de sistemas de regulação, um sistema aberto a um meio ambiente que é fonte de perturbações aleatórias, sobrevive, se organiza. Ashby chega a concluir, em seus estudos sobre a significação lógica do conceito de auto-organização, a impossibilidade lógica da auto-organização, em um sistema fechado, sem interação, sem trocas efetivas com seu ambiente.

Foi em fevereiro de 1943, que Schrödinger proferiu uma série três de conferências no Trinity College, em Dublin, sob os auspícios do Dublin Institute for Advanced Studies (DIAS) sob o título What is Life. A essa altura, a temática da mecânica quântica, cuja forma mecânica da onda ele descobriu em 1926, já fazia mais de 10 (dez) anos. No capítulo I (um) do pequeno livro publicado em 1944 (Schrödinger, 2010), a partir das 
conferências proferidas no Trinity College, Schrödinger explica que, a maior parte das leis físicas, está sujeita ao caos em uma escala reduzida, ao que ele chama ordem a partir da desordem. O cientista exemplifica o princípio utilizando a difusão - fenômeno que pode ser modelado como um processo extremamente ordenado, mas que é essencialmente causado por movimento randômico dos átomos ou moléculas. Seu argumento é de que a vida depende, em última instância, da ordem.

Nos capítulos II e III de What is Life?, Schrödinger (2010) mostra a importância do papel das mutações na evolução dos organismos, e discute o papel e os mecanismos da hereditariedade. Essas considerações inspiraram desenvolvimentos futuros em diversas áreas, como a concepção da estrutura em hélice da cadeia de DNA (ácido desoxirribonucléico). No capítulo IV, o cientista discute a estabilidade das moléculas, afirmando que esta não pode ser explicada pelas leis da física clássica mas, sim, pela natureza da mecânica quântica, relacionando, em última instância, as mutações aos saltos quânticos (quantum leaps). No capítulo $V$, ele defende que os sólidos verdadeiros, que são permanentes e estáveis como as moléculas, são cristais. Para o cientista, a estabilidade das moléculas e dos cristais é regida pelo mesmo princípio e, estas, podem ser consideradas os germes de um sólido. Ele acredita que o material hereditário deva ser uma molécula que, ao contrário do cristal, não se repete.

É no capítulo VI, que Schrödinger fala especificamente da relação entre o Princípio da Ordem a Partir da Ordem e sua relação com a segunda lei da termodinâmica, segundo a qual a entropia apenas aumenta. O cientista explica que a matéria viva, evita a deterioração do equilíbrio termodinâmico, alimentando-se de entropia negativa. No sétimo e último capítulo do livro, Schrödinger afirma que o Princípio da Ordem a Partir da Ordem não é absolutamente novo em física, - a natureza segue esse princípio com algumas exceções que ele aponta, como o movimento dos corpos celestiais, por exemplo. De um modo geral, para Schrödinger, a matéria viva mantém seu estado de ordem à custa de causar desordem crescente no universo. 
O que Atlan vem propor no final da década de 1970 é que, o organismo em sua organização, pode ser descrito como algo entre o cristal e a fumaça ${ }^{12}$. A organização é auto-organização e tem no ruído seu princípio organizador. A noção de organização em Atlan está intimamente ligada à complexidade pelo ruído e suas significações. Nas palavras do cientista,

\begin{abstract}
A informação que um sistema teria sobre si mesmo, aquela que vimos ser passível de aumentar sob o efeito do que nos parece ser um ruído (e que então medimos por uma informação que nos falta), é realmente o que permite ao sistema funcionar, e até mesmo existir como sistema. Trata-se, pois, do conjunto dos efeitos, estruturais e funcionais, da recepção de informação transmitida dentro do sistema nos diferentes subsistemas e nos diferentes níveis de organização do sistema. Trata-se, de fato, da significação dessa informação para o sistema. (ATLAN, 1992, p.74).
\end{abstract}

Essa é a forma através da qual, para Atlan, é possível introduzir os efeitos do sentido, a significação, numa teoria quantitativa da organização - a partir do Princípio da Complexidade a Partir do Ruido. E o que seria essa dita complexidade sistêmica? Atlan fala da complexidade como medida negativa, como relacionada aos níveis de organização do sistema sendo uma medida da informação que nos falta sobre o sistema, da incerteza sobre o sistema. Na compreensão de Atlan, "[...] a complexidade é uma desordem aparente onde temos razões para presumir uma ordem oculta; ou ainda, a complexidade é uma ordem cujo código não conhecemos." (ATLAN, 1992, p.67).

No contexto da presente pesquisa, na medida em que propomos estudar os processos criativos coletivos em artes digitais como sistemas complexos adaptativos, as noções de Atlan sobre os sistemas humanos, numa perspectiva dos complexos sociais, são basilares para construir nosso olhar, para entendermos de que forma é possível integrar a autoobservação ao sistema. Segundo Atlan, “[...] nos sistemas humanos, o observador é não apenas um elemento do sistema (eventualmente estendido ao sistema inteiro), mas é também um meta-sistema que o contém, na medida em que ele o observa." (ATLAN, 1992, p.82).

Para o biólogo, nos sistemas sociais, as relações entre o nível elementar e o nível global são invertidas, sendo, o conteúdo, ao mesmo tempo, o continente - "O indivíduo está

\footnotetext{
${ }^{12}$ Uma referência ao título de seu livro originalmente publicado em 1979 pela Éditions du Seuil, sob o título original 'Entre le cristal et la fumée. Essai sur l'organization du vivant.'
} 
contido no sistema, do ponto de vista de uma observação 'objetiva', isto é, se esquecermos que é ele o observador. Na verdade, sua situação de observador faz com que o código individual seja, ao mesmo tempo, mais geral do que o código social, na medida em que a observação engloba o observado." (ATLAN, 1992, p.82). Nessas relações existe uma evidente riqueza organizacional, posto que os indivíduos que constituem o sistema dispõem de significações que se situam simultaneamente no nível dos elementos do sistema, um nível elementar, e no nível geral que engloba a sociedade, o universo do observador.

Numa perspectiva que dialoga com a de Atlan, a noção de organização autopoiética, dos biólogos Humberto Maturana e Francisco Varela, discute a organização do ser vivo, indo do nível celular (tomando como pressuposto a convencional realidade bioquímica), ao nível social, numa perspectiva ecológica, tendo a complexidade como moldura. A tese dos autores ajuda a discutir as relações entre os elementos de um complexo - no caso, um sistema complexo adaptativo. A perspectiva trazida pela autopoiese, ajuda a compreender de que forma essas relações, estão envolvidas no fenômeno da produção do próprio sistema enquanto estrutura. A proposta dos autores é a de que "[...] os seres vivos se caracterizam por - literalmente - produzirem de modo contínuo a si próprios," (MATURANA; VARELA, 2007, p.52) o que indicam quando chamam a organização que os define de organização autopoiética.

Os autores partem para um detalhamento dessas relações, que argumentam serem mais perceptíveis no plano celular, e utilizam a organização celular como ponto de partida para ilustrarem a autopoiese enquanto fenômeno. Na argumentação dos biólogos, os componentes moleculares de uma unidade autopoiética celular, deverão estar dinamicamente relacionados, numa rede contínua de interações referida no contexto da bioquímica como metabolismo celular.

Ampliando o conceito de organização autopoiética para o nível social, os autores discutem o que chamam acoplamento de terceira ordem, ou seja, quando há um acoplamento como o que ocorre a nível celular, entre organismos com sistema nervoso, dando origem a uma fenomenologia peculiar. Quando se estabelecem acoplamentos dessa ordem, segundo os pesquisadores, as unidades resultantes, embora transitórias, 
geram uma fenomenologia interna específica. Essa fenomenologia "[...] se baseia no fato de que os organismos participantes satisfazem suas ontogenias individuais principalmente por meio de seus acoplamentos mútuos, na rede de interações recíprocas que formam ao constituir as unidades de terceira ordem." (MATURANA; VARELA, 2001, p.214).

Os pesquisadores mostram que, esses acoplamentos, que acontecem com diferentes complexidades e estabilidades, são o resultado natural da congruência das derivas ontogênicas dos organismos sendo, estes, no ponto de vista dos biólogos, necessários para a continuidade de uma linhagem nos organismos com reprodução sexuada. Nesses casos, é comum a ocorrência de algum grau de acoplamento comportamental na geração e criação dos filhotes. Essa visão traz a noção de que, tanto organismos como sociedades, pertencem à mesma classe de metassistemas formados pela agregação de unidades autônomas, celulares ou multicelulares. Nas palavras dos pesquisadores, "[...] os organismos seriam metassistemas com componentes de autonomia mínima, ou seja, com componentes de muito pouca ou nenhuma dimensão de existência independentes. Já as sociedades humanas seriam metassistemas com componentes de autonomia máxima, isto é, com componentes de muitas dimensões de existência independente." (MATURANA; VARELA, 2001, p.220).

No contexto da presente pesquisa, essa visão é interessante por trazer implícita a noção de alto grau de interdependência entre indivíduos (organismos) em complexos sociais. Essa noção pode ajudar a compreender a forma e o caráter dos acoplamentos que se evidenciam na formação de coletivos em artes digitais, em seus processos organizacionais.

\subsection{Os fenômenos emergentes}

Em um contexto em que "[...] a adequada caracterização da emergência ainda é contestada"13 (BEDAU; HUMPHREYS, 2008, p. 3, tradução nossa), a consideração de que algum fenômeno é emergente deve ser analisada a partir de evidências suportadas por discussões que envolvam conceitos fundamentais capazes de ajudar a caracterizar e

\footnotetext{
${ }^{13}$ Do original em inglês: "[...] the proper characterization of emergence still is contested" (BEDAU; HUMPHREYS, 2008, p. 3)
} 
compreender o próprio objeto de estudo em comparação com outros fenômenos. Mark Bedau e Paul Humphrey, editores de um instigante Reader sobre Emergência publicado em 2008 pelo MIT Press, observam que, o estudo e consideração de fenômenos como emergentes, deve ser cuidadoso, não se devendo abandonar simplesmente as abordagens não emergentes e reducionistas que, em muitos casos, fornecem dados importantes sobre os fenômenos em questão. Os editores chegam a afirmar que, muitas das concepções de emergência desenvolvidas e defendidas pelos autores que integram - Reader, são consistentes com muitas concepções reducionistas. No entanto é fato que, a consideração de muitos fenômenos como emergentes, têm ajudado a entender a organização e a complexidade sistêmicas, já que, a ideia de emergência, por mais multifacetada que seja, está ligada em sua gênese à ideia de sistema.

No capitulo The Rise and Fall of Britsch Emergenticism, Brian McLaughlin (2008) aponta o primeiro tratamento filosófico da questão da emergência (apesar de não estar ai, referida pelo termo específico emergência) como o tratado A System of Logic, Ratiocinative and Inductive, publicado em 1843, pelo empiricista John Stuart Mill. Nesse trabalho, Mill formula cinco princípios do raciocínio indutivo conhecidos como Método de Mill. A intenção do pesquisador era construir uma abordagem transdisciplinar, no que se refere às operações intelectuais dos seres humanos, procurando, como ele mesmo afirma, "[...] harmonizar as partes verdadeiras de teorias discordantes, fornecendo as conexões de pensamento necessárias para conectá-las, e desembaraçando-as de erros com os quais elas estão sempre mais ou menos entrelaçadas." ${ }^{.14}$ (MILL, 1946. Preface, tradução nossa).

Em Mill, o conceito de emergência, está relacionado às leis heteropáticas ${ }^{15}$,- leis que, em contraste com as leis homopáticas, que seguem seu princípio de Composição de Causas, segundo a qual o efeito conjunto de várias causas é igual à soma dos seus efeitos em separado, não cumprem esse princípio, podendo gerar novas propriedades não redutíveis aos seus componentes. Essa ideia se aplica ao processo de formação de todos

\footnotetext{
${ }^{14}$ Do original em inglês: [...] to harmonize the true portions of discordant theories, by supplying the links of thought necessary to connect them, and by disentangling them from the errors with which they are always more or less interwoven;" (MILL, 1946, Preface)

${ }^{15}$ No livro de Lloyd Morgan Emergent Evolution, segundo Brian McLaughlin: "The concept of emergence was dealt with (to go no further back) by J. S. Mill in his logic (Bk. III. Ch. Vi 2) under the discussion of "heteropathic laws in causation, (1923, p.2)." (MORGAN apud MCLAUGHLIN, 2008, p.25)
} 
complexos a partir de regras simples na interação entre suas partes. Posteriormente à publicação de Mill, foi um aluno seu, George Henry Lewis, quem utilizou pela primeira vez no livro Problems of Life and Mind, de 1875, o termo emergência para se referir aos efeitos das leis heteropáticas ${ }^{16}$. Segundo Bedau e Humphreys, Mill não considerou o princípio de composição de causas como universalmente verdadeiro porque ele também insistiu que, o que ele chamou de leis heteropáticas, "[...] operavam em determinadas ciências. Essas leis abrangem processos nos quais a composição do princípio de causas é violada, resultando em algo para o qual, para mencionar uma frase famosa, 'o todo é mais que a soma das partes.",17 (BEDAU; HUMPHREYS, 2008, p.11, tradução nossa).

O referido princípio das leis heteropáticas, ilustra de forma simples o papel da imprevisibilidade em relação à emergência. Mill tece seu argumento utilizando como exemplo a combinação dos átomos de oxigênio e hidrogênio na composição da água. Apenas pela junção das propriedades individuais dos átomos de hidrogênio e de oxigênio, e pelo conhecimento de suas leis, não é possível deduzir que a molécula $\mathrm{H} 2 \mathrm{O}$, resultará de sua combinação: essa combinação envolve novidade ontológica. Mill continua seus argumentos com um exemplo poético,

\begin{abstract}
Tomemos, por exemplo, as leis heteropáticas da mente, essa porção dos fenômenos de nossa natureza mental que são análogos a fenômenos químicos mais que a fenômenos dinâmicos; como quando uma paixão complexa é formada pela coalizão de vários impulsos elementares. Ou uma emoção complexa, por vários simples prazeres ou dores, dos quais ela é o resultado, sem ser o agregado, ou em qualquer aspecto homogênea com ele. O produto, nesses casos, é gerado por esses vários fatores, mas os fatores não podem ser reproduzidos a partir do produto: apenas como um jovem pode se transformar em um homem velho, mas um homem velho não pode se transformar em um jovem. ${ }^{18}$ (MILL, 1946, p.256, tradução nossa).
\end{abstract}

Dessa forma, partindo de trabalhos como o de Mill, e de outros que o sucederam nessa linha, como o já referido George Henry Lewis e outros nomes citados por Brian

\footnotetext{
${ }^{16}$ Segundo Lloyd Morgan, "The word "emergent," as contrasted with "resultant," was suggested by G. H. Lewes in his Problems of Life and Mind (Vol. II Prob. V. ch. lii, p. 412) (pp.2-3)" (MORGAN apud McLAUGHLIN, 2008, p.25)

${ }^{17}$ Do original em inglês: "[...] operated in certain sciences. Such laws cover process in which the composition of causes principle is violated, resulting in something for which, to sue a famous phrase, "the whole is more than the sum of the parts." (BEDAU; HUMPHREYS, 2008, p.11)

${ }^{18}$ Do original em inglês: "Take, for instance, the heteropathic laws of mind; that portion of the phenomena of our mental nature which are analogous to chemical rather than to dynamical phenomena; as when a complex passion is formed by the coalition of several elementary impulses. Or a complex emotion by several simple pleasures or pains, of which it is the result, without being the aggregate, or in any respect homogeneous with them. The product, in these cases, is generated by its various factors; but the factors cannot be reproduced from the
} product: just as a youth can grow into an old man, but an old man cannot grow in to a youth." (MILL, 1946, p.256) 
McLaughlin, como Samule Alexander em seu Space, Time, and Deity, de 1920, e Lloyd Morgan, em seu Emergent Evolution, de 1923, é possível retomar os primórdios das abordagens recentes da temática da emergência, a partir de uma perspectiva filosófica.

Nas abordagens contemporâneas, o próprio conceito engloba uma série de ideias que aparecem em diferentes definições de emergência como irredutibilidade, imprevisibilidade, novidade conceitual, novidade ontológica, holismo, auto-organização e superveniência. A atenção e interesse direcionados ao estudo da emergência, na ciência e filosofia contemporâneas, têm contribuído para ampliar ainda mais esse leque. 0 panorama em torno da ideia de emergência que procuraremos construir aqui considera ambas as perspectivas, filosóficas e científicas contemporâneas em torno do tema. As discussões em torno do conceito se baseiam, muitas vezes, no estudo de exemplos de fenômenos emergentes.

No que se refere à emergência aparente, a vida é ela mesma uma fonte vasta de exemplos observáveis e, de certa forma, didáticos, que contribuem para um entendimento primário do próprio conceito. No entanto, um fenômeno em ciência, seja ele qual for, deve ser explicado por uma série de leis de diferentes graus de generalidade. Segundo os pesquisadores Carl Hempel e Paul Oppenheim, no artigo On the idea of emergence, falando sobre níveis de explanação, análise e emergência, o conceito de emergência tem sido usado,

[...] para caracterizar certos fenômenos como 'novidade', e isso não meramente no sentido psicológico de ser inesperado, mas no sentido teórico de ser inesperável, ou imprevisível, com base na informação relativa às partes espaciais ou outros constituintes dos sistemas nos quais os fenômenos ocorrem, e as quais, nesse contexto, são frequentemente referidas como 'totalidades'19 (HEMPEL; OPPENHEIM, 2008, p.64, tradução nossa).

Na concepção dos pesquisadores, as noções de explanação e análise que suportam o conceito de emergência, clamam por observações críticas e correspondentes mudanças no próprio conceito de emergência. Como parte da questão, em primeiro lugar, eles apontam o fato de que não há como considerar um todo como emergente antes de se

\footnotetext{
${ }^{19}$ Do original em inglês: [...] to characterize certain phenomena as 'novel,' and this not merely in the psychological sense of being unexpected, but in the theoretical sense of being unexpectable, or unpredictable, on the basis of information concerning the spatial parts or other constituents of the systems in which the phenomena occur, and which in this context are often referred to as 'wholes,' (HEMPEL; OPPENHEIM, 2008, p.64)
} 
definir quais são suas partes. Uma segunda questão, se refere ao fato de, a caracterização de um todo como emergente, estar relacionada à evidência de que sua ocorrência não pode ser inferida unicamente através do conhecimento das propriedades de suas partes. Uma última questão está relacionada ao fato de a previsibilidade de uma dada característica de um todo, baseada em informações especificadas de suas partes ser dependente de leis gerais e teorias disponíveis. Essas considerações, segundo os pesquisadores, sugerem a seguinte redefinição de emergência: "A ocorrência de uma característica $W$ em um objeto $W$ é emergente relativamente a uma teoria $T$, uma relação parcial $P t$, e uma classe $G$ de atributos se essa ocorrência não puder ser deduzida através de $T$ a partir de uma caracterização das partes-Pt de $w$ com relação a todos os atributos em G."20 (HEMPEL; OPPENHEIM, 2008, p.64, tradução nossa, grifo do autor).

Essa formulação, na visão de Hempel e Oppenheim, explica o significado da emergência no que se refere a eventos de um certo tipo, ou seja, a ocorrência de algumas características $W$ no objeto $W$. A visão dos pesquisadores é interessante, na medida em que relaciona emergência, não a características, mas a eventos. Mesmo considerando as contradições e incertezas em torno do conceito ele mesmo, a noção de emergência, como afirma Brian McLaughlin (McLAUGHLIN, 2008, p.81) desempenhou um papel proeminente na filosofia da primeira metade do século $X X$, tendo, na última década desse século, se tornado novamente o foco das atenções.

No artigo Emergence and Supervenience (2008) o autor discute, numa abordagem contextualizada no Emergenticismo Inglês, como o conceito de superveniência pode ser empregado, utilizando-o para explicar a noção de emergência. McLaughlin apresenta a noção de James van Cleve de propriedade emergente, a partir da publicação Emergence vs. Panpsychism: Magic or Mind Dust? (VAN CLEVE, 1990) que invoca a noção de superveniência. O pesquisador McLaughlin, fala das duas principais noções de superveniência encontradas na literatura atual sobre o tema. A primeira é a de que não pode haver uma diferença de um tipo sem uma diferença de outro tipo, ou seja, não há como, por exemplo, existir uma diferença mental sem haver uma diferença física. A segunda noção de superveniência se refere à relação entre propriedades. Por exemplo

${ }^{20}$ Do original em inglês: "The occurrence of a characteristic $W$ in an object $W$ is emergent relative to a theory $T$, a part relation $P t$, and a class $G$ of attributes if that occurrence cannot be deduced by means of $T$ from a characterization of the Pt-parts of $w$ with respect to all the attributes in G." (HEMPEL; OPPENHEIM, 2008, p.64) 
(MCLAUGHLIN, 2008, p.90), ter uma certa propriedade mental requer que se tenha alguma propriedade física que a suporte.

Em artigo em que apresenta e discute diversas dimensões do conceito de superveniência, David Chalmers traz uma definição interessante. Nas palavras de Chalmers, "a noção de superveniência formaliza a ideia intuitiva de que um conjunto de fatos pode determinar totalmente outro conjunto de fatos." ${ }^{21}$ (CHALMERS, 2008, p.411, tradução nossa). Segundo o autor, a ideia de superveniência foi introduzida por Moore em 1922 (MOORE, 1922, apud CHALMERS, 2008, p.420) e referida em publicação pela primeira vez por Hare, em 1952 (HARE, 1952, apud CHALMERS, 2008, p.420).

Chalmers fala dos trabalhos do pesquisador Jaegwon Kim, responsável por uma sofisticada teoria da superveniência. No livro que reúne ensaios escritos por Kim ao longo de um período de 20 (vinte) anos, nomeadamente na Parte I - Events and Supervenience, o autor apresenta e discutes vários conceitos de superveniência. Segundo Chalmers (2008), Kim lembra que David Hume, em sua celebrada discussão sobre causalidade, identifica quatro constituintes prima face da relação de causalidade conjunção constante, continuidade espaço-temporal, prioridade temporal e conexão necessária. A questão colocada pelo pesquisador, Kim se refere ao que essas quatro relações dizem sobre a natureza das entidades às quais se relacionam. Kim formula três versões da causalidade de Hume, para discutir a estrutura dos eventos relacionando à noção de superveniência, caracterizando o que define como superveniência fraca, forte e global (dos termos originais em inglês: weak, strong e global supervenience).

Essas noções são abordadas e rediscutidas por David Chalmers (2008, p.413), que traz outras diferentes noções, e ilustra as relações mostrando, por exemplo, que o que chama superveniência local implica superveniência global, mas não o contrário. Para o autor, "[...] é plausível que propriedades biológicas supervenham globalmente sobre propriedades físicas, em que todo mundo fisicamente idêntico ao nosso pode também

\footnotetext{
${ }^{21}$ Do original em inglês: "the notion of supervenience formalizes the intuitive idea that one set of facts can fully determine another set of facts."(CHALMERS, 2008, p.411) 
ser biologicamente idêntico. [...] mas eles não supervêm localmente."22 (CHALMERS, 2008, p. 413, tradução nossa). No entanto, como o pesquisador ressalta, a distinção entre superveniência global e local, por exemplo, não faz sentido quando se trata da questão da experiência da consciência - porque é como se, na medida em que a consciência supervém ao físico, ela supervenha localmente. Na abordagem de Chalmers, a distinção entre superveniência lógica (ou conceitual) e a superveniência natural (ou empírica) ganha importância. Um exemplo é o fato de, em um nível global, as propriedade biológicas, segundo o autor, supervenirem logicamente sobre as propriedades físicas.

Retomando a questão da emergência, de um modo geral, pode-se dizer que as noções e, sobretudo os exemplos de emergência, apesar da imensa variedade de abordagens, envolvem o comportamento de algum tipo de sistema complexo. O estudo da emergência está, dessa forma, intimamente e historicamente atrelado ao estudo desses sistemas. No entanto, nem todas as abordagens pertencem às ciências da complexidade. Como afirmam Mark Bedau e Paul Humphreys (BEDAU; HUMPHREYS, 2008, p.209, tradução nossa), "[...] vários artigos científicos discutem emergência especificamente no contexto da mecânica quântica," 23 tendendo, no entanto, a serem muito técnicos.

Trabalhos como o de Michael Esfeld, da University of Lausanne, Suiça, aproximam a quântica e o estudo dos sistemas complexos. No artigo Quantum entanglement and a metaphysics of relations, Esfeld propõe uma caracterização filosófica do entrelaçamento quântico a partir de uma moldura metafísica. Nas palavras do pesquisador, seus argumentos vão de encontro a uma “[...] metafísica das relações baseada na caracterização do entrelaçamento quântico em termos de não separabilidade, dizendo respeito, desse modo, ao entrelaçamento como uma espécie de holismo." ${ }^{24}$ (ESFELD, 2004, p.1, tradução nossa). É dessa forma que a noção de entrelaçamento, extrapolando as fronteiras da quântica e para além da conexão com fenômenos emergentes, pode ajudar a entender as relações entre elementos, entre elementos e todo e deste com o ambiente, nos estudo de sistemas complexos.

${ }^{22}$ Do original em inglês: "[...] it is plausible that biological properties supervene globally on physical properties, in that any world physically identical to ours would also be biologically identical. [...] but they do not supervene locally." (CHALMERS, 2008, p. 413)

${ }^{23}$ Do original em inglês: "[...] a number of scientific articles discuss emergence specifically in the context of quantum mechanics" (BEDAU; HUMPHREYS, 2008, p.209)

${ }^{24}$ Do original em inglês: "[...] metaphysics of relations based on a characterization of quantum entanglement in terms of non-separability, thereby regarding entanglement as a sort of holism. (ESFELD, 2004, p.1) 


\title{
2.6. Entrelaçamento quântico e Decoerência
}

Einstein, Podolsky e Rosen, no famoso artigo publicado em maio de 1935 na Physical Review, Can Quantum-Mechanical Description of Physical Reality Be Considered Complete?, partem do fato de que, na mecânica quântica, no caso de duas quantidades descritas por operadores não-comutantes, o conhecimento de uma opõe-se ao conhecimento da outra. Nesse artigo, referido consensualmente como Paradoxo Einstein-Podolsky-Rosen (a partir do termo em inglês EPR - Einstein-Podolsky-Rosen Paradox), os cientistas consideram que, ou a descrição da realidade fornecida pela função de onda não é completa, ou essas duas quantidades referidas não podem ter realidade simultânea. Os cientistas concluem que, a função de onda, não provê uma descrição completa da realidade física. Eles chegam a essa conclusão baseando-se na premissa de que, para uma teoria ser considerada completa, cada elemento da realidade física deve ter sua contra partida na teoria física. Nas palavras de Einstein, Podolsky e Rosen,

\begin{abstract}
Anteriormente nós provamos que ou (1) a descrição quantum-mecânica da realidade dada pela função de onda não é completa ou (2) quando os operadores correspondentes a duas qualidades físicas não comutam as duas quantidades não podem ter realidade simultânea. Partindo então do pressuposto de que a função de onda não fornece uma descrição completa da realidade física, nós chegamos à conclusão de que duas quantidades físicas, com operadores não comutantes, podem ter realidade simultânea. Assim, a negação de (1) leva à negação da outra única alternativa (2). Somos então forçados a concluir que a descrição quantum-mecânica da realidade física dada pela função de onda não é completa. ${ }^{25}$ (EINSTEIN; PODOLSKY; ROSEN, 1935, p.780, tradução nossa).
\end{abstract}

A posição dos cientistas é um exemplo clássico da atmosfera de insegurança dos primórdios da teoria quântica. Como afirma Peter J. Riggs, no livro Quantum Causality: Conceptual Issues in the Casual Theory of Quantum Mechanics, "os primeiros dias da teoria quântica foram um período de grande perplexidade e desilusão para aqueles envolvidos na tentativa de formular um esquema teórico consistente dos fenômenos

\footnotetext{
${ }^{25}$ Do original em inglês: "Previously we proved that either (1) the quantum-mechanical description of reality given by the wave function is not complete or (2) when the operators corresponding to two physical quantities do not commute the two quantities cannot have simultaneous reality. Starting then with the assumption that the wave function does give a complete description of the physical reality, we arrived at the conclusion that two physical quantities, with noncommuting operators, can have simultaneous reality. Thus the negation of (1) leads to the negation of the only other alternative (2). We are thus forced to conclude that the quantum-mechanical description of physical reality given by wave functions in not complete." (EINSTEIN; PODOLSKY; ROSEN, 1935, p.780)
} 
atômicos." 26 (RIGGS, 2009, p.19, tradução nossa) Segundo Riggs, as colocações de Heisenberg no trecho abaixo ilustram a atmosfera do momento:

\begin{abstract}
[...] um estudo intensivo de todas as questões concernentes à interpretação da teoria quântica em Copenhagen finalmente levou a um completo esclarecimento da situação. Mas não era uma solução que alguém poderia facilmente aceitar. Lembro-me de discussões com Bohr que se prolongavam por várias horas até tarde da noite e terminavam quase em desespero, e quando, no final da discussão fui sozinho para uma caminhada no parque vizinho, eu repetia para mim mesmo de novo e de novo a questão: pode a natureza ser tão absurda quanto ela nos parece nos experimentos atômicos? ? $^{27}$ (HEISENBERG 1989, p.30 apud RIGGS, 2009, p. 19, tradução nossa).
\end{abstract}

As inquietações de Heisenberg, não só eram pertinentes no contexto em que foram proferidas quanto o são, ainda hoje, para o debate contemporâneo em mecânica quântica. No entanto, apesar de parecer absurda em muitos aspectos, a mecânica quântica, como afirma Riggs, "[...] é uma das duas teorias mais bem confirmadas experimentalmente em toda a história da física (a outra sendo, com certeza, a Relatividade)" 28 (RIGGS, 2009,p.20, tradução nossa), existindo poucas discordâncias sobre seu aparato matemático.

A Interpretação de Copenhagen (também referida como Teoria Quântica Ortodoxa, que se deve originalmente a Niels Bohr e Werner Heisenberg (que trabalhavam juntos em Copenhagen em 1927), progredindo com trabalhos de Max Born, Wolfgang Pauli, John von Neumann, entre outros, alcançou supremacia na comunidade física. A interpretação de Copenhague defende que, em mecânica quântica, os resultados são indeterminísticos, não se podendo especular além do que pode ser medido. Além, essa interpretação implica a admissão de que o ato de observar provoca o colapso da função de onda que se modifica instantaneamente para refletir a escolha aleatória do processo de medição. No entanto, nomes como Murray Gell-Mann, ganhador do Prêmio Nobel de Física em 1969, contestam essa posição, afirmando que "Bohr promoveu a lavagem cerebral de

\footnotetext{
${ }^{26}$ Do original em inglês: "The early days of quantum theory were a period of great puzzlement and disillusion for those involved in trying to formulate a consistent theoretical scheme of atomic phenomena." (RIGGS, 2009, p.19)

${ }^{27}$ Do original em inglês: "[...] an intensive study of all questions concerning the interpretation of quantum theory in Copenhagen finally led to a complete clarification of the situation. But it was not a solution which one could easily accept. I remember discussions with Bohr which went through many hours till very late at night and ended almost in despair, and when at the end of the discussion I went alone for a walk in the neighbor park I repeated to myself again and again the question: can nature possibly be as absurd as it seems to us in there atomic experiments? (HEISENBERG 1989, P.30 apud RIGGS, 2009, p. 19)

${ }^{28}$ Do original em inglês: "[...] is one of the two best experimentally confirmed theories in the whole history of physics (the other being, of course, Relativity)" (RIGGS, 2009,p.20)
} 
uma geração inteira de físicos na crença de que o problema [da interpretação da mecânica quântica] tinha sido resolvido cinquenta anos atrás."29 (GELL-MANN, 1972 apud RIGGS, 2009, p.20, tradução nossa).

Críticas como as de Gell-Mann, se apoiam no fato de que, o processo de observação nos experimentos, é de caráter não físico. A alternativa principal à Interpretação de Copenhagen é a Interpretação de Everett dos Mundos Paralelos ou, a Interpretação de Muitos Mundos (referente aos trabalhos desenvolvidos posteriormente por Bryce DeWitt). Essa interpretação formulada inicialmente pelo cientista Hugh Everett em sua tese de PhD na Princeton University, tenta dar conta de alguns processos nãodeterminísticos em mecânica quântica. As várias versões da proposta que emergiram a partir de então, compartilham, de um modo geral, dois princípios basilares. O primeiro considera a existência de uma função de estado universal, obedecendo à equação de Schrödinger para todo tempo e para a qual, não há colapso da função de onda. Esse princípio é complementado pela ideia de que, esse estado universal, é uma sobreposição quântica de vários e possivelmente infinitos, estados idênticos de universos paralelos não comunicantes. Esses princípios vão de encontro aos da Teoria Quântica Ortodoxa, contradizendo objetivamente as asserções da Interpretação de Copenhagen no que se refere ao colapso da função de onda provocado pelo ato de observar no processo de medição.

Juntamente com o Paradoxo Einstein Podolsky e Rosen, de 1935, o experimento conhecido como O Gato de Schrödinger (Schrödinger's Cat Paradox) é, na verdade, um experimento imaginário. O experimento de Erwin Schrödinger, publicado no artigo Die gegenwärtige Situation in der Quantenmechanik (The present situation in quantum mechanics, na tradução para o Inglês) foi publicado no periódico Naturwissenschaften (Natural Sciences). Esse artigo aparece no mesmo ano em que Einstein e os colegas publicaram, anteriormente, o artigo onde questionavam a completude da descrição quantum-mecânica da realidade. No referido artigo, Schrödinger afirma, em uma nota de rodapé, ter sido motivado pela publicação do EPR. O experimento ilustra a visão de Schrödinger sobre o que acreditava ser o problema central da Interpretação de

${ }^{29}$ Do original em inglês: "Bohr brainwashed a whole generation of physicists into believing that the problem [of the interpretation of quantum mechanics] had been solved fifty year ago." (GELL-MANN, 1972 apud RIGGS, 2009, p.20) 
Copenhagen da mecânica quântica aplicada à realidade. $O$ experimento apresenta um gato que pode estar tanto vivo quanto morto, dependendo de um evento randômico anterior. Nas considerações do cientista,

\begin{abstract}
Uma pessoa pode mesmo montar casos bem ridículos. Um gato está preso em uma câmara de aço, juntamente com o seguinte dispositivo (que deve ser protegido contra a interferência direta do gato): num contador Geiger há uma pequena quantidade de substância radioativa, tão pequena, que talvez no decurso de uma hora um dos átomos decaia, mas também, com igual probabilidade, talvez nenhum; se isso acontecer, o tubo do contador descarrega e através de um relé libera um martelo que quebra um pequeno frasco de ácido cianídrico. Se alguém deixou este sistema sozinho por uma hora, pode-se dizer que o gato permanece vivo se nesse meio tempo o átomo não decai. A função-psi do sistema inteiro poderia ser expressa por ter em si o gato vivo e o morto (com perdão da expressão) misturado ou dividido em partes iguais. ${ }^{30}$ (SCHRÖDINGER, 2010, grifo do autor).
\end{abstract}

Schrödinger utiliza o exemplo para ilustrar suas colocações acerca dos Problemas de Medição na Teoria Quântica Ortodoxa. No experimento o cientista evidencia que não é possivel saber o resultado antes que ele seja medido, ou seja, que se olhe dentro da caixa. Como explica Riggs, "se assumirmos que o estado do gato é descrito por um vetor de estado, então previamente à observação, a Teoria Quântica Ortodoxa dita que o vetor de estado do gato está em uma superposição correspondente ao gato estar ambos vivo e morto!”31 (RIGGS, 2009, p.36, tradução nossa). A descrição de uma entidade quântica por uma superposição como esta é aceitável. No entanto essa situação não condiz com a realidade factual observável em escala macroscópica.

Assim temos que, os dois principais paradoxos da mecânica quântica, se baseiam na hipótese do realismo - a da existência objetiva de elementos da realidade e no princípio da localidade, utilizado no artigo de Einstein, Podolsky e Rosen, segundo o qual, "elementos da realidade pertencendo a um sistema não podem ser afetados pela

\footnotetext{
${ }^{30}$ Do original em inglês: "One can even set up quite ridiculous cases. A cat is penned up in a steel chamber, along with the following device (which must be secured against direct interference by the cat): in a Geiger counter there is a tiny bit of radioactive substance, so small, that perhaps in the course of the hour one of the atoms decays, but also, with equal probability, perhaps none; if it happens, the counter tube discharges and through a relay releases a hammer which shatters a small flask of hydrocyanic acid. If one has left this entire system to itself for an hour, one would say that the cat still lives if meanwhile no atom has decayed. The psi-function of the entire system would express this by having in it the living and dead cat (pardon the expression) mixed or smeared out in equal parts." (SCHRÖDINGER, 2010)

${ }^{31}$ Do original em inglês: "If we assume that the cat's state is described by a state vector, then prior to observation Orthodox Quantum Theory dictates that the cat's state vector is in a superposition corresponding to the cat being both alive and dead!" (RIGGS, 2009, p.36)
} 
medição realizada a uma distância do tipo espacial em outro sistema, mesmo se os sistemas interagiram anteriormente."32 (RIGGS, 2009,p.34, tradução nossa). Desse modo, não existe possibilidade real de qualquer ação à distância para sistemas separados espacialmente. No original em Alemão, para além da famosa apresentação do gato à qual é dedicado um único parágrafo, o artigo apresenta um panorama amplo do pensamento do cientista sobre o tema tratado. Nesse artigo de 1935 que Schrödinger faz uso da palavra Verschränkung (entanglement, na tradução para o inglês e entrelaçamento, na tradução para o português), dando sequência às explicações sobre o fato de, o ato de medição, suspender a lei que "[...] em caso contrário governa a dependência temporal contínua da função-psi e provoca nela uma mudança bastante diferente, não regida por nenhuma lei mas antes dedicada pelos resultados da medição."33 (SCHRÖDINGER, 2010, tradução nossa).

Schrödinger argumenta que, leis da natureza diferentes das habituais, não podem aplicar-se apenas durante uma medição que, numa visão objetiva, é um processo natural como qualquer outro e não pode interromper o curso regular de eventos naturais. Ele não admite que o estado, que é a função-psi - soma máxima de conhecimento sobre um dado sistema, possa ser diferente para parte e todo nesse mesmo sistema. Para Schrödinger, o resultado de experimentos que comprovariam o fato, é absurdo, já que, um sistema como um todo, deve estar em algum tipo de estado. Ainda, se o estado é a função-psi, e esta é desconhecida para o subsistema ou as partes do sistema observado, então simplesmente não existe função-psi, e o sistema não está em estado algum.

O cientista continua considerando que a porção de conhecimento sobre o sistema, que deve flutuar na forma de declarações condicionais disjuntivas entre dois objetos estudados (as duas partes de um mesmo sistema ou subsistemas), não pode ocorrer se trazemos os dois subsistemas de partes opostas do mundo e os colocamos juntos sem interação. Dessa forma, essas duas partes do sistema, não sabem nada uma sobre a outra. Uma medição em uma, não pode possivelmente fornecer qualquer compreensão

\footnotetext{
32 Do original em inglês: "elements of reality pertaining to one system cannot be affecte by measurements performed at a space-like distance on another system, even if the system previously interacted." (RIGGS, 2009,p.34)

${ }^{33}$ Do original em inglês: "[...] otherwise governs continuous time-dependence of the psi-function and brings about in it a quite different change, not governed by any law but rather dedicated by the results of the measurement." (SCHRÖDINGER, 2010)
} 
do que pode ser esperado da outra. Qualquer entrelaçamento de predições que aconteça pode, obviamente, apenas voltar ao fato de que "[...] os dois corpos em um momento anterior formaram em um sentido verdadeiro um sistema, ou seja, estavam interagindo, e deixaram pra trás traços um no outro."34 (SCHRÖDINGER, 2010, tradução nossa). Assim, para Schrödinger, se dois corpos cada um desses conhecendo-se maximamente, entram em uma situação em que influenciam-se mutuamente e são então novamente separados, então ocorre o que ele chama entrelaçamento do nosso conhecimento dos dois corpos.

Como mostra Rae (RAE, 2002), no livro Quantum Mechanics, publicado pela primeira vez no início dos anos 1980, novas aplicações de conceitos da mecânica quântica que foram desenvolvidos durante as últimas duas décadas do século $X X$, refletem o entendimento crescente de um certo número de conceitos primários, basilares, e sua aplicação a novos fenômenos previstos ou observados. Entre essas ideias, que vão do tele transporte quântico à criptografia (Quantumcryptography) estão as de entrelaçamento quântico e de decoerência quântica.

A noção de entrelaçamento, como vimos, diz respeito à inseparabilidade dos elementos de um dado conjunto quântico. Mesmo após a interação entre os elementos ter cessado a inseparabilidade ou entrelaçamento originários, pode afetar o estado de um elemento quando outro elemento está sujeito a uma ação não unitária, como uma medição, delineamento ou termalização. Na quântica contemporânea, segundo Rae, "[...] a palavra 'entrelaçamento' se refere a um estado quântico de duas ou mais partículas no qual as probabilidades de medição em uma delas depende do estado da outra, mesmo pensando que aqui não existe interação entre elas." ${ }^{35}$ (RAE, 2002, p.245, tradução nossa).

O outro conceito chave, a decoerência de sistemas quânticos abertos, é uma consequência do entrelaçamento do sistema com o seu ambiente. H. Dieter Zeh, no artigo Roots and Fruits of Decoherence, publicado no livro Quantum decoherence:

\footnotetext{
${ }^{34}$ Do original em inglês: "[...] the two bodies at some earlier time formed in a true sense one system, that is were interacting, and have left behind traces on each other." (SCHRÖDINGER, 2010)

${ }^{35}$ Do original em inglês: "[...] the word 'entanglement' refers to a quantum state of two or more particles in which the probabilities of the outcome of measurements on one of them depend on the state of the other, even thought here is no interaction between them." (RAE, 2002, p.245)
} 
Poincaré Seminar 2005, ilustra o conceito de decoerência quântica utilizando como exemplo o fato de os estados rotacionais de objetos macroscópicos serem muitos densos. Segundo o pesquisador, em consequência desse fato, "[...] eles não podem resistir ao entrelaçamento com seu ambiente mesmo no caso de interações muito fracas." $^{36}$ (ZEH, 2006, p.156, tradução nossa).

As suas reduzidas matrizes de densidade devem sempre representar estados mistos, enquanto a localidade dessas interações leva à expulsão de “[...] elementos nãodiagonais preferencialmente na representação posição ou 'ponteiro'., 37 (ZEH, 2005, p.156, tradução nossa). É esse fenômeno que é reconhecido atualmente como decoerência. Para o pesquisador (ZEH, 2005, p.157), um dos mais importantes frutos da ideia de decoerência, entendida como um entrelaçamento universal, num dado sistema em estudo, é o fato de não serem requeridos quaisquer conceitos de mecânica clássica em um nível fundamental.

Como explica o pesquisador, para objetos macroscópicos, "[...] os quais podem ser suficientemente isolados, a física experimental tem uma escolha entre medições mutuamente exclusivas ('conjugadas'), enquanto propriedades macroscópicas são decoeridas por seu inevitável ambiente de uma maneira geral e específica." ${ }^{38}$ (ZEH, 2006 , p.157, tradução nossa). Isso explica a aparência clássica dos objetos macroscópicos. Do mesmo modo, como mostra Zeh, "[...] o mundo clássico parece local para nós, desde que entrelaçamento não-local se torna imediatamente incontrolável: ele é decoerido.”39 (ZEH, 2006, p.157, tradução nossa). Segundo Akulin, Kurizki e Lidar (2007), a despeito de que novos insights sobre entrelaçamento e decoerência, não existem ainda respostas completas e inequívocas para as questões fundamentais da transição do comportamento quântico para o clássico.

\footnotetext{
${ }^{36}$ Do original em inglês: "[...] they cannot resist entanglement with their environment even in the case of very weak interactions." (ZEH, 2005, p.156)

37 Do original em inglês: "[...] non-diagonal elements preferentially in the position or "pointer' representation." (ZEH, 2005, p.156)

${ }^{38}$ Do original em inglês: "[...] which can be sufficiently isolated, the experimental physicist has a choice between mutually exclusive ('conjugate') measurements, while macroscopic properties are decohered by their unavoidable environment in a general and specific maner." (ZEH, 2005, p.157)

${ }^{39}$ Do original em inglês: "[...] the classical world appears local to us, since nonlocal entanglement becomes immediately uncontrollable: it is decohered." (ZEH, 2005, p.157)
} 
A fim de resolver as questões pendentes do processo de transição do pensamento clássico para o quântico, ou chamada transição quântica-clássica, estudando o controle do entrelaçamento quântico e da decoerência sem as restrições convencionais, os pesquisadores acreditam que, um caminho, é se aventurar no domínio dos Sistemas Complexos Quânticos (termo abreviado para QTACS, a partir do termo em inglês, Quantum Complex Systems), consistindo estes, por definição, "[...] de um grande número de elementos inseparáveis ou tendo muitos graus de liberdade acoplados." ${ }^{40}$ (AKULIN; KURIZKI; LIDAR, 2007, tradução nossa).

A intenção é a de que os trabalhos envolvendo entrelaçamento quântico nos QUACS, e mesmo seu entrelaçamento com o ambiente (o que caracteriza a decoerência), possam levar à criação de um novo quadro conceitual que extrapole os limites subatômicos à baixas temperaturas, sendo capazes de dar conta, englobando, fenômenos comuns tanto aos átomos frios em campos de laser, às grandes moléculas, aos gases e sólidos quânticos, podendo essa visão ser aplicada, por exemplo, a campos como a computação e processamento de informação.

Os pesquisadores (AKULIN; KURIZKI; LIDAR, 2007) acreditam que, esses progressos, podem ajudar a responder questões centrais como, por exemplo, se o entrelaçamento desempenha um papel essencial na evolução de grandes coleções de sistemas complexos ou mesmo, quais são os limites de tamanho e complexidade de sistemas e conjuntos ainda controláveis por uma intervenção externa.

Um importante avanço no estudo do entrelaçamento quântico (GREENBERGER et al, 1990), aconteceu em 1989, quando Daniel Greenberger, Michael Horne, e Anton Zeilinger, consideraram estados correlacionados de três ou mais partículas entrelaçadas. Eles mostraram que depois de duas das três partículas terem sido medidas, a medição da terceira partícula se tornou um teste entre realismo local e mecânica quântica na medida em que cada um predizia um valor diferente para o resultado da medição. Isso eliminou a dependência estatística encontrada no Teorema de Bell. Esse teorema mostra que, as previsões estatísticas da Teoria Quântica, são aproximadamente corretas. Isso implica

\footnotetext{
${ }^{40}$ Do original em inglês: "[...] of a large number of inseparable elements or having many coupled degrees of freedom." (AKULIN; KURIZKI; LIDAR, 2007) 
que, em certos casos, o princípio da causalidade local, que afirma que os eventos em uma região no espaço são aproximadamente independentes das variáveis sujeitas ao controle de medidores em regiões distantes e no mesmo momento, deve falhar.

Usualmente, a física quântica é aplicável a sistemas em escala atômica a baixas temperaturas. Um exemplo clássico pode ser a dinâmica quântica de um elétron em um átomo de hidrogênio. A baixas temperaturas, as energias típicas que caracterizam saltos dos elétrons são centenas de vezes maiores do que a energia térmica do ambiente ao qual o sistema está exposto. Assim, o ruído do ambiente torna-se insignificante em comparação com as energias dos saltos dos elétrons e, portanto, o ambiente não interfere na quântica do sistema.

Essas noções começam a ser contestadas, como mostra o artigo publicado em 2010 no periódico Physical Review Letters, Bringing Entanglement to the High Temperature Limit. onde os pesquisadores Fernando Galve, Leonardo Pachón e David Zueco' (GALVE et al, 2010) mostraram que, ao contrário do que se acredita comumente, um sistema macroscópico a altas temperaturas pode também sustentar comportamentos quânticos.

O experimento mostra que, quando um sistema não está em equilíbrio térmico, a temperatura inferior do ambiente ao qual ele está exposto, não fornece uma escala de energia relevante com relação ao comportamento quântico do sistema. Os cientistas propõem uma técnica para entrelaçar dois osciladores, os quais podem ser tanto átomos quanto peças vibratórias de silicone, a temperaturas mais altas que as usuais para experimentos em quântica. Para átomos, a temperatura do ambiente pode estar por volta de $50^{\circ}$ Kelvin. A equipe acredita que, essa técnica, pode produzir avanços no estudo de entrelaçamento quântico em temperaturas dificeis de atingir (a partir da expressão em inglês: entanglement at difficult-to-reach temperatures) 


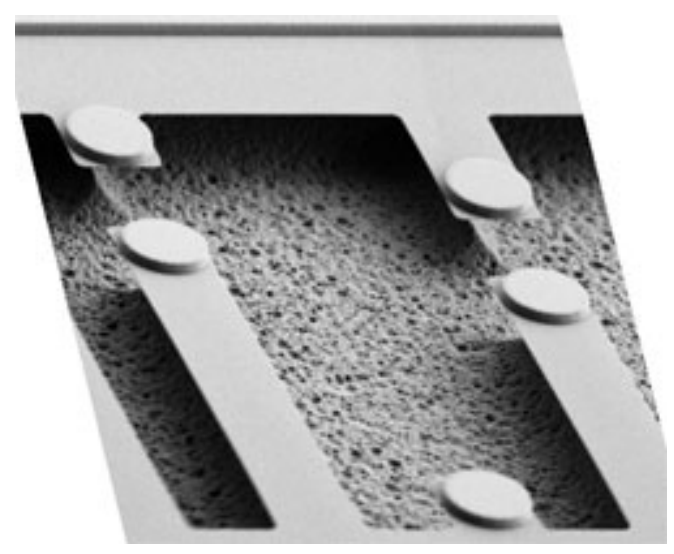

Figura 1.02 // Nano-diving-boards: Os balanços de nitreto de silício na figura são macroscópicos embora tenham menos de 50 mícrons de largura. Essa estrutura faz parte de experimentos que objetivam entrelaçar quanticamente objetos macroscópicos.

\subsection{Nos domínios da Interação Quântica}

Para além dos domínios subatômicos da mecânica quântica, um tema emergente na área de Interação Quântica (a partir do termo em inglês QI - Quantum Interaction), é o uso de espaços semânticos léxicos, como os espaços de Hilbert, para captar o significado das palavras. Segundo o professor N. P. Landsman, do Institute for Mathematics, Astrophysics, and Particle Physics, da Radboud University, em Nijmegen, Holanda, os chamados Espaços de Hilbert, têm um papel central em áreas como a matemática, notavelmente em análise, incluindo também geometria (diferencial), estocástica e, ainda, teoria dos números, entre outros.

Segundo o professor, "a noção de um espaço de Hilbert fornece a base matemática da mecânica quântica." "11 (LANDSMAN, 2010, p.3, tradução nossa). A definição de espaços semânticos léxicos foi dada pela primeira vez por John Von Newman, mesmo antes do próprio Hilbert, em 1927. Esse conceito generaliza a noção de espaço Euclidiano estendendo os métodos da álgebra vetorial e do cálculo do plano euclidiano bidimensional e tridimensional para espaços com qualquer número de dimensões, finito ou infinito.

\footnotetext{
${ }^{41}$ Do original em inglês: "the notion of a Hilbert space provides the mathematical foundation of quantum mechanics." (LANDSMAN, 2010, p.3)
} 
Pesquisadores da Robert Gordon University (2010), em Aberdeen, Reino Unido, responsáveis pela organização do Fifth International Quantum Interaction Symposium, que acontecerá em Aberdeen, em Junho de 2011, mostram que, a Interação Quântica, tem sido aplicada a domínios os mais diversos, como inteligência artificial, linguagem humana, cognição, biologia, ciência política, economia, e interação social. O objetivo do simpósio que está em sua décima quinta edição, é o de discutir de que formas a teoria quântica pode ter interfaces com, e ajudar a resolver problemas com eficiência em, domínios não-quânticos

É nesse contexto que, segundo alguns pesquisadores interessados em Interação Quântica (BRUZA et AL, 2008), existem evidencias iniciais de que, o fenômeno do entrelaçamento quântico, existe em um espaço semântico e pode, potencialmente, desempenhar um papel crucial na determinação da semântica incorporada. No trabalho apresentado no artigo Characterizing Pure High-order Entanglements in Lexical Semantic Spaces via Information Geometry, os pesquisadores Yuexian Hou e Dawei Song, propõem entrelaçamento puro de ordem elevada (que não pode ser reduzido ao efeito de composição dos entrelaçamentos de ordem inferior), como um indicador de entidades semânticas de alto nível.

Segundo os pesquisadores, a emergente linha de pesquisa envolve a captura de significado de palavras baseando-se, como referido anteriormente, nos espaços semânticos léxicos, de múltiplas dimensões (como espaços de Hilbert). Para eles, a intuição é a de que "[...] seres humanos encontrando um novo conceito frequentemente derivam seu significado via experiência acumulada dos contextos nos quais o conceito aparece. Portanto, o significado de uma palavra pode ser capturado examinando seus padrões de co-ocorrência com outras palavras, no uso da língua (por exemplo, num corpo de textos)."42 (HOU; SONG, 2010, tradução nossa).

Um espaço semântico típico é o Hiperespaço Análogo à Linguagem (a partir do termo em inglês HAL - Hyperspace Analogue to Language). Os pesquisadores afirmam que, de

\footnotetext{
${ }^{42}$ Do original em inglês: "[...] humans encountering a new concept often derive its meaning via the accumulative experience of contexts in which the concept appears. Therefore, the meaning of a word can be captured by examining its co-occurrence patterns with other words in the language use (e.g., a corpus of texts)." (HOU; SONG, 2010)
} 
um modo geral, o espaço semântico tem demonstrado uma compatibilidade cognitiva com o processo humano de processamento da informação. Nesse contexto o que Hou e Song propõem é, baseando-se no método desenvolvido a partir da moldura da Geometria Informacional, um modelo de espaço vetorial expandido que envolve informação de alta ordem sensível ao contexto. O objetivo é caracterizar contextos de recuperação de informação de alto nível.

Com base nos métodos desenvolvidos, os pesquisadores propõem um modelo expandido de espaço vetorial que envolve alta ordem de sensibilidade ao contexto de alta ordem de informação e visa caracterizar contextos de recuperação de alto nível. Algumas ideias iniciais sobre a aplicação dos métodos propostos na expansão de consulta e de classificação de textos, também são apresentados. O método desenvolvido possibilita assim, caracterizar a ordem intrínseca dos entrelaçamentos (quânticos) e distinguir entrelaçamentos de alta-ordem, dos de baixa-ordem.

Seguindo uma abordagem que se aproxima das experiências com espaços semânticos léxicos, as noções de entrelaçamento quântico e decoerência podem ajudar, na presente tese, a compreender de que forma um elemento do sistema pode influenciar outros elementos. Pode ajudar a entender como eles se influenciam mutuamente a partir das conexões em rede e, ainda, na sua relação com o ambiente. A intenção aqui, não é a de aplicar objetivamente esses conceitos a macrosistemas, mas de utilizá-los para pensar o processo criativo a partir de uma perspectiva sistêmica, com foco no caráter emergente e auto-organizacional do complexo.

Retomando a abordagem de Michael Esfeld, que aproxima quântica e o estudo dos sistemas complexos, falando de entrelaçamento quântico e a metafísica das relações, encontramos a ideia de que "[...] falar de não-separabilidade nos fornece uma compreensão convincente do que está acontecendo no entrelaçamento quântico."43 (ESFELD, 2004, p.8, tradução nossa).

\footnotetext{
${ }^{43}$ Do original em inglês: "[...] speaking of non-separability provides us with a convincing understanding of what is going on in quantum entanglement." (ESFELD, 2004, p.8)
} 
Esfeld apresenta casos de entrelaçamento quântico que, no seu ponto de vista, podem ser vistos como casos de não-separabilidade nos quais "[...] existe apenas um estado comum determinando certas correlações obtidas entre o sistema em questão sem que seja possível atribuir estados significantes [...] para cada um dos sistemas em questão, e isso ser relativo a outros sistemas." ${ }^{44}$ (ESFELD, 2004, p.8, tradução nossa).

A noção de não-separabilidade remete ao fato de que, o estado de dois ou mais sistemas são não-separáveis se, e somente se, apenas o estado conjunto do todo determina completamente as propriedades dependentes de estado de cada um dos sistemas e as correlações entre esses sistemas. Assim, é a partir dessa caracterização de nãoseparabilidade, que o pesquisador afirma que, "[...] qualquer caso de entrelaçamento quântico é um caso de não-separabilidade, e não-separabilidade é a razão pela qual o entrelaçamento quântico é uma espécie de holismo."45 (ESFELD, 2004, p.8, tradução nossa). Esfeld define o entrelaçamento quântico em uma perspectiva holística da seguinte forma:

\begin{abstract}
1) Entrelaçamento quântico mostra que existem relações não-supervenientes entre sistemas físicos acima e além das relações espaço-temporais ( relações fortemente não-supervenientes em contraste com relações fracamente nãosupervenientes) 2) As relações não-supervenientes do entrelaçamento entre as partes de uma totalidade quântica equivalem ao todo tendo propriedades intrínsecas que não supervém sobre propriedades das partes

3) Essas propriedade do todo vem para a não-separabilidade no seguinte sentido: as partes tem algumas das propriedades que pertencem à família de propriedades que fazem de alguma coisa um sistema quântico, não separadamente, mas apenas dessa forma: existem propriedades do todo que indicam a maneira através da qual as partes estão relacionadas umas às outras com respeito a algumas propriedades que fazem de algo um sistema quântico. ${ }^{46}$ (ESFELD, 2004, p.8, tradução nossa).
\end{abstract}

\footnotetext{
${ }^{44}$ Do original em inglês: "[...] there is only a joint state determining certain correlations that obtain among the systems in question without it being possible to attribute significant states [...] to each of the systems in question, and be it relative to the other systems." (ESFELD, 2004, p.8)

${ }^{45}$ Do original em inglês: "[...] any case of quantum entanglement is a case of nonseparability, and non-separability is the reason why quantum entanglement is a sort of holism." (ESFELD, 2004, p.8)

${ }^{46}$ Do original em inglês: 1) Quantum entanglement shows that there are non-supervenient relations among physical systems over and above the spatio-temporal relations (strongly non-supervenient relations in contrast to weakly non-supervenient relations). 2) The non-supervenient relations of entanglement among the parts of a quantum whole amount to the whole having intrinsic properties that do not supervene on intrinsic properties of the parts. 3) These properties of the whole come to non-separability in the following sense: the parts have some of the properties that belong to the family of properties which make something a quantum system not separately, but only in this way: there are properties of the whole which indicate the manner in which the parts are related with each other with respect to some of the properties that make something a quantum system." (ESFELD, 2004, p.8)
} 
Esfeld relaciona sua abordagem, que implica a reposição de uma metafísica de propriedades intrínsecas por uma metafísica das relações, à própria metafísica de Aristóteles onde "existe uma pluralidade de coisas individuais (substâncias) que são caracterizadas, cada uma, por propriedades intrínsecas (formas)" 47 (ARISTÓTELES apud ESFELD, 2004, p.2, tradução nossa) e a uma proeminente concepção contemporânea da tese de David Lewis de Superveniência Humeana (do termo em inglês Humean supervenience). Em Lewis, no nível básico do mundo, existem apenas qualidades locais, no sentido de propriedades intrínsecas instanciadas por pontos espaço-temporais, ou partículas do tamanho de pontos, ou forças de campo em pontos espaço-temporais, sendo que, os pontos espaço-temporais, podem ser qualificados como coisas individuais nesse contexto.

\subsection{Sistemas de Sistemas ou o Complexo Adaptativo}

A perspectiva das ciências da complexidade que procuramos construir no presente capítulo, e as ideias de entrelaçamento e decoerência quânticos, numa perspectiva de diálogo com a ideia de espaços estoricizados apresentada no capítulo anterior, constituem a tessitura do olhar para o sistema - para sua complexidade, sua organização, para suas emergências. Esse olhar visa dar suporte ao desenho de um modelo de observação para o estudo dos processos criativos coletivos em artes digitais como sistemas complexos adaptativos. As emergências desses processos, que podem ser os trabalhos produzidos como parte de uma série são, dentro da perspectiva construída aqui, dependentes do modo como o sistema é organizado. Segundo Mihata, adaptação complexa é caracterizada, "[...] não apenas por um alto grau de interação entre as parte componentes mas também pelo modo como a natureza particular dessa interação - o modo como o sistema está organizado - gera resultados não literalmente relacionados às condições iniciais." ${ }^{48}$ (MIHATA, 1997, p.31, tradução nossa).

René Thom (1989), no contexto da Teoria da Catástrofe, em seu livro Structural Stability And Morphogenesis, fala de morfogênese e das mudanças não-lineares, súbitas, como saltos, catástrofes, nos processos organizacionais de sistemas complexos. Mais de meio

\footnotetext{
${ }^{47}$ Do original em inglês: "there is a plurality of individual things (substances) that are characterized by intrinsic properties (forms) each" (ARISTÓTELES apud ESFELD, 2004, p.2)

${ }^{48}$ Do original em inglês: "[...] not only by a high degree of interaction among component parts but also by the way that the particular nature of this Interaction - the way that the system is organized - generates outcomes not linearly related to initial conditions." (MIHATA, 1997, p.31)
} 
século antes de Thom, Henri Poincaré introduziu o conceito de espaço de fase, representando todos os possíveis comportamentos de um dado sistema como um todo coerente. Foi esse espaço de fase que René Thom explorou para classificar mudanças súbitas, as quais chamou de catástrofes. Posteriormente, um entusiasta das ideias de Thom, Christopher Zeeman, cunhou o termo Teoria da Catástrofe.

Compreender a catástrofe é essencial para um entendimento dos processos organizacionais. Se existe um princípio organizador, ele nasce de encontros aleatórios, no diálogo entre ordem e desordem, na e pela catástrofe. A catástrofe é a mudança de forma do sistema, fenômeno morfogenético em sua essência. Edgar Morin, abordando a relação entre catástrofe e morfogênese, ressalta o fato de que, é na dinâmica morfogenética, que o surgimento da inter-relação, da organização e do sistema, são três faces de um mesmo fenômeno, onde a organização, numa primeira definição, pode ser entendida como "[...] o encadeamento de relações entre componentes ou indivíduos que produz uma unidade complexa ou sistema, dotada de qualidades desconhecidas quanto ao componentes ou indivíduos." (MORIN, 2003, p.133).

\section{interações}

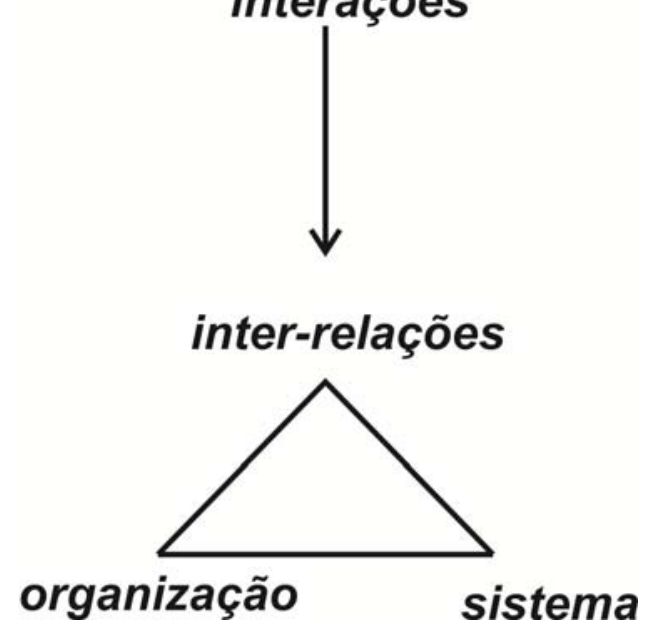

Figura 2.02 // O surgimento da inter-relação, da organização, do sistema são as três faces de um mesmo fenômeno.

É assim que, a organização enquanto fenômeno, conecta de maneira inter-relacional os elementos, acontecimentos, ou indivíduos diversos que, dessa forma, se tornam os 
componentes de um todo sistêmico. Ligando inter-relação e totalidade, a organização é - que confere alguma estabilidade e solidez às ligações entre as partes do sistema e assegura ao todo sistêmico a possibilidade de duração e de adaptação frente ao ruído, às perturbações aleatórias em sua relação com o ambiente.

Interações são inconcebíveis sem desordem - sem diferença, turbulência, distúrbios, que podem causar encontros entre os elementos de sistemas que são, simultaneamente, abertos e fechados em relação às trocas com o ambiente, capazes de se reorganizar frente ao ruído. São essas as características que podem estar presentes em certos processos criativos coletivos em artes digitais, permitindo estudar esses processos como sistemas complexos adaptativos - processos que se confundem com o próprio coletivo enquanto conjunto de elementos, sujeitos em inter-relação num todo organizado. 


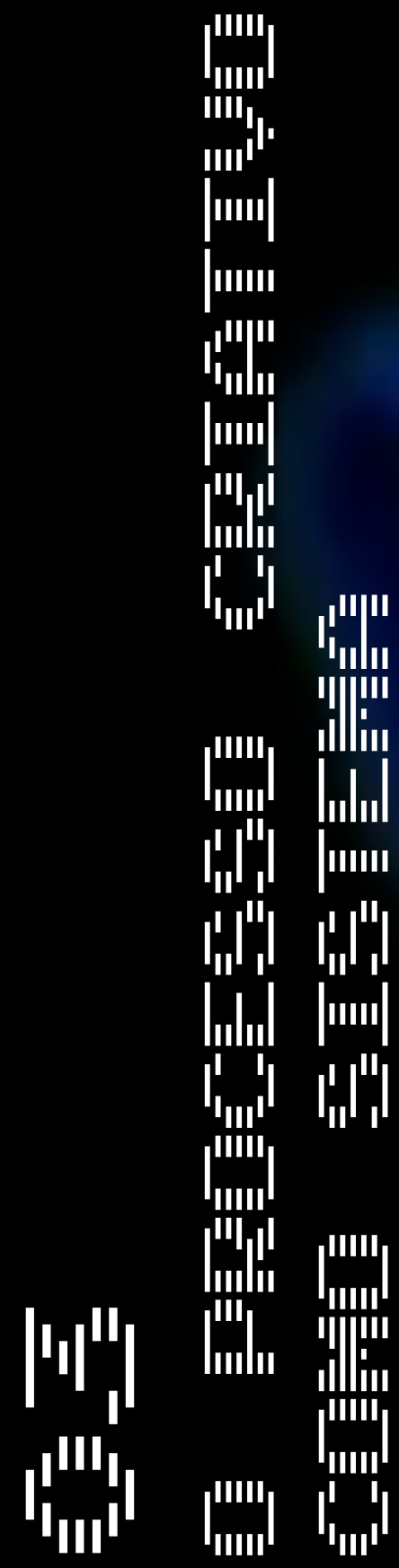




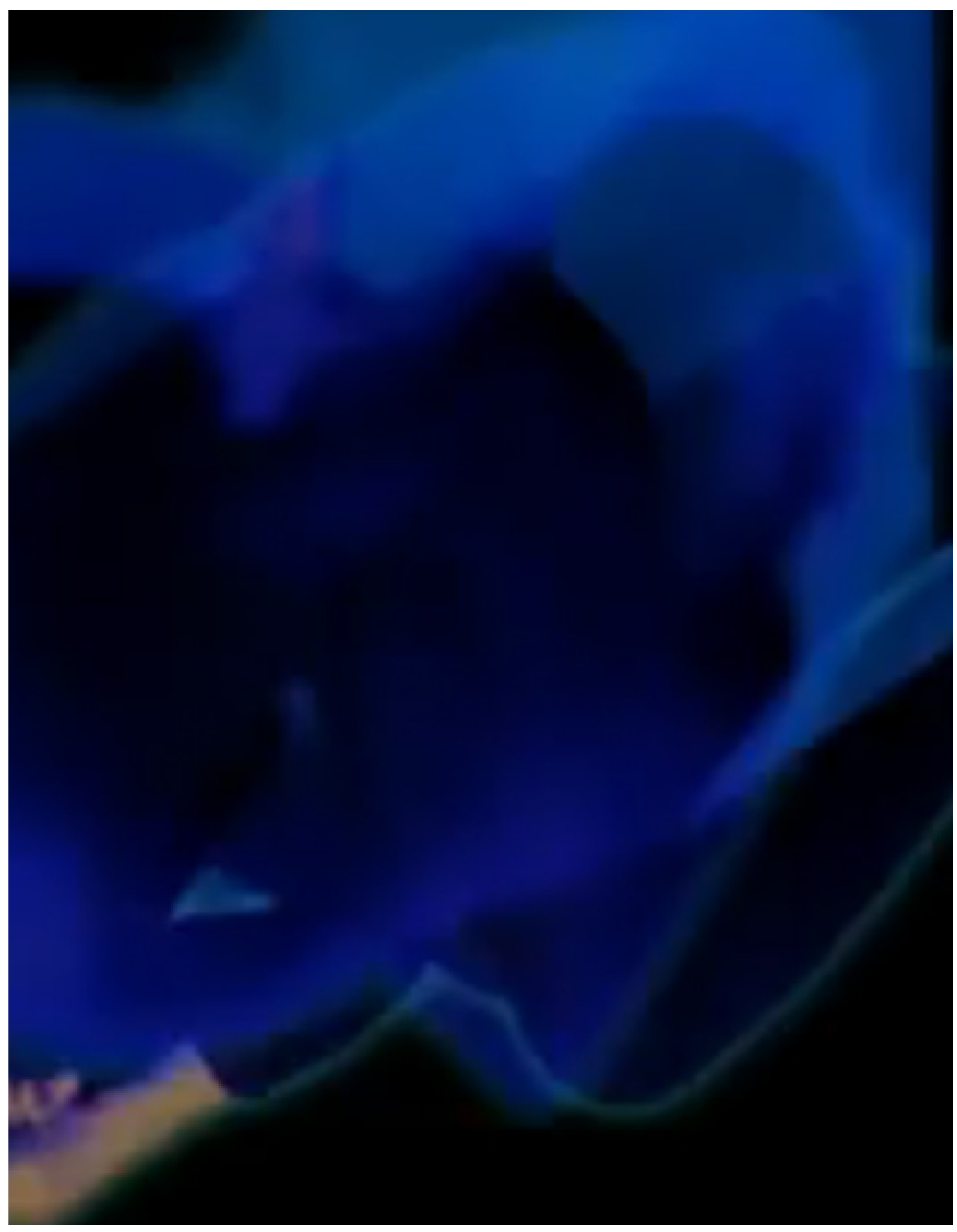




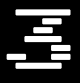

Neste capítulo, nos dedicamos à construção de um modelo, a partir das referências conceituais das ciências da complexidade, como forma de dar ao sistema visibilidade de si. A proposta incorpora a dinâmica de colecionar e inter-relacionar espaços estoricizados gerados no e pelo processo de auto-organização sistêmico. O objetivo é contribuir para visualizar o sistema, que é o processo criativo coletivo em artes digitais, como estrutura dinâmica, mutante, metamórfica. 
Nós necessariamente nos expressamos por meio de palavras usualmente pensamos em termos espaciais.

Henri Bergson, 2001, p.XIX

'Do original em inglês: "We necessarily express ourselves by means of words and we usually think in terms of space."(BERGSON, 2001, p.XIX) 


\subsection{O método da complexidade; a complexidade como método}

O desafio a que nos propomos no presente trabalho, é o de dar suporte a um entendimento do processo criativo coletivo em artes digitais como um sistema complexo adaptativo. Esse desafio se estrutura em várias instâncias. Numa primeira instância, trouxemos alguns conceitos a partir das ciências da complexidade para construir a base, esforço ao qual nos dedicamos no capítulo anterior. Em uma instância intermediária, que pretendemos explorar no presente capítulo, utilizamos esses conceitos basilares para desenhar uma estrutura capaz de dar visibilidade ao sistema - à sua dinâmica, às conexões entre as partes, destas com o todo, e do todo com o ambiente. É a partir dessa estrutura, que é a tessitura de uma dinâmica, que nos lançaremos à observação de processos criativos coletivos em artes digitais nos capítulos subsequentes.

Partimos, em um primeiro momento, que remete às reflexões constantes no Memorial de Qualificação da presente pesquisa, de uma perspectiva quase que exclusivamente baseada em medidas sistêmicas de organização e complexidade, na busca de caminhos para definir o sistema, para delinear seus limites, suas aberturas e fechamentos em relação ao ambiente. As leituras nesse estágio anterior da pesquisa, relativas às diferentes medidas utilizadas por vários autores para medir a complexidade e organização sistêmicas em esforços muitas vezes classificatórios, ajudaram a construir uma compreensão do sistema enquanto estrutura - estrutura dinâmica, adaptativa, dependente de diálogos, das inter-relações entre as partes.

No entanto, mais que parâmetros capazes de ajudar a definir o que viria a ser nosso sistema, quais suas partes, as conexões, os seus limites, havia a necessidade de um modelo, uma malha, capaz de dar visibilidade à estrutura sistêmica. É no contexto dessas investigações que uma questão vai se tornando cada vez mais evidente e relevante para a pesquisa: se o nosso sistema se constrói a partir do fluxo de informações, dos eventos, num contínuo entre ordem, desordem e organização, nas e pelas inter-relações, de que forma seria possivel visualizar essas informações, as mensagens e os significados relacionados?

O artifício encontrado, e que se construiu ao longo do processo de pesquisa, foi o de mapear as narrativas e antenarrativas emergentes como forma de dar visibilidade à 
informação em fluxo, à organização sistêmica a partir de eventos e de ações. O processo de construção desse artifício, que podemos em alguma medida chamar de um método, implicou diálogo aberto e confrontação com diversos pesquisadores ao longo dos quatro anos de pesquisa - colegas com interesses que germinam num cruzamento entre artes, arquitetura, ciências, tecnologias, filosofia, antropologia. Método, no sentido da construção de um olhar, de uma moldura para pensar, num sentido que se aproxima da noção de método em Edgar Morin.

Esse método da complexidade, "[...] se opõe à conceituação dita 'metodológica' em que ela é reduzida a receitas técnicas. Como o método cartesiano, ele deve inspirar-se em um princípio fundamental ou paradigma." (MORIN, 2003, p.37). Para Morin, a diferença é justamente o paradigma, não se tratando de obedecer a um princípio de ordem através da eliminação da desordem, de claridade, eliminando o obscuro, "[...] de distinção (eliminando as aderências, as participações e as comunicações), de disjunção (excluindo o sujeito, a antinomia, a complexidade). [...] trata-se, ao contrário, de ligar o que estava separado através de um princípio de complexidade." (MORIN, 2003, p.37).

As leituras de Descartes e seu método para duvidar, constituíram parte importante no caminho de amadurecimento da presente abordagem. O processo de leitura se transformou em reflexão e experimentação. Experimentação nos domínios incertos e caóticos da busca por entender de que forma as interações entre partes de um sistema envolvidas em dinâmicas informacionais, produzem um todo significante em meio ao acaso, a flutuações, incertezas, ruídos.

O exercício de escrita emergente compartilhada realizado com a pesquisadora Jennifer Kanary Nikolov(a), colega no Planetary Collegium - On Dematerialization: A Collaborative Treatise on Information, Consciousness and Imagination or Random Conversations Around Information or a Fairy Tale (título que aparece na última versão do documento em 01 de Agosto de 2010) emerge como parte do próprio processo-método - um olhar de dentro do próprio olhar em construção.

As consideração de Morin sobre um método que se constrói durante a pesquisa, ajudam a ilustrar e entender esse processo. Segundo o pensador, [...] o método só pode se 
construir durante a pesquisa; ele só pode emanar e se formular depois, no momento em que o termo se transforma em um novo ponto de partida, desta vez dotado de método." (MORIN, 2003, p.36).

Numa referência às meditações de René Descartes (DESCARTES, 1971), o referido exercício de escrita emergente, começa como um convite, a escrever em conjunto, meditações sobre as ideias de informação, consciência e imaginação, de forma hipertextual e livre:

\begin{abstract}
Espero que essas meditações que estou convidando minha cara colega Jennifer Nikolov(a) para escrever conjuntamente, possam nos proporcionar diversão. E, apenas por diversão e por acaso, esse exercício de escrita emergente sobre informação, consciência e imaginação, possa possivelmente estimular a trocar os óculos antiquados dos que ainda hoje acreditam em corpos e matéria; que acreditam em alma e no dualismo mente-corpo; [...] que acreditam em história, em ciência, em bordas e limites em geral, em verdade, em sanidade e normalidade, prova e precisão. . (RIBEIRO; NIKOLOV(A), 2010, tradução nossa).
\end{abstract}

Posteriormente, essa dinâmica deu origem à criação da página Bubbles ${ }^{3}$, hospedada na rede social Facebook. Bolhas, como bolhas de significado que emergem de diálogos aleatórios; que ligam significados emergentes; como emergências. A ideia e a iniciativa nasceram a partir de um tutorial informal das pesquisadoras com o professor Roy Ascott em Plymouth, em julho de 2010 .

Nesse momento, foi interessante observar como o acaso era capaz de construir o processo - os pesquisadores como pescadores de informações no fluxo, juntando, conectando, em função dos interesses de pesquisa, dos objetivos. Foi interessante observar, como a vida pessoal e todas as referências pertencentes a esse universo, se entrelaçavam com a pesquisa em sua gênese - o processo de construção do conhecimento não exclui os sujeitos que participam de sua construção e, sobretudo, ele

\footnotetext{
${ }^{2}$ Do original em inglês: "I hope these meditations I'm inviting my dear colleague Jennifer Nikolova to write together, could give us lots of fun. And, just for fun and by chance, this emergent writing exercise on 'information, consciousness and imagination', may possibly to stimulate in changing the old fashion glasses of people that still nowadays believes in bodies and matter; who believes in soul and in the mind-body dualism; [...] who believes in history, in science, in borders and limits in general, in truth, in sanity and normality, prove and precision." (RIBEIRO; NIKOLOV(A), 2010)

${ }^{3}$ RIBEIRO, Clarissa; NIKOLOV(A), Jennifer Kanary. Bubbles. Initiated by Clarissa Ribeiro and Jennifer Kanary Nikolov(a) (based on a little document called 'By Chance1(12) or (13)'. Disponível em: <http://www.facebook.com/pages/Bubbles/133809999992423?v=wall>. Acesso em: 07 jan. 2011.
} 
é construído em conjunto, nas e pelas inter-relações. É assim que, o olhar construído na presente tese, é inseparável daquele que olha. O observador é parte da observação, é parte da construção daquilo mesmo que observa, amalgamado.

Abordagens como as do pesquisador Tim Ingold, da University of Aberdeen, na Escócia, no artigo Bringing Things to Life: Creative Entanglements in a World of Materials, propõem pensar e discutir, de que forma as conexões entre elementos em um sistema que pode ser ele mesmo nosso espaço de interações na sociedade, constroem esse mesmo sistema. Essas conexões são mais que conexões, são, para o pesquisador, entrelaçamentos. Segundo Ingold, quando fala de entrelaçamento de coisas, se refere precisa e literalmente "[...] não uma rede de conexões, mas a uma trama de linhas entrelaçadas de crescimento e de movimento."4 (INGOLD, 2010, p.3, tradução nossa). A proposta é não se ater, na observação do sistema e seu processo dinâmico de organização, à materialidade, mas, sim, aos fluxos. Como defende o pesquisador,

\begin{abstract}
Estamos obrigados, como Deleuze e Guattari dizem, a seguir esses fluxos, traçando o padrão da geração da forma, onde quer que eles possam levar. [...] devo determinar o sentido específico no qual o movimento, ao longo desses padrões, é criativo: trata-se de ler criatividade 'para frente', como um ingresso improvisatório com processos formativos, ao invés de 'para trás', como uma abdução de um objeto finalizado para uma intenção na mente de um agente. Finalmente, devo mostrar que os caminhos ou trajetórias ao longo dos quais se desenrola a prática improvisatória não são conexões, não descrevem relações entre uma coisa e outra. Eles são mais linhas ao longo das quais as coisas continuamente vem a ser." (INGOLD, 2010, p.3, tradução nossa).
\end{abstract}

A visão de Ingold retoma a questão da geração da forma a partir, não simplesmente da rede de conexões que constituem um complexo, mas de uma malha de linhas de movimento e crescimento, entrelaçadas. Morin, em O Método 1: a natureza da natureza, na parte em que fala sobre genealogia e generatividade da informação, relaciona geração de forma - da forma do próprio sistema -, a partir de processos informacionais. Morin relaciona, em última instância, informação e generatividade. Apesar de estar

\footnotetext{
${ }^{4}$ Do original em inglês: "[...] not a network of connections but a meshwork of interwoven lines of growth and movement." (INGOLD, 2010, p.3)

${ }^{5}$ Do original em inglês: "We are obliged, as Deleuze and Guattari say, to follow these flows, tracing the paths of form-generation, wherever they may lead. Fourth, I shall determine the specific sense in which movement along these paths is creative: this is to read creativity 'forwards', as an improvisatory joining in with formative processes, rather than 'backwards', as an abduction from a finished object to an intention in the mind of an agent. Finally, I shall show that the pathways or trajectories along which improvisatory practice unfolds are not connections, nor do they describe relations between one thing and another. They are rather lines along which things continually come into being." (INGOLD, 2010, p.3)
} 
tratando da organização viva, dos organismos como complexos generativos, a visão construída pelo pensador, ajuda a entender as relações entre informação, organização, e morfogênese sistêmica. Para Morin, a informação emerge ao mesmo tempo em que emerge um complexo generativo e uma organização comunicacional. Quando isolamos e ligamos essa informação generativa, podemos considerar que esta "é a configuração improvável e estabilizada, de caráter engramático (signo) e arquival, que, no interior do protoaparelho generativo, é necessária à repetição ou reprodução exata ao infinito dos processos de regeneração e de re-generação." (MORIN, 2003, p.394, grifo do autor).

Enquanto signo, a informação permite ao complexo se reproduzir. Enquanto relação, essa mesma informação está intimamente ligada ao seu processo organizacional e, enquanto diferença, é ela que permite ao sistema se diferenciar. Morin não deixa, no entanto, de lembrar que a informação é um conceito complexo que, por sua complexidade, não é elucidado nem elucidativo. Diante dessas considerações, ele propõe sondar sua origem, ressaltando de antemão que o problema da origem da informação se encerra na questão da generatividade.

Dentro da lógica dessa compreensão, vemos que um complexo informacional (complexo, pois a informação supõe comunicação, circulação, aparelho, entre outros) deve ser concebido não na origem, mas ao longo de um processo. Processo esse em que uma organização produtora de si, uma organização autopoiética na compreensão de Maturana e Varela, se autoproduz. Essa organização, sistema complexo adaptativo, deve ser considerada em relação ao seu ambiente em um processo organizacional, circuito tetralógico que não é um círculo vicioso, mas um circuito através do qual se operam transformações irreversíveis, gêneses.

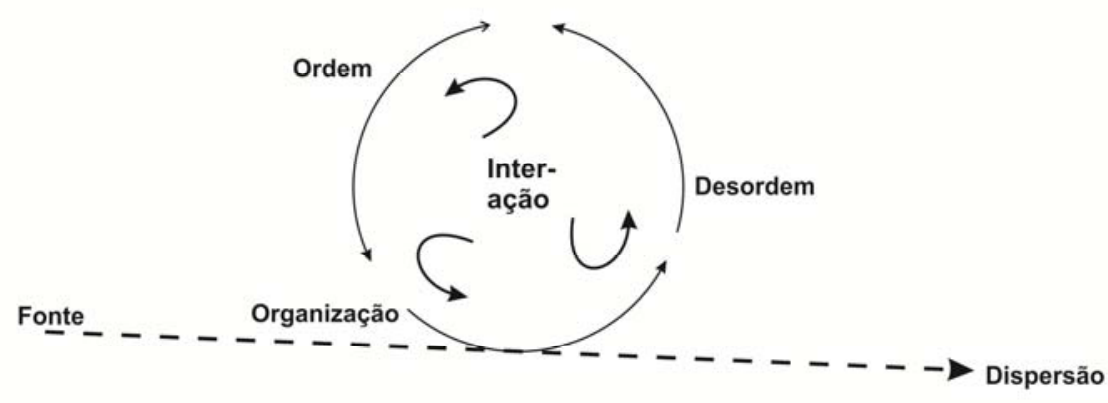


Figura 1.03 // Circuito irreversível em espiral

Discutindo esses processos em relação à segunda lei da termodinâmica, e à questão da entropia, Morin fala desse circuito como um circuito irreversível em espiral, resultando da catástrofe, e que não cessa de tomar forma por meio da relação desordem/ordem/organização. Esse circuito é enriquecido pela integração do segundo princípio da termodinâmica - a desordem produz ordem e organização a partir de interações, a ordem e a organização produzem desordem a partir de transformações e tudo o que produz ordem e organização também produz desordem.

\subsection{Fios e tessitura}

$\mathrm{Na}$ construção do nosso olhar a partir da complexidade para o processo criativo, a especificidade está no critério adotado, baseado no conceito de espaços estoricizados. Como dissemos anteriormente, a ideia central é desenhar formas de mapear os diálogos em processos criativos coletivos em artes digitais para estudar esses mesmos processos como sistemas e os trabalhos artísticos gerados como emergências. Assim, a ideia de espaços estoricizados é artifício basilar para construir uma rede de significados, ajudando a visualizar a própria infraestrutura do sistema: seus níveis de organização, as relações entre as partes, entre as partes e o todo, e desses com o ambiente/contexto.

Como já vimos no Capítulo 1, espaços estoricizados podem ser descritos como a coleção de estórias construídas a partir da nossa experiência, na dinâmica de interpretar o mundo para responder, para agir. Na perspectiva de Baskin, podemos considerar que "[...] experienciamos a vida como um espaço definido pelas estórias que aceitamos para explicar os eventos que aconteceram, e continuam a acontecer, ao nosso redor."6 (BASKIN, 2008, p.1, tradução nossa). Trazendo essas noções para o contexto da presente pesquisa, podemos considerar que, integrar um coletivo artístico que tem como objetivo o desenvolvimento de trabalhos de arte digital, pode depender da negociação de estórias compartilhadas pelos membros do grupo.

\footnotetext{
${ }^{6}$ Do original em inglês: [...] experience life as a space defined by the stories we've accepted to explain the events that have happened, and continue to happen, around us." (BASKIN, 2008, p.1) 
Como parte da construção do olhar a partir da complexidade, o envolvimento nos processos criativos do coletivo O Duplo foi de importância central. O coletivo, que teve em sua primeira formação, a autora da presente Tese como diretora artística, e as pesquisadoras na área de arte digital, Renata La Rocca e Graziele Lautenschlaeger, se estruturou como um laboratório de observação da prática, uma forma de dar ao sistema visibilidade de si. Em depoimento cedido para a presente pesquisa, Renata La Rocca, fala que, em sua experiência no coletivo, a percepção é a de que,

[...] o trabalho vai sendo construído pelo acaso, que produz encontros dentro e fora do coletivo, e uma contaminação das experiências de cada integrante do grupo. O trabalho vai sendo revisado o tempo todo. A partir do momento em que aparece uma nova ideia, uma nova entrada, você precisa revisar, reformular seu pensamento para incorporar ou não. É dessa forma que vai se construindo o processo da criação. Ao mesmo tempo há a questão do emissor (quem está fazendo a obra) e do repertório que ele possui, que influenciam na própria criação. Mas ao mesmo tempo quando a gente fala do repertório, e isso é uma dificuldade para mim no meu trabalho, acredito que existam outras camadas além do próprio repertório em nível consciente, aquele que você adquiriu lendo, estudando, existem outras camadas invisíveis, do inconsciente." (LA ROCCA, 2011)

É no processo de negociação, que o próprio coletivo se constrói como sistema, como organização autopoiética. Dessa forma, ele se diferencia do meio e pode produzir emergências no processo organizacional. É através dessa negociação que "[...] cada grupo define a natureza do mundo e como as pessoas no grupo devem responder para prosperar."” (BASKIN, 2008, p.1, tradução nossa). Os espaços estoricizados podem afetar o comportamento dos membros do grupo, enquanto elementos do sistema, através da ação combinada de narrativas dominantes - contextuais, ambientais -, e antenarrativas estórias particulares relacionadas ao nível individual (vide Capítulo 1). Para Baskin, "Esta interação cria uma rede de interpretação, significado e conhecimento que caracteriza qualquer agrupamento humano.". (BASKIN, 2008, p.1, tradução nossa).

\subsection{O complexo generativo: informação e morfogênese}

Partimos da consideração de que, nos sistemas que pretendemos estudar, os processos informacionais, organizacionais, estão na gênese da sua estrutura. A partir de Maturana e

\footnotetext{
${ }^{7}$ Do original em inglês: "[...] each grouping defines the nature of the world and how people in the group must respond to prosper." (BASKIN, 2008, p.1)

${ }^{8}$ Do original em inglês: "This interplay creates a network of interpretation, meaning and knowledge that characterizes any human grouping." (BASKIN, 2008, p.1)
} 
Varela (2001, p.54), podemos considerar que a estrutura de um sistema diz respeito aos componentes e relações que o constituem e que configuram sua organização. Essa dinâmica morfogenética, se estrutura em função das relações, das trocas, das negociações entre elementos, entre elementos e o todo sistêmico, entre elementos e o todo, e o ambiente. É partindo dessa perspectiva que começamos a estruturar nosso modelo que contribui para revelar a organização e revelar o sistema.

No design do seu Chaos Model, David Raccoon combina "[..] uma simples, orientada a pessoas, solução de problemas em loop com fractais, para descrever a estrutura interna de um projeto"9 (RACCOON, 1995, p.55, tradução nossa), na área de engenharia de software. Raccoon interpreta seu modelo para revelar o significado atrás da estrutura, mostrando que, desenvolvedores, usuários e tecnologias, interagem como partes do que ele chama uma dança complexa. O diagrama do modelo de Raccoon é uma referência interessante na construção do nosso próprio modelo, que é trama para capturar significado emergente mapeando os espaços estoricizados, dando ao sistema visibilidade de si.

A dinâmica de capturar antenarrativas e narrativas, que podem reintegrar e re-influenciar o próprio processo do qual fazem parte, é ponto de partida para relacionar os espaços estoricizados. Tendo como partido a compreensão da lógica organizacional de um sistema complexo adaptativo, consideramos, para a construção do nosso modelo, a seguinte estrutura sistêmica de níveis ou instâncias de organização:

- A instância inferior, que representa o conceito do que o trabalho artístico pode ser;

- A instância superior, que representa as diversas versões, que são trabalhos artísticos prontos para serem exibidos - emergências da dinâmica do sistema;

- As instâncias-entre, que representam o trabalho coletivo, as partes do sistema trabalhando juntas, interagindo, influenciadas pelo conceito do que o trabalho artístico pode vir a ser, e pelo objetivo de produzir um trabalho artístico.

\footnotetext{
${ }^{9}$ Do original em inglês: "[...] a simple, people-oriented, problem-solving loop with fractals to describe the structure within a project [...]."(RACCOON, 1995, p.55)
} 
Além dessas três instâncias, está o ambiente do sistema, o contexto que influencia o sistema em todas as suas instâncias através dos throughputs ou taxa de transferência volume de dados transferidos de um lugar para outro. Segundo Hübler, "sistemas complexos tem uma grande taxa de transferência de dados em contraste com muitos outros sistemas físicos, seu comportamento emergente frequentemente depende de eventos históricos."10 (HÜBLER, 2005, p.15, tradução nossa).

Consideramos aqui que nosso sistema-processo criativo coletivo, é simultaneamente aberto e fechado em relação ao ambiente. Isso é o que viabiliza as trocas, as transferências, a entrada e saída de dados, informações. A abertura e o fechamento são definidores da própria complexidade do sistema. Hübler lembra que, "sistemas complexos são sistemas abertos, onde o fluxo de um meio através do sistema é grande. Para fazer tornar um sistema complexo nós aumentamos a taxa de transferência de dados até que algo inesperado aconteça: um padrão emerja no sistema ou o sistema comece a oscilar."11 (HÜBLER, 2005, p.15, tradução nossa).

No que se refere ao objeto de estudo que são os processo criativos coletivos em artes digitais, partindo da perspectiva construida nos capítulo anteriores, a instância interior pode ser descrita como uma coleção de referências e conhecimentos. Os processos nessa instância envolvem ferramentas, meios, tecnologias e metodologias, referências artísticas e teóricas, repertório de um modo geral e as referências de caráter pessoal e culturais - que convergem em uma ideia do que o trabalho artístico pode vir a ser.

A despeito de essa convergência de referências e conhecimentos poder ser descrita como basilar para um processo criativo emergente, a instância inferior tende a estar fora do universo de controle dos artistas que integram um coletivo. Por exemplo, uma linguagem de programação determina de que forma as funções podem ser construídas, mas não, de que forma as aplicações artísticas dessa linguagem podem ser construídas. É importante notar que, recursos técnicos e tecnologias, podem mudar no decurso de

\footnotetext{
${ }^{10}$ Do original em inglês: "complex systems have a large throughput and contrasting to many other physical systems, its emerging behaviour often, depends, on historical events." (HüBLER, 2005, p.15)

Do original em inglês: "Complex systems are open systems, where the flow of a medium through the system is large. To make a system complex we increase the throughput until something unexpected occurs: a pattern emerges in the system or the system stars to oscillate." (HÜBLER, 2005, p.15)
} 
um projeto, assim como novas referências teóricas e artísticas podem ser descobertas ou encontradas por acaso.

É nas instâncias-entre que, a dinâmica de produzir um trabalho artístico, permite ao artista atualizar a organização, interferindo na instância inferior da estrutura sistêmica. Esse movimento é parte do próprio processo auto-organizacional. É importante compreender que, enquanto elementos do sistema, os artistas envolvidos trabalham, atuam, em todas as instâncias do sistema. No entanto, eles passam a maior parte do tempo trabalhando nas instâncias-entre.

Cada instância do sistema é resultado da rede dinâmica de influências que se configura entre todos os elementos do sistema e deles e do todo com o ambiente. Alcançar o objetivo do sistema de produzir trabalhos artísticos influencia fortemente a instância superior, assim como as referências e conhecimentos técnicos e teóricos influenciam a instância inferior. 


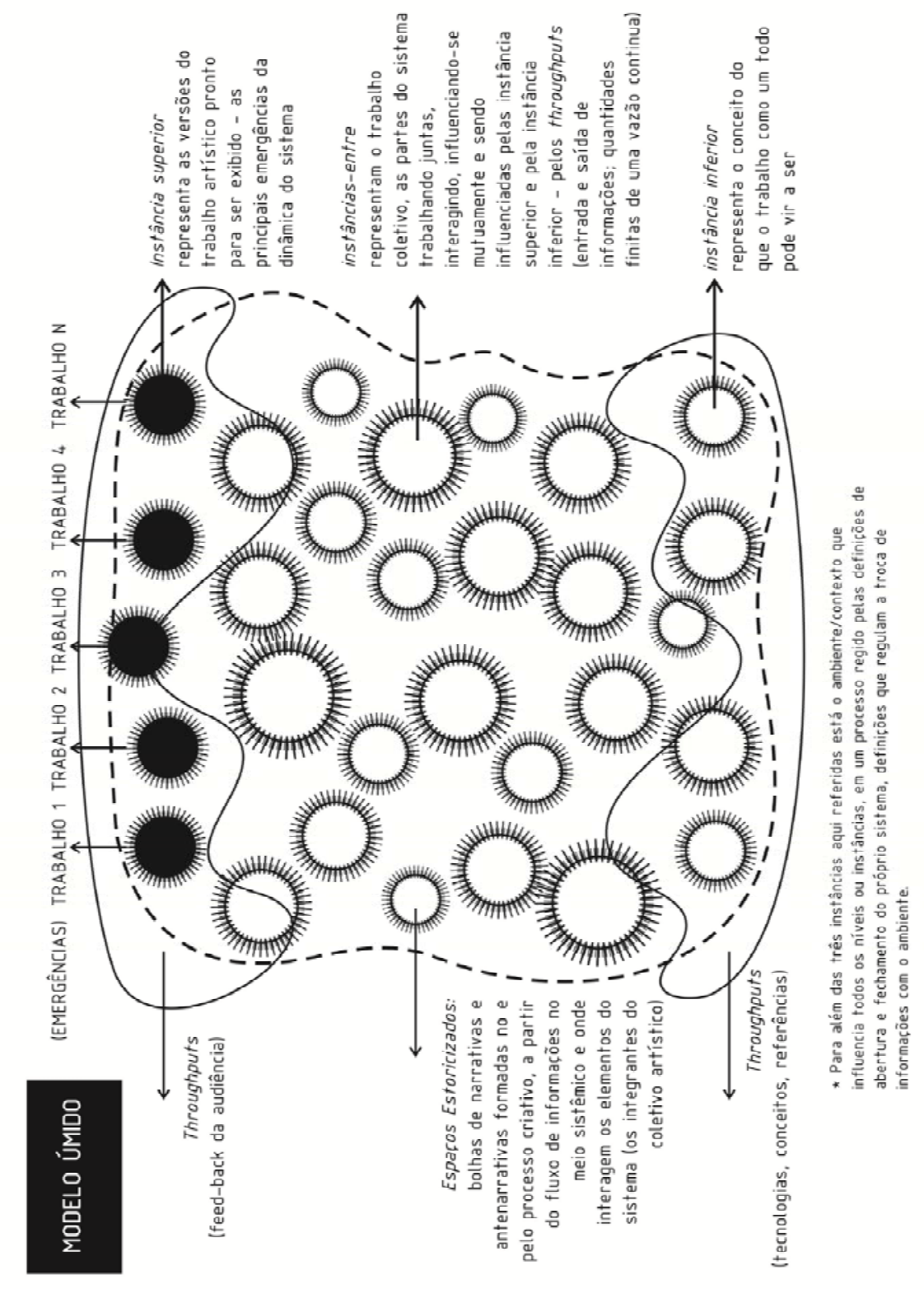

Figura 2.03 // Modelo Umido (Vide anexo A) 
Para resolver problemas relacionados às instâncias-entre, os artistas de um dado coletivo devem isolar estes problemas do restante do sistema, considerando questões pertinentes à instância inferior como, por exemplo, de que forma tecnologia, metodologia e outras referências ou ferramentas, podem convergir para implementar o conceito. Simultaneamente, os artistas envolvidos devem considerar questões relacionadas à instância superior como, por exemplo, o que o trabalho artístico significa para a audiência - o resultado deve ser significante e a solução, exequível. Ações realizadas em uma instância afetam as outras instâncias o tempo todo em uma dinâmica recursiva.

Na construção do nosso modelo, a metáfora é a de um meio úmido - moist media (ASCOTT, 2003) -, no qual a informação circula como que em um fluido de dados, e não através de conexões lineares. As conexões são multidimensionais e podem acontecer em diversos niveis de realidade. Na definição de Basarab Nicolescu,

\begin{abstract}
[...] por 'nível de Realidade', nós intentamos designar um conjunto de sistemas que são invariantes sobre certas leis: por exemplo, entidades quânticas são subordinadas por leis quânticas, as quais se afastam radicalmente de leis do mundo físico. Isso quer dizer que dois níveis de Realidade são diferentes se, passando de um para o outro, existe uma quebra nas leis e uma quebra nos conceitos fundamentais (como, por exemplo, causalidade). ${ }^{12}$ (NICOLESCU, 2002, tradução nossa, grifo do autor).
\end{abstract}

Ao nível do sujeito, os níveis de realidade também estão relacionados aos níveis de percepção da realidade pelo sujeito observador - realidade multidimensional e multireferencial. É importante compreender que os níveis de Realidade são diferentes dos níveis de organização, em uma abordagem sistêmica. Os níveis de organização não implicam ruptura dos conceitos fundamentais, pertencendo, vários níveis de organização, a um mesmo nível de Realidade. Assim, na presente abordagem, consideramos os diferentes níveis de realidade como relacionados aos sujeitos que integram, enquanto elementos, a trama sistêmica que eles mesmos constroem em diálogo.

\footnotetext{
${ }^{12}$ Do original em inglês: "[...] by the 'level of Reality', we intend to designate an ensemble of systems that are invariant under certain laws: for example, quantum entities are subordinate to quantum laws, which depart radically from the laws of the physical world. That is to say that two levels of Reality are different if, while passing from one to the other, there is a break in the laws and a break in fundamental concepts (such as, for example, causality)." (NICOLESCU, 2002)
} 
Como referência para o design do nosso modelo, procuramos uma metáfora visual que fosse significante para representar uma estrutura sistêmica fluida, onde os sujeitos enquanto elementos, e seus espaços estoricizados, estão inter-relacionados em um meio úmido. Uma representação interessante encontrada durante a pesquisa, está no trabalho desenvolvido por pesquisadores da Southampton University, no Reino Unido. Os pesquisadores estão desenvolvendo um novo tipo de tecnologia de processamento de informação, inspirado em processos químicos de sistemas vivos. Os pesquisadores $\mathrm{Dr}$. Maurits de Planque, bioquímico, e Dr. Klaus-Peter Zauner, cientista da computação, pretendem adaptar os processos cerebrais no que definem como um cenário de processamento de informação úmido. A adaptação deverá ser realizada por meio de produtos químicos, inseridos em um tubo, que se comportarão como transistores em um chip de computador.

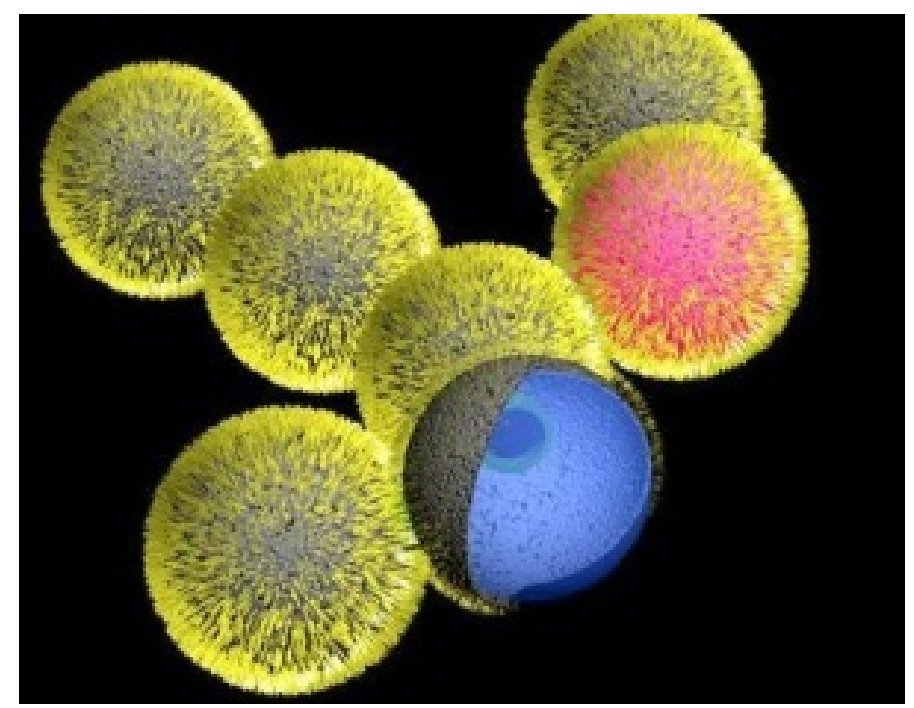

Figura 3.03 // Representação de sistemas computacionais úmidos que imitam o funcionamento do cérebro, da rede neuronal.

Até o momento, o que foi desenvolvido na referida pesquisa ainda é um líquido cerebral mínimo e rústico. Segundo o Dr. Zauner, o computador final será úmido como é o nosso cérebro. O propósito do estudo é desenvolver um sistema artificial que processe a informação da mesma forma que o cérebro. O modelo visual que ilustra as estruturas celulares artificiais mostra bolhas cuja superfície, a membrana, contém uma série de conectores, o que torna essas bolhas abertas ao ambiente, a conexões, troca de informações. 
Em nosso modelo, partindo dessa metáfora visual, cada espaço estoricizado é uma bolha permeável de significado com possibilidade de estabelecer conexões com outras bolhas. A informação flui através desses espaços estoricizados que tem um lugar no tempo complexo generativo do sistema - através deles é possível percorrer a história evolutiva do sistema.

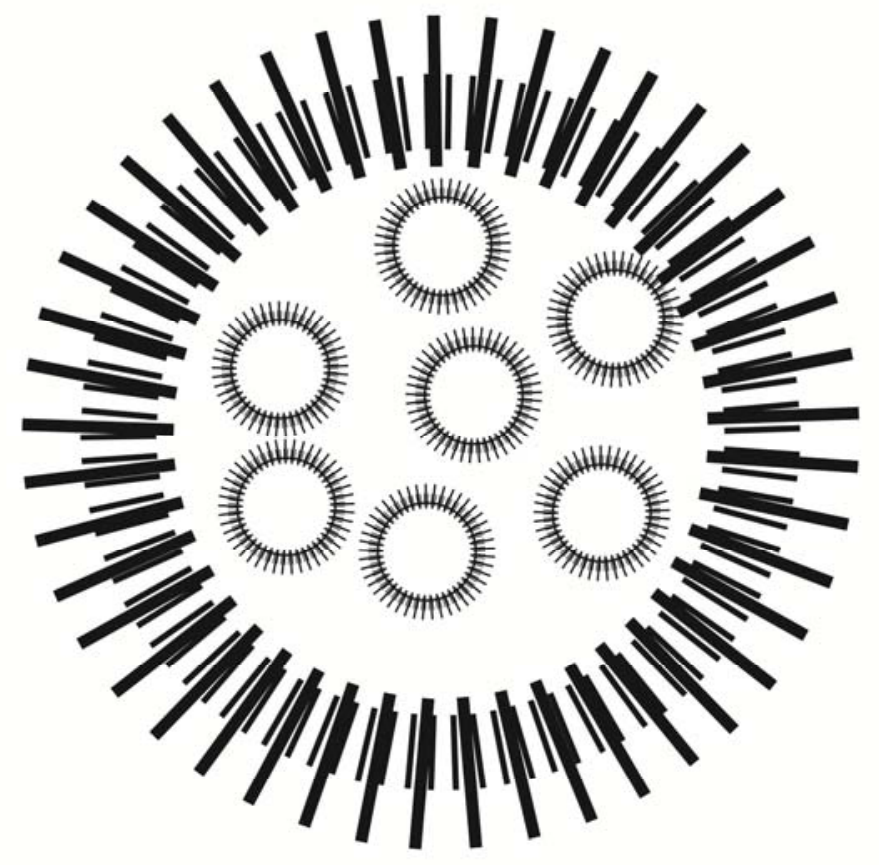

Figura 4.03 // Espaços Estoricizados representados no Modelo-bo/ha: bolhas que reúnem uma coleção de narrativas a antenarrativas estando relacionadas aos sujeitos enquanto elementos do sistema que integram

As pequenas e diversas hastes, em cada uma das bolhas que são a representação dos espaços estoricizados no Modelo-bolha, representam, não as conexões em si, mas evidenciam a possibilidade de infinitas conexões. Essas conexões existem em potência e não se estabelecem por relações de vizinhança, mas de significado e, muitas vezes, em função do acaso, e de forma randômica.

\subsection{Da Impressão à imaginação}

A estrutura e o modelo que propomos aqui como artifício para dar visibilidade a essa estrutura, são uma aproximação à organização do sistema. Em todas as instâncias, é a 
informação que circula que constrói a própria tessitura sistêmica nas e pelas interações e inter-relações. O desafio aqui é encontrar formas para capturar quadros (frames) a partir das informações que circulam, para que seja possivel observar a organização enquanto processo, a complexidade do complexo adaptativo.

Em um primeiro momento, poder-se-ia pensar em realizar registros contínuos através de captura de áudio e vídeo, documentando as reuniões de um coletivo artístico, para analisar a interação entre os membros. No entanto, de qualquer maneira, esse processo por mais longo e minucioso, não deixaria de ser um registro, algo que se coloca em lugar de. Segundo Lucia Santaella e Winfried Noth,

\begin{abstract}
Todo registro ou signo da realidade tem uma vida emprestada, quer dizer, representa algo que está fora do registro e continua a existir apesar do registro. Por mais perfeito que o registro possa ser, há sempre uma disparidade, há sempre algo do objeto que o signo não pode capturar. Entre as coisas e os signos, abre-se o hiato da diferença. O signo pode estar no lugar do objeto, pode indicar o objeto, pode representar o objeto, mas não pode ser o objeto. (SANTAELLA; NOTH, 1997, p.137).
\end{abstract}

Nossa busca aqui é por artifícios para ajudar a capturar significados no processo de comunicação, como uma rede de pescadores, uma teia. Não é uma busca por mecanismos precisos para uma coleta sistemática dados. Não há a intenção de construir uma matriz onde seja possível cruzar dados selecionados por um observador-pinça a partir de conversas e vídeos pré-gravados a partir de critérios previamente definidos visando uma análise quantitativa. A busca é por entender como as interações, incorporando todo um universo subjetivo de referências e relações, produzem trabalhos artísticos como emergências no processo criativo coletivo. Esse entendimento que buscamos, não é exato, não é preciso. É entendimento que visa alimentar futuras poéticas; é entendimento poético ele mesmo.

Nesse processo de busca, que é processo de construção do método em uma dinâmica emaranhada com o próprio processo criativo da série Instantes de Metamorfose (vide Capítulo 5), do qual a autora participa integrando o coletivo O Duplo, as explorações randômicas dos contos de Jorge Luis Borges em seu O Livro dos Seres Imaginários, levaram à sugestiva alegoria estruturada por Étienne Bonnot Condillac em seu Traité des Sensations, de 1754. 
A alegoria de Condillac é mencionada por Borges no conto Dois animais metafísicos (BORGES, 2007), como relacionada ao problema da origem das ideias. O tratado de Condillac é, na verdade, uma ampliação do anterior ensaio de John Locke sobre a compreensão humana. Esse ensaio de Locke pode ser considerado mais uma contribuição para a psicologia do que para a filosofia propriamente dita. Segundo John W. Yolton, editor da edição de 1972 do An Essay Concerning Human Understanding, no primeiro volume do ensaio, o Livro Segundo é dedicado a um mapeamento das formas através das quais nos tornamos conscientes do mundo e de nossas operações mentais.

Se pensarmos na abordagem de Locke como um método, no sentido que discutimos no início desse capítulo, é interessante observar as afinidades entre o pensamento de Locke e Descartes e de que forma essas afinidades influenciaram o trabalhos de Locke. Como afirma Paul Strathern, apesar de admirar o método de Descartes, Locke "desconfiava do raciocínio de Descartes e da dedução como método de chegar à verdade sobre o mundo. Na visão de Locke essa só poderia ser descoberta por indução: método científico."13 (STRATHERN, 1996, p.26, tradução nossa).

Em seu tratado, Locke afirma que as observações humanas, direcionadas aos objetos externos sensíveis, ou às operações internas sobre o percebido ou refletido, são o que alimenta nossa compreensão com material para pensar. Essas são, para ele, as fontes do conhecimento humano, de onde nascem todas as ideias. No segundo livro de seu ensaio, a que chama Das Ideias, no capítulo I sobre as ideias em geral e sua origem (BOOK II: OF IDEAS, Chapter l: Of ideas in general, and their original), Locke fala de sensações e do que chama ideias de reflexão.

Nas palavras do filósofo, "com o tempo, a mente vem refletir em suas próprias operações sobre as ideias obtidas através da sensação e, portanto, armazena um novo conjunto de ideias, o qual chamo ideias de reflexão. Essas são impressões que são produzidas nos nossos sentidos por objetos exteriores que são extrínsecos à mente."14 (LOCKE, 1972,

\footnotetext{
13 Do original em inglês: "He mistrusted Descartes' reasoning and deduction as a method of arriving at the truth about the world. In Locke's view this could only be discovered by induction: scientific method." (STRATHERN, 1996, p.26)

${ }^{14}$ Do original em inglês: "In time, the mind comes to reflect on its own operations about the ideas got by sensation and thereby stores itself with a new set of ideas, which I call ideas of reflection. These are the impressions that are made on our senses by outward objects that are extrinsical to the mind."( $\mathrm{LOCKE}, 1972$, p.89)
} 
p.89, tradução nossa). Assim, para Locke, a primeira capacidade do intelecto humano é a de que a mente está equipada para receber a impressão produzida sobre ela através dos sentidos pelos objetos exteriores, ou por suas próprias operações quando reflete sobre eles.

Locke continua, no capítulo seguinte (Chapter II: of simple ideas), considerando que, nos processos de entendimento da natureza e da extensão do nosso conhecimento, precisamos observar um importante fato sobre as ideias de um modo geral - algumas são simples e outras são complexas. As ideias simples são, para ele, o material de todo nosso conhecimento, sendo sugeridas e fornecidas à mente por dois únicos caminhos que são as sensações e a reflexão. Segundo Locke, "quando o conhecimento é uma vez armazenado com essas ideias simples, ele tem o poder de se repetir, comparar e uni-las, até uma variedade quase infinita, e então pode produzir à vontade novas ideias complexas." ${ }^{15}$ (LOCKE, 1972, p.90-91, tradução nossa).

No que se refere às chamadas ideias complexas, elas são produzidas na mente pela combinação de várias ideias simples na formação de um novo todo. É através da comparação, que duas ideias distintas são combinadas, sem necessariamente uni-las, originando a ideia de uma relação entre elas. A abstração, por sua vez, separa alguns aspectos de uma ideia de suas circunstâncias específicas, formando uma nova ideia. É a repetição contínua desses processos que origina, para Locke, todas as ideias que os seres humanos são capazes de ter.

De um modo geral, o desafio de Locke era mostrar como todas as ideias são derivadas de uma experiência dupla - as sensações externas e a inspeção interna das operações mentais. Entre as diversas operações mentais, ele discute algumas como a comparação, o discernimento, disposição, e a abstração. A partir dessas considerações sobre a relação entre processos mentais e ideias, Locke se convence de que não há nada no intelecto que não tenha estado anteriormente nos sentidos, todas as ideias derivando-se assim, da experiência. Segundo John W. Yolton "Há lugares onde ele parece interpretar isso como uma tentativa de mostrar como cada ideia, não importa o quão complexa e

\footnotetext{
${ }^{15}$ Do original em inglês: "When the understanding is once stored with these simple ideas, it has the power to repeat, compare and unite them, even to an almost infinite variety, and so can make at pleasure new complex ideas." (LOCKE, 1972, p.90-91)
} 
aparentemente removida da sensação, é redutível a algum conjunto de ideias simples do sentido."16 (YOLTON, 1972, p.XVIII, tradução nossa).

No que se refere às ideias complexas, Locke fala de três variedades: Modos, Substâncias, e Relações. Um Modo simples é uma ideia complexa da qual todas as partes componentes são variações de combinações de uma ideia simples. No entanto, quando fala de Modos mistos, Locke considera que essas são ideias complexas, construídas pela mente. A faculdade de reflexão se coloca de modo ambíguo no programa de Locke. Como considera Yolton, as tentativas de Locke, de discutir os diferentes caminhos através dos quais as ideias podem ser consideradas como derivadas da experiência, acabam se transformando em discussões sobre o significado das ideias, como prazer, dor, raiva, duração, poder, o infinito.

Segundo Geraldine Carr (CARR, 1930, p.XV, tradução nossa), responsável pela primeira tradução para o inglês do Traité des Sansation, publicado em 1754 por Condillac, a importância do filósofo não reside em sua exposição e expansão das ideias de John Locke mas, no fato de ele ter dado uma completa reorientação para a filosofia, dado uma nova direção ao questionamento filosófico que é, em última análise, a da posição idealista da filosofia francesa moderna, algo semelhante ao que Locke fez dirigindo a filosofia inglesa para uma posição realista. A respeito da abordagem de Condillac em seu tratado, Carr escreve que, esta, "[...] merece e vai corresponder a um estudo cuidadoso, para lidar exaustivamente com o problema que está na base de toda a teoria do conhecimento, a natureza das informações que recebemos através dos sentidos." ${ }^{17}$ (CARR, 1930, p.XV, tradução nossa).

O século XVIII foi a era dos Enciclopedistas. A especulação filosófica era concentrada no problema da natureza e da dependência do conhecimento no funcionamento de vários órgãos sensores e, mais que uma questão metafísica, era uma questão psicológica. $O$ grande interesse da exploração da relação entre os sentidos e os processos mentais,

\footnotetext{
${ }^{16}$ Do original em inglês: "There are places where he seems to interpret it as an attempt to show how every idea, no matter how complex and apparently removed from sensation, is reducible to some set of simple ideas of sense." (YOLTON, 1972, p.XVIII)

${ }_{17}$ Do original em inglês: "[...] deserves and will repay careful study, for it deal exhaustively with the problem which lies at the basis of all theory of knowledge, the nature of information which we receive through the senses." (CARR, 1930, p.XV)
} 
surgiu no estudo de Diderot da Psicologia do Surdo e do Mudo (DIDEROT, 1993). Segundo Carr, Condillac, em seu tratado, segue aproximadamente o mesmo método de Diderot, supondo, por usa vez, um ser humano que era desprovido de todas as sensações até que os sentidos vão sendo estimulados. O interessante em Condillac é o fato de utilizar o artifício de, despertando sucessivamente cada um dos sentidos, discutir "[...] as modificações consequentes da relação entre eles."18 (CARR, 1930, p.XVII, tradução nossa).

Com a intenção de analisar o progresso das ideias humanas, a gênese de nossas faculdades, Condillac construiu uma ficção arbitrária, uma espécie de fantasia, onde imaginou uma estátua de mármore, com estrutura orgânica idêntica à de um ser humano, que era, no entanto, insensível, no sentido de estar desprovida de todos os sentidos ou pelo fato de estes, num primeiro momento, não estarem despertos. Sua ideia era a de analisar que tipo de conhecimento esse ser imaginário poderia ter, se seus sentidos fossem sendo despertados um a um. Ele começa despertando o sentido do olfato, depois o paladar, a audição, a visão e por último o tato, considerando ainda cada um dos sentidos em relação aos demais. No trecho intitulado The First cognition of a man limited to the sens of smell, Condillac escreve:

\section{A PRIMEIRA COGNIÇÃO DE UM HOMEM LIMITADO AO SENTIDO DO OLFATO \\ I - A estátua limitada ao sentido do olfato pode apenas conhecer odores: Nossa estátua sendo limitada ao sentido do olfato sua cognição não pode se estender além dos odores. Ela não pode mais ter ideias de extensão, forma ou qualquer coisa exterior a si, ou exterior a suas sensações, então ela pode ter ideias de cor, som, gosto." 19 (CONDILLAC,1930, p.3, tradução nossa).}

Segundo Carr, Condillac chega à conclusão de que uma sensação, é uma modificação da consciência, e não nos ensina nada sobre o mundo externo, ou seja, as sensações como cheiro, sabor, etc., separadamente ou combinadas, não fornecem a priori, ideias dos objetos externos. Falando sobre um homem hipotético limitado ao sentido do olfato, e como os diferentes graus de prazer e dor são os princípios da cognição, Condillac

\footnotetext{
${ }^{18}$ Do original em inglês: "[...] the modifications consequent on the relations between them."18 (CARR, 1930, p.XVII, tradução nossa)

${ }^{19}$ Do original em inglês: THE FIRST COGNITION OF A MAN LIMITED TO THE SENSE OF SMELL

I - The statue limited to the sense of smell can only know odours: Our statue being limited to the sense of smell its cognitions cannot extend beyond smells. It can no more have ideas of extension, shape or anything outside itself. or outside its sensations, than it can have ideas of colour, sound, taste. (CONDILLAC, 1930, p.3)
} 
considera que, na primeira sensação olfativa, a capacidade da estátua de sentir é integralmente devida à impressão formada a partir dos seus órgãos sensoriais. A estátua começa, assim, só em um segundo momento, "[...] a gozar e a sofrer." 20 (CONDILLAC, 1930, p.4, tradução nossa).

A memória, em Condillac, é uma sensação transformada, que pode ser comparada com uma sensação presente e, a partir dessa comparação, pode-se perceber relações como diferença, semelhança. Perceber essas relações é formar um julgamento sobre elas. 0 filósofo acredita que, os poderes da mente - amor, ódio, esperança, medo, vontade também são sensações transformadas. Dessa forma, todos os poderes da mente são relacionados, em sua origem, a simples sensações.

Nas palavras de Condillac, considerando que a estátua distingue nela mesma uma sucessão, "[...] sempre que a substância odorifera está causando uma impressão no órgão sensorial ele mesmo, existe outro cheiro presente na memória, porque a impressão de outra substância odorífera subsiste no cérebro, para o qual os órgãos sensoriais transmitiram-na."21 (CONDILLAC, 1930, p.7, tradução nossa). O processo de comparação que acontece na sequência, consiste em dar atenção a duas ideias simultaneamente. Por exemplo, tendo a estátua cheirado repetidamente rosa e cravo, a atenção ativa causada pela memória fica dividida entre as lembranças que permanecem dos cheiros de rosa e cravo.

Em seguida ao processo de comparação, existe o julgamento, que consiste na percepção de uma relação entre duas ideias que são comparadas. Depois do julgamento, a reflexão e, desta, à imaginação. Para Condillac, o ato de recordar coisas exclusivamente do passado é o que entendemos como memória. Ao ato de recordar com tamanha força que essas coisas parecem presentes, chamamos imaginação. Nas palavras do filósofo, a "imaginação acontece então em nossa estátua assim como a memória, e estas duas faculdades diferem apenas como mais e menos. A memória é o início de uma imaginação

\footnotetext{
${ }^{20}$ Do original em inglês: "[...] begins to enjoy or to suffer." (CONDILLAC, 1930, p.4)

${ }^{21}$ Do original em inglês: "[...] whenever as odoriferous substance is making an impression on the sense organ itself there is another smell present to the memory, because the impression of another odoriferous substance subsists in the brain, to which the sense organ has already transmitted it." (CONDILLAC, 1930, p.7)
} 
que ainda tem pouca força, a imaginação é a mesma memória enriquecida com toda a animação do que ela é suscetível."22 (CONDILLAC, 1930, p.18, tradução nossa).

O modo como Borges retoma as ideias de Condillac no conto Dois animais Metafísicos, resume os estágio de processamento e interação das ideias a partir das sensações, das impressões até a construção de memórias e à imaginação. É dessa forma sintética que utilizamos a alegoria de Condillac para construir os estágios ou camadas de percepção em que se organiza o processo de captura dos espaços estoricizados no estudo do processo criativo coletivo como sistema. Relacionamos a cada um dos elementos do sistema um espaço estoricizado particular, como uma bolha de narrativas e antenarrativas que se conecta a outras bolhas, outros elementos no complexo. No conto de Borges, a alegoria de Condillac é referida da seguinte forma:

O problema da origem das ideias adiciona duas curiosas criaturas à zoologia fantástica. Uma foi imaginada em meados do século XVIII; a outra, um século depois. A primeira é a "estátua sensível" de Condillac. Descartes professou a doutrina das ideias inatas; Etienne Bonnot de Condillac, para refutá-lo, imaginou uma estátua de mármore, organizada e conformada como o corpo de um homem, e residência de uma alma que nunca teria percebido ou pensado. Condillac começa por atribuir um só sentido à estátua: o olfativo, talvez o menos complexo de todos. Um cheiro de jasmim é o princípio da biografia da estátua; por um instante, haverá unicamente esse cheiro no universo, melhor dizendo, esse cheiro será o universo, que um instante depois, será cheiro de rosa, e depois de cravo. Que na consciência da estátua haja um cheiro único, e já teremos a atenção; que perdure um cheiro quando o estímulo tiver cessado, e teremos a memória; que uma impressão atual e outra do passado ocupem a atenção da estátua, e teremos a comparação; que a estátua perceba analogias e diferenças, e teremos o juízo; que a comparação e - juízo ocorram novamente, e teremos a reflexão; que uma lembrança agradável seja mais vívida que uma impressão desagradável, e teremos a imaginação. Engendradas as faculdades do entendimento, as da vontade surgirão depois: amor e ódio (atração e aversão), esperança e medo. A consciência de ter atravessado muitos estados dará à estátua a noção abstrata de número; a de ser cheiro de cravo e ter sido cheiro de jasmim, a noção do eu. (BORGES, 2007, p.28-29).

Da impressão à imaginação, os níveis da alegoria de Condillac se transformam em subsistemas dentro de subsistemas, dentro da arquitetura sistêmica representada no nosso Modelo Úmido. Assim, impressão, atenção, memória, comparação, julgamento,

\footnotetext{
22 Do original em inglês: "Imagination has then its place in our statue as well as memory, and these two faculties differ only as more and less. Memory is the commencement of an imagination which has yet little force: imagination is the same memory enriched with all the liveliness of which it is susceptible."22 (CONDILLAC, 1930, p.18)
} 
reflexão e imaginação são, ainda, diferentes níveis de percepção, instantes dentro do tempo sistêmico - instantes de metamorfose em um tempo complexo que está relacionado a uma espécie de evolução criativa (BERGSON, 2010) do sistema.

É nesse ponto que encontramos relações entre Condillac e Bergson. O objetivo de Condillac é mostrar que o conhecimento vem pelo hábito e pela reflexão, ambos tendo sua origem e gênese nos sentidos. Segundo Carr, "Bergson também reconhece instinto e inteligência como dois diferentes modos através dos quais nós apreendemos realidade e por meio dos quais recebemos e utilizamos diferentes tipos de conhecimento." 23 (CARR, 1930, p.XXV, tradução nossa). Assim, a teoria do instinto e da reflexão encontra desenvolvimentos importantes nos trabalhos de Bergson onde, instinto e inteligência, são modos de atividade heterogêneos e complementares.

Em seu Creative Evolution (BERGSON, 2010) no primeiro capítulo, Bergson traça uma linha de demarcação entre o inorgânico e o organizado, ressaltando que "[...] a divisão da matéria organizada em corpos separados é relativa aos nossos sentidos e ao nosso intelecto."24 (BERGSON, 2010, p.109, tradução nossa). No segundo capítulo, ele mostra que, a mesma oposição, pode ser traçada entre instinto e inteligência. No capítulo III, Bergson se propõe a tentar uma gênese do intelecto, ao mesmo tempo como uma gênese dos corpos materiais. Na compreensão de Bergson, "Intelectualidade e materialidade foram constituídas, em detalhe, por adaptação recíproca." 25 (BERGSON, 2010, p.109).

\subsection{Níveis de Percepção e Realidade}

Trazendo essa noção para o nosso Modelo Úmido, podemos entender a gênese de uma consciência sistêmica, consciência do todo, inteligência do todo, simultaneamente e concomitantemente à gênese da arquitetura sistêmica, à morfogênese. Em ambos, Condillac e Bergson, a inteligência não nos dá um conhecimento direto e atual da

\footnotetext{
${ }^{23}$ Do original em inglês: "Bergson also recognizes instinct and intelligence as two different modes by which we apprehend reality and by means of which we receive and use different kinds of knowledge. (CARR, 1930, p.XXV) ${ }^{24}$ Do original em inglês: "[...] the division of organized matter into separate bodies is relative to our senses and to our intellect." (BERGSON, 2010, p.109)

${ }^{25}$ Do original em inglês: "Intellectuality and materiality have been constituted, in detail, by reciprocal adaptation." (BERGSON, 2010, p.109)
} 
realidade, mas apenas sua representação em um mundo de objetos no espaço, um mundo de ações e reações mensuráveis.

É através do instinto, um modo de conhecimento oposto à inteligência, que construímos nossos pontos de vista como oposto à visão externa da realidade, da vida como é vivida. Bergson propõe, em certo ponto, pensar na hipótese de consideramos as coisas do ponto de vista da extensão e não apenas da duração, supondo que, em vez de agir, sonhássemos. Então, "Ao mesmo tempo, o eu é disperso; nosso passado, que até então ainda estava reunido dentro do impulso visível que ele nos comunicava, é quebrado em milhares de lembranças tornadas externas uma para a outra." 26 Assim, nossa personalidade "[...] descende em direção ao espaço. Ela se encosta ao seu redor em sensação."27 (BERGSON, 2010, p. 117, tradução nossa).

Falando de dialética como um relaxamento da intuição, Bergson acredita que através dela, muitos acordos são possíveis. A dialética é necessária para por a intuição à prova. É para ele, por meio dessa intuição prolongada, que o filósofo pode concordar com seus pensamentos e, os filósofos, podem concordar entre si, alcançando o objetivo da filosofia para o qual um contínuo ir e vir entre natureza e mente, é necessário. Nas considerações de Bergson,

\begin{abstract}
Quando colocamos nosso ser de volta em nossa vontade, e nossa vontade nela mesma no impulso que prolonga, nós entendemos, sentimos, que a realidade é um crescimento perpétuo, uma criação feita sem fim. Nossa vontade realiza já esse milagre. Cada trabalho humano no qual há invenção, cada ato voluntário no qual há liberdade, cada movimento de um organismo que manifesta espontaneidade, traz algo novo ao mundo. Verdade, isso são apenas criação e forma. ${ }^{28}$ (BERGSON, 2010, p.137, tradução nossa).
\end{abstract}

Não existe sistema durável, na compreensão de Bergson, que não seja ao menos em algumas de suas partes, vivificado pela intuição. Trazendo essa compreensão para nossa

\footnotetext{
${ }^{26}$ Do original em inglês: "At once, the self is scattered; our past, which till then was gathered together into the invisible impulsion it communicated to us, is broken up into a thousand recollections made external to one another." (BERGSON, 2010, p,117)

${ }^{27}$ Do original em inglês: "[...] descends in the direction of space. It coasts around it continually in sensation." (BERGSON, 2010, p,117)

${ }^{28}$ Do original em inglês: "When we put back our being into our will, and our will in itself into the impulsion it prolongs, we understand, we feel, that reality is a perpetual growth, a creation pursued without end. Our will already performs this miracle. Every human work in which there is invention, every voluntary act in which there is freedom, every movement of an organism that manifests spontaneity, brings something new into the world. True, this are only creation and form." (BERGSON, 2010, p.137)
} 
abordagem, um sistema, para que seja criativo, deve prescindir de liberdade, envolver uma espontaneidade que traz algo novo, a possibilidade de emergência de algo novo. Invenção num movimento em espiral no tempo - em um circuito irreversível em espiral.

Optamos por colecionar as antenarrativas e narrativas que integram os espaços estoricizados, em um lugar onde a linha entre consciente e inconsciente é tênue. A opção por utilizar dinâmicas de escrita e desenho emergentes realizadas a intervalos temporais foi influenciada pela participação em exercícios de escrita emergente realizados pela autora, bem como pela leitura do livro de Clarice Lispector, Água Viva (LISPECTOR, 1998), que constitui, ele mesmo, um instigante exercício de escrita emergente.

Nessa dinâmica, o tempo não é o tempo aparente e linear dos intervalos entre as dinâmicas. Evidencia-se e é intrínseca, uma temporalidade interna, dos processos mentais, de recordação e exploração das memórias construídas a partir de impressões, de outras memórias, até se tornarem imaginação e a coleção desses diversos processos dentro do processo criativo, potencialmente convergir na realização de um trabalho artístico. Cada bolha de significado, cada espaço estoricizado, tem seu tempo interno - o tempo das antenarrativas e narrativas que o constituem.

Vemos em Bergson que, para a coexistência de sensações inextensivas dar origem ao espaço, "[...] deve existir um ato da mente o qual leva todos ao mesmo tempo e colocaos em justaposição: esse ato inédito é muito parecido com o que Kant chama de uma forma a priori de sensibilidade." ${ }^{29}$ (BERGSON, 2001, p.94, tradução nossa). Se nos propusermos a caracterizar esse ato, veremos que ele consiste, essencialmente, de intuição ou, em vez dessa concepção, de um meio vazio homogêneo. Por isso, para Bergson, é difícil chegar a outra concepção de espaço que não a de que "[...] espaço é o que nos habilita a distinguir um número de sensações idênticas e simultâneas umas das outras." 30 (BERGSON, 2001, p.94-95, tradução nossa).

\footnotetext{
${ }^{29}$ Do original em inglês: "[...] there must be an act of the mind which takes them all at the same time and sets them in juxtaposition: this unique act is very like Kant calls an a priory form of sensibility." (BERGSON, 2001, p.94) ${ }^{30}$ Do original em inglês: "[...] space is what enables us to distinguish a number of identical and simultaneos sensations from one another." ${ }^{30}$ (BERGSON, 2001, p.94-95)
} 
No nosso Modelo-Bolha, onde cada um dos espaços estoricizados engloba 7 (sete) níveis de percepção dos sujeitos que são os elementos do sistema - impressão, atenção, memória, comparação, julgamento, reflexão, e imaginação -, a coleção de espaços estoricizados, tende a se ampliar no e com o processo organizacional do sistema. É a partir dessa coleção de espaços estoricizados que é possível a emergência de novas narrativas, e de antenarrativas e sua natureza não-linear, randômica.

O processo de captura das narrativas e antenarrativas integrantes de espaços estoricizados se baseia, como já referido, em dinâmicas de escrita e desenho emergente, podendo haver gravação de vídeos com depoimentos na forma de brainstorming. As experiências iniciais que são o ponto de partida para a realização das dinâmicas de colecionar antenarrativas e narrativas podem ser realizadas a partir de conversas e discussões presenciais ou online entre os integrantes do coletivo, ou de experiências da audiência em uma instalação que está sendo exibida, por exemplo. Contribuindo para a construção do Modelo Úmido, as atividades relacionadas a cada um dos níveis na dinâmica são os seguintes:

1) Impressão (desenhos emergentes produzidos imediatamente após a experiência e/ou gravação de vídeo com depoimento na forma de brainstorming);

2) Atenção (escrita emergente produzida aproximadamente 1 (uma) hora após a experiência e/ou gravação de vídeo com depoimento na forma de brainstorming);

3) Memória (escrita emergente e desenho produzidos aproximadamente 1 (um) dia após a experiência);

4) Comparação (escrita emergente produzida aproximadamente 1 (uma) semana após a experiência, que pode ser combinada com a produção de um painel semântico):

5) Julgamento (escrita emergente produzida aproximadamente 1 (um) mês após a experiência);

6) Reflexão (escrita emergente produzida aproximadamente 2 (dois) meses após a experiência);

7) Imaginação (escrita emergente e desenho produzidos aproximadamente 3 (três) meses após a experiência). 


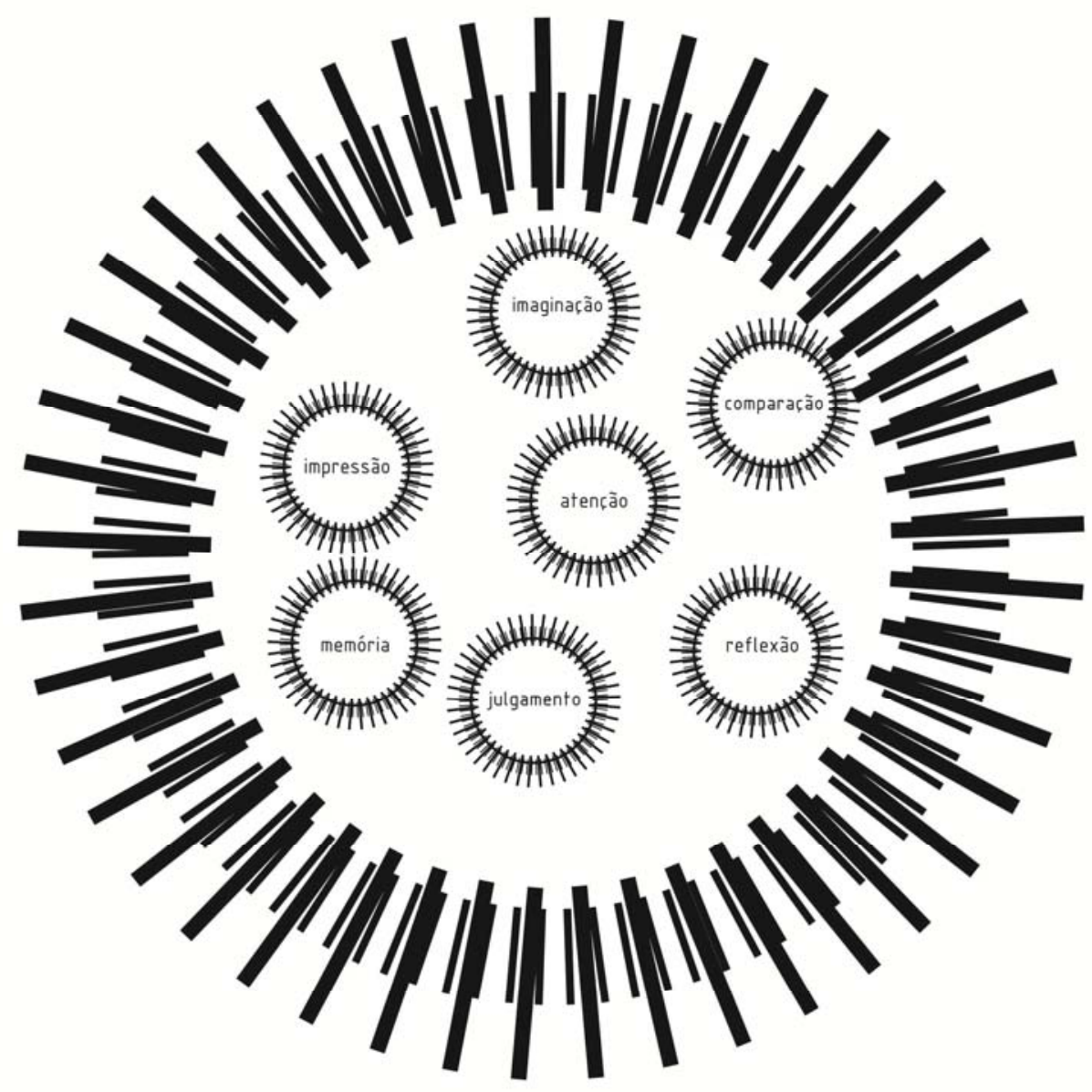

Figura 5.03 // Espaços Estoricizados e os níveis de percepção em que se agrupam as narrativas e antenarrativas - da impressão à imaginação. (Modelo-Bolha)

Integrado a esse processo de construção de um modelo como um olhar a partir da complexidade para os processos criativos em artes digitais, incorporamos no processo de construção do presente trabalho, duas instâncias de estudos de caso como parte empírica da pesquisa que se desenvolve nos capítulos seguintes. Em uma primeira instância, analisamos o processo criativo do coletivo Transmute, dirigido por Keith Armstrong e, em um segundo momento, apresentamos a série Instantes de Metamorfose, desenvolvida pela autora enquanto integrante do coletivo O Duplo. 


\subsection{Colecionando narrativas: testando a dinâmica}

Com o objetivo de estruturar o método, foram realizadas algumas dinâmicas de captura de antenarrativas com a colaboração dos colegas do grupo Transtechnology Research ${ }^{31}$ da Universidade de Plymouth, Reino Unido. A dinâmica fez parte das atividades de uma das reuniões informais de pesquisa que estruturávamos em conjunto, No Doctor's Day um espaço para dialogar, sem a presença dos orientadores, sobre as pesquisas individuais e sobre possíveis ideias conjuntas. Após um momento inicial de discussão aberta, o exercício, vinculado ao processo criativo da segunda versão da série Instantes de Metamorfose, foi proposto. A atividade implicava a concordância individual em participar de algumas etapas da dinâmica que aconteceriam via e-mail.

A atividade consistia em ler o conto Dois Animais Metafísicos, de Jorge Luis Borges (BORGES, 2007), após algumas considerações feitas acerca das ideias de Condillac e Lotze presentes no texto, como partido conceitual para o desenvolvimento do trabalho artístico em questão. A intenção era estimular uma reflexão sobre as diferentes formas de tradução e adaptação dessas ideias, levando em consideração o processo criativo do coletivo O Duplo em andamento, o que incluía a primeira versão de Instantes de Metamorfose.

Finalizando as discussões introdutórias, a leitura teve início após a apresentação de um vídeo de 3 (três) minutos apresentando Instantes de Metamorfose 01. Depois da leitura, os pesquisadores Rita Cachao, Joana Griffin, John Vines e Taslima Begum, foram convidados a produzir desenhos emergentes expressando, de forma livre, as relações que construíram a partir das dinâmicas iniciais, e que retratavam suas primeiras impressões, se constituindo no decorrer do exercício como atenção e como memória.

Transcrevemos aqui o texto enviado por John Vines, em 09 de abril de 2010, referente ao terceiro nível de percepção na dinâmica de captura de antenarrativas, sendo relativo à memória, e tendo sido realizado 1 (um) dia após a experiência. No texto de Vines, podemos observar que, além da referência à experiência inicial em um processo de recordação, há uma conexão com suas reflexões na pesquisa individual na área de

\footnotetext{
${ }^{31}$ TRANSTECH. Transtechnology Research. Disponivel em: <http://trans-techresearch.net/>. Acesso em: 29 jan. 2011. 
Design. Nessa pesquisa, Vines "[...] investiga criticamente os pressupostos que fundamentam o conhecimento científico sobre cognição no envelhecimento e de que forma estes são aplicados por designer de novas tecnologias." ${ }^{32}$ (VINES, 2011). Vejamos o texto de Vines:

\begin{abstract}
Tentando voltar minha mente ao momento em que eu estava desenhando a imagem... Eu estava pensando sobre a ideia do pensamento sistêmico que você havia introduzido e como se relacionava à minha própria perspectiva em design, que está sempre lutando para entender as relações entre o orgânico (ou humano) e artificial (ou o tecnológico). Comecei de minha tentativa de pensar sobre o ar fluindo através de uma passagem direcionada; a partir desta, surgiu um caça de alguma forma. O piloto humano nessa situação é indescritivel em termos de linguagem comum como psicologia, como um ser orgânico e como sendo definível; a figura sombria não apresenta não mais que um ponto de interrogação. Isto não é para favorecer a tecnologia em detrimento do orgânico, no entanto, como a tecnologia e o orgânico agem juntos como um sistema transparente, existem árvores e rios crescendo ao lado do avião! $!^{33}$ (VINES, 2010).
\end{abstract}

Observado o desenho produzido por John Vines, e que se refere ao primeiro nível de percepção, a impressão, tendo sido produzido imediatamente após a experiência, e tendo levado aproximadamente 1 (hora) para ser finalizado, o significado das formas só pode ser desvendado após o contato com o texto em que ele traduz as conexões que construiu a partir da experiência inicial.

\footnotetext{
32 Do original em inglês: "[...] investigates the assumptions that underlie the scientific knowledge of ageing cognition as they are applied by designers of novel technologies." (VINES, 2011)

${ }^{33}$ Do original em inglês: "Trying to get my mind back to when I was drawing the image...I was thinking about the idea of the systems thinking you had introduced and how that related to my own perspective on design, which is always struggling to understand the relations between the organic (or the human) and the artificial (or the technologically). I started off my trying to think of air flowing through a directed passage; from this a jet fighter emerged somehow. The human pilot in this situation is indescribably in common language terms as a psychology, as an organic being and as a definable being; the shadowy figure presents no more than a question mark. This is not to favor the technological over the organic, however, as the technology and organic act together as a transparent system hence why there are trees and rivers growing on the side of the plane!" (VINES, 2010)
} 


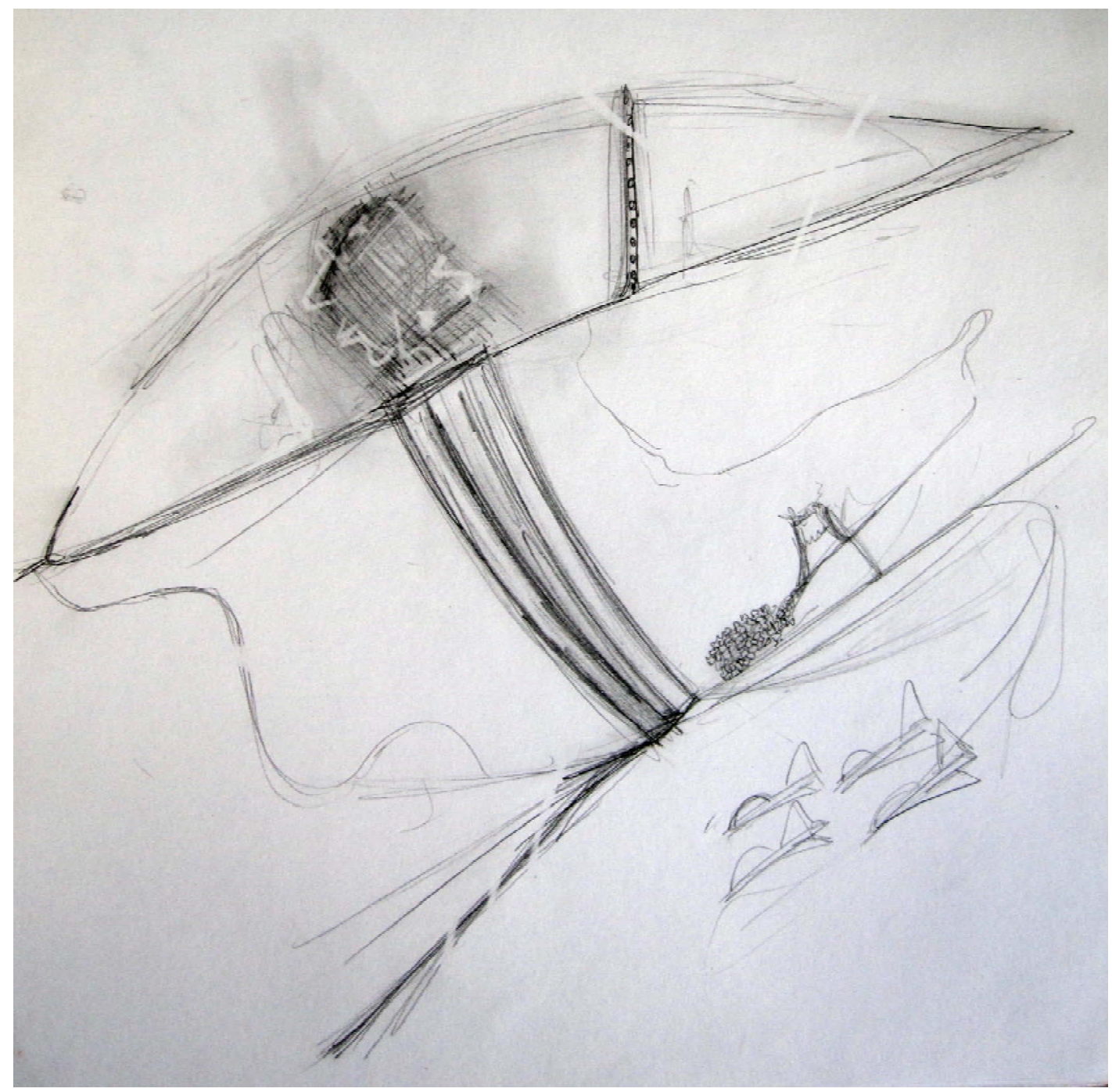

Figura 6. 03 // Desenho emergente produzido por John Vines imediatamente após a experiência.

Foi interessante observar, através dos desenhos produzidos que, a partir da leitura do texto e da perspectiva colocada pelas discussões iniciais, emergiram universos representacionais completamente distintos. Os participantes concordaram em dar continuidade à dinâmica, enviando textos emergentes produzidos dois ou três dias após a experiência inicial. A intenção de realização da dinâmica foi a de entender como exercícios dessa natureza poderiam ajudar a captar antenarrativas nas dinâmicas 
informacionais, em processos criativos coletivos. Aqui, transcrevemos um pequeno excerto do longo texto enviado pela pesquisadora Joana Griffin, integrando a dinâmica de coleção de antenarrativas:

Eu deveria escrever isso rapidamente, talvez sem pensar muito sobre isso, um pouco como quando eu fiz o desenho. Quando eu fiz o desenho eu estava lembrando o texto. O texto me impressionou por sua ideia: a de que estava propondo uma sensação bem inicial, uma primeira sensação, e, em seguida, baseando-se nisso, e dizendo como conceitos distintos surgiram, como comparação, memória e imaginação. Agora eu penso nisso, é como uma história da criação, mas falando sobre a criação de ideias, estados de ser, ao invés de coisas físicas, como os morros e as pessoas e os oceanos, que é uma história fantástica da criação! Quando fiz o desenho eu sei que eu estava pensando sobre cosmologia. Eu fico sobrecarregada com as minhas pesquisas com esse conceito de cosmologia - está tudo certo e então, ler sobre o perfume da rosa sendo tudo, inteiramente tudo foi tão pacífico. No meu desenho eu começo com a rosa, eu acho que era com o cheiro da rosa que a história começava, talvez eu esteja errada, e eu fiz uma espécie de aquário de ouro, não totalmente completo em torno dela porque era esse o incrível conceito de partida - o cheiro de rosas como uma espécie de bolha de tudo, do universo. ${ }^{34}$ (GRIFFIN, 2010, tradução nossa).

É interessante observar, a partir dos textos e dos desenhos emergentes produzidos pelos dois participantes aqui referidos que, assim como John Vines, Griffin também relaciona a experiência no texto emergente produzido por ela, com seu universo de pesquisa, com seus interesses em cosmologia. Em sua tese ela explora narrativas culturais sobre tecnologia de redes de satélites com a intenção de observar "conexões que as pessoas fazem em geral sobre espaçonaves e experiências específicas nesse campo de desenvolvimento de tecnologias [...] como a comunicação com objetos no espaço sideral."35 (GRIFFIN, 2011, tradução nossa).

\footnotetext{
${ }^{34}$ Do original em inglês: I should write this quickly, maybe without thinking about it too much, a bit like when I made the drawing. When I made the drawing I was remembering the text. The text struck me by its idea: that it was proposing a very beginning sensation, a first sensation and then building on this and saying how separate concepts emerged, like comparison, memory and imagination. Now I think about it, it's like a creation story, but talking about the creation of ideas, states of being instead of physical things like the hills and people and oceans, which is a fantastic creation story!! At the time I know I was thinking about cosmology. I get weighed down with my research with this concept of cosmology - its everything right and so to read about the scent of the rose being everything, entirely everything was just so peaceful. In my drawing I start with the rose, I think it was the scent of the rose the story began with, maybe I'm wrong, and I made a kind of gold fish bowl, not quite complete around it because that was this amazing starting concept - the rose scent as a kind of bubble of everything, of the universe. (GRIFFIN, 2010)

${ }^{35}$ Do original em inglês: "[...] connections people in general have with spacecraft and the specific experiences of those in the field of developing these technologies, such as visits to launch sites and communicating with objects in outer space." (GRIFFIN, 2011)
} 


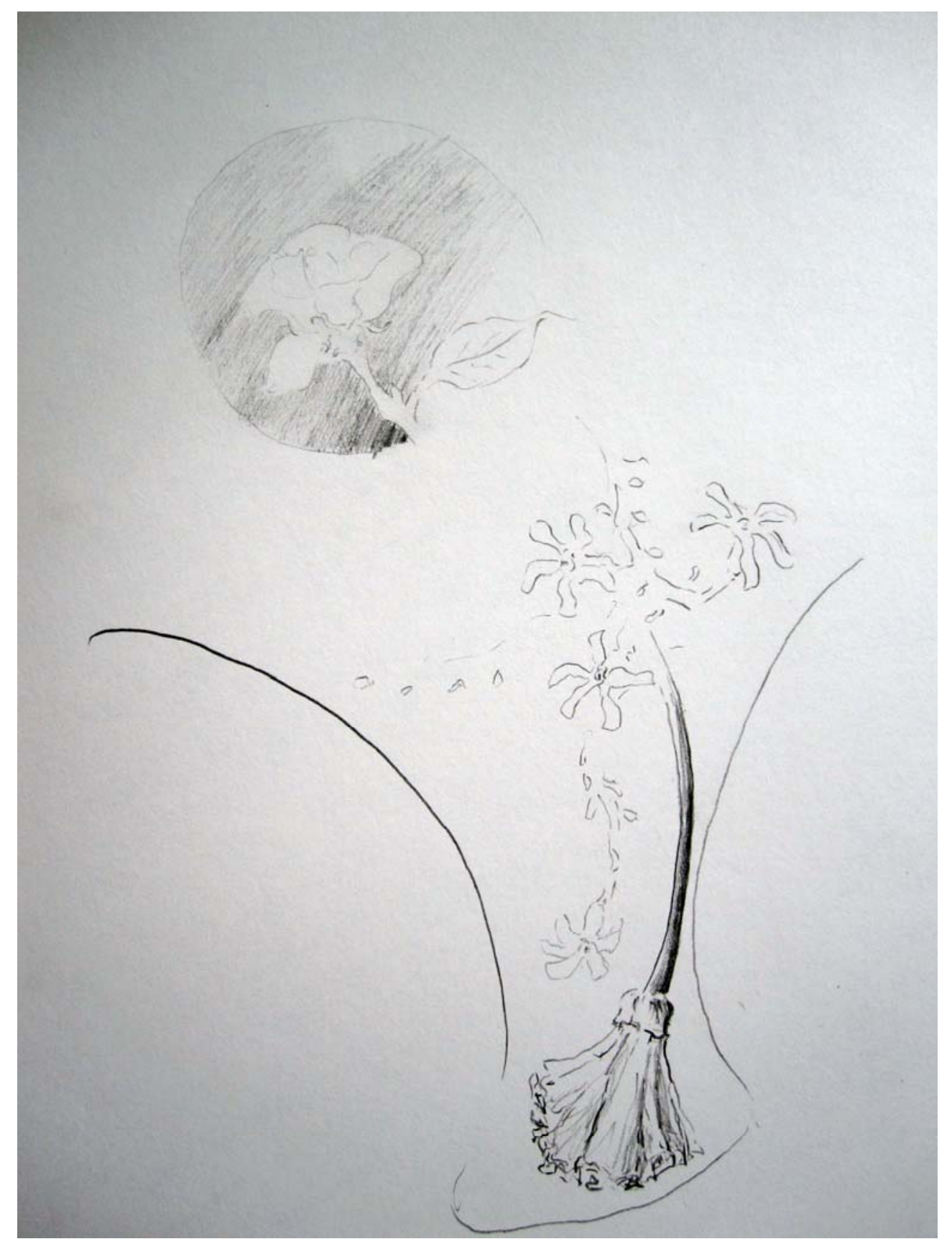

Figura 7. 03 // Desenho emergente produzido por Joana Griffin imediatamente após a experiência. 
De um modo geral, o exercício realizado com os colegas do grupo Transtechnology Research, contribuiu para a estruturação do exercício de captura das antenarrativas e narrativas, na medida em que mostrou ser possível identificar uma série de conexões, a partir dos desenhos e dos textos produzidos nas dinâmicas. Essas conexões que remetem a níveis de percepção dos sujeitos envolvidos, a níveis de realidade. Incorporando essas dinâmicas, o Modelo Úmido apresentado e discutido no presente capítulo, se coloca como base estrutural para pensar processos criativos coletivos em artes digitais como sistemas complexos adaptativos. Essa abordagem se propõe centralizada no sujeito observador e agente, considerando os diversos níveis de realidade e percepção que simultaneamente integramos e construímos nos domínios dinâmicos e caóticos da criatividade. 


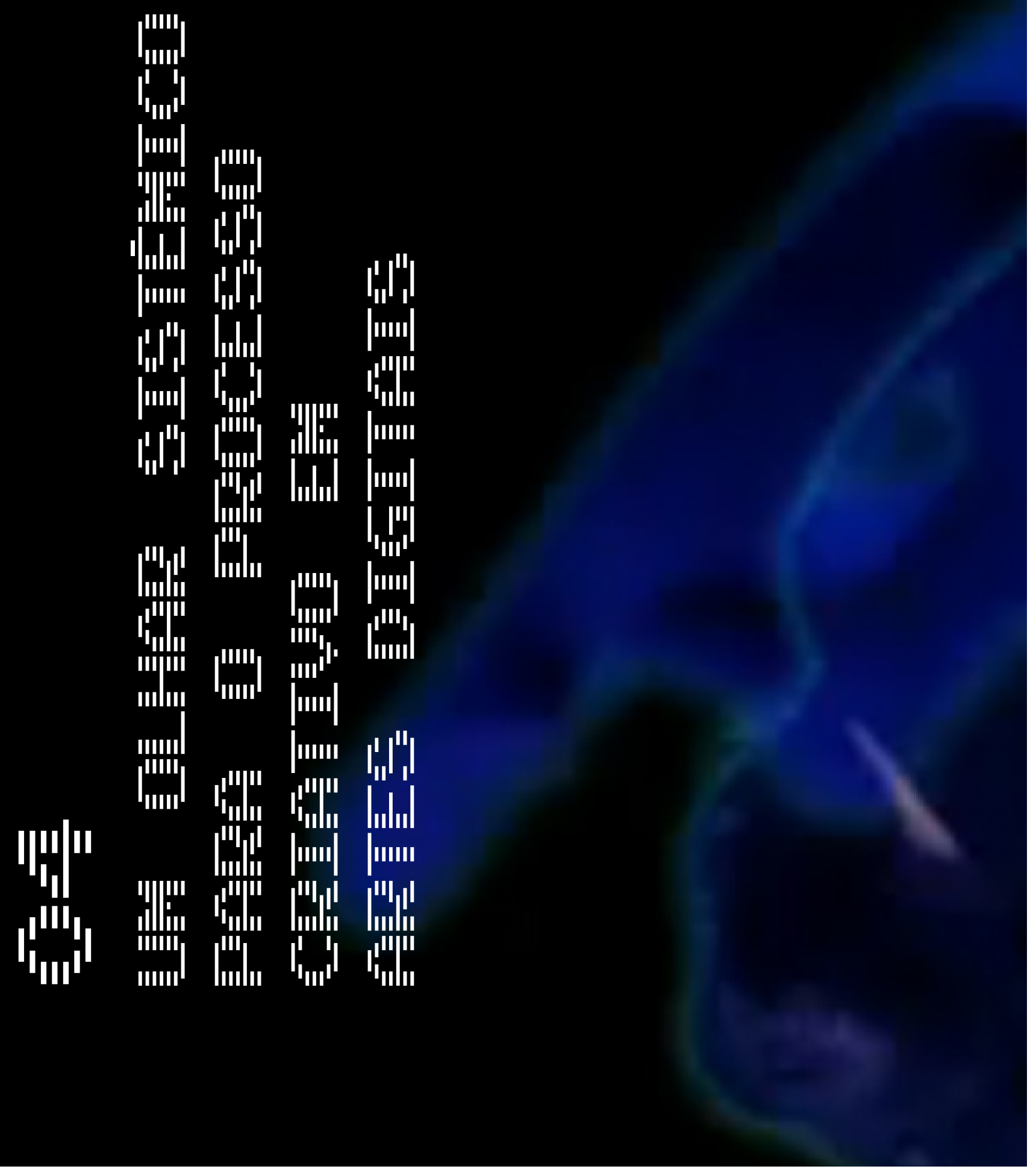




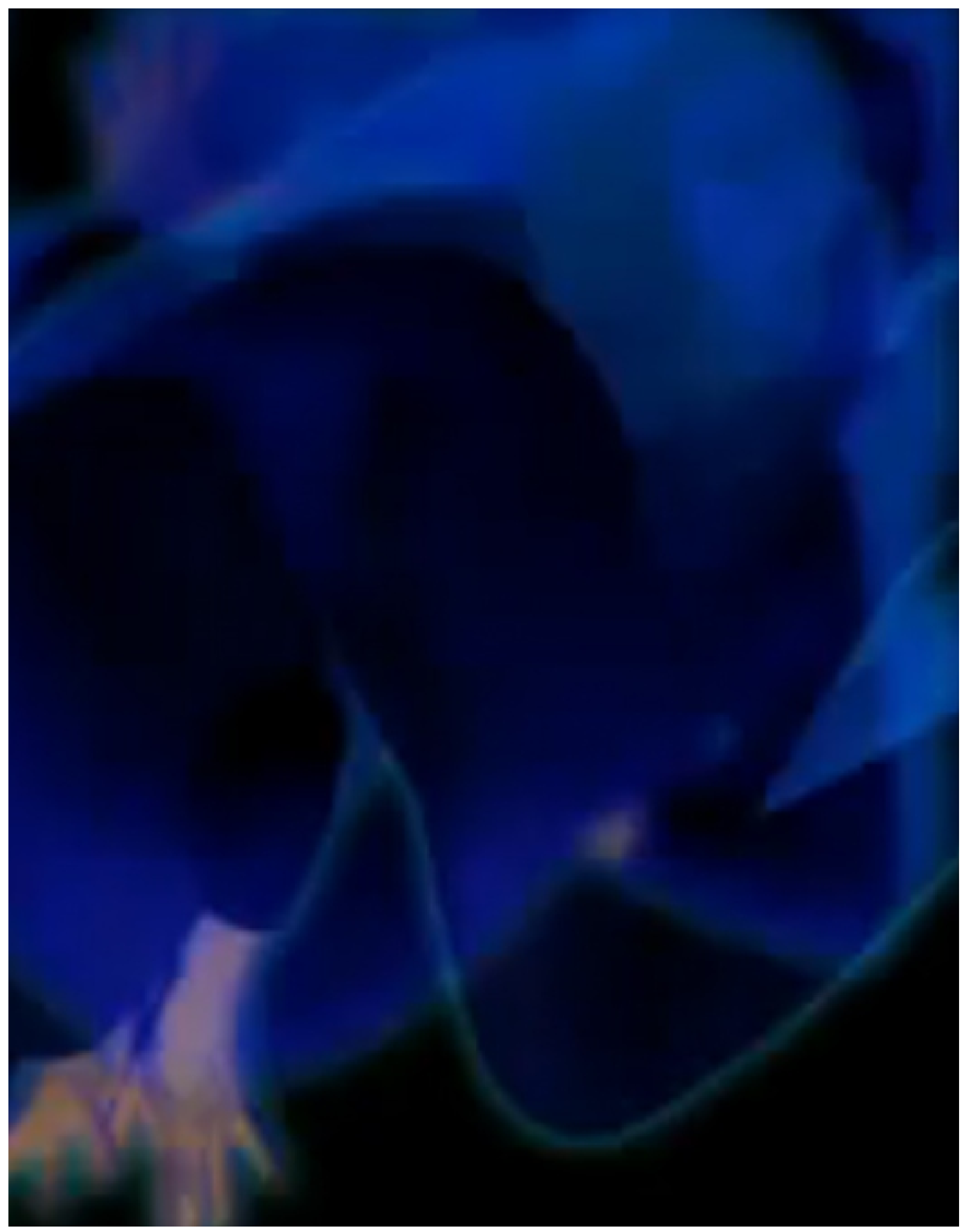


高

Nesse capítulo, trazemos a perspectiva do modelo proposto no capítulo anterior, para discutir o processo criativo coletivo em artes digitais como sistema complexo adaptativo. Essa perspectiva é considerada como entrada, para discutir a complexidade e a organização no estudo de caso, onde analisamos o trabalho do coletivo Transmute. 
A verdadeira revolução tecnológica na arte e na sociedade não reside simplesmente nessa conectividade global de pessoa para pessoa, mente para mente (significante como isso é), mas no seu poder de proporcionar a libertação do eu, libertação para o eu, o fictício 'euunificado' da filosofia ocidental. Esta hibridologia do eu reside na nossa capacidade agora de ser muitos eus, telematicamente em muitos lugares ao mesmo tempo, a nossa criação de si levando a muitas personalidades e identidades de série."

Roy Ascott, 2008, p. 24

\subsection{O boom telemático: Entrelaçados, Hibridizados, Múltiplos}

O pensamento cibernético, sistêmico, informacional, complexo, nos permitiu, nas últimas décadas, explorar as dimensões micro e macro da assim chamada realidade, do mundo dos fenômenos. Permitiu construir máquinas ratiocinatrix em escala nano, duplicar o indivíduo, alterar sua estrutura em sua gênese, simular, entender "[...] como o design e construção do nosso mundo poderiam constituir um processo emergente, substituindo a antiga abordagem top-down com uma metodologia botton-up." 2 (ASCOTT, 2006, p.9, tradução nossa).

'Do original em inglês: "The real technological revolution in art and in society lies not simply in this global connectivity of person-to-person, mind to mind (significant as that is), but in its power to provide for the release of the self, release from the self, the fictive 'unified self' of Western philosophy. This hybridology of the self lies in our ability now to be many selves, telematically in many places at the same time, our self creation leading to many personas and serial identities." (ASCOTT, 2008, p.24)

${ }^{2}$ Do original em inglês: "[...] how the design and construction of our world could constitute an emergent process, replacing the old top-down approach with a botton-up methodology." (ASCOTT, 2006, p.9) 
Ampliando-se exponencialmente com cada vez mais velocidade, os sistemas telemáticos ${ }^{3}$ permitem conexões em vários níveis, expandindo a consciência ao nível global, e permitindo ao eu ser vários, múltiplos e sobrepostos, entrelaçados em tempo e espaço independentes de geografia. Estamos simultaneamente presentes em várias realidades e acessando diversos níveis de realidade em cada uma destas. Como coloca Roy Ascott no artigo The Ambiquity of Self: living in a variable reality, o eu encontra "[...] presença física no ecoespaço, presença de aparição no espaço espiritual, telepresença no ciberespaço, e presença vibracional no nanoespaço."4 (ASCOTT, 2008, p.25, tradução nossa, grifo do autor). Para o professor Ascott, nesse cenário, a nova arte digital é "[...] imaterial e úmida, numinosa e aterrada, enquanto a mente tecnoética habita ambos, o corpo e é distribuída ao longo do tempo e do espaço." ${ }^{5}$ (ASCOTT, 2008, p.25, tradução nossa).

Assim, uma realidade sincrética emerge do que Ascott chama uma coerência cultural de intensa interconectividade, da coerência quântica como base da realidade, e da coerência espiritual da nossa consciência multinível. A arte digital nesse contexto é tão múltipla, híbrida, entrelaçada como os multiple selves (ASCOTT, 2008) em seu reino telemático multidimensional. Arte realizada em rede, coletivamente, envolvendo o conhecimento e domínio de uma miríade de técnicas, tecnologias, a articulação de saberes, referências, práticas, poéticas, múltiplas dimensões de realidades, artistas múltiplos também.

A presente pesquisa se articula em torno da intenção de dar visibilidade à estrutura sistêmica e multidimensional dessa prática, dar visibilidade de si a essas poéticas do entrelaçamento. A interatividade é central nessa arte que faz parte de um momento de transição cultural na medida em que "[...] permite ao indivíduo participar plenamente no trabalho de um sistema, mesmo que esse sistema opere no nível conceitual,

\footnotetext{
${ }^{3}$ O termo Sistemas Telemáticos se refere ao todo uso integrado de telecomunicações e informática, também referido como TICs ( Tecnologias de Informação e Comunicação)

${ }^{4}$ Do original em inglês: "[....] physical presence in ecospace, apparitional presence in spiritual space, telepresence in cyberspace, and vibrational presence in nanospace." (ASCOTT, 2008, p.25)

${ }^{5}$ Do original em inglês: "[...] immaterial and moist, numinous and grounded, while the technoetic mind both inhabits the body and is distributed across time and space." (ASCOTT, 2008, p.25)
} 
comportamental ou ambiental, quer ele seja utilitário ou artístico." ${ }^{\circ}$ (ASCOTT, 2003, p.266, tradução nossa).

É nesse processo de transição que noções como conectividade, imersão, interação, transformação e emergência são elementos-chave: "Conectividade de pessoas, lugares, ideias, mídia, sistemas / Imersão do espectador no data space do artista / Interação com elementos do sistema que são encontrados / Transformação da mídia e da consciência do espectador / Emergência de novos dados, imagens, formas, estruturas e sistemas."7 (ASCOTT, 2003, p.267, tradução nossa, grifo do autor).

\subsection{Sistemas de Sistemas: a dinâmica da datapoo/}

Se referindo ao contexto da arte digital como um todo, enquanto consultor do Ars Electronica Centre, em Linz, Áustria, Roy Ascott cunhou o termo datapool (ASCOTT, 2003). Tanto o termo, quanto as considerações que fazem parte de sua própria definição, ajudam precisamente a compreender ambos, o sistema maior - a arte digital em nível global - e o menor, os subsistemas, que podem ser os processos criativos coletivos em artes digitais, no contexto da presente abordagem, Como explica Ascott,

A datapool é algo no qual, e dentro do qual, os dados em todos os seus modos fluem - infinitamente transformados através da interação humana - e da qual ela emerge, arte-em-fluxo, fluindo em outros domínios, outras piscinas, outros afluentes do oceano de dados. Estas e outros tais organismos culturais exigem novos comportamentos por parte do público espectador: não mais observar, ficar atrás, olhar de longe e julgar, mas mergulhar na datapool, mergulhar na sua mutabilidade líquida, participar em suas rotantes transformações, navegar suas bases de conhecimento, mergulhar para essa suas profundezas de significado. Isso clama por novos padrões no acesso público à arte, a arte não como objeto finito, mas como processo e sistema, um fluido, fluxo em movimento de configurações de dados, incorporado em redes, nas telas, em estruturas materiais, em instalações e ambientes, abertos infinitamente a transformação e mudança." (ASCOTT, 2003, p. 270, tradução nossa, grifo nosso).

\footnotetext{
${ }^{6}$ Do original em inglês: "[...] empowers the individual to participate fully in the working of a system, whether that system operates at the conceptual, behavioral, or environmental level, and whether it is utilitarian or artistic." (ASCOTT, 2003, p.266)

${ }^{7}$ Do original em inglês: "Connectivity of people, places, ideas, media, systems. Immersion of the viewer in the data space of the artist. Interaction with elements of the system that are encountered. Transformation of media and of the consciousness of the viewer. Emergence of new data, images, forms structures and systems." (ASCOTT, 2003, p.267)

${ }^{8}$ Do original em inglês: "The datapool is that into which, and within which, data in all its modes flows - endlessly transformed through human interaction - and from which it emerges, art-in-flux, flowing on into other domains, other pools, other tributaries of the data sea. This and other such cultural organisms call for new behaviours on the part of the viewer public: no longer to observe, stand back, look from a distance and judge, but to plunge into the datapool, immerse in its fluid changeability, share in its swirling transformations, navigate its knowledge bases,
} 
Como vimos, as considerações do professor Ascott se aplicam também ao sistema menor, ao processo criativo coletivo. Processo-sistema, fluxo de dados incorporados em estruturas em rede, tessituras informacionais significantes, abertos à transformação e mudança, organização da qual diversos trabalhos artísticos podem ser considerados emergências.

\subsection{O olhar para o complexo: Estudo de Caso - O Coletivo Transmute}

O nosso objetivo na realização do presente estudo de caso é analisar o processo criativo do coletivo Transmute como forma de dar visibilidade à sua organização sistêmica, discutir suas emergências, o entrelaçamento entre seus elementos, suas conexões com outros sistemas, como os que envolvem os trabalhos realizados pelo diretor artístico Keith Armstrong ${ }^{9}$, para além do coletivo Transmute. É, enfim, apresentar o coletivo como processo, o processo como um sistema complexo adaptativo.

Falando sobre a natureza de um dos trabalhos desenvolvidos pelo coletivo Transmute, Intimate Transaction, Tony Fry, pensador na área de eco design, observa que, as origens do trabalho são muito mais uma questão de discutir as ideias do que falar de uma fusão entre arte visuais e tecnologia, e a apropriação e inversão que ela envolve de formas e métodos de jogos de computador. Essas ideias dizem respeito, sobretudo, à exploração de uma noção plural de ecosofia.

Como referido em várias publicações do coletivo Transmute, existe uma preocupação evidente com a crise ecológica que vivemos e que envolve um problema de causalidade circular: ao mesmo tempo em que causamos os problemas ambientais que temos que confrontar, esses problemas são inerentes ao sistema natural que contribui para que sejamos o que somos, nos comportemos de certas formas, interferindo no ecossistema. Keith Armstrong considera que, sua prática em arte digital, que inclui os trabalhos como

dive to its depths of meaning. This is to call for new standards in public access to art, art not as finite object but as process and system, a fluid, moving stream of data configurations, embodied in networks, on screens, in material structures, in installations and environments, endlessly open to transformation and change." (ASCOTT, 2003, p. 270)

${ }^{9}$ Keith Armstrong é diretor de criação, designer de mídias e integrador de sistemas, trabalhando em conjunto com equipes multidisciplinares. É fundador e diretor do coletivo interdisciplinar 'Transmute'. É editor de Queensland, para o National Arts Newspaper Realtime, e é membro da QUT Creative Industries Media-Architecture Integration Advisory Panel para o governo de Queensland e para o Hassell Partners Architects. 
integrante do coletivo, objetiva contribuir para mudar esse panorama de crise ecológica através de uma abordagem do fazer artístico que chama ground media.

Segundo Armstrong, ground media seria uma forma de prática artística que se estrutura em torno da compreensão de que, nossa crise ecológica, é também uma crise cultural, perpetuada pelo nosso sentimento de separação das ecologias materiais e imateriais das quais dependemos. Essa visão, segundo Armstrong, "[...] concorda com a concepção Aristotélica da praxis que concerne aos pensamentos e ações que compõem a nossa vida ética e política, com foco em promover o bem estar humano e, por extensão, bemestar não-humano."10 (ARMSTRONG, 2008, tradução nossa).

Essa noção se insere no que Armstrong chama de uma praxis ecosófica, que objetiva criar contextos nos quais a audiência, tanto durante o trabalho quanto depois de terem se envolvido, "[...] adquire entendimentos de sua co-dependência energética tanto com outros interatores ou espectadores dentro do trabalho e, através da associação metafórica com os mundos ecológico e eco-social conectados além."” (ARMSTRONG, 2008, tradução nossa).

No contexto dessa praxis ecosófica, no que se refere especificamente ao trabalho Intimate Transactions, a obra convida a refletir sobre a possibilidade de novos sujeitos ecológicos ou socioambientais. Como observa Tony Fry, "Fundamentalmente, a intenção interativa do trabalho foi criar um meio para refletir sobre um tipo particular de experiência - a experiência do nosso ser relacionalmente ligado como um corpo coletivo." ${ }^{12}$ (FRY, 2010, tradução nossa). Assim, através de estratégias interativas e intervenções performáticas, foram criadas experiências nas quais os participantes paulatinamente constroem uma compreensão de seus papéis compartilhados em redes de relações energéticas complexas que os conectam a outros habitantes do trabalho artístico, através de associações metafóricas com os mundos social e ecológico, para

\footnotetext{
${ }^{10}$ Do original em inglês: "[...] concurs with the Aristotelian conception of praxis which concerns the thoughts and actions that comprise our ethical and political life, focused upon furthering human well being, and by extension, nonhuman well being." (ARMSTRONG, 2008)

"Do original em inglês: "[...] gain understandings of their energetic co-dependency both with other interactors or spectators within the works and, through metaphorical association, with the connected ecological and eco-social worlds beyond." (ARMSTRONG, 2008)

${ }^{12}$ Do original em inglês: "Crucially, the interactive intent of the work was to create a means to reflect upon a particular kind of experience - the experience of our being relationally connected as a collective body." (FRY, 2010)
} 
além do contexto da obra. Como explica Armstrong, "Os participantes são encorajados a refletir sobre suas ações tanto durante quanto após o trabalho, através de conversação e escrita, de forma a compreender gradualmente o leque de fatores locais e em rede, moldando as suas experiências e as influências sistêmicas que os afetam." 13 (ARMSTRONG, 2008, tradução nossa).

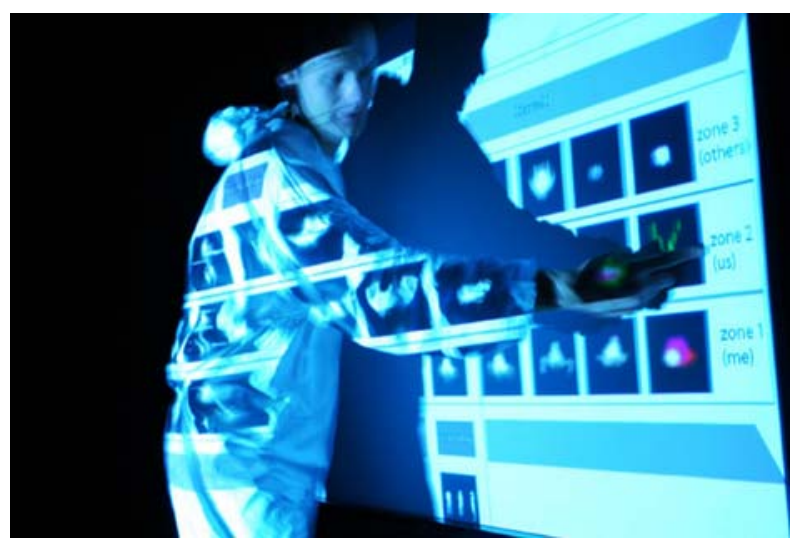

Figura 1.04 // Keith Armstrong demonstra a estrutura teórica de Intimate Transactions, 2003

Essa praxis ecosófica é parte essencial do conjunto de informações que integra a base do sistema que é o processo criativo coletivo do qual emergem os trabalhos Grounded Light (2003) e Shifting Intimacies (2006), sendo também evidente na proposta de um vestível prototípico chamado In_Step (2007). Esses trabalhos não são, nas considerações práticas dos artistas, produtos do coletivo Transmute. No entanto, se consideramos o coletivo como processo e esse processo como um sistema, podemos incluir essas obras como emergências no processo auto-organizacional de um complexo onde, a noção de uma praxis ecosófica, aparece na base da estrutura sistêmica. Complexo do qual emergem trabalhos como Liquid Gold (2001), Transact (Flesh/Skin/Bone) (2002) e, como últimas emergências estudadas aqui, as diferentes versões de Intimate Transactions.

\footnotetext{
${ }^{13}$ Do original em inglês: "Participants are therefore encouraged to reflect upon their actions both during and after the work through conversation and writing in order to gradually understand the range of local and networked factors shaping their experiences and the systemic influences that affect them." (ARMSTRONG, 2008)
} 
Os trabalhos incluídos no estudo de caso, e que constituem sub-estudos de caso, por sua vez, compartilham uma base conceitual que é a base conceitual do coletivo Transmute, na instância inferior do nosso Modelo Úmido, influenciando todas as outras instâncias e, por conseguinte, as conexões entre os elementos do sistema.

\subsection{Grounded Light (2003)}

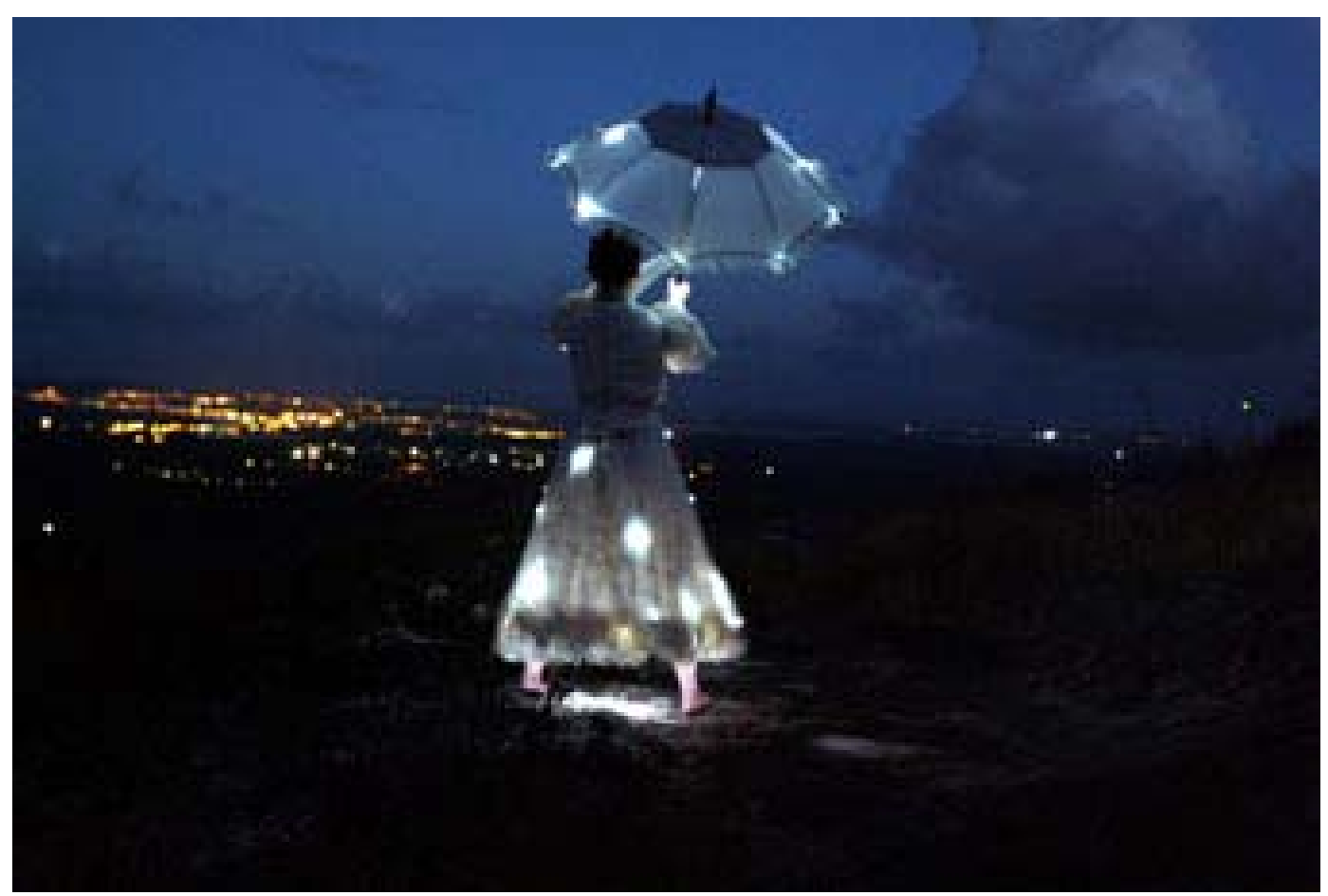

Figura 2.04 // Performance de Lisa O’Neill em Grounded Light no topo do Monte Tinbeerwah

O trabalho Grounded Light, que foi apresentado no Monte Tinbeerwah, Noosa Hinterland, Queensland, Austrália - um popular mirante na região, no Noosa Gallery Floating Land Festival, em 2003, se sustenta, em grande parte, a partir das ideias do filósofo australiano pós-colonial Paul Carter. Carter em seu livro The Lie of the Land (CARTER, 1996) chama atenção à profunda desconexão entre os Australianos caucasianos e a paisagem que imaginam habitar.

Mesmo movendo-se sobre o solo, muitas camadas se colocam entre esses habitantes e a terra propriamente dita. Em Grounded Light, os artistas exploram o conceito de 
ancoramento (groundedness). Esse é um conceito fundamental em ecologia, remetendo a deslocamentos culturais e ontológicos que, em caso de nunca serem abordadas, discutidas, interferem profundamente nas interações com a paisagem, com a terra na qual vivemos.

A partir do Monte Tinbeerwah, como relata Armstrong, pode-se "[...] observar a forma geral do terreno, a concentração de vida na costa, as cicatrizes profundas do desmatamento da floresta e, com o pôr do sol, os pontos de luz de habitações humanas."14 (ARMSTRONG, 2008, tradução nossa). Muito da história da colonização pode ser lida através das marcas nesse meio ambiente. Para Armstrong, uma possível leitura é a de que a colonização em território Australiano aconteceu, não dentro, mas sobre a terra. Paul Carter, em seu livro, clama por uma consciência ecológica que seja capaz de amenizar, confrontar essa sensação de não-pertencimento, não-enraizamento, o que, para ele (CARTER, 1996), pode ser evocado por meio de poéticas ambientalmente fundamentadas.

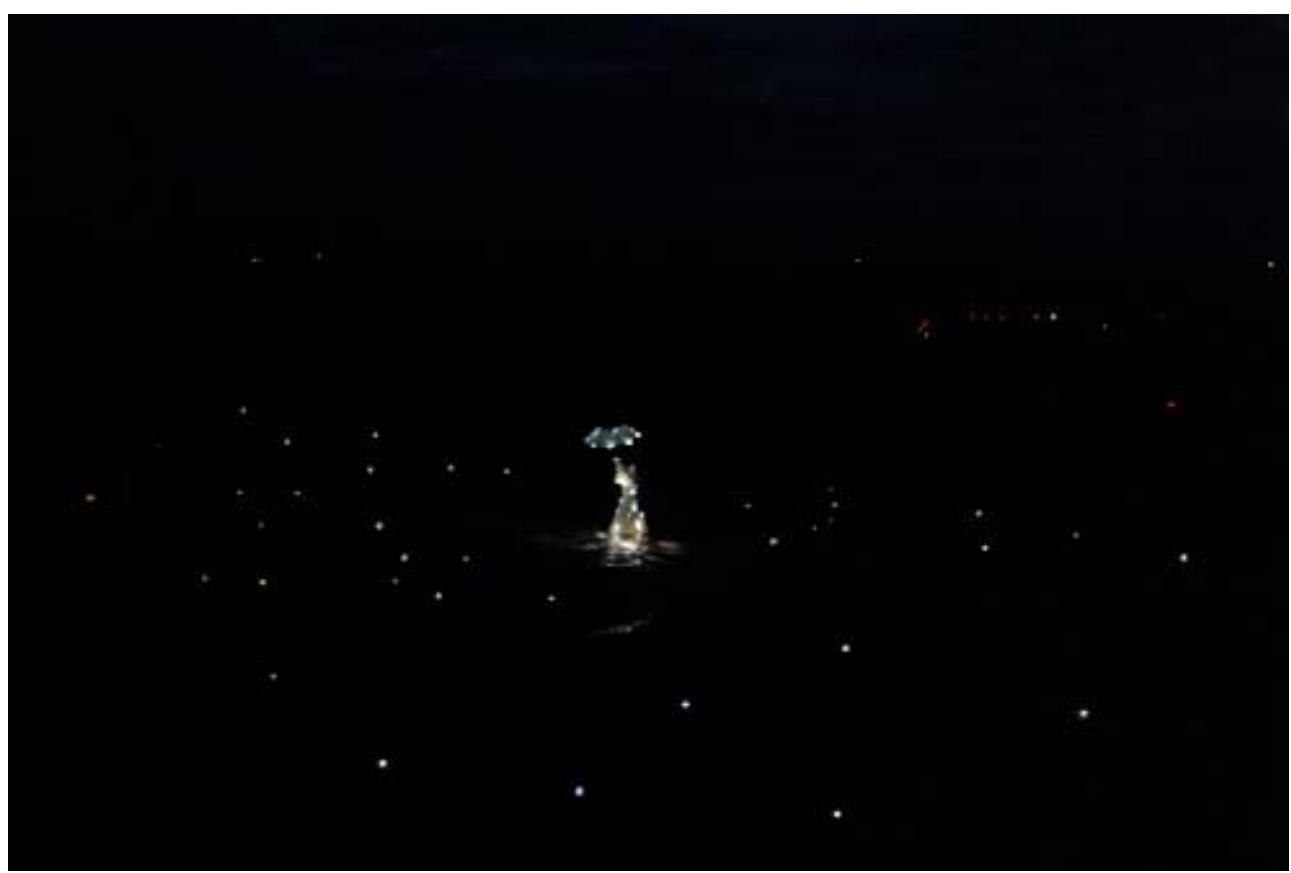

Figura 3.04 // Lisa O’Neill, cercada pelas luzes no topo do Monte Tinbeerwah, Grounded Light.

\footnotetext{
${ }^{14}$ Do original em inglês: "[...] can observe the general shape of the land, the flocking of life to the coast, the deep scars of forest clearing, and, as the sun sets, the pinpoint lights of human dwellings."(ARMSTRONG, 2008)
} 
A performance em Grounded Light foi executada numa noite sem lua, pela performer Lisa O’Neill (integrante do coletivo Transmute), vestida com um figurino de época, dentro do qual podiam ser percebidos pontos de luz iluminando sutilmente o vestido - a imagem era a de uma mulher arrogante com seu vestido colonial que, vista à distância, parecia flutuar sobre a montanha. A trilha sonora, composta pelo trombonista Bem Marks criava uma atmosfera comovente e assustadora, sendo reproduzida por um equipamento instalado em um guarda-sol portado pela performer e também iluminado. No entanto, o estilo da performance realizada pela artista sugeria, como ficou claro para Armstrong, uma relação intensa com o solo.

Os sons foram compostos com bases sonoras não convencionais para trombone, que lembram os sons do didgeridoo ${ }^{15}$ - instrumento típico dos aborígenes australianos. No decorrer da jornada/performance até o alto da montanha, um convite em código morse foi enviado. Enquanto a performance era realizada, uma resposta inesperada veio da Blackened Mountain, situada a 4 (quatro) quilômetros de distância do Monte Tinbeerwah. Esse evento de comunicação e conexão entre lugares normalmente desconexos, relembra comunicações ponto a ponto que, no passado, foram importantes para a coesão social, e fazem uma alusão à compreensão da nossa imobilidade dialógica, cinética, em relação à terra.

No final do percurso, a performance atinge o cume do Monte Tinbeerwah e é acompanhada pela vista dramática de $360^{\circ}$ (trezentos e sessenta graus) das luzes do Shire, flutuando sobre o chão, abaixo do monte. Na última curva antes de alcançar o cume, deparava-se com uma instalação composta de 120 LEDs brancos, afixados no chão por pequenas hastes finas. Esses pontos de luz se destacavam na escuridão formando uma malha visual que parecia se juntar visualmente aos pontos de luz no vale abaixo que, à distância, tomavam dimensão reduzida num diálogo entre luzes térreas e flutuantes. Segundo o curador Kevin Wilson, o trabalho não apenas "[...] cria algo como fornece um espelho para ver um lugar com maior profundidade."16 (WILSON apud ARMSTRONG, 2008, tradução nossa).

\footnotetext{
${ }^{15}$ O didgeridoo é um instrumento de sopro feito de madeira natural desenvolvido por aborígenes Australianos a mais de 1500 anos e ainda em uso na Austrália.

${ }^{16}$ Do original em inglês: "[...] create something as provide a looking-glass to see a place in greater depth." (WILSON apud ARMSTRONG, 2008)
} 
Para Armstrong, as reflexões que aconteceram no decorrer do processo criativo, que culminou com a realização da performance, posteriormente deram início a um processo de formulação dos conceitos de grounded media, e sub-ecologia da praxis ecosófica. Essa observação é importante quando consideramos esses conceitos como influentes na instancia inferior na leitura através do Modelo Úmido do processo criativo do Transmute. No entanto, é importante observar a não-linearidade desse processo organizacional. O próprio Armstrong (ARMSTRONG, 2008), considera que, praxis direcionadas por metodologias, são raramente lineares em sua natureza tendo, o segundo trabalho coletivo a partir do qual uma abordagem grounded media surgiu, sendo desenvolvido apenas dois anos depois de Grounded Light, em 2005.

Embora Grounded Light não envolva usualmente a interação direta de uma audiência, como em outros trabalhos realizados por Armstrong, o envolvimento físico de audiências andando, tocando o chão durante a experiência/performance foi, como relata o diretor artístico, "[...] fundamental para um entendimento incorporado do conceito de ancoramento."17 (ARMSTRONG, 2008, tradução nossa). Além, o trabalho apresenta e desenvolve imagens relacionadas ao lugar, que trazem para discussão e reflexão questões ecológicas que se tornam centrais no processo criativo.

\subsection{Shifting Intimacies (2006)}

Shifting Intimacies é uma instalação interativa inspirada em performance. O trabalho foi comissionado via uma residência do diretor artístico Keith Armstrong em Londres, em 2005, vinculado ao Arts Council of England, Institute of Contemporary Arts (ICA). A obra foi apresentada no ICA $^{18}$ durante o festival de dança e mídia Capture 4. Armstrong trabalhou de forma colaborativa com a coreógrafa Charlotte Vincent e com o artista sonoro integrante do coletivo Transmute, Guy Webster.

O objetivo central da obra era o de chamar a atenção para os ciclos ecológicos generativos, que envolvem reciclagem de nossos corpos no próprio processo de geração da vida. A metáfora da poeira foi utilizada como uma espécie de metáfora conectiva, representando estados transitórios entre morte e vida, de forma visual, auditiva, literal e

\footnotetext{
${ }^{17}$ Do original em inglês: "[...] critical to an embodied understanding of the concept of groundedness." (ARMSTRONG, 2008)

${ }^{18}$ ICA - Institute of Contemporary Arts. Ver: http://www.artscouncil.org.uk/rfo/institute-of-contemporary-arts/
} 
conceitual. Armstrong se refere à metáfora, falando da poeira como a matéria à qual a vida e tudo retornam e, simultaneamente, a partir da qual tudo se constrói - poeira dispersa no universo, cruzando, conectando, diversas dimensões temporais.

No decurso do período de 10 (dez) minutos na instalação, o participante é convidado a andar livremente em um espaço escuro, medindo 25 (vinte e cinco) por 12 (doze) metros. No espaço, um ambiente sonoro circundante conta com 7 (sete) canais de som interativo, sendo possível mover-se ao redor, e entre duas telas circulares com projeções de vídeo a partir do teto.

O chão é coberto por areia, que fica como memória na sola dos calçados dos participantes quando deixam a obra. Sobre o chão, são também projetados outros dois vídeos. Há ainda a projeção de mais um vídeo sobre a Tela 1 (Screen One) - coberta com areia fina e branca. Esse vídeo se baseia em ideias "[...] de uma nova vida/emergência invocada pela imagem de um corpo a emergir lentamente a partir de um substrato aquoso. O vídeo está infinitamente em loop e fornece constância com o espaço."19 (ARMSTRONG, 2008, tradução nossa).

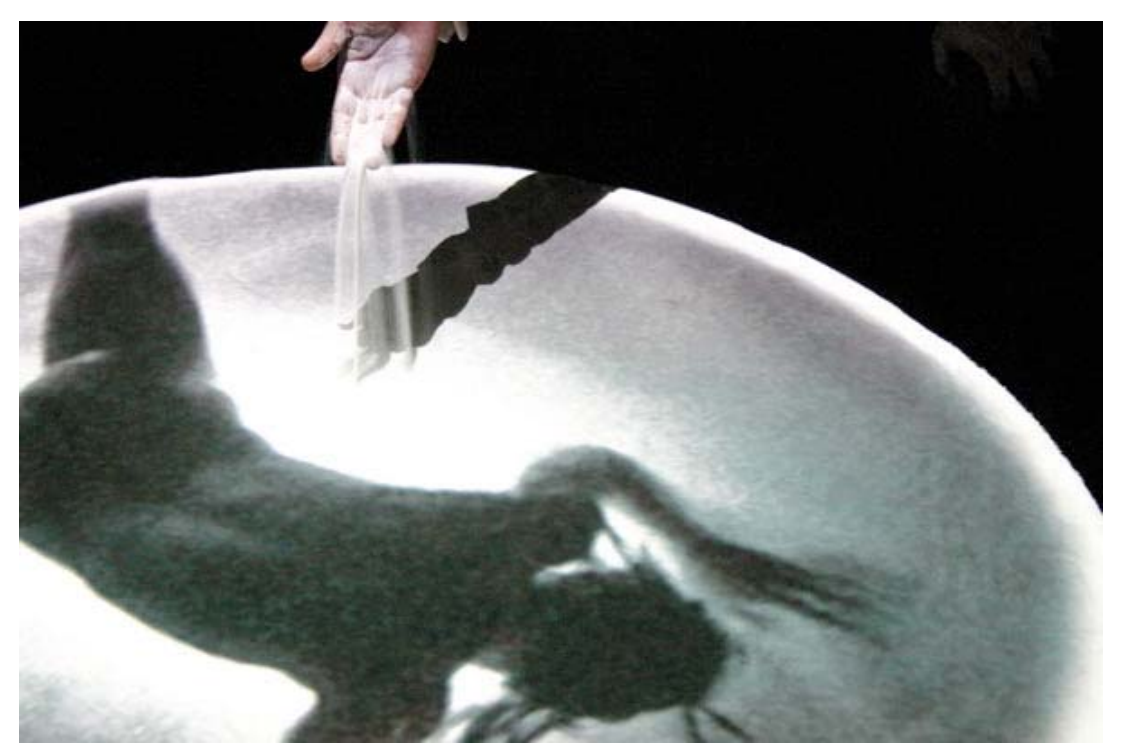

Figura 4.04 // Shifting Intimacies tela com areia

\footnotetext{
${ }^{19}$ Do original em inglês: "[...] of new life/emergence invoked through the image of a body slowly emerging from a watery substrate. It loops endlessly and provides constancy within the space." (ARMSTRONG, 2008)
} 
O vídeo projetado na Tela 2 (Screen Two) se baseia nas ideias de evolução, morte e retorno a partir da poeira. Esse vídeo se desenvolve em tempo real a partir de uma série de estágios coreografados pelos padrões de percurso da audiência no espaço da instalação. Uma série de sensores instalados no ambiente permite ao sistema evoluir as imagens digitais e os sons em tempo real, através da inclusão no software de um algoritmo baseado em vida artificial que, segundo o diretor artístico, "[...] inspira-se nas profundezas do imaginário criando um paralelo digital para as poeiras físicas da obra. ."20 (ARMSTRONG, 2008, tradução nossa).

As projeções sobre o chão coberto de areia evocam processos de re-mixagem, transformação e desintegração do corpo - primeiro à areia e, finalmente, à poeira. Armstrong considera que, a natureza interativa delicada do trabalho "[...] garante que muito do material audiovisual é gerado diretamente e coreografado por movimentos de corpo inteiro dos participantes. Isso envolve cada participante e seu corpo em uma parceria co-criativa e performática com o trabalho."21 (ARMSTRONG, 2008, tradução nossa). Este modo sutil de interação é moldado por uma trilha sonora com instruções codificadas poeticamente e que cada participante escuta imediatamente antes de entrar no ambiente.

Como seres vivos que sofrem processo de envelhecimento e morte em seus ciclos de vida, somos dependentes de complexas ecologias - físicas, interpessoais, com a biosfera. Se referindo a esses ciclos, a obra Shifting Intimacies (2006) examina preconceitos ocidentais associados a processos ecológicos no confronto da morte, do morrer, do ser enterrado, assim como relacionadas ao nascimento. Nas palavras de Armstrong, "como acontece com o primeiro projeto Grounded Light, enquanto estes temas centrais não podem ser imediatamente associados a práticas ecológicas convencionais, eles afetam profundamente nossas concepções de quem e o que somos."22 (ARMSTRONG, 2008, tradução nossa).

\footnotetext{
${ }^{20}$ Do original em inglês: "[...] infuses itself deep within the imagery creating a digital parallel to the work's physical dusts." (ARMSTRONG, 2008)

${ }^{21}$ Do original em inglês: "[...] ensures that much of the audiovisual material is directly generated and choreographed by participants' whole body movements. This implicates each participant and their body in a cocreative, performative partnership with the work." (ARMSTRONG, 2008)

22 Do original em inglês: "As with the first project Grounded Light, whilst these core themes may not be immediately associated with conventional ecological practices they profoundly affect our conceptions of who and what we are." (ARMSTRONG, 2008)
} 


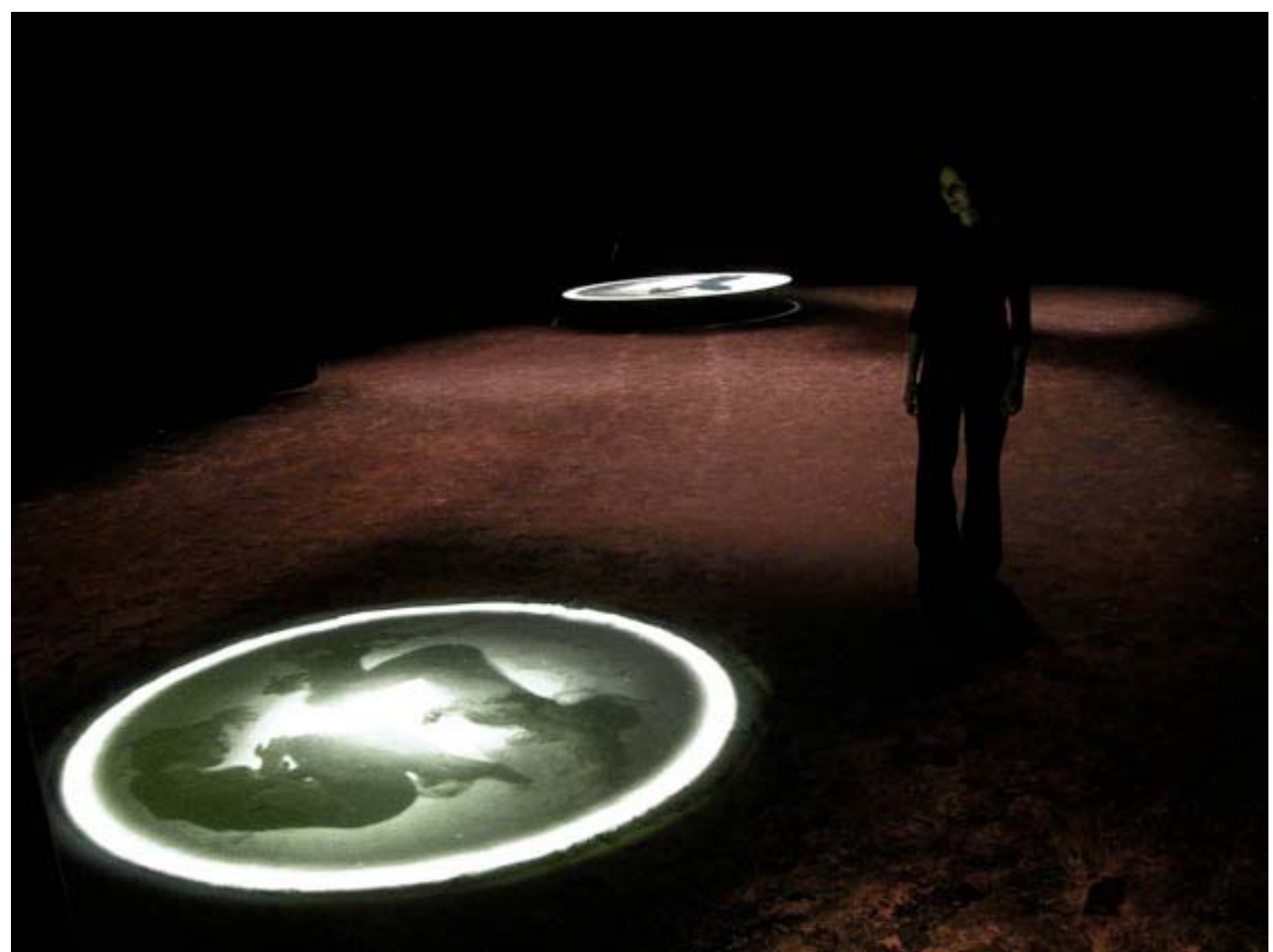

Figura 5.04 // Shifting Intimacies, ICA, London.

É interessante observar como uma série de ideias-chave emergiram das reflexões nesse trabalho, e amadureceram na abordagem do conceito de grounded media. Podem ser observadas semelhanças evidentes e fortes dessa obra com a obra que a antecede Grounded Light. Essas semelhanças incluem o papel central do caminhar, a existência de um material básico pervasivo - a poeira -, que alimenta o trabalho em todas as suas instâncias. Há o projeto de um script baseado em processos cíclicos influenciados por deriva e fluxo, diretamente conectados aos ritmos de deriva de cada participante no espaço

As conexões vitais exploradas na obra entre engajamento físico e conhecimento, foram subsequentemente exploradas em um protótipo de vestível, In_Step, desenvolvido em janeiro de 2007, durante o workshop Australian Network for Art and Technology's 
ReSkin, em Canberra. In_step compreende um conjunto de bandagens costuradas com sensores leves e flexíveis para tecido, que vestem o pé, dos dedos ao tornozelo. Esses sensores se comunicam com um dispositivo leve na mão do participante, contendo atuadores eletromecânicos que vibram gentilmente através do tecido, em compasso com a qualidade do andar.

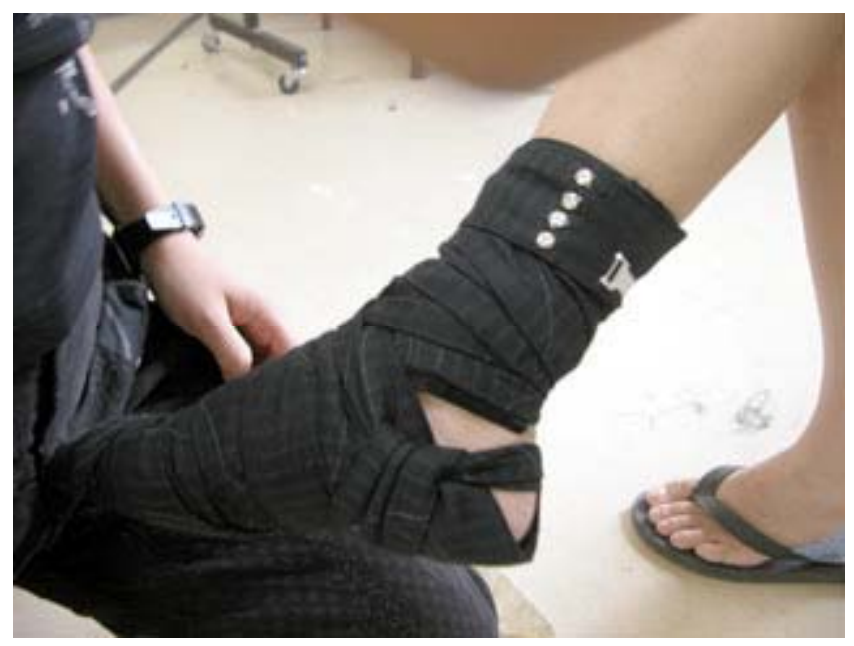

Figura 6.04 // In_Step, 2007 - Sensory Foot Bandage

Este dispositivo de feedback pode ser dado a outra pessoa para que ela sinta as qualidades, traduzidas, do caminhar de outrem. O trabalho envolveu a criação de uma série de performances para serem realizadas por participantes por um dado período de tempo, permitindo às pessoas examinarem as qualidades do andar uns dos outros. Essa é uma abordagem incorporada ao fazer artístico que também é crítica para o conceito de grounded media. Segundo Armstrong, essa abordagem é adotada "[...] não só para salientar a importância dos corpos dos participantes nos trabalhos, mas também para trazer para o primeiro plano a sensibilidade dialogada, engajada que sustenta a sua concepção e produção."23 (ARMSTRONG, 2008, tradução nossa).

\footnotetext{
${ }^{23}$ Do original em inglês: "[...] not only to stress the importance of the participants' bodies in the work, but also to foreground the conversational, engaged sensibility that underpins its conception and production." (ARMSTRONG, 2008)
} 


\subsection{Coletivo Transmute: o coletivo como processo; o processo como sistema}

O coletivo Transmute, tendo Keith Armstrong como diretor artístico, Lisa O’Neill como performer e Guy Webster como diretor de som, foi formado em 1998, em torno da simpatia por ideias discutidas em conjunto em outros trabalhos além do coletivo instituido, como a de grounded media, e a de uma prática ecosófica. Além, existia a vontade de desenvolver instalações performáticas. Com o tempo, a equipe foi sendo expandida para incluir programadores, engenheiros elétricos e cientistas ecológicos.

A partir da perspectiva do Modelo Úmido, podemos estruturar o processo evolutivo do coletivo Transmute em alguns estágios principais marcados pela emergência de trabalhos artísticos prontos para serem exibidos. No primeiro estágio, temos dois projetos piloto que, segundo Armstrong, forneceram as bases para futuros desenvolvimentos - Liquid Gold, de 2001, e Transact (Flesh/Skin/Bone), de 2002. A decisão da equipe foi a de que, o núcleo do projeto interativo computacional desses trabalhos, seria inspirado pelos fluxos energéticos dentro de ecologias descritas cientificamente. A ideia era produzir, nessas obras, transmissão energética e padrões metafóricos de recepção, numa referência a recursos comunicativos e conectivos dos sistemas que sustentam a vida.

Essas ideias de transferência de energia, tem uma sinergia com a prática da performer que integra o coletivo, a diretora de performance Lisa O'Neill, que trabalha com a tradição Japonesa do Suzuki Theatre. Essa tradição incorpora um método de treinamento de atores focalizado no centro energético de cada um e explorando relações baseadas em energia entre um ator e os demais atores que integram o grupo, e destes com a audiência. Uma técnica que considera o entrelaçamento, a partir de energias vitais, entre os indivíduos que, em um dado momento, se organizam em uma dinâmica, fazendo parte de um mesmo todo sistêmico.

Esse modelo sistêmico de intercâmbio relacional, transferência e ressonância, não apenas influenciou, como explica Armstrong (2006), o desenvolvimento de metáforas de fluxos energéticos no design da interação via computador, mas também permitiu conceber 
posteriormente a instalação Intimate Transactions como uma experiência performática duracional.

\subsubsection{Liquid Gold (2001)}

O primeiro projeto piloto da sequência de trabalhos diretamente relacionados à emergência da instalação Intimate Transactions, Liquid Gold, consistiu em uma série de performances simultâneas realizadas nas cidades de Brisbane, na Austrália e em Sheffield, na Inglaterra. Essas performances foram controladas precisamente através de fusos horários. Para conectar esse locais com uma audiência online, foi utilizado um servidor para chat customizado chamado animador de ideia (em inglês, idea animator), funcionando tanto no espaço físico, onde eram realizadas as performances, quanto na Internet. As performances foram lideradas por Lisa O’Neill, sediada em Brisbane, e remixadas por Keith Armstrong.

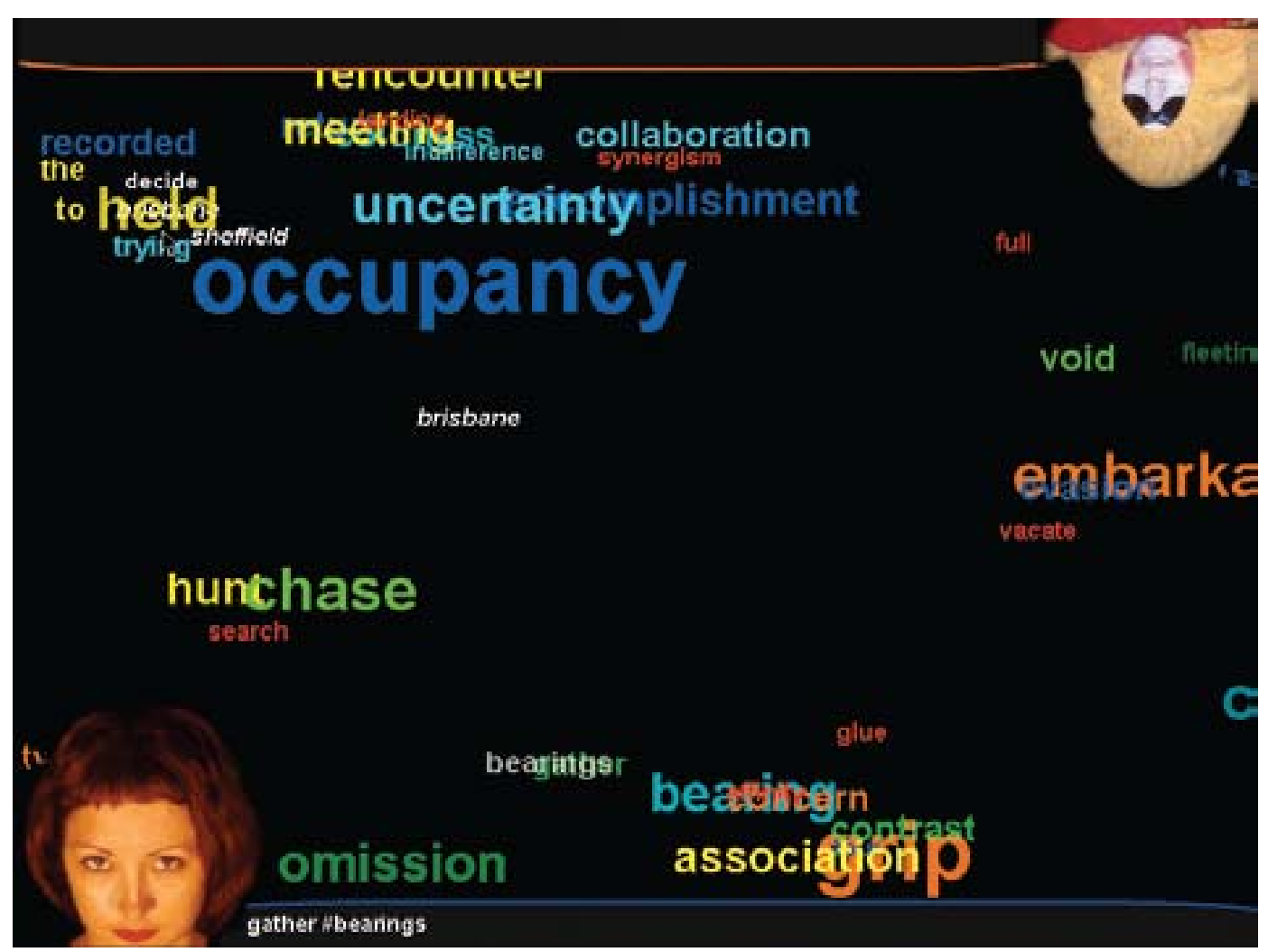

Figura 7.04 // Animador de /deia (captura de uma exibição na tela do computador), Liquid Go/d Online, 2001. 
A ideia central da obra se baseia na jornada de uma mulher que acontece fisicamente no interior renovado da área industrial de Brisbane, em um espaço onde funcionou uma casa de força (powerhouse) e, virtualmente, através de uma série de mundos virtuais fantásticos, que integram a instalação, projetados em uma tela. A intenção é que, essa jornada, ajude o personagem a reconciliar fantasmas do passado com a jornada em direção a seu recém-imaginado futuro.

No decorrer das performances, dois escritores (um na Austrália e outro na Inglaterra) traduziam em texto o que eles estavam testemunhando localmente. Os textos, as palavras, eram convertidos em animações projetadas ao vivo nos locais das performances, tanto em Brisbane quanto em Sheffield, e compartilhadas online com a audiência remota. Essa audiência podia clicar em palavras particulares, fazendo com que avatares online gravitassem em sua direção, permitindo, segundo Armstrong, "[...] um fluxo constantemente circulante de ideias e emoções." ${ }^{24}$ (ARMSTRONG, 2006, tradução nossa). Para o diretor artístico, a estrutura conectiva e distributiva de Liquid Gold constituiu uma importante experiência para o coletivo Transmute. Essa experiência se refere ao potencial de instalações performáticas em rede, envolvendo fluxo de imagens e conectando uma audiência online através de experiências híbridas que envolvem jogo, diversão.

\subsubsection{Transact (Flesh/Skin/Bone) (2002)}

Segundo projeto piloto, Transact (Flesh/Skin/Bone), foi exposto na Tasmanian State Art Gallery em Hobart, Austrália, em 2002. A proposta aludia à relação entre o clima interno do corpo e às, sempre cambiantes, condições atmosféricas, das quais o ambiente corporal também depende. $O$ trabalho foi influenciado por formas de performance Japonesas conhecidas como Body Weather, que se referem a interações dinâmicas entre as condições atmosféricas e a performance que acontece em um determinado lugar.

Outra referência a práticas orientais na área de performance e atuação, foi a utilização do entendimento de equilíbrios dinâmicos entre pele, carne e osso do método Suzuki de treinamento de atores. A pele se refere à aparência do artista/performer, a carne, ao

${ }^{24}$ Do original em inglês: "[...] a constantly circulating flow of ideas and emotions." (ARMSTRONG, 2006) 
resultado de um treino disciplinado e o osso, se refere às características inerentes ao corpo do ator/performer.

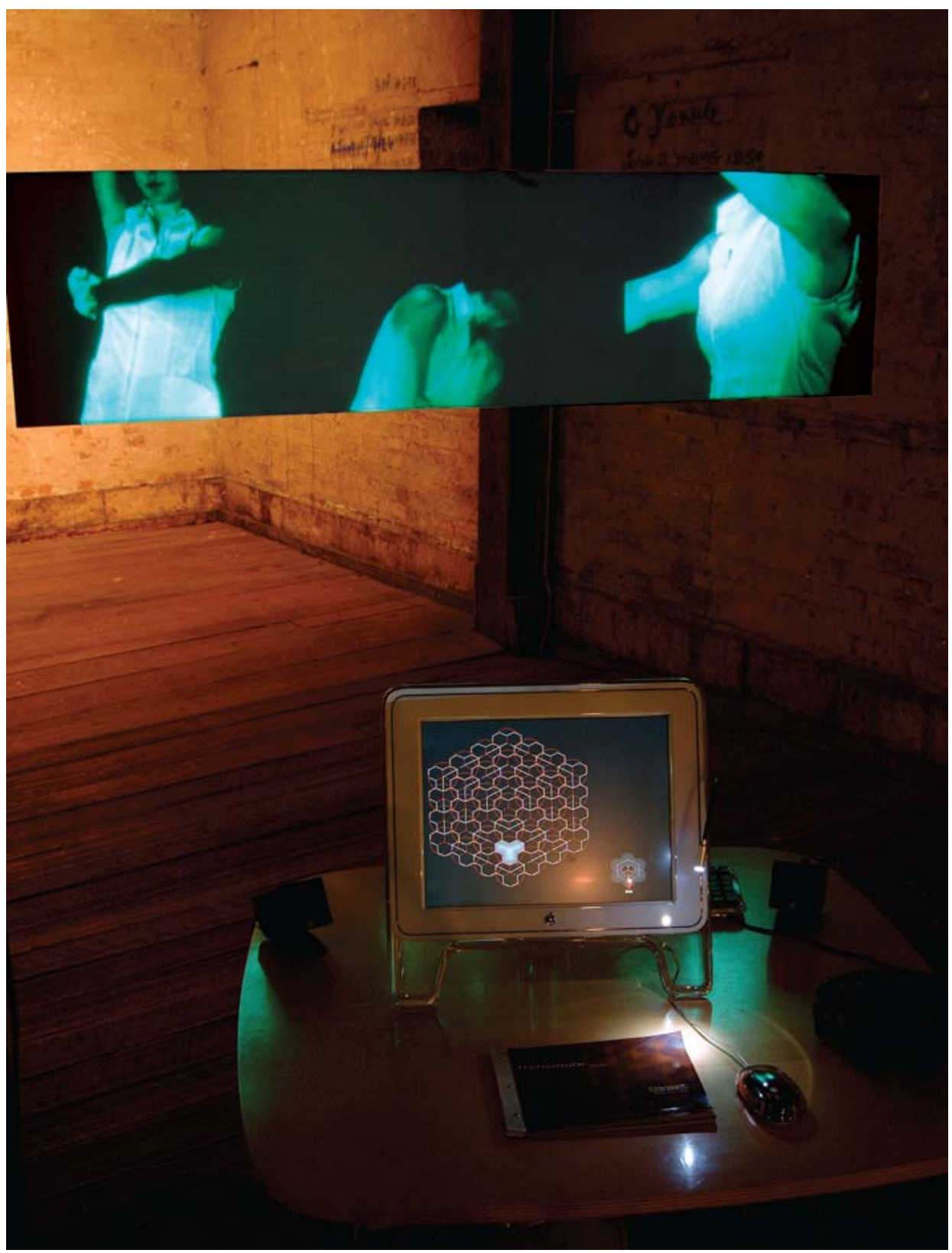

Figura 8.04 // Foto da instalação Transact (Flesh/Skin/Bone) em exibição na Tasmania State Gallery, Hobart, Australia, 2002 
Assim como no trabalho Liquid Gold (2001), que o antecede, a obra inclui a performance de Lisa O'Neill. A instalação tem duas telas de projeção com som espacial não linear, projetado por Guy Webster, criando uma atmosfera que, segundo Armstrong, se caracteriza por "[...] uma profunda sensação de incerteza." ${ }^{25}$ (ARMSTRONG, 2006, tradução nossa).

Esta obra envolveu ainda, uma metodologia interativa de construção de script, criada por Gavin Sade, inspirada pelas estruturas de malha quadradas, encravadas como colmeias, recorrentes na natureza. A referência a essas estruturas, permitiu ao coletivo organizar a dinâmica da instalação, e as imagens performáticas, em células que eram recombinadas e justapostas em tempo real. O participante poderia, assim, controlar indiretamente o trabalho através de uma interface aparentemente simples, que permitia selecionar parâmetros para características relacionadas a cada uma das instâncias, pele, carne e ossos.

\subsubsection{Intimate Transactions: primeira versão}

Como mencionado anteriormente, os trabalhos Liquid Gold (2001) e Transact (Flesh/Skin/Bone) (2002), constituíram experimentos iniciais realizados pelo coletivo Transmute, que se construíram dentro de uma praxis ecosófica, inspirados por noções e estruturas ecológicas, envolvendo performance como parte de instalações em rede, e sendo multilocais. Tanto em Transact (Flesh/Skin/Bone) quanto em Liquid Gold, a audiência que participava, tendo disposição para colaborar, se tornou cada vez mais envolvida com a obra, com seu conteúdo, forma e estrutura, compreendendo seu papel e lugar dentro das relações fluidas do trabalho.

A partir de reflexões possibilitadas a partir do processo de realização desses trabalhos, o coletivo experimenta o que Armstrong (ARMSTRONG, 2006) chama de um desenvolvimento eco-conceitual (Stage Two: Eco-conceptual Development), e alcança o que podemos chamar de um segundo estágio de organização, na perspectiva sistêmica da presente abordagem. Segundo o diretor artístico do coletivo, na medida em que observavam a interação dos participantes com Liquid Gold e Transact, cada vez mais os integrantes do coletivo perceberam "[...] o poder da coreografia no design de sistemas

${ }^{25}$ Do original em inglês: "[...] a deepening sense of uncertainty." (ARMSTRONG, 2006) 
interativos, interfaces e caracterização virtual." ${ }^{\text {26 }}$ (ARMSTRONG, 2006, tradução nossa). O coletivo decidiu enfatizar ainda mais, a partir dessas observações, a performatividade no trabalho, movendo os participantes no sentido de um papel mais ativo.

Desse ponto em diante, o trabalho do grupo passa a requerer um envolvimento ativo por parte da audiência, dos participantes, através da incorporação da necessidade de movimentação do corpo como um todo, para interagir. O coletivo abraça a ideia de que, os efeitos desencadeados por uma interação física sustentada, podem perpassar todos os aspectos computacionais e experimentais de trabalhos futuros.

Devido a essa ênfase no corpo e nos movimentos físicos como base para a interação, uma estrutura que serviria de suporte para o corpo físico, tornou-se um aspecto importante no desenvolvimento do próximo trabalho do coletivo - Intimate Transactions. Essa ênfase emerge na prática do grupo como um elemento conceitual perpassando e influenciando a organização do coletivo enquanto sistema. A estrutura/suporte deveria ser robusta e ter uma forte presença física. Ao mesmo tempo, a estrutura deveria ser confortável o suficiente para não distrair os participantes, uma vez que estivessem envolvidos na experiência - não deveria interferir na possibilidade de imersão na obra. Esses parâmetros iniciais foram os que orientaram o projeto de uma espécie de prateleira para o corpo que foi realizado em parceria como o designer de mobiliário e artista visual Zeljko Markov.

Equipada com um sistema computacional em rede, a peça acabou por constituir o que o coletivo chamou de um híbrido de peça de mobiliário e dispositivo para interação, pressupondo e convidando a um envolvimento físico particularmente ativo. O dispositivo requeria que os participantes fizessem contato corporal completo com o suporte para os pés e para as costas, e que estivessem em constante movimentação.

A intenção do coletivo era a de produzir uma experiência incorporada de interação. Armstrong menciona a definição de embodiment de Paul Dourish (2001), que incorpora um status participativo que inclui conversas e ações, à medida que os participante

\footnotetext{
${ }^{26}$ Do original em inglês: "[...] the power of choreography in the design of interactive systems, interfaces and virtual characterization." (ARMSTRONG, 2006)
} 
desvendam o universo no qual estão imergindo. A ideia do coletivo era a de que o dispositivo permitisse aos participantes, "[...] tornarem-se imersos fisicamente nas operações sistêmicas de Intimate Transactions e, ao mesmo tempo, estar envolvidos com múltiplos processos de diálogo, de intercâmbio e transferência." ${ }^{27}$ (ARMSTRONG, 2006, tradução nossa).

Essas ideias dialogam, entre outras, com o princípio ecosófico que Arne Naess explora em seu artigo de 1973 The Shallow and the Deep, Long-Range Ecology Movement (NAESS, 1973). Esse princípio implica mover-se através do simples entendimento de uma pessoa em um ambiente através de uma imagem de campo total relacional (relational total-field image), o que traduz um engajamento participativo complexo. Naess, em sua abordagem, chama a atenção para a falta de compreensão da abordagem dos ecologistas, na época, pela comunidade científica, requerendo atenção e envolvimentos menos superficiais. A partir dessas considerações, Naess caracteriza o que seriam um movimento Ecológico Superficial (The Shallow Ecology movement), e um Profundo movimento Ecológico (The Deep Ecology movement), que se caracterizaria, em primeiro lugar, pela "rejeição da imagem do homem-no-ambiente em favor de uma imagem de campo total relacional."28 (NAESS, 1973, p. 95, tradução nossa).

Esse modelo de campo total, dissolve não apenas o conceito homem-no-meio ambiente, mas todo conceito compacto de coisa-no-meio, exceto quando se referindo a um nível preliminar e superficial de comunicação. É dialogando com noções como essas que, o coletivo Transmute, opta por aumentar ou ampliar a experiência ecológica ou relacional da instalação e desenvolve uma abordagem conceitual à lógica da interação em torno do termo subjetividade ecológica de Elizabeth Baker, pesquisadora da área de sustentabilidade e mentora do projeto.

Com a colaboração de Baker, o coletivo concebeu 3 (três) conceitos interconectados Eu, Nós, e Outros (Me, Us and Other). Baker descreve esses conceitos, que podemos chamar instâncias de interação, da seguinte forma: "Eu é [...] o que os participantes

\footnotetext{
${ }^{27}$ Do original em inglês: "[...] to become immersed within Intimate Transactions' systemic operations physically and, at the same time, be engaged with multiple processes of dialogue, exchange and transfer." (ARMSTRONG, 2006 )

${ }^{28}$ Do original em inglês: Rejection of the man-in-environment image in favour of the relational, total-field image. Organisms as knots in the biospherical net ou field of intrinsic relations." (NAESS, 1973, p. 95)
} 
identificam como eles mesmos [...] Nós é (para a maioria das pessoas) outras pessoas como eu [...] um termo mais abrangente [...] Outros [...] é aquela coisa que não é como eu [...] com a qual não tenho nenhuma ligação." ${ }^{29}$ (BAKER apud ARMSTRONG, 2006, tradução nossa).

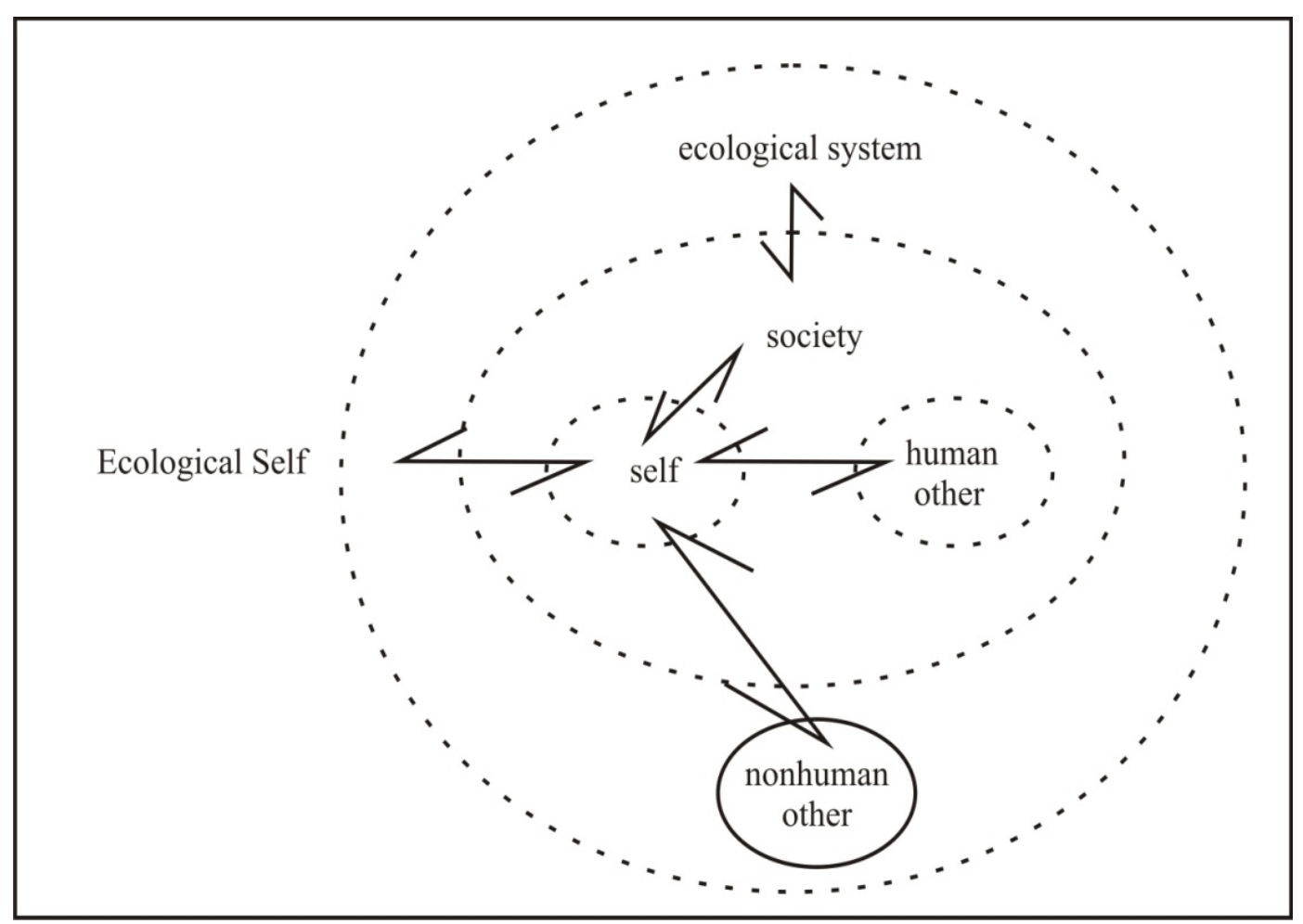

Figura 9.04 // Diagrama da Autocobertura Ecológica (Ecological Selfhood), (1997), por Elizabeth Baker

A lógica conceitual desse trio de estados, Eu, Nós, Outros, foi incorporada a uma variedade de mídias para ser ativada em resposta aos movimentos corporais dos participantes. Cada um dos artistas colaboradores, foi convidado a interpretar cada um dos estados Eu, Nós e Outros dentro do seu próprio domínio de atuação/colaboração performance, som, imagem visual, design da interface. A ideia era a de "[...] premiar os participantes através deste feedback sensorial quando trouxessem vontade de colaborar,

${ }^{29}$ Do original em inglês: "Me is [...] that bit the participant identifies as themselves [...] Us is (for most people) other people like me $[. .$.$] a more inclusive term [\ldots]$ Other $[\ldots]$ is that stuff which is not like me $[\ldots]$ that I have no connection to." (BAKER apud ARMSTRONG, 2006) 
com base em sua compreensão emergente de seu próprio lugar e papel dentro de uma série de tarefas complexas, mudando as relações."30 (ARMSTRONG, 2006, tradução nossa).

Zeljko Markov projetou o suporte para o corpo, de forma a dar liberdade e facilitar a coreografia de movimentos corporais sutis, através dos três estados. Em um primeiro nível de interação, o suporte permitiu uma série de movimentos corporais em direção a uma transição contínua entre confinamento e abertura.

O estado $E$, requeria que as duas mãos do participante estivessem pressionando a parte do suporte que está atrás do participante. Uma transição para o estado Nós, requeria crescente extensão da parte superior do corpo e do braço, levando a uma posição em que o corpo está estendido como um todo, correspondente ao estado Outros. Esse estado, por sua vez, requer, na dimensão virtual da instalação, que o participante entre na escuridão, em direção ao espaço-tela posicionado à sua frente.

Nesse caminho, os movimentos do participante passam por uma transição de uma instância privada e confinada a um estado de alcance estendido. No que se refere à parte técnica, um sistema de reconhecimento de gestos, controlado por câmeras, permite registrar e retransmitir os movimentos através dos estados Nós e Outros. O sistema pode, assim, dar feedback ao participante através das várias mídias que estão combinadas e são afetadas em tempo real.

No projeto para o som, Guy Webster cria uma espécie de progressão, que pode ser percebida como pessoal e próxima, quando no estado Eu. Esse som espacializado se torna familiar no estado Nós, passando a ser distante e estranho, e gerando uma espacialidade abstrata, no estado Outros. Além, um alto-falante é instalado no suporte para o corpo, produzindo um certo grau de vibração sônica nas costas do participante.

A mídia visual inclui representações de corpos fantasmagóricos e fragmentos de texto que flutuam na interface e que são extraídos do conto de ítalo Calvino A nuvem de Smog

${ }^{30}$ Do original em inglês: "[...] to reward participants through this sensory feedback when they brought a willingness to collaborate, based upon their emergent understanding of their own place and role within a series of complex, shifting relationships." (ARMSTRONG, 2006) 
(CALVINO, 1992) - conto que fala da obsessão compulsiva de um homem com uma poluição física e psicológica que está envolvendo seu complicado relacionamento amoroso. As formas corpóreas e textos foram organizados em bases de dados e marcados com características relacionadas aos conceitos Eu, Nós e Outros. Isso significa que, as frases e palavras organizadas em grupos de conceitos, emergem de uma massa, uma nuvem de palavras no fundo da projeção, e pairam no primeiro plano de uma grande tela inclinada na frente dos participantes, que se encontram posicionados no suporte. Segundo Armstrong, "Combinações de imagens corporais também apareceram, com suas formas físicas, alinhadas com os vários estados, Eu (apertado, rítmico, familiar); Nós (liso, fluindo, aberto, acolhedor) e Outros (estranho, trepidação, improvável)."31 (ARMSTRONG, 2006, tradução nossa).

A instalação, em sua primeira versão, foi apresentada em 2003 para um grupo de colegas que trabalham com explorações semelhantes, no Brisbane Powerhouse Centre for the Live Arts, com o objetivo de capturar feedback da audiência. De um modo geral, o coletivo observou que, os participantes, atingiram um grau de relacionamento forte e integrado entre a sua interação e o feedback sensual que combina som, imagem e vibrações. Eles relatam ainda que, o objetivo de incorporação do princípio ecosófico de re-situar o Eu em relação ao Outro ecológico, também foi compreendido pelos participantes.

Essa primeira versão de Intimate Transactions foi construída em função da participação ativa de um único indivíduo, mapeando os efeitos de suas ações. Na fase subsequente, a proposta se amplia para uma versão multi-local, com vários participantes interagindo a partir de diferentes locais físicos, conectados em rede. Nos testes com a primeira versão da instalação, o feedback dos participantes foi importante para que a instalação sofresse essa transformação, para que uma outra versão pudesse acontecer como emergência no processo organizacional do coletivo enquanto estrutura sistêmica. Segundo Armstrong,

[...] a partir do feedback que recebemos, também nos tornamos cientes de um problema de design. Alguns participantes relataram serem incapazes de se localizar facilmente na obra. Eles tinham dificuldade em relacionar as ações do

\footnotetext{
${ }^{31}$ Do original em inglês:"Combinations of bodily images also appeared, with their physical forms aligned to the various states: Me (tight, rhythmical, familiar); Us (smooth, flowing, open, welcoming); and Other (strange, juddering,improbable)." (ARMSTRONG, 2006)
} 


\begin{abstract}
seu corpo com as mudanças nas imagens e nas paisagens sonoras. Isto levou a uma percepção de falta de agência. O feedback sugeriu que uma representação direta controlável do participante através de um avatar na tela poderia tornar a navegação através da interface visual muito mais fácil. ${ }^{32}$ (ARMSTRONG, 2006, tradução nossa).
\end{abstract}

Nessa primeira versão, o coletivo optou por não fazer representações literais dos participantes na forma de avatares. Os participantes eram representados por forçaschave, que afetavam o ambiente e podiam visualizar sua presença representacional sendo construida através dos efeitos de suas ações, que provocavam mudanças nas cores, velocidade, combinação, replicação e processamento. Existia uma satisfação do coletivo como um todo com relação a sutiliza e delicadeza dessa representação e do caráter das interações.

No entanto, a percepção da equipe, que construiu uma intimidade com a instalação como um todo, durante um longo período de trabalho dedicado ao desenvolvimento da obra, era diferente da percepção de uma audiência que tinha que entender a obra e interagir num tempo limitado a, no máximo, 30 (trinta) minutos. A partir dessas considerações, a proposta sofreu alterações que envolveram repensar e reprojetar a interação como um todo, bem como a metodologia utilizada para o design visual do ambiente.

${ }^{32}$ Do original em inglês: "[...] from the feedback we received, we also became aware of a design problem. Some participants reported feeling unable to easily locate themselves within the work. They had difficulty relating their body's actions to the changes in the work's imagery and soundscapes. This led to a perceived lack of agency. Feedback suggested that a direct, controllable representation of the participant through an on-screen avatar would make navigating through the visual interface much easier." (ARMSTRONG, 2006) 


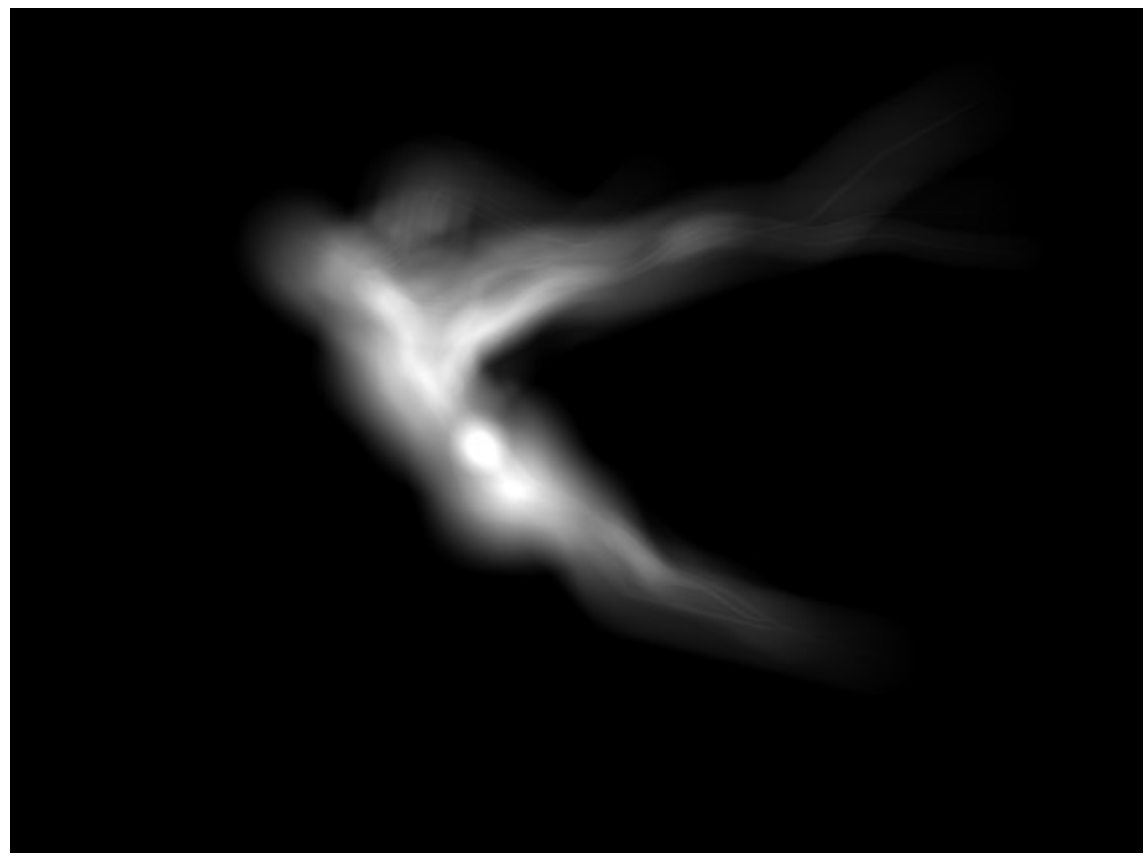

Figura 10.04 // Força de Mudança, Intimate Transactions.

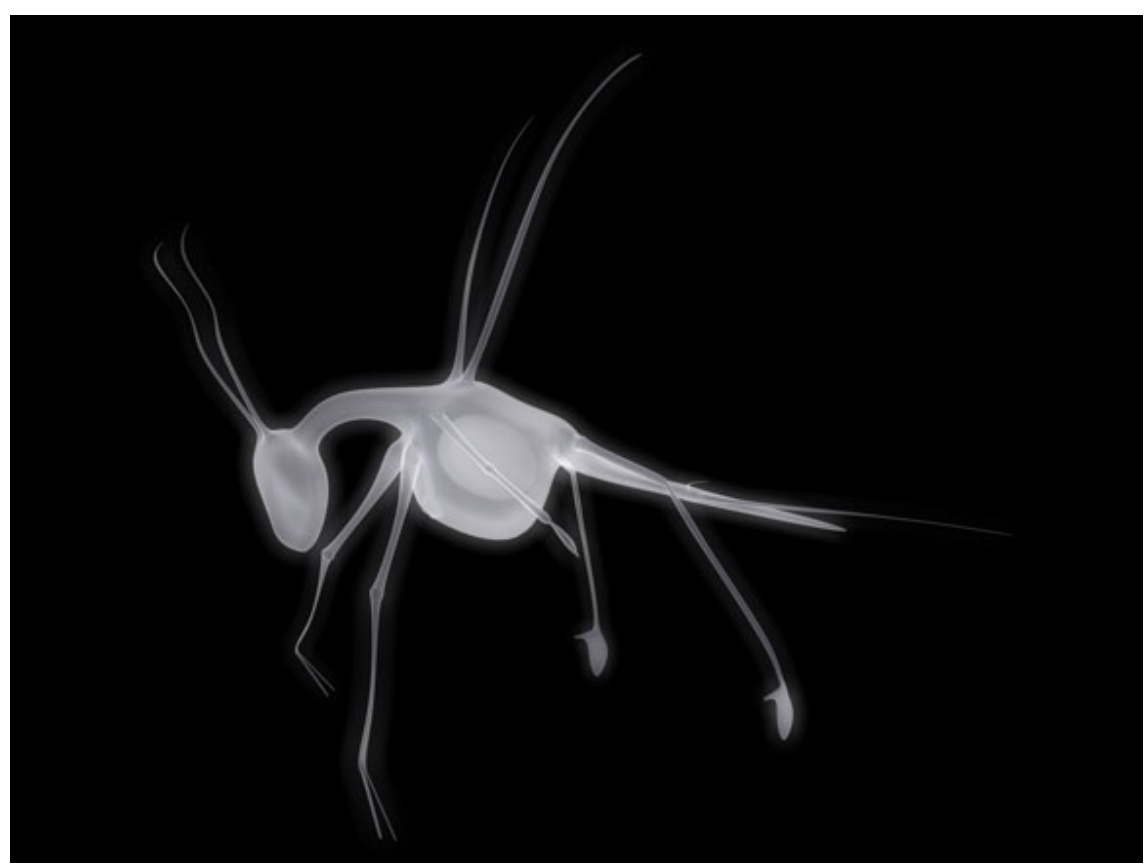

Figura 11.04 // Força de Conflito, Intimate Transactions.

146 


\subsubsection{Intimate Transactions: versão multiusuário}

Na versão multiusuário de Intimate Transactions, a representação dos participantes, na dimensão virtual em rede da instalação, acontece por meio de uma espécie de encarnação em um corpo virtual, numa abordagem coletiva e conectiva de uma ecologia particular que subverte as categorias normativas de identidade. Uma ecologia em que Eu, Nós e Outros se interconectam e se misturam intimamente.

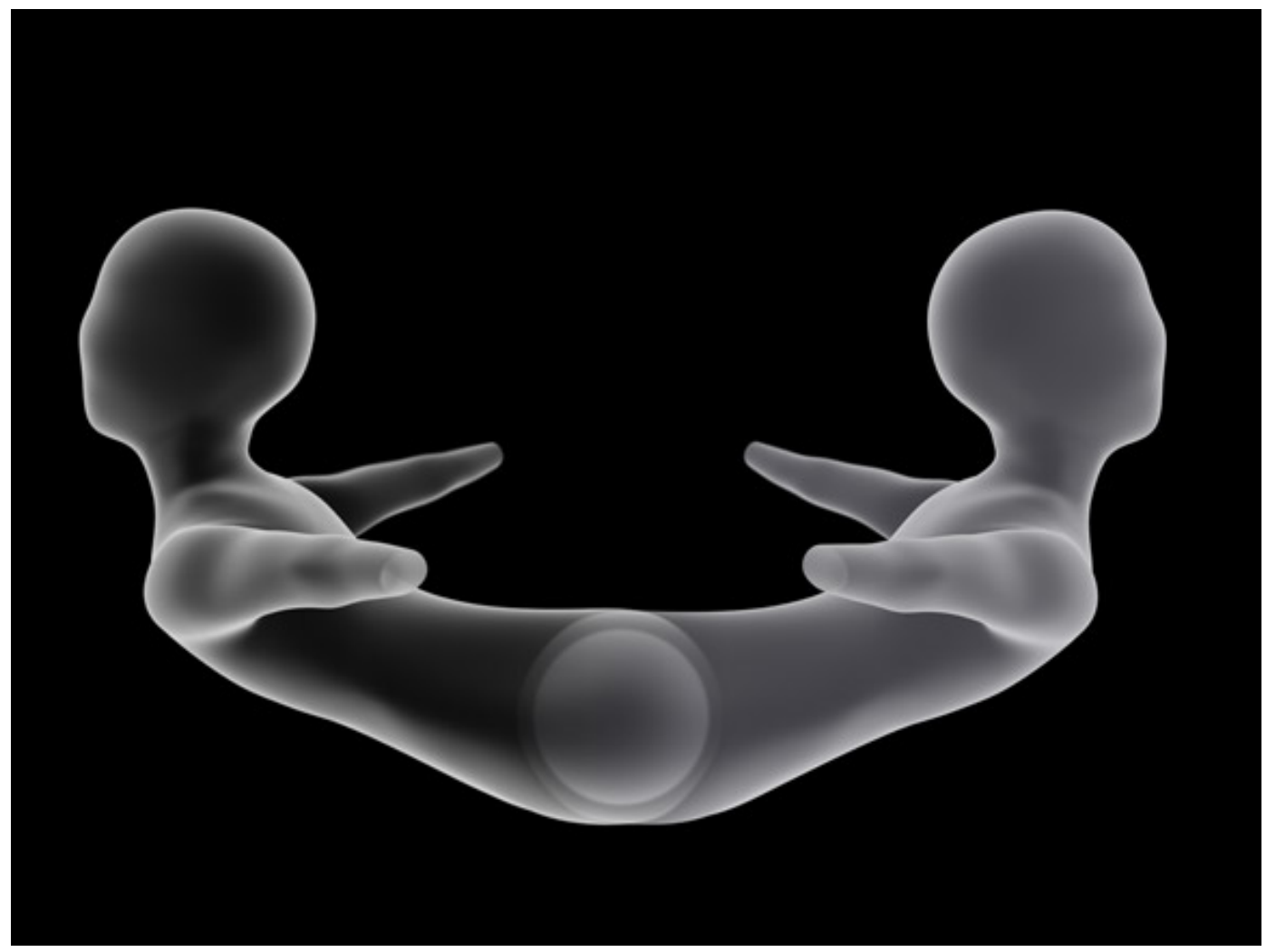

Figura 12.04 //Joined Body Avatars (Avatares de corpos unidos), Intimate Transactions

Quando a ideia do avatar foi introduzida, não existia ainda a intenção de transformar a instalação em uma versão multiusuário. O que aconteceu foi que, a incorporação de um avatar, sugeriu a possibilidade de uma nova estrutura de acordo com engines de jogos multi-player que normalmente usam avatares para representar as posições e atividades de um participante. Segundo Armstrong, dentro do modelo de design de jogos multi- 
player, "[...] o avatar normalmente interage e tem diálogo com outros personagens. Este modelo sugere, pois, a perspectiva de evolução do trabalho em uma aplicação multiusuário."33 (ARMSTRONG, 2006, tradução nossa).

Se observarmos o processo criativo do coletivo Transmute a partir da perspectiva sistêmica do Modelo Úmido, vemos que o acaso estimulou, num processo de reorganização do sistema a partir do ruído, o desenvolvimento de uma versão do trabalho que era multiusuário e em rede. Essa versão envolvia dois espaços instalativos distintos, cada um equipado com um suporte para o corpo conectado a um servidor com rede distribuída.

Essas mudanças demandaram extensivas alterações no design da instalação como um todo. Segundo Armstrong, as transformações aconteceram quando ele cursava o pósdoutorado na Queensland University of Technology ${ }^{34}$ (QUT) Creative Industries Research and Applications Centre, financiado pelos governos Federal e Estadual Australianos. No primeiro ano de cooperação, foi desenvolvido um protótipo de software em rede e dois suportes para o corpo (a segunda geração desses suportes), que incluíam inovações como plataforma móvel para os pés e um mecanismo no apoio para as costas, sendo sensível à pressão. Como relata Armstrong, esses suportes "foram testados e refinados através de exibições públicas e avaliações durante uma residência de três semanas no Performance Space, em Sydney." 35 (ARMSTRONG, 2006, tradução nossa).

\footnotetext{
${ }^{33}$ Do original em inglês: "[...] the avatar usually interacts with, and has dialogue with, other characters. This model therefore suggested the prospect of evolving the work into a multi-user application." (ARMSTRONG, 2006) 34 http://www.qut.edu.au/

${ }^{35}$ Do original em inglês: "were tested and refined through public showings and evaluations during a three week residency at the Performance Space, Sydney." (ARMSTRONG, 2006)
} 


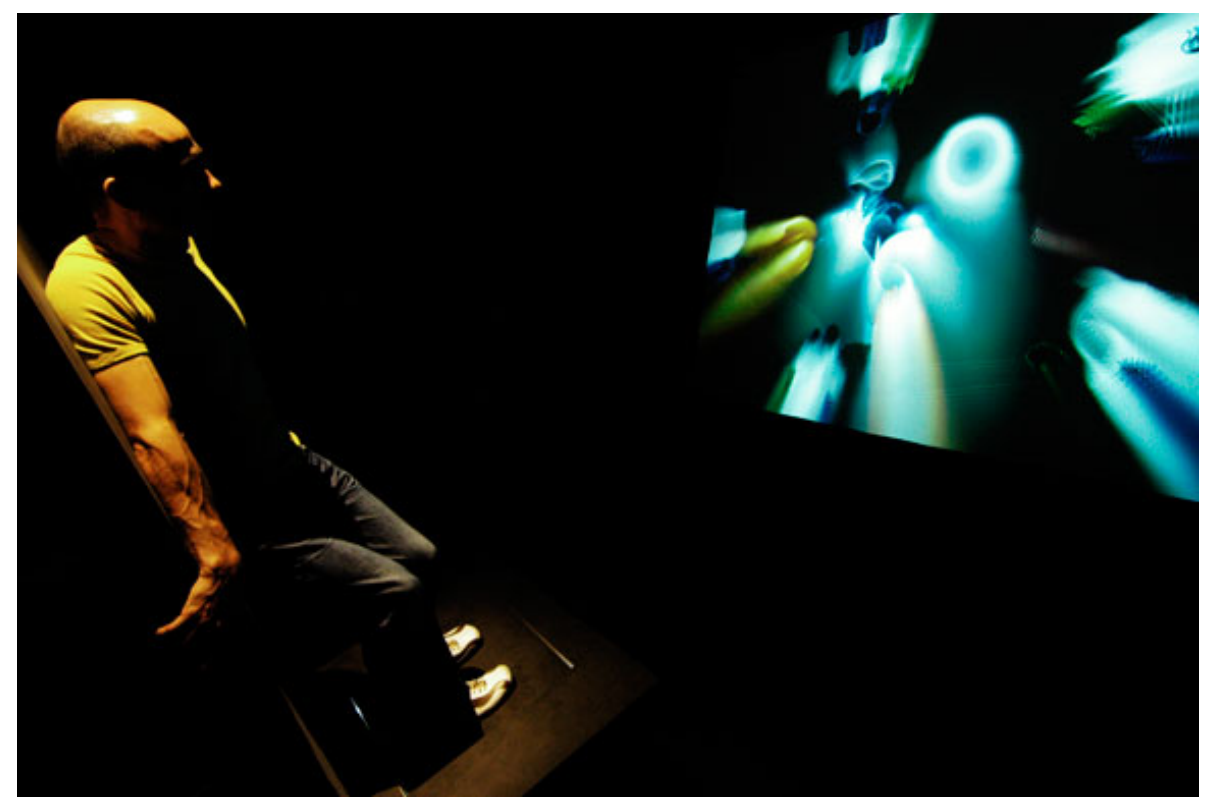

Figura 13.04 // Intimate Transactions, prateleira para o corpo.

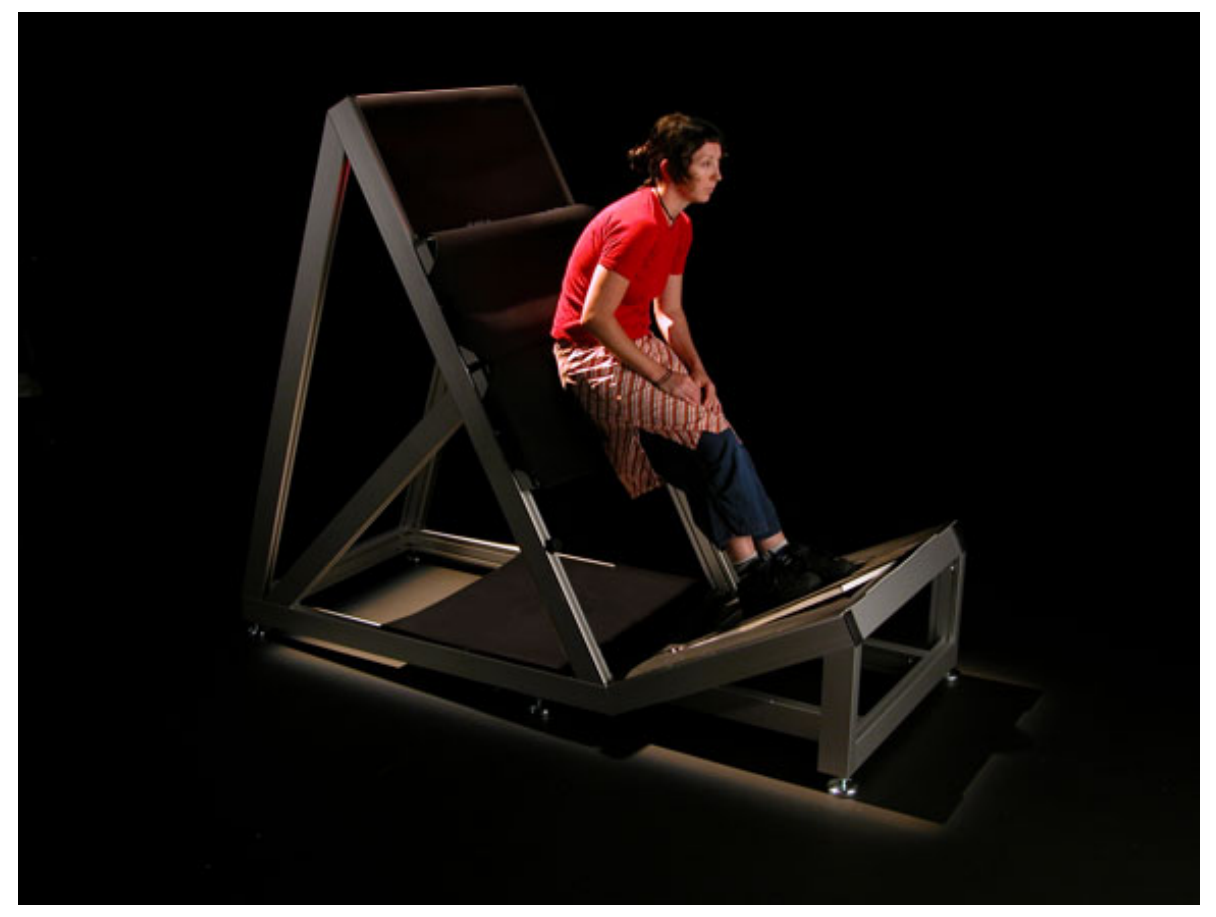

Figura 14.04 // Instimate Transactions, Lisa O'Neill na prateleira para o corpo 
No segundo ano de cooperação, a equipe começou a trabalhar com a Australasian CRC for Interaction Design (ACID), como parte de um projeto de pesquisa do Australian Creative Industries Network ( $A C I N$ ), que se estruturava em torno do potencial de comunicação em ambientes de redes distribuídos. O suporte dos parceiros envolveu uma verba maior, e a entrada de novos pesquisadores colaboradores como o Royal Melbourne Institute of Technology (RMIT), o Spatial Information Architecture Lab (SIAL), - Australian Centre for the Moving Image (ACMI), e a University of Queensland.

Assim, o coletivo Transmute, que estava envolvido, aceitou a oportunidade de estender o projeto, o que possibilitaria refinamento da proposta e da abordagem do design ecosófico, dentro de uma praxis ecosófica e da interação colaborativa, dando pleno suporte à implementação da uma versão multiusuário. No desenvolvimento dessa nova versão, a equipe decidiu que, enquanto o projeto poderia continuar a operar em torno da ideia de transferência de energia, a introdução de uma dimensão de rede necessariamente requeria uma reinterpretação do paradigma Eu/Nós/Outros.

Essa reinterpretação se fez necessária porque a interação não podia mais acontecer simples e restritamente entre o ambiente online e seus habitantes simbólicos criados na primeira versão. O objetivo agora era promover, viabilizar e facilitar a interação entre o ambiente e mais de um participante. Além, "devido a base ecosófica do trabalho, isso foi importante para promover um sentido de intimidade, colaboração e reciprocidade entre eles." ${ }^{36}$ (ARMSTRONG, 2006, tradução nossa).

Essa mudança foi trabalhada pelo coletivo, por exemplo, através de alterações no design do sistema, o que colocou a necessidade de incorporar, na equipe, designers computacionais para construir um modelo de sistema que pudesse acomodar uma aplicação online. Marcos Càceres, com experiência em design da interação, ampliou o design do sistema, estrutural e conceitualmente, concebendo uma estrutura em camadas computacionais, que poderiam englobar os princípios centrais de sistemas ecológicos como evolução e mudança.

\footnotetext{
${ }^{36}$ Do original em inglês: "Because of the ecosophical underpinning of the work, it was important to promote a sense of intimacy, collaboration and reciprocation between them." (ARMSTRONG, 2006)
} 
Esse sistema facilitava ainda o intercâmbio de objetos entre os dois participantes, de modo a fazer com que a equipe vislumbrasse um novo modelo computacional, cuja lógica era baseada na noção de transações - intercâmbios entre as partes que podem provocar mudanças para todas as partes, mudanças no todo. A navegação no sistema continuou, nessa versão multiusuário, e foi mantida a exploração do familiar ao não familiar progredindo nas instâncias Eu, Nós, Outros.

Assim, a estrutura exploratória, navegacional e interativa do trabalho foi adaptada a partir da progressão a priore Eu $\rightarrow$ Nós $\rightarrow$ Outros (familiar $\rightarrow$ não familiar). Nessa estrutura, navegar sem a intenção de interagir com outra criatura, ou outro participante, implica operação dentro da esfera Eu. Interações entre dois participantes acontecem na esfera Nós (ou seja, um lugar de relativa familiaridade/ empatia), ao passo que interações entre os participantes e criaturas indicam uma troca na esfera Outros. A exploração dessas idéias, a partir da colaboração do coletivo com Elizabeth Baker, contribuíram para explorar diversas questões dentro do trabalho, relacionadas a uma praxis ecosófica.

Nas considerações de Baker, sobre a primeira versão da instalação, a obra "[...] é uma maneira de explorar alteridade, estranhamento, incognoscibilidade de uma forma segura: uma analogia física / aural/ visual ao contar estórias. Porque é seguro, o indivíduo está mais propenso a explorar apenas um pouco mais, para se colocar em território desconhecido."37 (BAKER apud ARMSTRONG, 2006, tradução nossa). Dessa forma, os objetivos do interator são alcançados através da experiência de exploração. Essa experiência pode ajudar a aprender a ultrapassar os limites do que é familiar, aceitando o desconhecido, o que significa um aprendizado no desenvolvimento de uma consciência ecológica.

${ }^{37}$ Do original em inglês: "[...] is a way of exploring otherness, strangeness, and unknowability in a safe way: a physical/aural/visual analogy to storytelling. Because it is safe, the individual is more likely to explore just that little bit further, to take themselves into unfamiliar territory." (BAKER apud ARMSTRONG, 2006) 


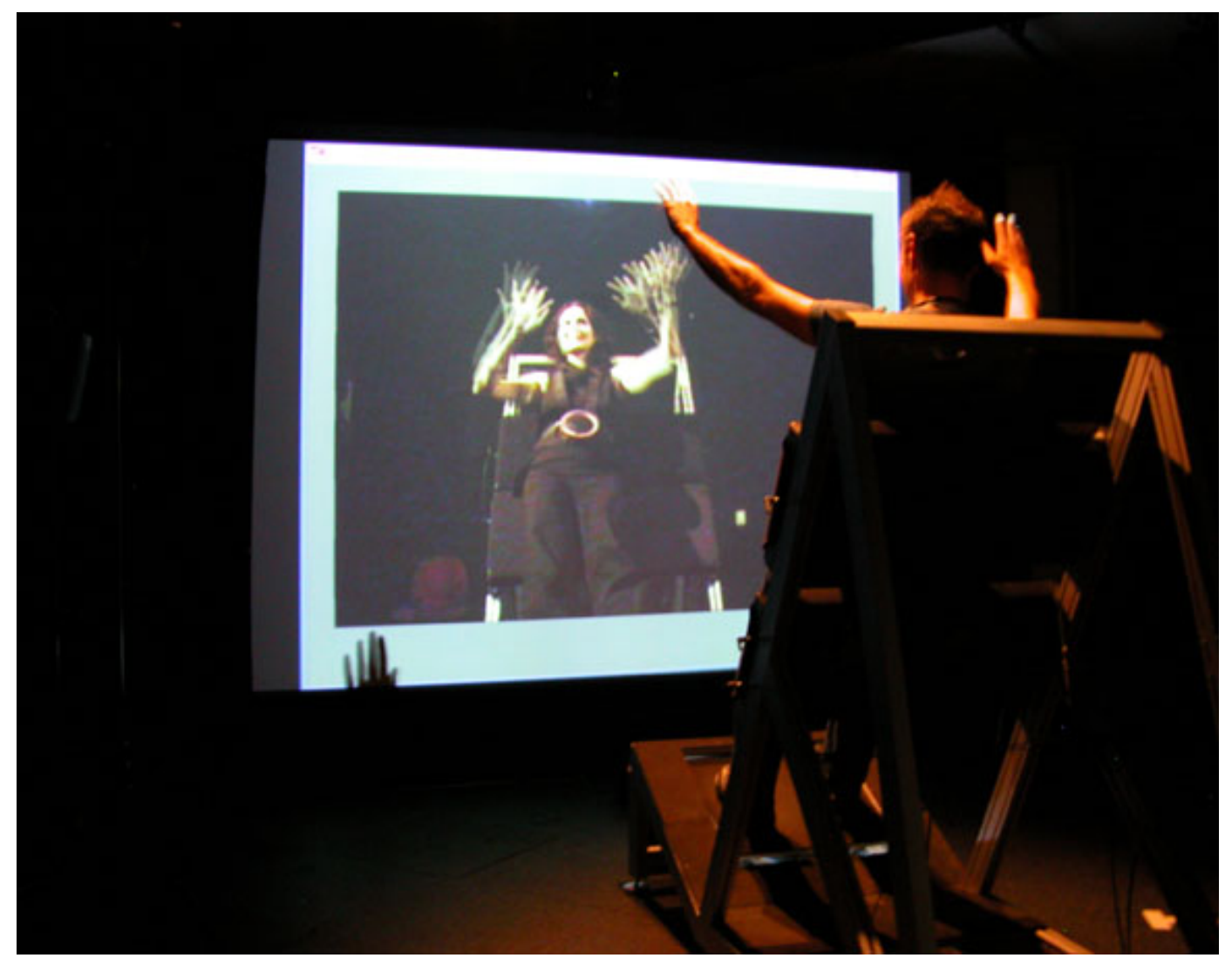

Figura 15.04 // Encontro surpresa de dois participante em rede, Intimate Transactions

Na versão multiusuário, no processo de exploração do ambiente da instalação pelos participantes, essas distinções se dissolvem na medida em que os sujeitos incorporam elementos de seus avatares fantasmagóricos e fazem trocas com os outros participantes em rede. O ambiente é estruturado de forma a estimular trocas, estimular a exploração pelo Eu da esfera Outros. 


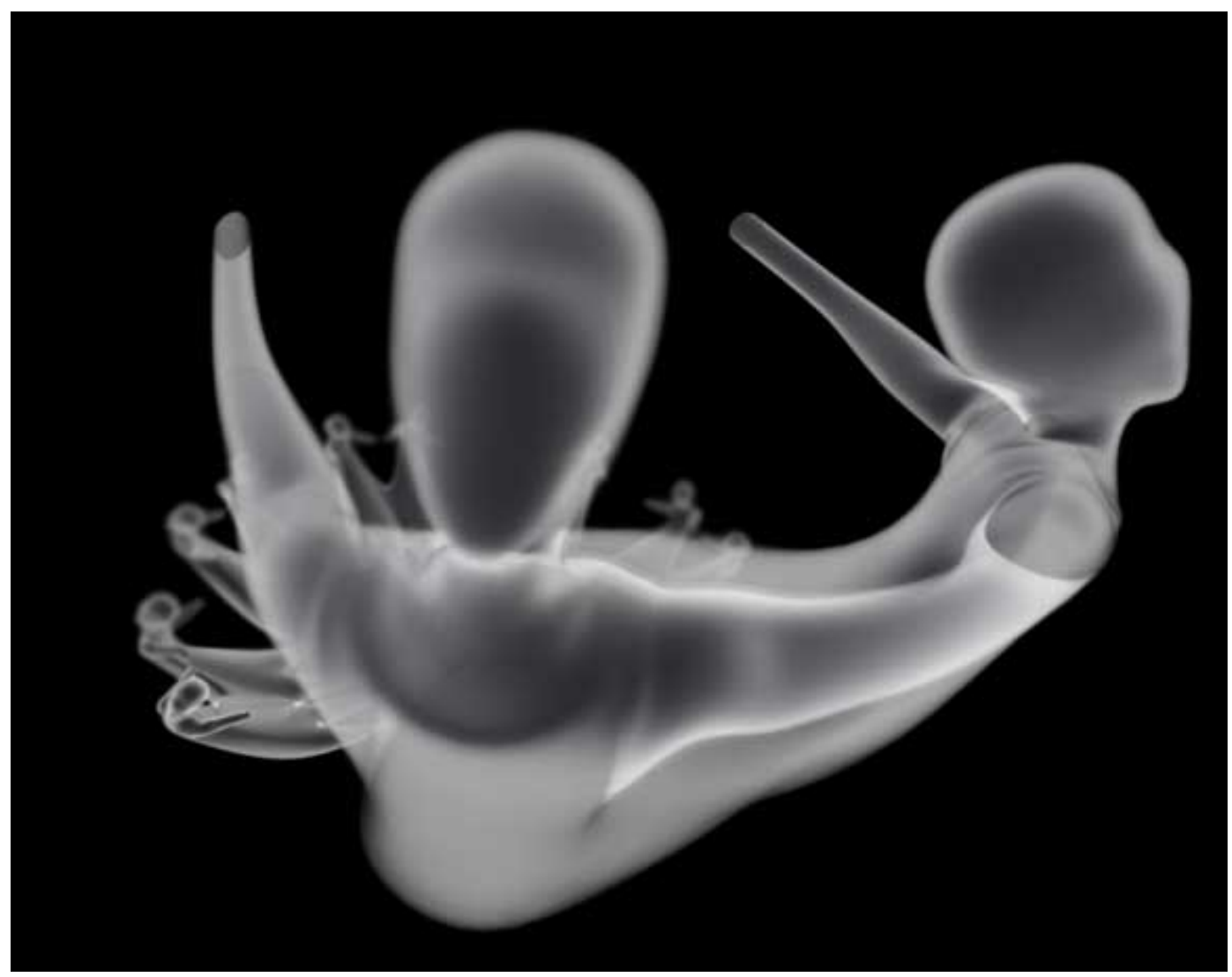

Figura 16.04 // Shared Body Group, Intimate Transactions

Um participante pode, por exemplo, incorporar imagens de outras criaturas. Esse processo é projetado para destruir lentamente as criaturas e seu ambiente. Esse processo de degeneração da criatura, é percebido por um rápido aumento da forma, diminuição de seu brilho e inabilidade para interagir. Em situações como a descrita, o sistema entra em um estado de falência onde o único modo de restabelecer sua saúde, e restaurar a energia global, é trabalhar colaborativamente, devolvendo as imagens a seus respectivos corpos.

Nesses processos, como explicam os artistas (ARMSTRONG, 2006), os participantes são encorajados a explorar os reinos relacionais das instâncias Nós e Outros. O primeiro, envolve a retirada de objetos das criaturas (que aparecem como ícones internos ou 
camadas de imagem dentro deles) e o participante incorpora esses objetos em seu próprio avatar. Esta estratégia de coleta é uma estratégia de jogo familiar, adotada em jogos de computador como forma de acumular pontos com a intenção de vencer o jogo.

Como na versão anterior, o ambiente interativo gerado por computador, que é projetado em uma tela posicionada na frente do participante, inclui uma não-narrativa baseada em texto a partir do conto A Nuvem de Smog, de ítalo Calvino (CALVINO, 1992, p.189-242). Nessa mesma projeção, está uma figura corpórea ambígua que se dissolve, deforma e transforma, oscilando entre estados de calma sublime e agitação pixelada. Essa figura é o avatar do participante. Imagem fantasmagórica, com bordas e formas inconstantes e indefinidas, que traduz a presença na dimensão virtual desse ambiente híbrido.

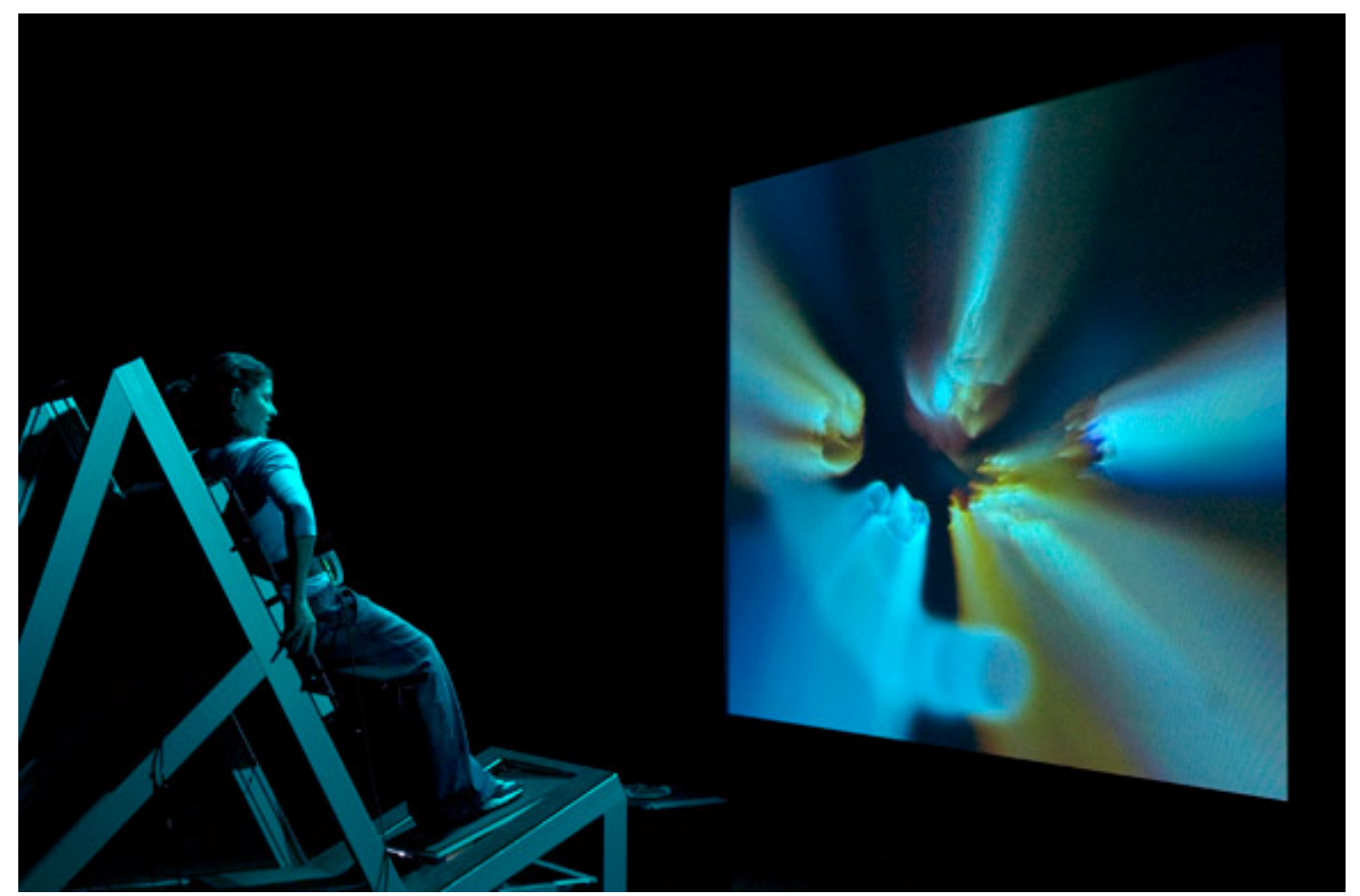

Figura 17.04 // Intimate Transactions, exibição no ACMI, Melbourne 


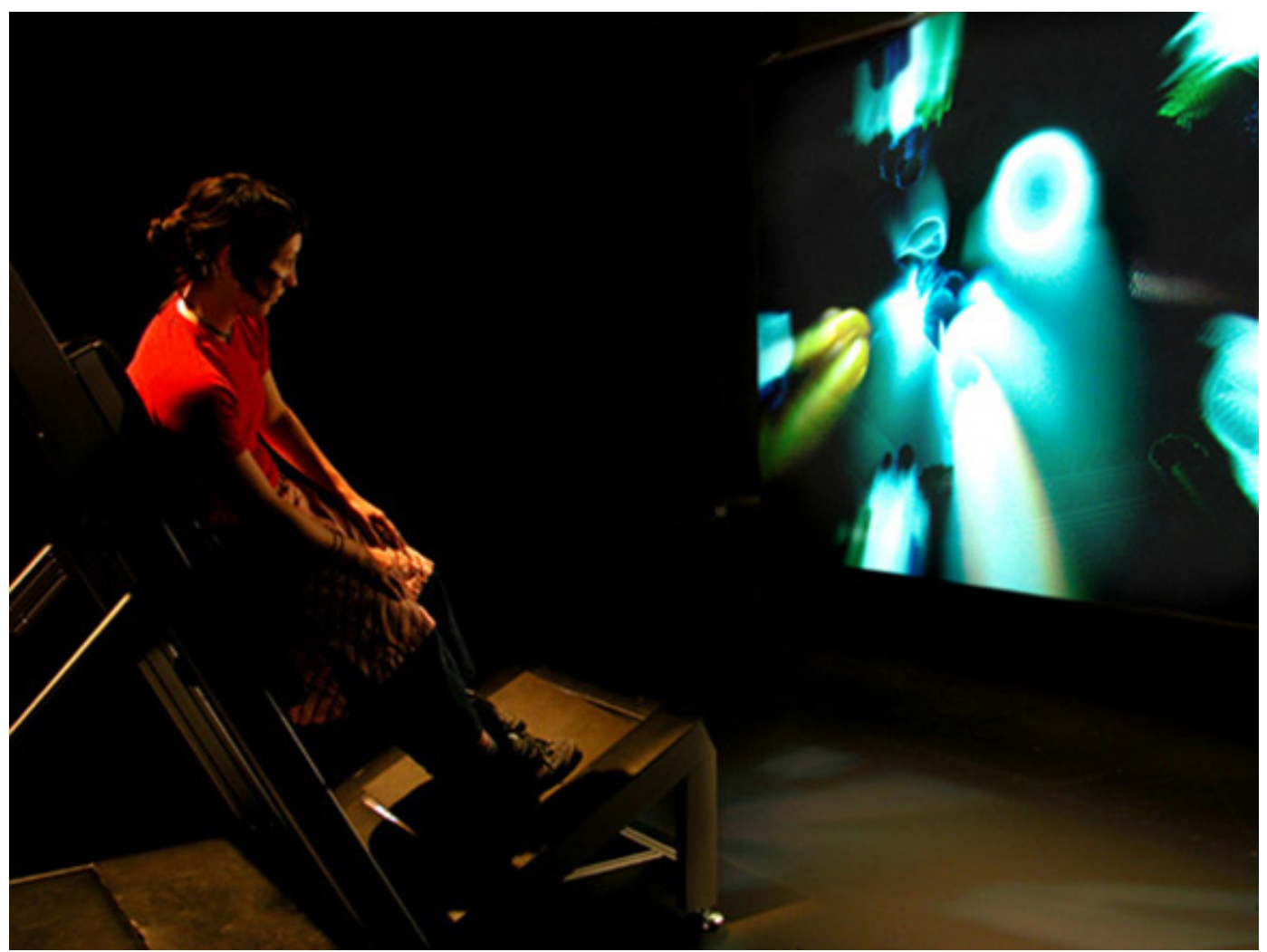

Figura 18.04 // Intimate Transactions

Em Intimate Transactions, uma das questões centrais é investigar de que forma interação e imersão podem ser lidas como performance, parecem performance, e como pode se dar essa relação. Segundo Armstrong, "Um interesse central é a influência da performance no design da experiência individual ou coletiva nesses trabalhos." 38 (ARMSTRONG apud CARROLI, 2004, tradução nossa). Para Carroli, essa aproximação proposta pelo Transmute depende, em primeiro lugar, do que se entende ou se define como performance e performatividade, o que, no caso, está relacionado a ideias de áreas como ecosofia e subjetividade ecológica, intimamente ligadas à noção de performatividade de Judith Butler.

\footnotetext{
${ }^{38}$ Do original em inglês: "a key interest is the influence of performance on the design of the participant or collective experience in such works." (ARMSTRONG apud CARROLI, 2004)
}

$$
155
$$


Butler fala de uma certa teatralização e uma certa produção performática da identidade em seus trabalhos teóricos. Ela coloca um desafio para o sujeito ecológico na forma de uma subversão - subversão da hegemonia do sujeito, no contexto de uma crítica da identidade. São as questões que a pesquisadora discute no livro Bodies That Matter (BUTLER, 1993), que parecem tomar forma na abordagem do coletivo Transmute. Nos corpos fantasmagóricos que contém e que refletem os sujeitos, que convidam o Eu a se misturar e se confundir com Nós e Outros.

Falando sobre a relação entre corpos e discurso, Butler (BUTLER, 2002) considera que discursos habitam corpos. Eles se acomodam em corpos que, na verdade, carregam discursos como parte visceral. Para além dessa referência à conexão entre corpos e discurso, podemos ler a presença de excertos do já referido conto de Calvino no ambiente da instalação, como artifício que pode ilustrar a noção de abjeção dos corpos de Judith Butler. Nas palavras da pesquisadora, o que considera a abjeção dos corpos pode ser notada, por exemplo,

[...] na matança de refugiados libaneses: o modo pelo qual aqueles corpos, aquelas vidas, não são entendidos como vidas. Podem ser contados, geralmente causam revolta, mas não há especificidade. [...] não é que o impensável, que aquilo que não pode ser vivido ou compreendido, não tenha uma vida discursiva; ele certamente a tem. Mas ele vive dentro do discurso como a figura absolutamente não questionada, a figura indistinta e sem conteúdo de algo que ainda não se tornou real. (BUTLER, 2002, p.163).

Calvino, em seu conto fantástico, discute questões que se referem à própria natureza do ser, da realidade, da existência dos corpos, em um panorama onde a angústia existencial e a insegurança ontológica atingem o homem, habitante da metrópole. É também a partir do uso do conto de Calvino como referência que se torna mais clara, para além das ideias de subjetividade ecológica, a referência do coletivo à abordagem da subjetividade dentro de um paradigma ético-estético, a partir de Félix Guattari. Para Guattari, "A subjetividade não é fabricada apenas através das fases psicogenéticas da psicanálise ou dos 'matemas do Inconsciente', mas também nas grandes máquinas sociais, massmediáticas, linguísticas, que não podem ser qualificadas de humanas." (GUATTARI, 1992, p.20). 
As questões centrais discutidas por Guattari dizem respeito às formas como produzimos subjetividade, como a capturamos, enriquecemos e reinventamos. Segundo Armstrong, seu objetivo em Intimate Transactions, " [...] foi descobrir se esse tipo de trabalho pode ser usado para criar contextos dentro dos quais os participantes poderiam refletir sobre conexões entre o 'problema de ecologia' e o problema proposto da humanidade/ subjetividade humana."39 (ARMSTRONG, 2008, tradução nossa).

De um modo geral, organizando de maneira pervasiva a estrutura conceitual do trabalho, a exploração da ideia de subjetividade ecológica de Elizabeth Baker e as relações construídas a partir dessa noção, contribuíram para explorar, no trabalho, questões que vão além da praxis ecológica, como, por exemplo, a produção de subjetividade.

\subsection{O Modelo Úmido}

Armstrong relata que, o início do seu interesse em ecologia, remonta ao final da década de 1990, em considerações seminais sobre papel poderia desempenhar a produção de arte digital, na possibilidade de engajamento com a questão ecológica. Armstrong menciona uma série de artistas vinculados a movimentos de arte ecológica que, nas décadas de 1980 e 1990, emergiram com abordagens que eram respostas a uma compreensão que se ampliava da crise ecológica mundial. Entre os artistas desse período, Armstrong destaca os nomes de Dominique Mazeud, Andy Goldsworthy e Joan Brassill, cujos trabalhos apontavam para uma responsabilidade humana pelos problemas ecológicos.

Envolvido com o universo da arte digital, Armstrong tentou encontrar formas de trabalhar questões ecológicas, aplicando "[...] os princípios do engajamento eco-político e eco-social através de um processo de investigação 'orientada à prática'." 40 (ARMSTRONG, 2006, tradução nossa). Para o artista, os trabalhos produzidos, poderiam ser inspirados pela possibilidade de uma mudança de paradigma na compreensão humana do seu papel como parte de complexos sistemas ecológicos. Para Armstrong (ARMSTRONG, 2006), ao invés de criar formas diretivas e didáticas, as obras poderiam

\footnotetext{
${ }^{39}$ Do original em inglês: "[...] was to discover whether such works could be used to create contexts within which participants might reflect upon connections between the 'problem of ecology' and the proposed problem of humanity/human subjectivity." (ARMSTRONG, 2004)

${ }^{40}$ Do original em inglês: "[...] the principles of eco-political and eco-social engagement through a process of 'practiceled' research." (ARMSTRONG, 2006)
} 
proporcionar quadros contextuais em que a audiência poderia ser encorajada a refletir sobre o problema da ecologia e os problemas da subjetividade humana que foram identificados por Fry, Guattari e outros.

Essa intenção se reflete na abordagem dos trabalhos realizados pelo artista como diretor artístico do coletivo Transmute, se referindo à adoção de uma série de práticas relacionadas à comunicação e interação. São essas práticas que possibilitam à audiência compartilhar experiências individuais, viabilizam interação social e confrontação de problemas ecológicos, explorando aspectos conectivos e sistêmicos da interação em rede.

A instalação Intimate Transaction, como última emergência do trabalho do coletivo Transmute que analisamos aqui, vista a partir de uma perspectiva sistêmica, traduz um histórico de interações não-lineares. Interações em processos randômicos de um sistema aberto que, durante sua evolução, incorporou novas partes (integrantes do coletivo) como forma de se adaptar a mudanças contextuais que se colocaram como ruídos. Um sistema que pode, assim, ser considerado sensível às condições iniciais e, influenciado pelas informações e taxa de transferência de dados em sua instância inferior no nosso Modelo Úmido, como, por exemplo, a premissa de uma praxis ecosófica e as diversas leituras e referências que deram suporte à construção dessa aproximação.

A partir de um mapeamento da dinâmica do sistema, que é o processo criativo do coletivo Transmute, podemos utilizar o Modelo Úmido, que foi apresentado e discutido no capítulo anterior, como forma de dar visibilidade à organização e complexidade desse sistema: 


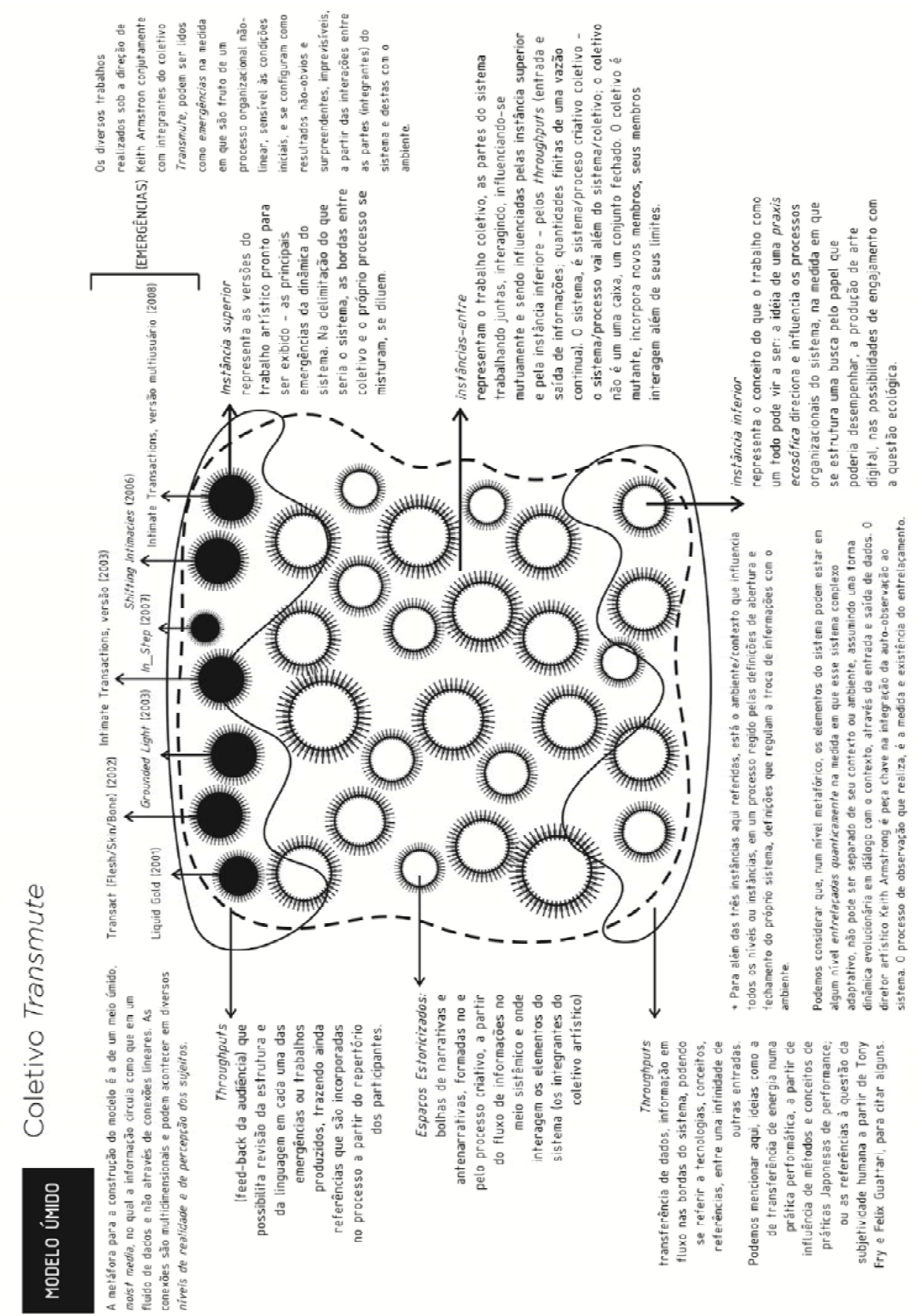

Figura 19.04 // Coletivo Transmute: Modelo Umido. Gráfico da autora. (vide anexo B) 
A intenção da utilização desse Modelo Úmido proposto, visa dar ao sistema visibilidade de si, de sua organização. A visualização do processo através do modelo pode ajudar a entender a natureza dinâmica e randômica dos processos criativos coletivos em artes digitais, mostrando de que forma as interações aleatórias e o caráter dessas interações entre os elementos, deles com o todo sistêmico e deste com o contexto/ambiente, possibilitam a emergência de diversos trabalhos numa dinâmica sensível às condições iniciais.

Esse sistema tem seu processo organizacional influenciado pela entrada e saída de dados em suas instâncias inferior e superior, na forma de conhecimentos técnicos e teóricos, referências, tecnologias, feedback da audiência. Em uma perspectiva mais ampla, a intenção é contribuir para a compreensão da natureza orgânica e complexa do processo criativo coletivo em arte digital.

\subsection{Transmute: complexidade e organização}

Olhando a partir da complexidade para o processo criativo do Transmute - processo que se estrutura em torno da exploração de alguns conceitos basilares, como uma praxis ecosófica, e a noção de grounded media -, é possível perceber que, entre outros, o acaso, as alterações no ambiente, influenciam na organização do sistema, levando à emergência de diversos trabalhos artísticos.

Os diversos trabalhos produzidos podem ser considerados emergências, na medida em que constituem resultados imprevisíveis da dinâmica sistêmica do Transmute. Enquanto emergência, cada um dos trabalhos artísticos da série, não resulta diretamente das ligações entre os integrantes do coletivo, mas do vislumbre da possibilidade de alcançar novos níveis organizacionais pelo coletivo.

Podemos considerar que esse processo é um sistema complexo adaptativo, na medida em que é evidente a inter-relação entre os integrantes do coletivo, sendo o sistema constituido pelos elementos em inter-relação. Mesmo em trabalho realizados além dos limites do coletivo, tanto a performer Lisa O’Neill, quanto o diretor de som Guy Webster, continuam a dialogar com o diretor artístico Keith Armstrong, construindo uma trama de 
relações que é a base da arquitetura sistêmica, se articulando a partir de uma base conceitual e da exploração de tecnologias.

Podemos considerar que o processo criativo do coletivo Transmute é um complexo organizado e adaptativo, na medida em que não responde passivamente aos eventos, se reorganizando em função de mudanças ambientais, contextuais. Isso fica evidente, por exemplo, quando o coletivo começa a trabalhar com a Australasian CRC for Interaction Design (ACID), como parte de um projeto de pesquisa do Australian Creative Industries Network (ACIN), e se reorganiza em função das mudanças, produzindo uma ampliação da instalação Intimate Transactions para uma versão multiusuário e em rede.

As partes do sistema que é o processo criativo do coletivo Transmute, podem estar em algum nível entrelaçadas quanticamente, na medida em que esse sistema complexo adaptativo não pode ser separado de seu contexto ou ambiente, assumindo uma forma dinâmica evolucionária em diálogo com o contexto, através da entrada e saída de dados.

De um modo geral, a perspectiva construída na presente pesquisa a partir da complexidade, sintetizada no Modelo Úmido, pode contribuir para compreender que é a auto-observação integrada a esse sistema, que é o processo criativo coletivo em artes digitais, que pode definir os entrelaçamentos, as conexões entre os sujeitos integrantes, de que forma eles se influenciam mutuamente, e as emergências do processo organizacional num meio úmido. 


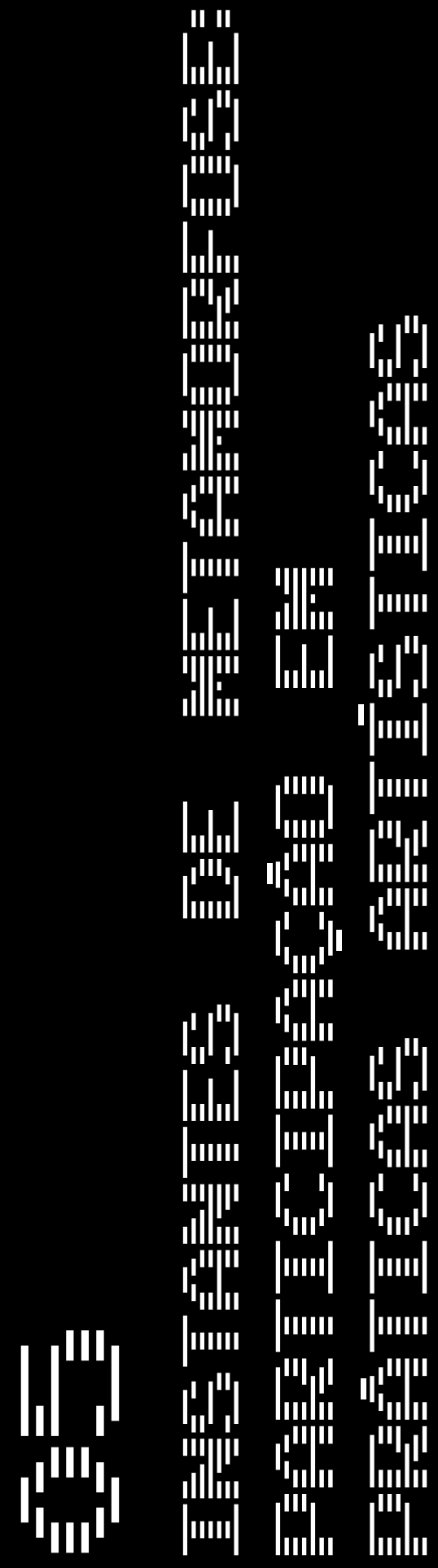




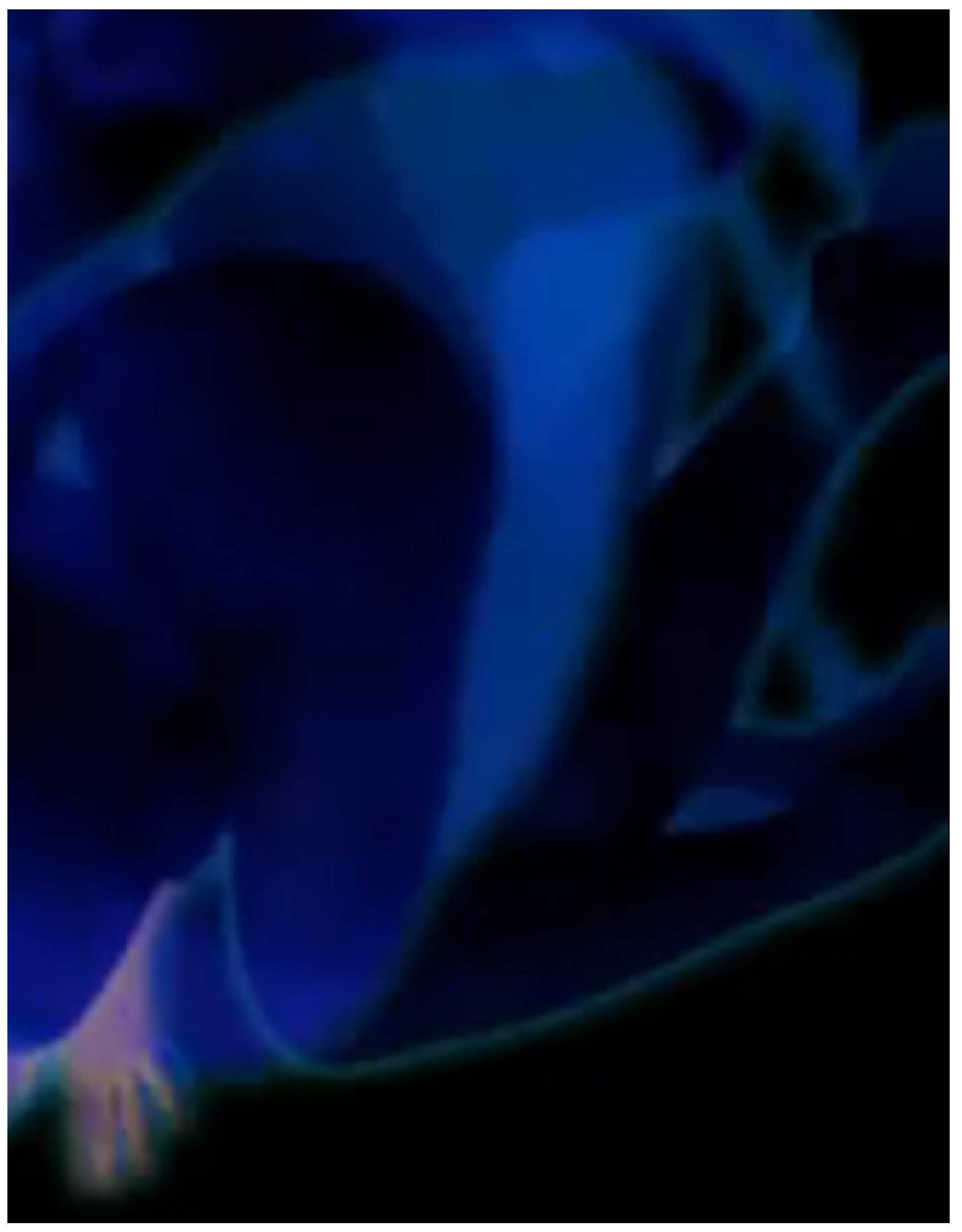




\section{를}

Esse capítulo se estrutura como um relato do envolvimento da autora em práticas artísticas coletivas. Desde o envolvimento em trabalhos desenvolvidos pelo grupo

Poéticas Digitais, até a participação no coletivo O Duplo, a necessidade de envolvimento com a prática artística está implícita na pesquisa como forma de integrar a autoobservação ao sistema. Esse esforço implica a construção de um ponto de vista que permita observar o conjunto constituído pelo observador e sua observação. 
Por enquanto o tempo é quanto dura um pensamento. Clarice Lispector, 1998, p.21 


\subsection{Poéticas Digitais}

O Grupo Poéticas Digitais, criado em 2002 no Departamento de Artes Plásticas da Escola de Comunicações e Artes da Universidade de São Paulo (ECA/USP), se constitui como um desdobramento do projeto WAwRWT, iniciado pelo professor Gilbertto Prado, que é o coordenador do grupo, em 1995. Segundo Prado, a intenção foi, "[...] gerar um núcleo multidisciplinar, promovendo o desenvolvimento de projetos experimentais e a reflexão sobre o impacto das novas tecnologias no campo das artes." (PRADO, 2011). Entre seus integrantes, estão professores, artistas, pesquisadores e alunos da graduação e da pós-graduação do Departamento de Artes Plásticas da ECA, apresentando uma composição diferente em cada um dos projetos realizados.

Na perspectiva da autora da presente Tese, a oportunidade de Integrar o grupo Poéticas Digitais desde 2007, ano de ingresso no programa de pós-graduação em Artes Visuais da ECA, em um momento anterior ao estabelecimento do coletivo O Dup/o, foi uma oportunidade de observar processos criativos com alto grau de caoticidade, que se desenvolviam numa teia de conexões randômicas entre seus integrantes, em dinâmicas dependentes de contexto.

Em uma perspectiva mais ampla, foi o interesse em metodologias processuais que se aproximassem de um pensar complexo e que, de alguma forma, partissem dessas noções para ajudar a entender esses mesmos processos criativos como organismos complexos, que trouxe consigo a necessidade de experimentação, de um envolvimento com processos criativos coletivos em arte digital, direcionando a participação da autora no Poéticas.

\subsubsection{Vídeo-poema Incógnito}

O primeiro trabalho do qual a autora participou como integrante do grupo Poéticas Digitais foi o vídeo-poema Incógnito (2007), que se articulou a partir do convite inicial por desenvolver uma proposta de trabalho de arte digital com vídeo e som digitais como uma exploração conceitual da palavra Incógnito. As ideias iniciais, trazidas pelos professores Gilbertto Prado e Silvia Laurentiz, foram discutidas ao longo de algumas semanas nas reuniões regulares do grupo. Em comunicação via e-mail em março de 2007, a mensagem enviada para o grupo pelo Professor Gilbertto dá uma dimensão das 
conexões tecidas no e pelo processo criativo coletivo do grupo e dos meios de comunicação utilizados nas trocas: A obra, com até 3 (três) minutos de duração, deverá versar sobre a palavra
incognito (it); incognito (fr, in); inkonigto (al), escolhida por V.Sa., e ser
entregue em matriz e duas cópias de igual qualidade, até 10/05/2007, nos
seguintes padrões: DVD / SVCD / VCD /CD-R-RW / DVD R-RW ou MP3.

Para o incognito, estamos usando uma pasta via ftp no servidor [...] vamos utilizando o computador do game para colocar os arquivos que desejarmos. [...] O lazzetta viu o trabalho hoje à tarde e estará trabalhando no som. A Silvia e eu, nos reuniremos na segunda às 13:00. Se alguém tiver mais alguma sugestão, por favor nos envie. A Clarissa ficou também de trabalhar alguns percursos e possibilidades. [...] Podemos utilizar as 2 máquinas para trabalhar, armazenar dados, enfim, para experimentar o que quisermos. (PRADO, 2007).

O resultado final, o vídeo-poema Incógnito, é uma viagem virtual no interior da palavra cógnito. De maneira similar, o som também é uma navegação interna pela palavra falada. A obra foi realizada para a mostra Palavras sem fronteiras: mídias convergentes, realizada na Academia Brasileira de Letras, Rio de Janeiro, com curadoria de Alberto Saraiva, de 01 a 29 de junho de 2007. Segundo Gilbertto Prado, o vídeo-poema Incógnito,

[...] tem insertado em um de seus frames (1/24) na parte inferior do quadro, a palavra "cógnito", que não é legível na cadência regular do vídeo (a menos que seja congelado), mas é percebido de forma subliminar pelo cérebro e não pela leitura convencional. É o único momento em que a palavra cógnito está formalmente apresentada por escrito, mas "visualmente" não é legível. O trabalho, apesar de ter uma câmera virtual passeando no interior da palavra cógnito modelada, não deixa transparecer a leitura externa da palavra em nenhum momento para o leitor, que vê somente um desfilar de planos e transparências. Da mesma maneira o som, que foi trabalhado como uma viagem sonora no interior da palavra cógnito, mas como resultado sonoro, ela não é identificável. É um trabalho sutil sobre as leituras possíveis do mundo e a percepção. (PRADO, 2011b). 


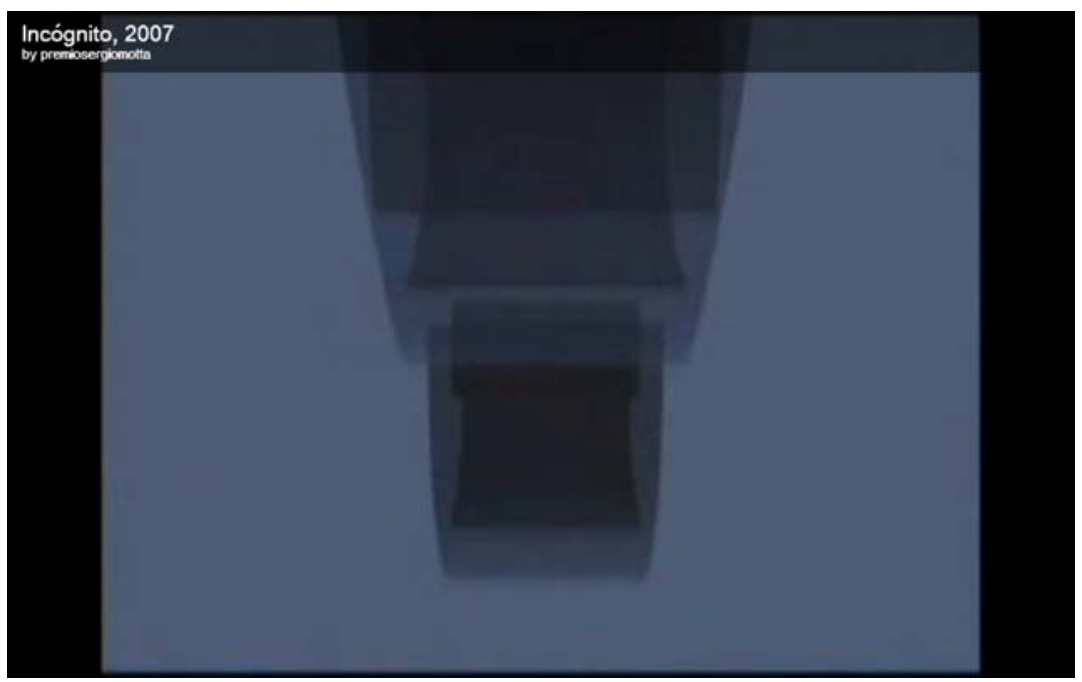

Figura 1.05// vídeo-poema Incógnito, grupo Poéticas Digitais

A obra de Gilbertto Prado e Silvia Laurentiz contou com a participação de Fernando lazzetta, responsável pelo projeto do som, e dos integrantes do Grupo Poéticas Digitais naquele momento, Andrei Thomas, Clarissa Ribeiro, Fábio Oliveira, Luis Bueno Geraldo e Mauricio Taveira. O trabalho também foi apresentado no evento Cópias llimitadas, NOEMA/Galeria Vermelho, Second Life/São Paulo, com curadoria de Giselle Beiguelman, em outubro de 2007. A obra integrou ainda a Mostra Paisagens, no Museu Reina Sofia (Madri), de 21 de Janeiro a 29 de Fevereiro de 2008, com Curadoria de Berta Sichel e Daniela Bousso, em parceria com o Prêmio Sergio Motta de Arte e Tecnologia. No que se refere ao processo criativo, em um diálogo aberto, a ideia inicial foi se transformando em função do fluxo de informações, de contaminações entre o repertório técnico, teórico, artístico, de cada um dos integrantes do grupo. Esse diálogo definiu escolhas no que se refere aos software que seriam utilizados, ao ambiente sonoro criado pela trilha, às cores, às transparências, à velocidade da animação, à forma de exibição e ao suporte.

\subsubsection{Pedralumen}

Em 2008 a instalação Pedralumen foi desenvolvida para ser apresentada na mostra Chain Reaction, no Museum of the City of Skopje, na Macedônia. Posteriormente, a obra integrou a Exposição Em Meios, no Museu Nacional da República, em Brasília. Em uma página na Internet, os visitantes podiam adicionar pedras/palavras a uma estrutura 
imaginária, como uma nuvem de palavras que flutua ao redor de uma pedra basilar azul, metáfora de um cubo de LEDs azuis (numa malha de 8X8X8), que se encontrava no espaço expositivo. Cada palavra acrescentada pelo visitante ao acessar a página online, passava a integrar a nuvem de palavras. A intensidade de brilho dos LEDs azuis que compõem o cubo físico, varia em função das intervenções na página online - a intensidade e frequência da luz, variam de acordo com as escolhas e nominações.

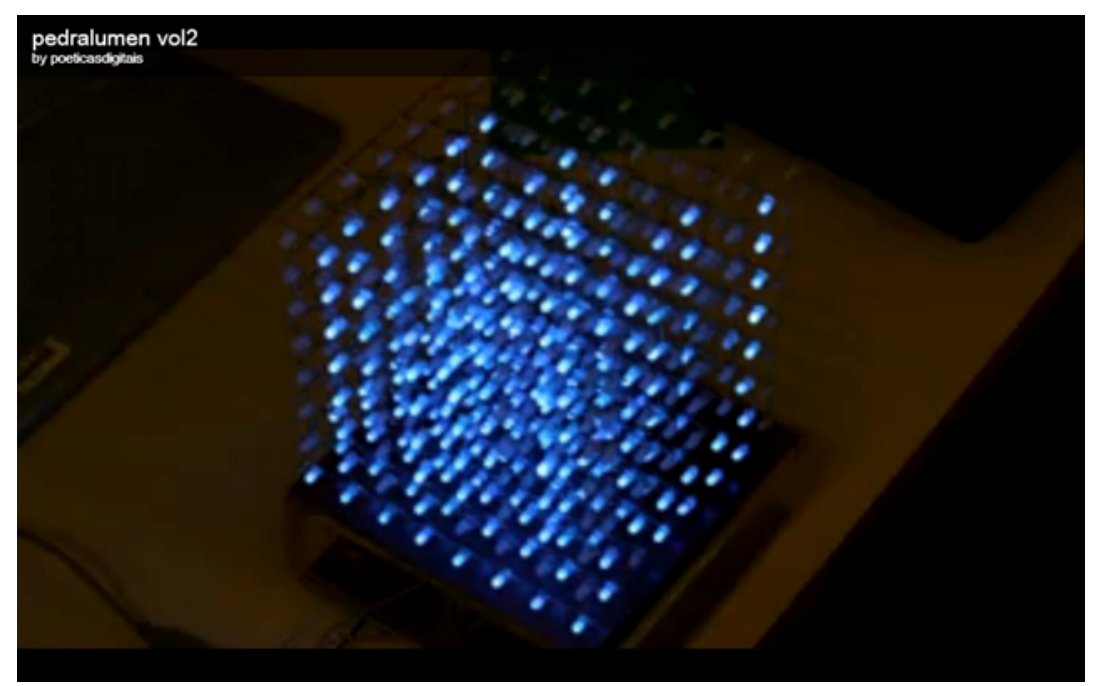

Figura 2.05// web-instalação Pedralumen, Poéticas Digitais

Essa web-instalação desenvolvida pelo grupo Poéticas Digitais, trata de escolhas, inscrições e partilha, do processo de dar nome às coisas, de colocar marcas e de escolhas de território, criando espaços partilhados de luz, provocando ações em cadeia de maneira simbólica e física, ideias anteriormente exploradas no trabalho Desertesejo. Desertesejo foi um projeto artístico de Gilbertto Prado desenvolvido no programa Rumos Novas Mídias, do Itaú Cultural, São Paulo, Brasil, em 2000. O projeto consistia em um ambiente virtual interativo multiusuário construido em VRML que permitia a presença simultânea de até 50 participantes. Desertesejo explora poeticamente a extensão geográfica, rupturas temporais, a solidão, a reinvenção constante e a proliferação de pontos de encontro e partilha. Como explica o artista, 


\begin{abstract}
Ao entrar no ambiente virtual, o viajante encontra uma caverna de cujo teto caem pedras suavemente. Qualquer uma delas é clicável. Após o clique, o viajante é transportado para um novo ambiente, no qual carrega essa pedra. Poderá então depositá-la em algum dos montes ("apaicheta" em aimará) presentes nos diferentes espaços. A pedra constituirá um marco da passagem desse viajante e ficará como uma indicação, para outros, de que ele esteve ali. (PRADO, 2011)
\end{abstract}

Esse trabalho foi apresentado em diversas exposições como a $A A A$ : Archiving as Art/ISEA- Centre Saint Charles, Universidade de Paris 1, França, em 2000, a Mostra de Arte Eletrônica da 13오 SIBGRAPI, em 2000, no 15 Videobrasil, SESC Pompéia, São Paulo em 2005.

\title{
5.1.3. Des/uz
}

Em maio de 2009 têm início no grupo Poéticas Digitais, as discussões em torno do trabalho Des/uz. Nos primeiros e-mails trocados pelos integrantes nessa época, estão questões relativas à forma como o conceito da obra poderia dialogar com o tema escolhido pela curadoria do evento onde o trabalho seria exposto e também questões que diziam respeito à tecnologia possivelmente utilizada na materialização.

Desde o início, o trabalho se estruturou a partir de um convite que para integrar a mostra que se intitularia Sedução, em um primeiro momento, com curadoria de Suzete Venturelli, como parte do $8^{\circ}$ Encontro Internacional de Arte e Tecnologia (\#8ART): arte, tecnologia e territórios ou a metamorfose das identidades. A leitura que o professor Gilbertto Prado fez da ideia de sedução, se estruturaram em torno da ideia de atração das mariposas pela luz, e das diversas analogias e transposições desse fenômeno para o âmbito cultural, relacionando à luz vermelha nas portas dos prostíbulos, à atração, à sedução. Como explica Gilbertto Prado,

Insetos utilizam a luz da lua e das estrelas como baliza de localização, mantendo-se em ângulo constante para ir e vir de seus criadouros. Com a luz artificial das nossas lâmpadas elétricas, os insetos passam a se confundir, buscando se aproximar das fontes de luz, voando em círculos, formando nuvens, atraídos pela luz em voltas sem fim. A luz que os atrai é a infravermelha, comprimento de onda que nosso olho humano não enxerga, mas potente atrator sexual das mariposas. Assim, frequências eletromagnéticas são veladamente percebidas, através dos tempos, sob a luz da lua ou elétrica, perpetuando a sobrevivência das espécies. (PRADO, 2011a). 
No evento que é realizado em Brasília desde 1989, o título/tema da exposição foi reconsiderado e alterado para Instinto, nome com o qual foi aberta à visitação em Setembro de 2009. Nas várias reuniões do grupo em que o trabalho foi discutido, ficou claro que as pontes conceituais com a ideia de sedução ganhavam ainda mais intensidade quando relacionadas também à ideia de instinto. A primeira consideração sobre a materialização das ideias fazia referência à utilização de LEDs com variações de luz vermelha, depois de algumas discussões em torno da utilização de LEDs RGB e os níveis de brilho.

Nas reuniões subsequentes, as discussões direcionaram a materialização final para a construção de uma malha de LEDs. Na versão final exposta pela primeira vez em Setembro de 2009, temos, no espaço expositivo, um cubo de LEDs transparentes (estruturados em uma malha de $8 \times 8 \times 8$, como na instalação Pedralumen) que emitem luz infravermelha, e caixas de som, que respondem simultaneamente ao fluxo de passantes, em um outro lugar - região de casas de luz vermelha -, como atrator, dissimulando um jogo de sedução velado. O fluxo dos passantes na área escolhida é capturado por uma câmera posicionada em um edifício com visão de topo do lugar.

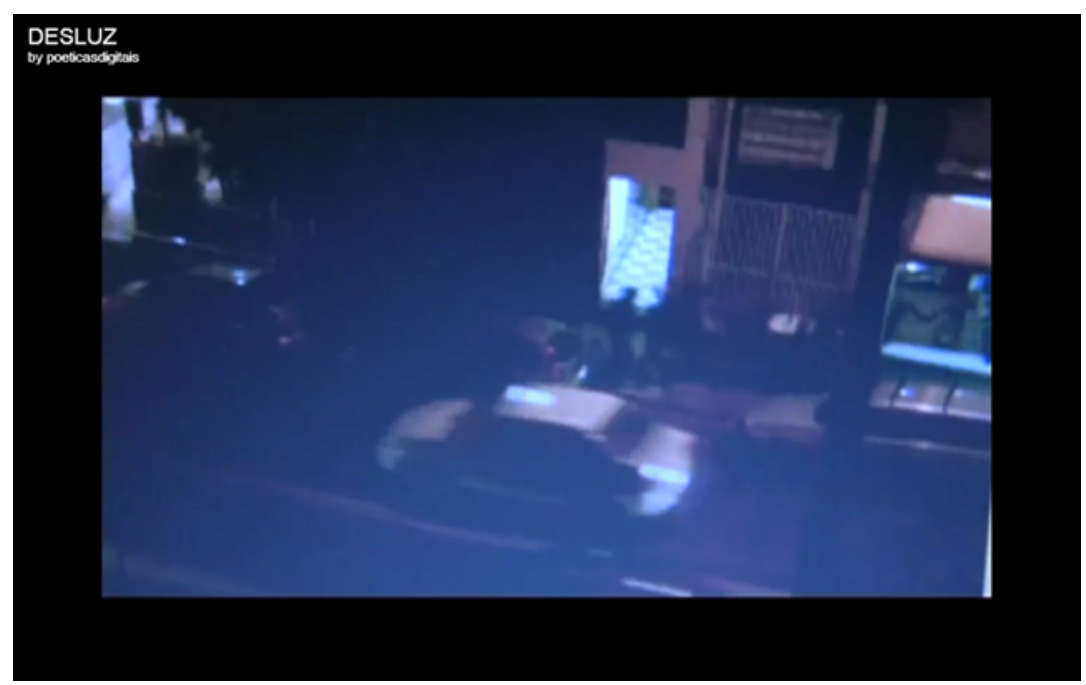

Figura 3.05// Des/uz, Poéticas Digitais 
As informações adquiridas alimentam o sistema instalado em espaço expositivo. A plataforma Processing ${ }^{1}$ foi utilizada para fazer a comunicação entre a placa Arduino ${ }^{2}$ e o um servidor localizado remotamente. O Arduino se comunica com a malha de LEDs a partir dos dados que recebe via servidor, alterando a intensidade de brilho. No entanto, apenas utilizando câmeras de aparelhos de celular é possível desvendar os padrões de brilho no cubo de LEDs - sem essa camada que se sobrepõe e desvenda, os LEDs mantêm seu aspecto transparente e sem luz. Simultaneamente, os autofalantes das caixas de som emitem frequências sonoras inaudiveis ao aparelho auditivo humano. Nas palavras de Gilbertto Prado, Des/uz é um trabalho sobre a descoberta do invisível, "[...] nossos lugares provisórios, nossos fluxos e grades, camadas que se sobrepõem sutilmente e nos atraem sem que as vejamos e traem nossos sentidos ocultos e tão aparentes [...]." (PRADO, 2011a).

Utilizando as câmeras de celulares como lentes de desvendar dimensões paralelas da realidade, o participante passa a enxergar toda uma nuvem de movimentações, que representam o fluxo de passantes nas áreas capturadas pela câmera remotamente, e transmitidas em tempo real. No que se refere ao processo, é interessante observar que todo o trabalho de pesquisa e masterização de técnicas e procedimentos desenvolvidos pelo grupo durante o processo de desenvolvimento da instalação Pedralumen, foram essenciais como pontos de partida para o desenvolvimento do projeto seguinte - Des/uz.

Durante o tempo em que foi possível à autora acompanhar como integrante do grupo Poéticas Digitais o desenvolvimento dos projetos aqui mencionados, o aprendizado referente às práticas artísticas em artes visuais e ao processo criativo coletivo em arte digital foram essenciais ao desenvolvimento da pesquisa que acontecia em paralelo. Essa experiência constituiu um laboratório onde foi possível observar a organização e a complexidade do processo do grupo, ou do grupo como processo, refletindo sobre as relações, a forma como as informações em fluxo iam moldando, construindo, fazendo emergir novas propostas.

\footnotetext{
'PROCESSING programming language, development environment, and online community. PROCESSING Programming language. Disponivel em: <http://processing.org/>. Acesso em 20 jan. 2011. ${ }^{2}$ ARDUINO an open-source electronics prototyping platform based on flexible, easy-to-use hardware and software. ARDUINO. Open source prototype plataform. Disponível em: <http://www.arduino.cc/>. Acesso em 20 jan. 2011.
} 


\subsection{Série Instantes de Metamorfose: a construção de um metapontodevista}

O coletivo O Duplo se estruturou no decorrer do processo de construção de um metapontodevista - um ponto de vista que permita observar o conjunto constituído pelo observador e sua observação (Morin, 2003, p.180). O coletivo uniu pesquisadores com afinidades de interesses que convergiam para o estudo de sistemas complexos a partir da cibernética, da teoria da informação e da sistêmica, abraçando um universo amplo de referências. O coletivo se configura, assim, como espaço de diálogo para troca de experiências no uso de tecnologias de hardware e software em explorações artísticas espaço que se abre para o compartilhamento dos repertórios, para a contaminação dos sujeitos pelos outros sujeitos.

Em meados de 2009, a autora convida a colega Renata La Rocca para construir um coletivo baseado em prática para o desenvolvimento de trabalhos em arte digital, com foco no desenvolvimento de instalações interativas, e em torno da exploração de processos de percepção e transformação dos sujeitos em contextos com características sistêmicas. A intenção era trabalhar a construção de experiências subjetivas que fossem simultaneamente processos de construção do eu e da realidade, processo de aquisição de consciência em vários níveis, explorando diversos níveis de realidade e seus desdobramentos.

A partir de algumas dinâmicas iniciais, onde propositadamente havia uma grande abertura para observação do acaso e do ruído como fatores-chave na auto-organização do processo criativo enquanto sistema, as pesquisadoras começaram a procurar interlocutores, por afinidade, que poderiam integrar o coletivo. Uma grande afinidade de interesses e referências era identificada com os pesquisadores integrantes ou exintegrantes do grupo de pesquisa Nomads.USP.

Nesse percurso, a interlocução com Graziele Lautenschlaeger começou de forma espontânea e casual, em conversas online, onde as trocas eram constantemente relacionadas às pesquisas em andamento e aos interesses em experimentações em arte digital. 


\subsubsection{Coletivo O Dup/o: Formação Inicial}

Em Junho de 2009 foi apresentada ao professor Gilbertto Prado uma proposta de workshop onde Lautenschlaeger propunha remontar a instalação - Don't Give Up! About a history that doesn't want to be told ${ }^{3}$ - que havia desenvolvido no periodo de estágio no programa de mestrado do Interface Culture ${ }^{4}$ em Linz, "[...] abrindo as caixas pretas do funcionamento de tudo." (LAUTENSCHLAEGER, 2009). Esse trabalho integrou a exposição do FILE 2009 em São Paulo e posteriormente a do FILE Rio em agosto de 2010. O professor Gilbertto foi aberto à proposta e o workshop aconteceu em um momento em que o grupo Poéticas Digitais estava envolvido com o desenvolvimento da instalação Des/uz, fazendo os testes com os LEDs, ajustando a programação do sistema. A interlocução foi interessante nesse momento, tendo, a pesquisadora Renata La Rocca, também participado do referido workshop.

A parceria com Renata La Rocca vem desde a graduação da autora em Arquitetura (1997-2002), tendo continuidade durante a realização do mestrado, quando houve a oportunidade de desenvolvimento paralelo das pesquisas no grupo Nomads.USP, na linha de pesquisa Processos de Design (NOMADS, 2011), sob orientação da Professora Anja Pratschke. Os diálogos sobre temas afins alimentavam e extrapolavam os limites das abordagens particulares, fazendo perceber as várias linhas de uma tessitura que ligavam a complexidade à cibernética e estas à antiga Arte da Memória 6 .

Fica evidente que, o histórico das parcerias que deram origem ao coletivo O Duplo, extrapola os limites temporais que definiriam o início do coletivo como referente a meados de 2009. Essa parceria, diálogo tecido em conjunto que constitui o próprio sistema-processo, curiosamente, se intensificou em dinâmicas não presenciais, que aconteceram via Skype, Messenger e trocas de e-mail, no período em que a autora passou a residir em Plymouth, Reino Unido, vinculada à Universidade de Plymouth, como

\footnotetext{
${ }^{3}$ LAUTENSCHLAEGER, Graziele. Don't Give Up! About a history that doesn't want to be told. Disponivel em: <http://www.youtube.com/videosdagra\#p/a/u/2/KbSQ8bVTv6k>. Acesso em: 14 jan. 2011.

${ }^{4} \mathrm{O}$ Interface Culture Program da Linz University of Arts, Department of Media, foi fundado em 2004 por Christa Sommerer e Laurent Mignonneau. O programa é focado no ensino de interação homem-máquina para desenvolver interfaces inovativas utilizando tecnologias da interface na confluência entre arte, pesquisa, aplicações práticas e design para investigar possibilidades sociais e culturais de implementação. Ver: Linz University of Arts. Interface Culture Program. Disponivel em: < http://www.ufg.ac.at/index.php?id=1594\&L=1>. Acesso em: 14jan. 2011.

${ }^{5}$ FILE - Festival Internacional de Linguagem Eletrônica. Disponível em:< http://www.file.org.br/>. Acesso em: 14 jan. 2011 .

${ }^{6}$ LA ROCCA, Renata. Arte da Memória e Arquitetura. 2007. 241f. Dissertação (Mestrado em Arquitetura) Escola de Engenharia de São Carlos da Universidade de São Paulo, São Carlos, 2007.
} 
pesquisadora visitante do CAiiA-Hub do Planetary Collegium, de Setembro de 2009 a Agosto de 2010. É nesse contexto que se gesta a série Instantes de Metamorfose.

\title{
5.3. Instantes de Metamorfose: desenvolvimentos iniciais
}

\begin{abstract}
Começamos a conversar a partir de uma ideia. Um start point. Você falou sobre ela, a ideia. A partir disso, do que li, entendi da sua ideia, fui colocando outras, a partir do meu repertório. Você foi colocando coisas do seu repertório. Depois a gente conversou com a Graziele. É lógico que tem que haver a negociação. Mas não sei se é a melhor palavra, negociação. Prefiro pensar na palavra rever, olhar de novo. (LA ROCCA, 2011, grifo nosso).
\end{abstract}

O processo de envolvimento da criação da primeira versão da série Instantes de Metamorfose se inicia no segundo semestre de 2009. Desde a Banca de Qualificação, realizada em 05 de fevereiro de 2009, havia a intenção de trabalhar com adaptações de contos de Jorge Luis Borges, de seu O Livro dos Seres Imaginários (BORGES, 2007), como entradas para discutir questões relacionadas a processos evolutivos, metamórficos, em processos de aquisição de consciência, onde o sujeito assume papel central.

Das primeiras ideias, onde uma materialidade fluida, orgânica, permeava as relações entre sujeito e espaço, até as propostas que emergiram das dinâmicas do coletivo $O$ Duplo, a necessidade de trabalhar a imaterialidade nas relações do sujeito com o espaço, nas relações sensoriais que permeiam processos que envolvem recordação, memória, imaginação, se tornou cada vez mais evidente com a evolução do processo.

Um histórico do processo foi sendo construído, de forma não-linear e livre, através de anotações em um livro de notas, em um primeiro momento, e posteriormente em dois blogs online - Instants of Metamorphosis ${ }^{7}$ e nos tópicos Instants of Metamorphosis e Let's Processing ${ }^{8}$ do blog Ladygogogoch ${ }^{9}$. Os primeiros desenvolvimentos do processo, documentados no livro de notas, ilustram a busca por referências que ajudassem a trabalhar dimensões permutáveis de significação do eu, instáveis, integradas com o não-

\footnotetext{
${ }^{7}$ RIBEIRO, Clarissa; LA ROCCA, Renata. Instants of Metamorphosis. Disponivel em: <http://instantsofmetamorphosis.blogspot.com/>. Acesso em: 14 jan. 2011

${ }^{8}$ LADYGOGOGOCH. Let's Processing. Disponível em:

<http://ladygogogoch.blogspot.com/search/label/Let's\%20Processing\%20//>. Acesso em 15jan. 2011.

${ }^{9}$ RIBEIRO, Clarissa. Ladygogogoch. Disponivel em: <http://ladygogogoch.blogspot.com/>. Acesso em: 14 jan. 2011.
} 
humano, com o imaterial, com o que transcende a realidade física na natureza, na tecnologia, nas palavras, nas histórias fantásticas.

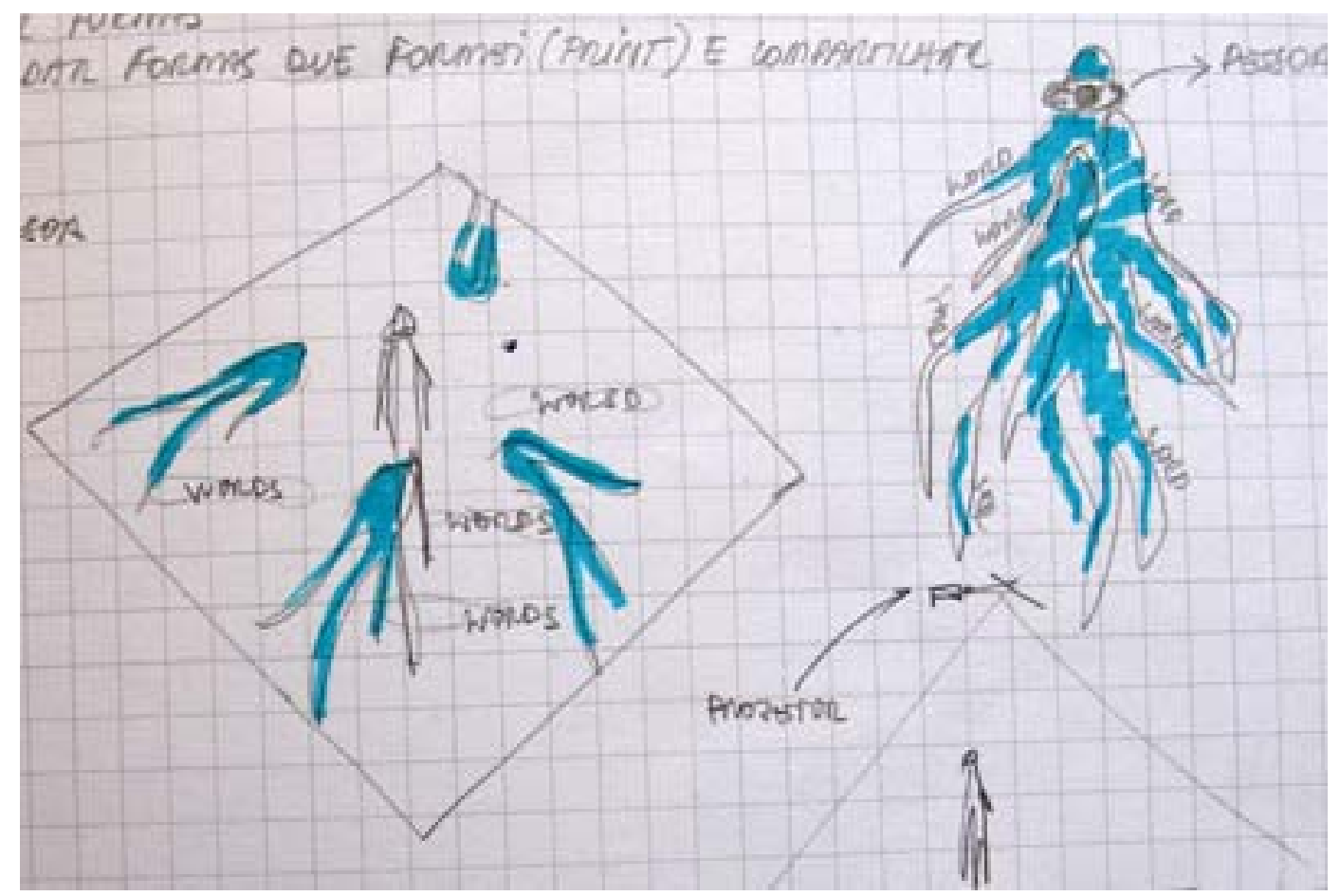

Figura 4.05// livro de notas: documentando o processo

Em paralelo, havia a busca por autores que dialogassem com Borges. Através de conversas informais com colegas para além das bordas do coletivo O Duplo, como os pesquisadores Marcos Marchetti e Ralf Flôres, de leituras e buscas online, a possibilidade de juntar os universos de Borges e o da escritora Clarice Lispector, foi se delineando e se destacando no processo. Foi assim que a leitura do livro Água Viva (1998) influenciou e direcionou a interpretação do conto $A$ Bao $A$ Qu - ser imaginário que simboliza a busca humana por evolução espiritual.

No livro de notas, os sketches iniciais mostravam uma tendência evidente de adaptação literal do conto de Borges (BORGES, 2007) e uma conexão na forma de colagens, mas de certa forma descolada, de excertos do livro Água Viva (LISPECTOR, 1998). 
No que se refere à parte técnica, havia a intenção de trabalhar com resposta do sistema à movimentação da audiência no cenário da instalação onde, essa movimentação, estaria vinculada a um processo de metamorfose a partir de formas orgânicas simples, às quais estariam unidos fragmentos textuais e sons.

Essas formar primárias se tornariam mais complexas, adquirindo silhueta humana, ao final do processo de transformação, quando o participante houvesse permanecido em contato com a obra por um período de alguns minutos. Várias aquarelas foram sendo produzidas em um bloco de para desenho, tamanho A3, que passou a ser utilizado para brainstorming na forma de sketches, a partir de sugestão do pesquisador, colega no Planetary Collegium, Professor Guto Nóbrega.

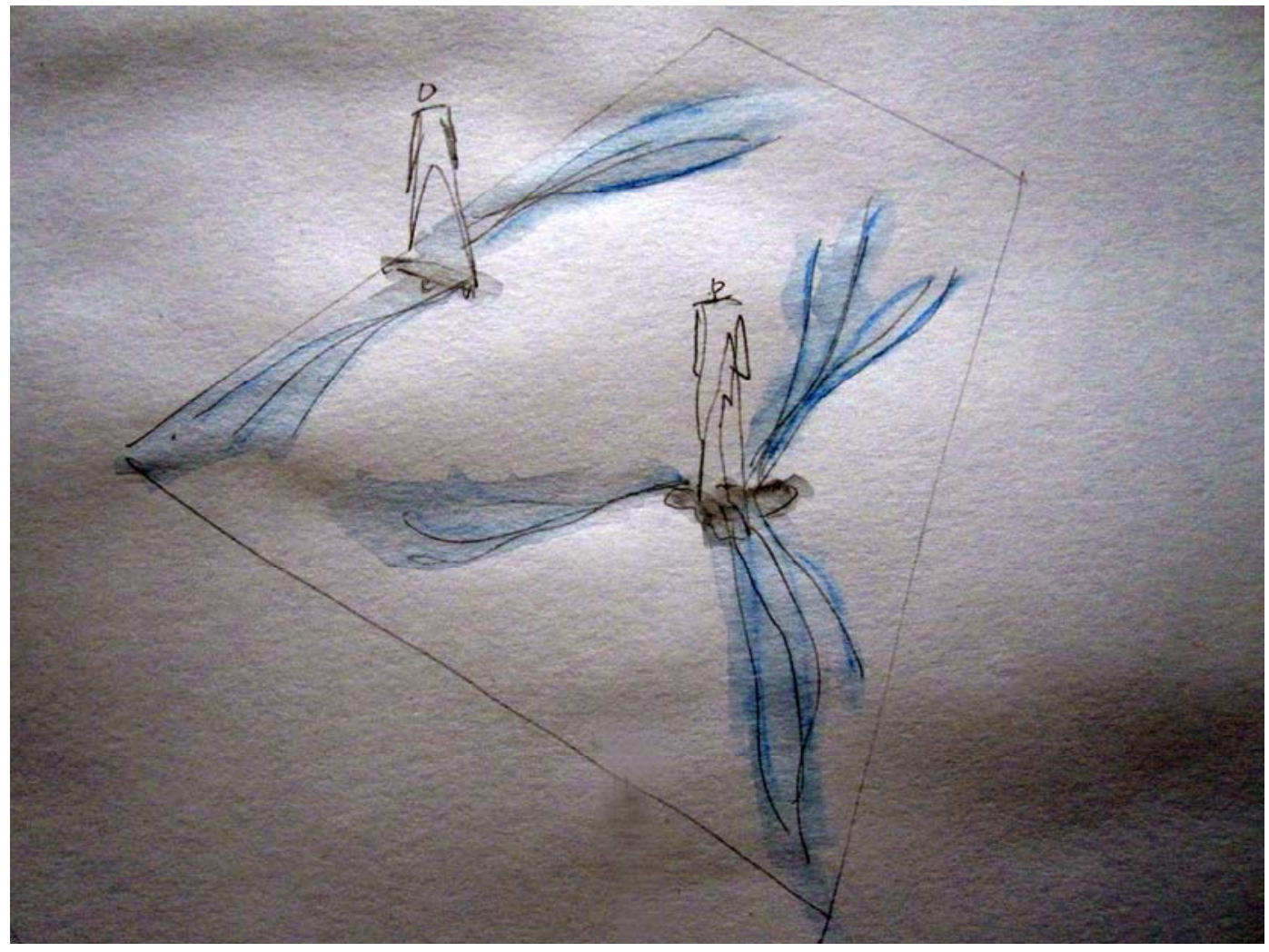

Figura 5.05// Instantes de Metamorfose 01: sketches iniciais no caderno de desenho - aquarelas 
Desde o início, não existia, de um modo geral, uma expectativa com relação à forma de interação da audiência - que as pessoas se movessem de uma determinada forma ou tentassem desvendar as funções de possíveis sensores escondidos. A ideia era a de que, na instalação, as imagens em movimento, os sons, as formas, convidassem a, simplesmente estar no trabalho, e deixar-se imergir na experiência, comportando-se de forma intuitiva e pessoal, num processo que envolve uma relação de aquisição de intimidade com a obra.

No período de estágio no Reino Unido (2009-2010), no início, a tendência foi a de encontrar soluções técnicas para executar as primeiras ideias, priorizando um aprofundamento no estudo da plataforma Processing em suas várias versões para sistema operacional Windows, disponíveis para download. A idéia, que estava sendo trabalhada nesse momento (segundo semestre de 2009), previa a configuração de um ambiente escuro, com projeção do teto para o chão, onde a audiência poderia caminhar tendo seus movimentos capturados por uma câmera. Essa câmera funcionaria com um sensor, fazendo com que uma criatura, em sua forma primária, a acompanhasse, no seu encalço. Se a pessoa permanecesse no espaço da instalação por alguns minutos, se movimentando e lendo fragmentos extraídos do livro Água Viva (LISPECTOR, 1998), que estavam conectados ao corpo da criatura na projeção, a criatura iria se transformando, num processo de metamorfose, até adquirir uma forma humana, a luz azul transparente, se intensificando.

Em tutoriais com o Professor Roy Ascott, orientador da pesquisa no exterior, nas dinâmicas das sessões compostas do Planetary Collegium, foi possível conversar sobre a metáfora da espiral conectada ao processo de evolução, de ascensão espiritual. O professor observou que seria importante entender esse, como um processo não finito - a busca não termina, é um processo contínuo. Essa ideia, da espiral, estava presente no trabalho desde os primeiro sketches, de forma periférica, trazida pela pesquisadora Renata La Rocca. No entanto, o professor Ascott, considerava a importância de que essa fosse a metáfora central, a imagem mais forte. Na versão final de Instantes de Metamorfose 01, o loop é utilizado como recurso poético e é referência à recursividade, à não-finitude do processo, à espiral ascendente-descendente, que muitos percorrem em busca de evolução espiritual. 
Em Plymouth, a interlocução com Guto Nóbrega foi decisiva no abandono das configurações dessas primeiras idéias de como o trabalho poderia vir a ser e no início da abertura para uma transformação dessas idéias. Isso só foi possível a partir de um diálogo seminal entre avanços na pesquisa e no domínio da tecnologia que poderia ser empregada, em reflexões sobre questões relacionadas ao espaço, às imagens, aos sons, às características da interatividade com a audiência. O artista - professor da Escola de Comunicação da Universidade Federal do Rio de Janeiro (ECO/UFRJ) - acreditava que era essencial uma desconstrução das concepções iniciais do trabalho, a abertura para novos diálogos e referências. Dizia ainda que esse processo deveria ser documentado através de desenhos emergentes para que fosse possível encontrar essências - da obra, dos artistas.

Um dia antes de regressar ao Brasil, Guto Nóbrega deu de presente à pesquisadora um livro do Studio Azurro (2008), quadrado, capa vermelha. No do livro, imagens de corpos projetados sobre mesas, superfícies. Integrando a partir desse momento o universo de referências de um dos integrantes do coletivo O Duplo, o contato com essas imagens influenciou a configuração final da obra através de processos subconscientes e conscientes de busca por metáforas capazes de traduzir os conceitos, as ideias. 


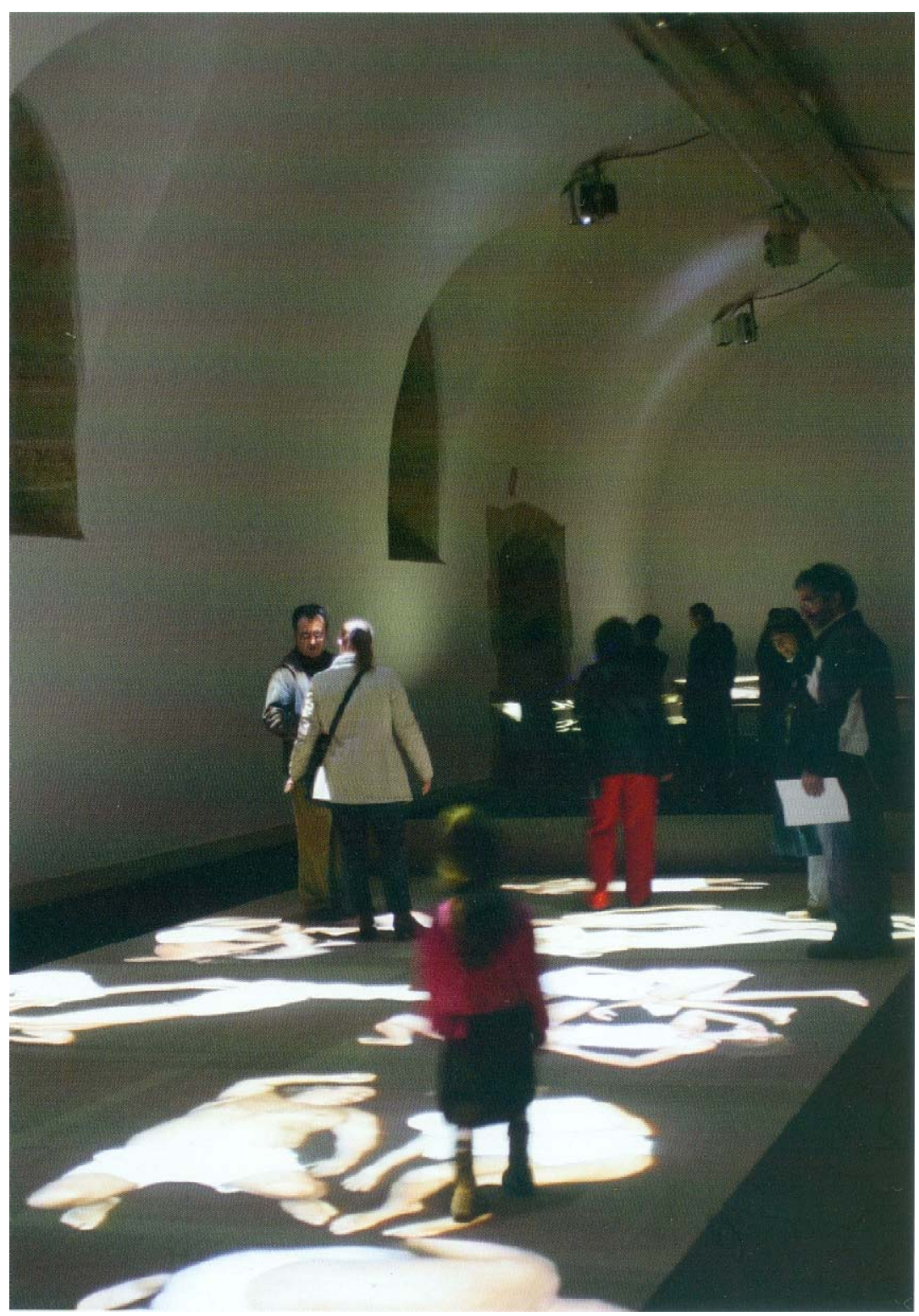

Figura 6.05// Studio Azurro, trabalho integrante da exposição Ambientes Sensibles, Sala Parapalló, 23 enero al 6 de abril de 2008.

O processo de descobertas e domínio de tecnologias de hardware e software aconteceu em diálogo com o processo de construção da obra, da parte conceitual. Um diálogo que está na base do processo organizacional - o domínio da técnica influenciou as decisões, 
as escolhas, a negociações das estórias entre os integrantes do coletivo. Em contrapartida, as estórias compartilhadas e o repertório de cada um dos integrantes do coletivo, influenciaram e direcionaram o aprendizado e o emprego das tecnologias de hardware e software num processo de contaminação dinâmico e generativo de mão dupla, que constrói ele mesmo o próprio sistema, é morfogenético.

A ideia da escada no conto de Jorge Luis Borges (2007) deu margem à imaginação de diversas estruturas possíveis - outras escadas, plataformas com roldanas, labirintos, espirais. Cada integrante do coletivo interpretava a metáfora de uma forma diferente, a partir das suas referências, e compartilhava e as transformava em diálogo. Em depoimento sobre a participação no coletivo O Dup/o, Graziele fala sobre o conto de Borges:

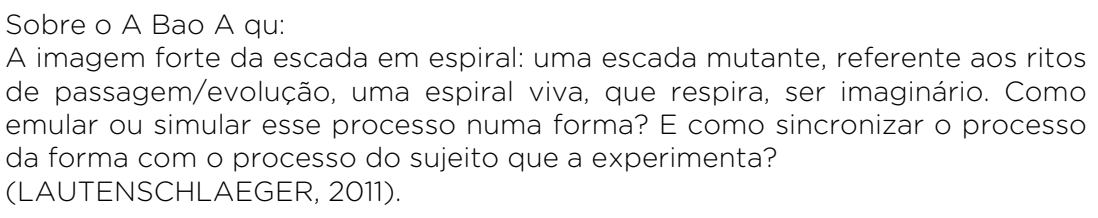

Haveria a necessidade de construção de uma estrutura? Seria interessante mapear uma possivel estrutura-escultura e fazer com que a projeção se encaixasse perfeitamente, como no obra de Pablo Valbuena ${ }^{10}$ trazida como referência por Lautenschlaeger? Questões como essas permearam os primeiros meses de discussões e direcionaram desenvolvimentos futuros.

${ }^{10}$ VALBUENA, Pablo. Augmented Sculpture series. Disponivel em: <http://www.pablovalbuena.com/>. Acesso em: 14 jan. 2011. 


\subsection{Série Instantes de Metamorfose: versão 01}

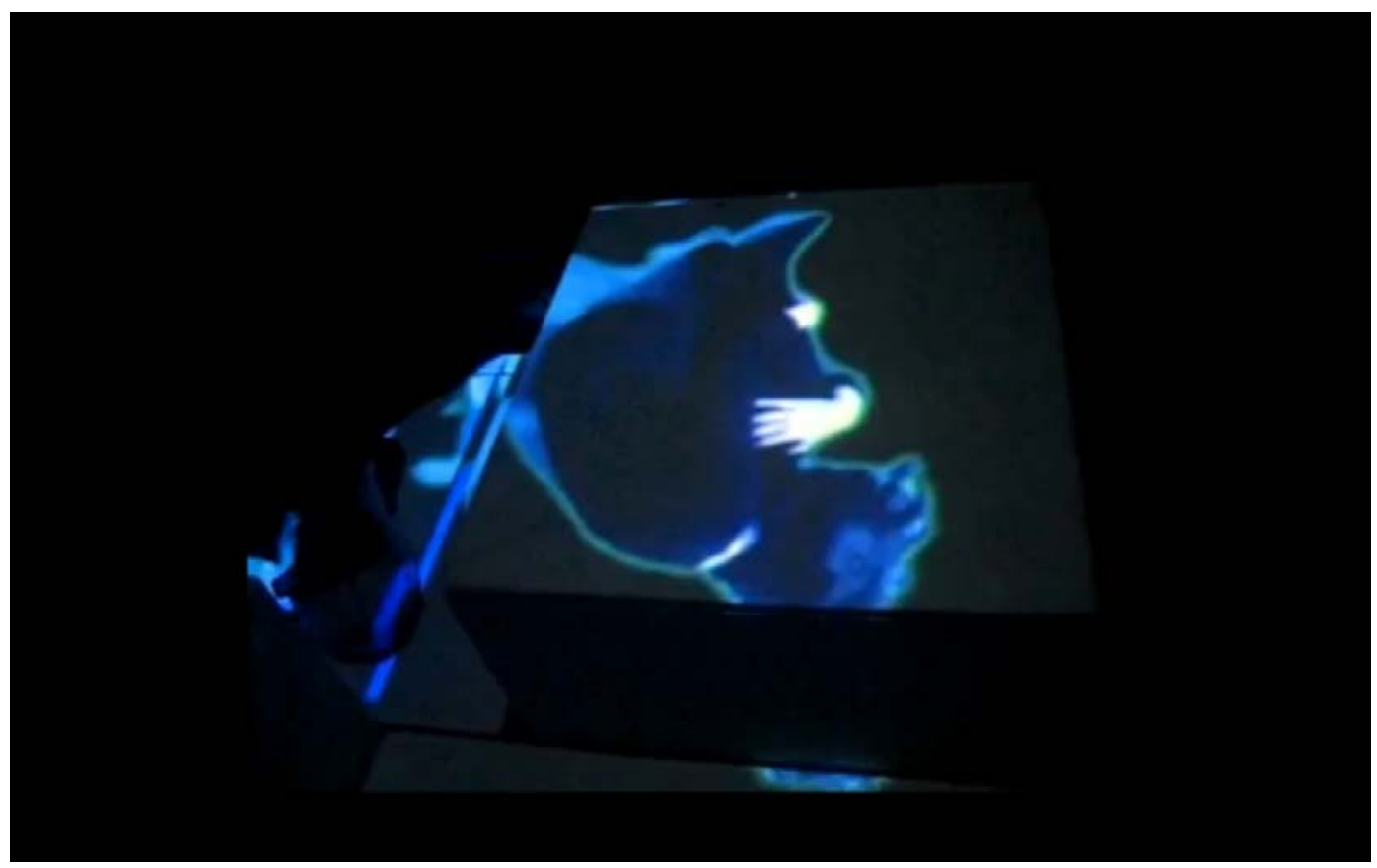

Figura 7.05// Instantes de Metamorfose versão 01

Primeiro trabalho produzido pelo coletivo O Duplo, Instantes de Metamorfose, é uma videoinstalação interativa que explora de forma poética processos caóticos e íntimos de reflexão sobre as transformações por que passa o Eu no processo de aquisição de consciência. Instantes de Metamorfoses de um ser sem gênero, it em diálogo incessante consigo e com o outro, em espaço e tempo imaginários, complexos, como no livro Água Viva, de Clarice Lispector (1998); A Bao A Qu que ganha forma e translucidez em seu corpo azul, no encalço dos que ascendem à Torre da Vitória em busca de evolução espiritual, como relatado no fascinante conto de Jorge Luis Borges (2007) no O Livro dos Seres Imaginários. Transcrevemos aqui, na íntegra, o breve conto de Jorge Luis Borges:

A bao a qu

Para contemplar a paisagem mais maravilhosa do mundo é preciso chegar ao último andar da Torre da Vitória, em Chitor. Existe ali um terraço circular que permite dominar o horizonte inteiro. Uma escada em caracol leva ao terraço, 
mas só têm coragem de subir os que não acreditam na fábula que diz o seguinte:

Na escada da Torre da Vitória vive desde o inicio do tempo o A Bao A Qu, sensível aos valores das almas humanas. Vive em estágio letárgico, no primeiro degrau, e só desfruta de vida consciente quando alguém sobe a escada. A vibração da pessoa que se aproxima lhe incute vida, e uma luz interior se insinua nele. Ao mesmo tempo, seu corpo e sua pele quase translúcida começam a mover-se. Quando alguém sobe a escada, o A Bao A Qu se posiciona quase nos calcanhares do visitantes e sobe pendurando-se à borda dos degraus curvos e gastos pelos pés de gerações de peregrinos. A cada degrau sua cor se intensifica, sua forma se perfeiçoa e a luz que ele irradia é cada vez mais brilhante. Comprova sua sensibilidade o fato de que ele só atinge sua forma perfeita no último degrau, quando aquele que sobe é um ser evoluído espiritualmente. Se não for, O A Bao A Qu fica como que paralisado antes de chegar, seu corpo incompleto, sua cor indefinida e a luz vacilante. O A Bao A Qu sofre quando não consegue se transformar-se totalmente, e sua queixa é um rumor que mal se percebe, semelhante ao roçagar da seda. Mas quando o homem ou a mulher que o fazem reviver estão cheios de pureza, O A Bao A Qu pode chegar até o último degrau, já completamente formado e irradiando uma viva luz azul. Seu retorno à vida é muito breve, pois quando o peregrino desce, O A Bao A Qu rola e cai até o degrau inicial, onde, já apagado e semelhante a uma lâmina de contornos vagos, espera o próximo visitante. Só é possível vê-lo bem quando chega à metade da escada, onde os prolongamentos de seu corpo, que, à maneira de bracinhos, ajudam-no a subir, definem-se com clareza. Há quem diga que ele olha com o corpo inteiro e que quando tocado lembra casca de pêssego. No decorrer dos séculos, o A Bao A Qu chegou uma última vez à perfeição. $O$ capitão Burton registra a lenda do A Bao A Qu em uma das notas de sua versão de As mil e uma noites. (BORGES, 2007, p.11-12).

Na versão final da instalação, uma vídeo performance realizada pela autora, é projetada em uma base volumétrica que compõe uma escultura-sujeito: referência à uma interminável espiral imaginária que pode-se ascender em busca de evolução espiritual. 0 som ambiente é o som irregular e profundo da respiração humana, referência a práticas de meditação que intencionam colocar o sujeito em contanto íntimo com sua essência.

Quando alguém escala a escultura-sujeito, espiral deconstruída, explorando os volumes, a projeção do vídeo segue seus movimentos, deixando estampados no chão, instantes congelados da vídeo performance, memórias da metamorfose do sujeito. Entre as referências para a composição da escultura que representa a espiral, estão a obra Spiral Movement (1951) de Mary Martin, a série Augmented Sculptures (2007-atual) de Pablo Valbuena e Embankment (2005) de Rachel Whiteread. 


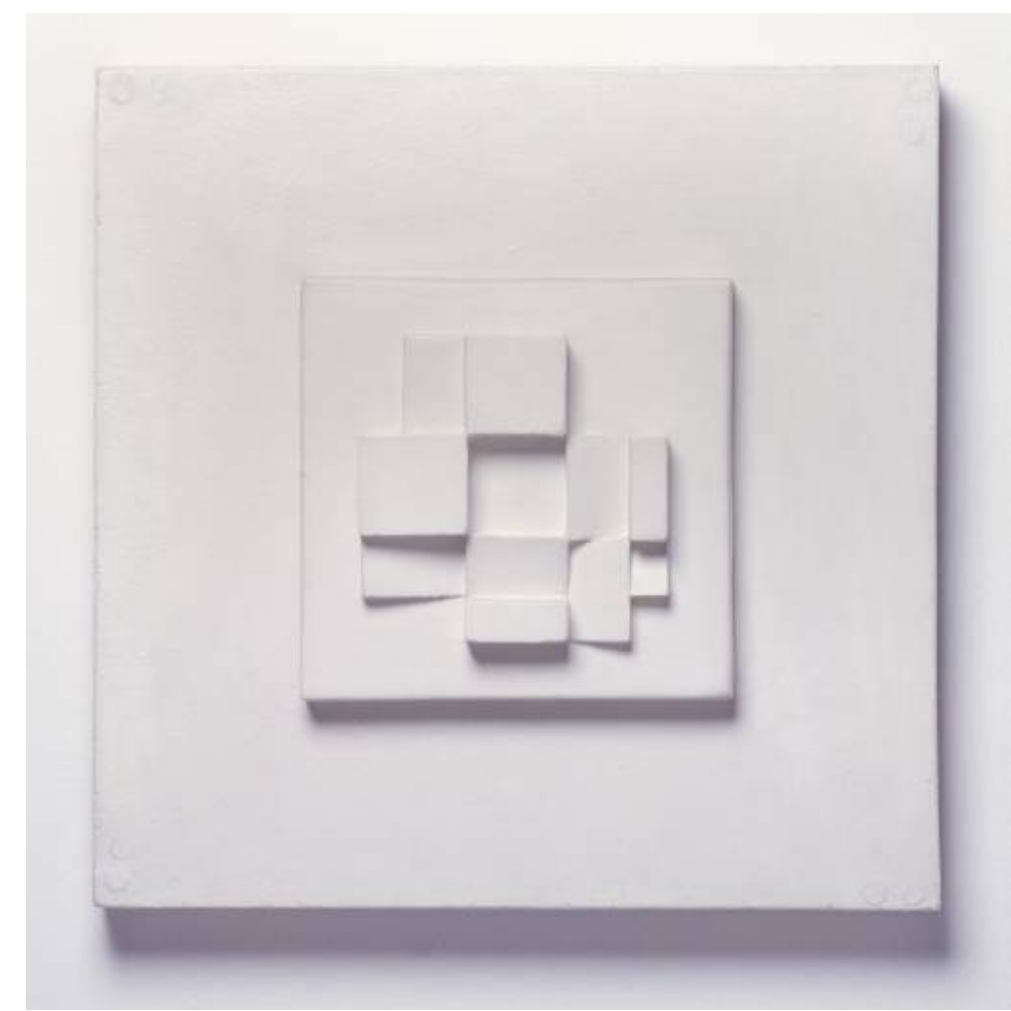

Figura 8.05// Spiral Movement (1951) de Mary Martin.

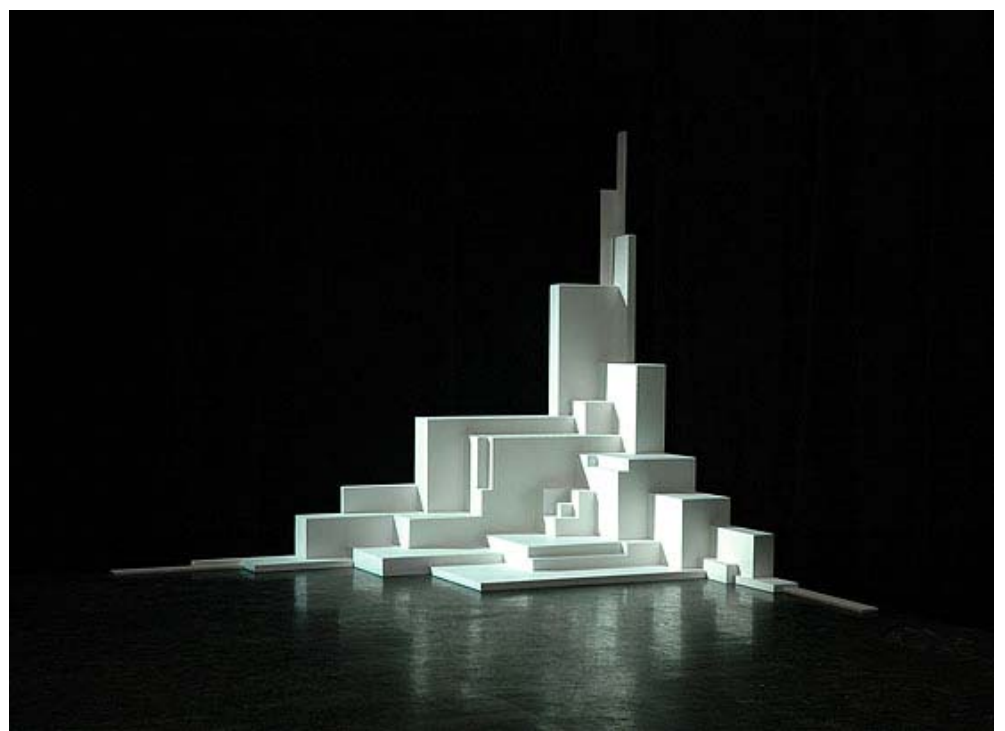

Figura 9.05// Augmented Sculptures (2007-atual) de Pablo Valbuena. 


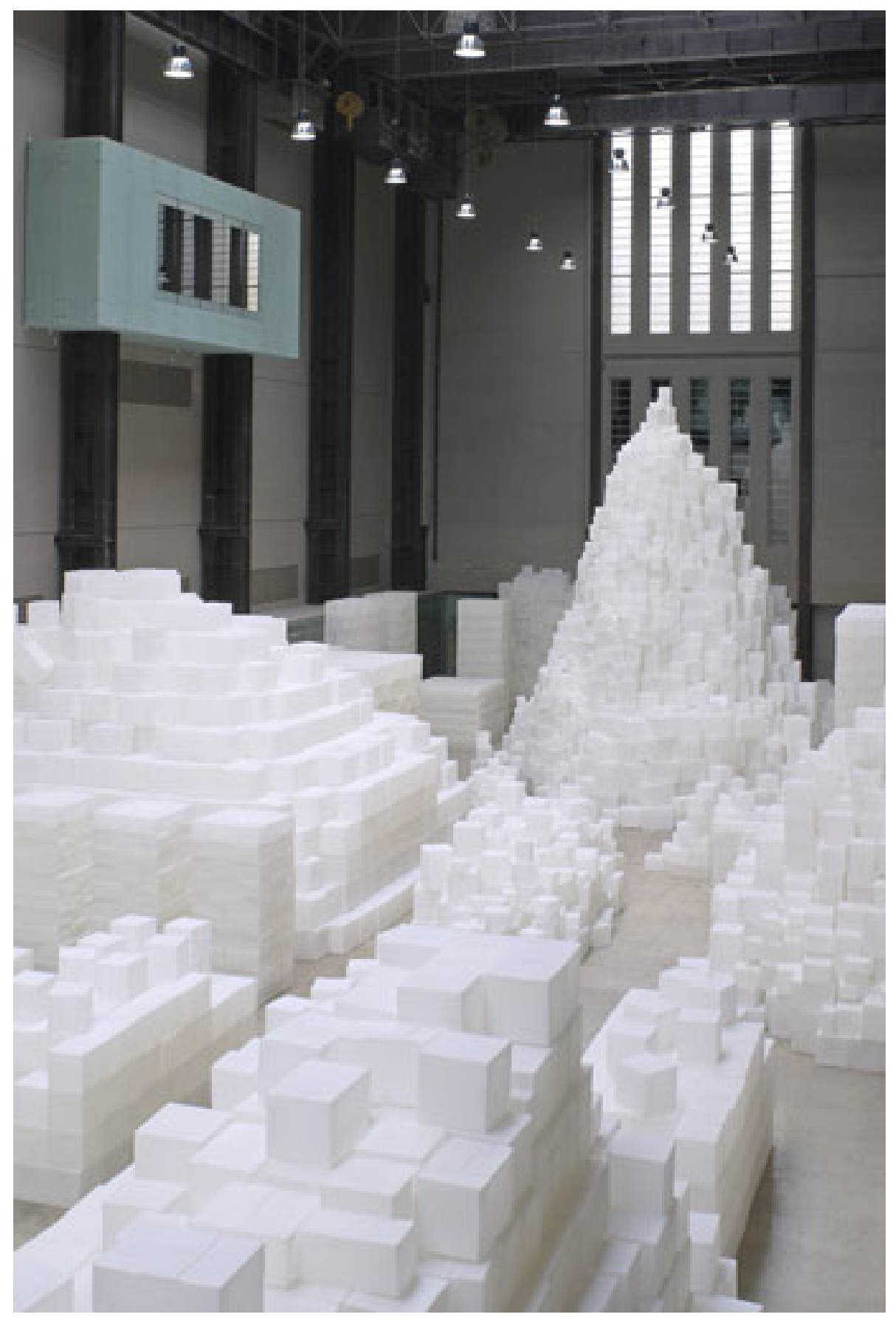

Figura 10.05// Embankment (2005) de Rachel Whiteread. 
As reflexões sobre processos de aquisição de consciência, de construção simultânea do eu em processo constante e infindável de diálogo consigo, com o outro, atravessando diversos níveis de realidade, foram intensamente influenciadas pelas leituras de autores como Jorge Luis Borges, Clarice Lispector e Henri Bergson, para citar alguns. Referimos aqui algumas frases selecionadas nas leituras realizadas pelos integrantes do coletivo $O$ Duplo do livro Água Viva:

\footnotetext{
É de uma pureza tal esse contato com o invisível núcleo da realidade. (LISPECTOR, 1998, p.21).

O mundo não tem ordem visível e eu só tenho a ordem da respiração. Deixome acontecer. (LISPECTOR, 1998, p.22).

A prece profunda é uma meditação sobre o nada. É o contato seco e elétrico consigo, um consigo impessoal. (LISPECTOR, 1998, p.22).

Quando penso no que já vivi me parece que fui deixando meus corpos pelo caminho. (LISPECTOR, 1998, p.67).
}

$\mathrm{Na}$ instalação, uma das ideias que foram construídas em função dessas noções, foi a de estimular a aquisição de intimidade com a escultura-sujeito em vários níveis. Na medida em o participante percebe sua interferência na posição da projeção desse ser imaginário que veste a escultura-sujeito, ele começa a criar uma aproximação, a tocar a superfície, buscado tocar o ser que se contorce, se transforma infinitamente no vídeo em loop.

Os movimentos dos participantes são capturados por uma webcam, que funciona como um sensor, mapeando as manchas brancas que se movimentam em seu campo de captura. O código em Processing 1.0.9 utiliza o mapeamento não linear desses pontos para orientar a projeção da vídeo performance em loop sobre a escultura-espiral, em função da interferência da presença da audiência. 


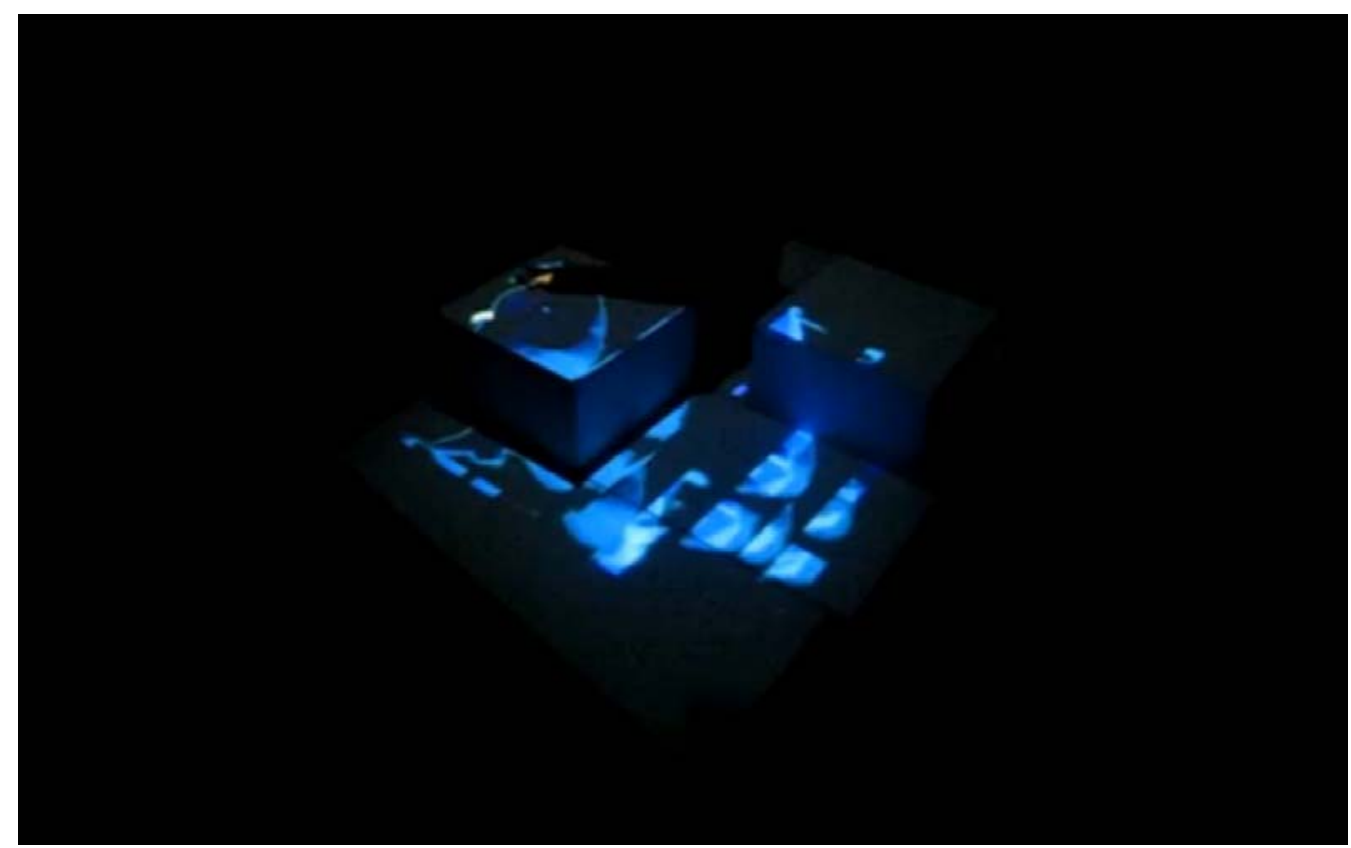

Figura 11.05// Instantes de Metamorfose versão 01

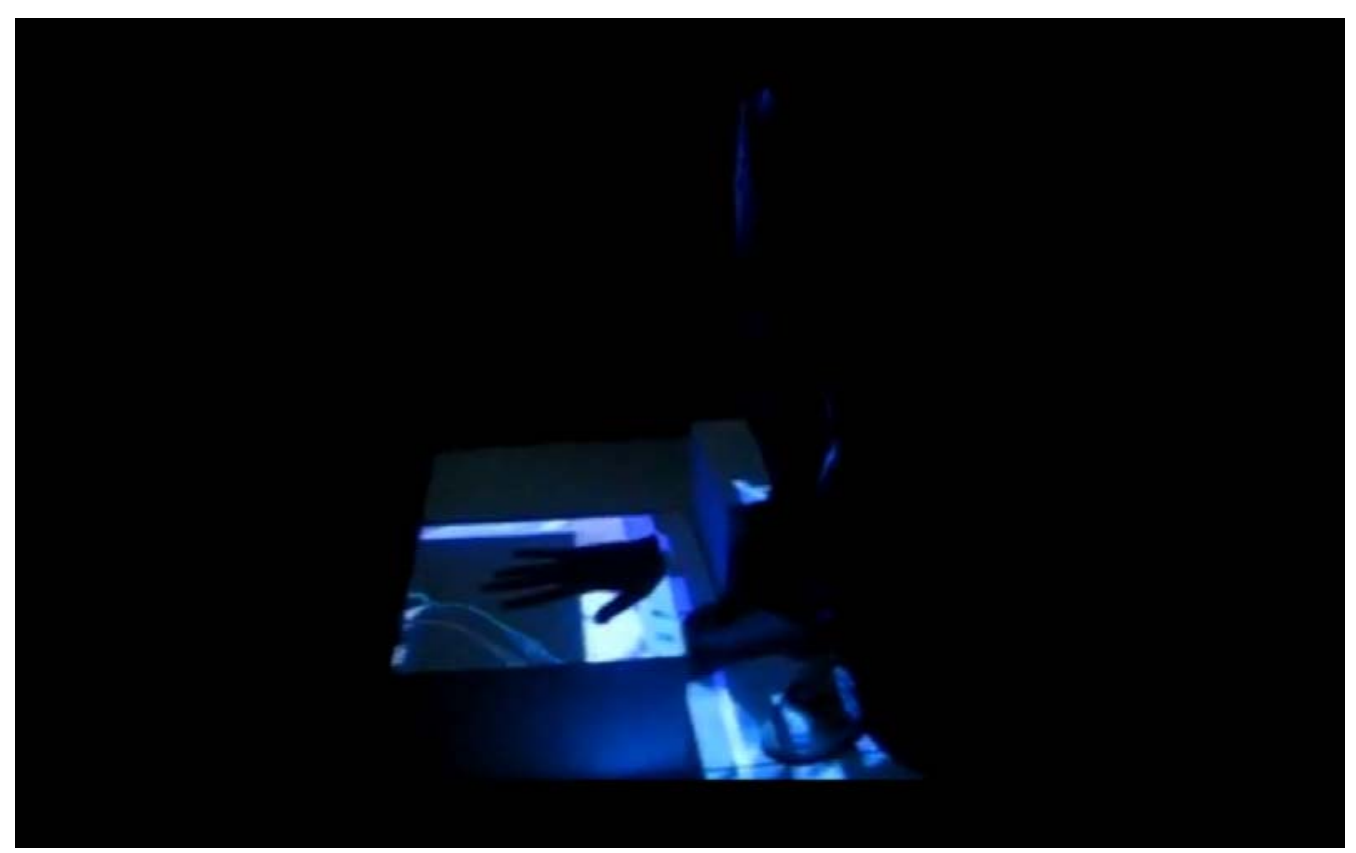

Figura 12.05// Instantes de Metamorfose versão 01 
Conceitualmente, o trabalho de arte é um sistema dinâmico e suas narrativas e antenarrativas, as histórias que conta e que contém, não têm fim e nem têm começo. Neste contexto, emergências podem ser estudadas como qualidades do sistema que são produzidas a partir de associações e ligações dinâmicas, acontecendo no nível do usuário e podendo ser, por exemplo, aquisição da consciência em um processo de troca de informações, em processos subjetivos de contato íntimo com a obra. Além, podemos falar de uma consciência emergente do próprio sistema, consciência do próprio processo criativo coletivo.

A imaterialidade da performance em vídeo e sua narrativa, convidam e estimulam a reflexões sobre consciência, numa alusão às bordas, limites, e às extensões virtuais que construímos para viver e dialogar, em uma perspectiva ecológica. Todas as ações, as trans-ações, estão integradas em um tempo que incorpora vários tempos, como um jardim de veredas que se bifurcam", espaços estoricizados infindáveis onde convivem seres imaginários, its, nós mesmos, e os outros.

A obra é desenhada para ser um ambiente meditativo, onde o participante reflita sobre o contínuo processo de transformação, de recriação, de reconstrução do eu e da realidade, esses instantes de metamorfose de sistemas de sistemas, processo infindável; evolução criativa.

Da filosofia, teologia, esoterismo, a ideia de que um ser evolui ou ascende um padrão cosmológico está relacionada à evolução espiritual. Henri Bergson em seu Creative Evolution (BERGSON, 1998), tece uma conexão entre os mundos material e imaterial. Nas palavras de Bergson,

Se a forma intelectual do ser vivo tem sido gradualmente modelada na ação recíproca e reação de certos corpos e seu ambiente material, como não deveria revelar-nos algo da essência do que esses corpos são feitos? A ação não pode mover-se no irreal. Uma mente nascida para especular ou para sonhar, admito, talvez permaneça fora da realidade, pode deformar ou transformar o real, talvez até criá-lo - como criamos figuras de homens e animais que nossa imaginação recorta das nuvens que passam. Mas um intelecto dobrado sobre o ato praticado e a reação a seguir, sentindo seus

\footnotetext{
"Uma referência ao conto de Jorge Luis Borges, "O jardim das veredas que se bifurcam". BORGES, J. L. O jardim das veredas que se bifurcam. In: BORGES, J. L. Ficções. Tradução de Carlos Nejar. São Paulo: Globo, 2001, p. 101114.
} 
objetos de forma a obter impressão móvel a cada instante, é um intelecto que toca algo de absoluto. ${ }^{12}$ (BERGSON, 1998, p.XI, tradução nossa).

Para Bergson, a essência da realidade é evolução e movimento. Existência, é um fluxo de vir a ser, mover-se, evoluir. Segundo Keith Ansell-Pearson, "a evolução criativa para Bergson envolve um jogo entre ordem e desordem, entre consciência e matéria inerte, entre a tensão e extensão, no qual contingência desempenha um papel importante.,13 (ANSELL-PEARSON, 1999, p.156, tradução nossa). Essa contingência é válida tanto para as formas adotadas e inventadas e para os obstáculos que podem ser encontrados, em qualquer momento, e em qualquer lugar. Segundo a Ansell-Pearson, em Bergson, "as duas únicas coisas necessárias para a evolução 'evoluir' são, primeiro, um acúmulo de energia e, em segundo lugar, uma canalização da energia elástica na variável e indicações indetermináveis." (ANSELL-PEARSON, 1999, p.156, tradução nossa).

Pensando na instalação Instantes de Metamorfose O1, como emergência que pertence à instância superior do sistema, na perspectiva do Modelo Úmido, essa emergência é um subsistema dentro do sistema que é o processo criativo coletivo do O Duplo. A experiência na instalação, convida à reflexão, permitindo aos participantes que se tornam momentaneamente partes do sistema, alcançar diferentes níveis de percepção e consciência. No sistema como um todo, o fluxo de informação de um nível ou instância para outro, é o que faz com que os trabalho artísticos como emergências sejam viabilizadas, emerjam.

No nível do sujeito que participa do sistema, na instância superior do Modelo Úmido, trazendo seu repertório, sua cultura, informações referentes a contexto, entre outras,

\footnotetext{
${ }^{12}$ Do original em inglês: "If the intellectual form of the living being has been gradually modeled on the reciprocal actions and reaction of certain bodies and their material environment, how should it not reveal to us something of the very essence of which these bodies are made? Action cannot move in the unreal. A mind born to speculate or to dream, I admit, might remains outside reality, might deform or transform the real, perhaps even create it - as we create the figures of man and animals that our imagination cuts out of the passing cloud. But an intellect bent upon the act performed and the reaction to follow, feeling its objects so as to get it mobile impression at every instant, is an intellect that touches something of absolute." (BERGSON, 1998, p.xi)

${ }^{13}$ Do original em inglês: "Creative evolution for Bergson involves a play between order and disorder, between consciousness and inert matter, between tension and extension, within which contingency plays a major role." (ANSELL-PEARSON, 1999, p.156)

${ }^{14}$ Do original em inglês: "The only two things required for evolution to 'evolve' are, first, an accumulation of energy, and, second, an elastic canalization of this energy in variable and indeterminable directions." (MULLARKEY, 1999, p.156)
} 
outras emergências são possíveis, como a aquisição de diferentes níveis de consciência nesses que são processos reflexivos.

\subsection{Instantes de Metamorfose: Espaços Estoricizados}

Como vimos em capítulos anteriores, nas considerações sobre a complexidade e criatividade sistêmicas, um sistema para que seja criativo deve implicar uma espontaneidade que traz novidade, na forma de emergências. Dando visibilidade ao sistema, os processos de captura de narrativas e antenarrativas, desvelam a própria arquitetura sistêmica - imaterial, mutável, dinâmica.

Nesses processos, alguns participantes se envolvem mais intensamente, outros menos. Participar desses processos perceptivos e mentais em dinâmicas emergentes, é uma experiência transformadora, não só ao nível do indivíduo, mas (e esse é um de nossos principais argumentos), ao nível do sistema, ao qual está integrada a observação. Os sujeitos se re-organizam incessantemente no e pelo fluxo de informações, pelo fluirconstruir das narrativas e antenarrativas, nas bolhas/espaços estoricizados.

Optamos por estruturar as dinâmicas de forma aberta e livre, contando, muitas vezes, com o acaso na própria construção e oportunidade de realização das dinâmicas. A instalação foi exibida durante o período de 2 (dois) meses em espaço expositivo cedido pela FAAL ${ }^{15}$, em Limeira, interior do Estado de São Paulo, durante o segundo semestre de 2010 .

Em um sábado à tarde, enquanto fazíamos ajustes e reparos na instalação, o som profundo e cíclico da respiração emitido pelos amplificadores, atraiu para o espaço um possível participante. O momento de trocas foi intenso, tendo o indivíduo interagido com a obra por mais de meia hora. O processo como um todo, que se estendeu além da experiência no espaço instalativo, incorporou desenho e escrita emergentes e a gravação de breves vídeo documentários com depoimentos na forma de brainstorming. Nesses processos é recorrente e constante a referência dos participantes a diversos outros trabalhos em literatura fantástica, artes visuais, assim como referências a autores nas áreas de filosofia e ciências de um modo geral.

${ }^{15}$ FAAL - Faculdade de Administração e Artes de Limeira. 
Contemplando as instâncias de transformação da informação e da experiência, as antenarrativas e narrativas colecionadas foram agrupadas em 7 (sete) níveis (vide Capítulo 03) - Impressão (desenhos emergentes produzidos imediatamente após a experiência e/ou gravação de vídeo com depoimento na forma de brainstorming); Atenção (escrita emergente produzida aproximadamente 1 (uma) hora após a experiência e/ou gravação de vídeo com depoimento na forma de brainstorming); Memória (escrita emergente e desenho produzidos aproximadamente 1 (um) dia após a experiência); Comparação (escrita emergente produzida aproximadamente 1 (uma) semana após a experiência, que pode ser combinada com a produção de um painel semântico); Julgamento (escrita emergente produzida aproximadamente 1 (um) mês após a experiência); Reflexão (escrita emergente produzida aproximadamente 2 (dois) meses após a experiência); Imaginação (escrita emergente e desenho produzidos aproximadamente 3 (três) meses após a experiência). Transcrevemos aqui a partir de vídeo gravado imediatamente após a experiência, uma das narrativas capturadas e que integram o espaço estoricizado de um dos participantes:

\begin{abstract}
Uma das referências que me lembra esse trabalho aqui, é o Begotten. O filme é inteiro preto e branco, sem tons de cinza [...] faz uma metáfora à história da criação da humanidade, e se estrutura em torno de três personagens - Deus Mutilado, Pedaço de Carne que Convulsiona (que no caso era o ser humano), a Mãe Natureza. O filme inteiro não tem fala nenhuma, só expressão corporal. Por exemplo, o personagem que representa o ser humano, ele não anda, ele vai rastejando o filme inteiro, tendo espasmos, convulsões [...]. É um filme perturbador por assim dizer. Esse movimentos aqui, na tentativa se libertar dessa bolsa azul, me lembram bastante o filme. [...] o som também me lembrou bastante, porque o filme, [...] é constituído apenas de ruídos. Não tem fala nenhuma, é o silêncio e tem um ruído no fundo, assim bem baixinho. (NASCIMENTO, 2010).
\end{abstract}

O mesmo participante produziu desenho emergente imediatamente após a interação (Figura 13.05). Entre as referências que emergiram no processo de brainstorming, estão o filme Begotten, (BEGOTTEN, 1990) e o livro Os Cantos de Maldoror, Conde de Lautréamont - pseudônimo do poeta francês de origem uruguaia, Isidore Ducasse (LAUTRÉAMONT, 1970). Os curtos vídeos contendo as fragmentadas antenarrativas (ver Capítulo 1), assim como as referências mencionadas pelo participante, podem ser acessados no blog Instants of Metamorphosis, na categoria Storied Spaces V.O1'

\footnotetext{
${ }^{16}$ INSTANTS OF METAMORPHOSIS. Storied Spaces v.01. Disponivel em:

<http://instantsofmetamorphosis.blogspot.com/search/label/Storied\%20Spaces\%20v.01>. Acesso em: 15 jan. 2011.
} 


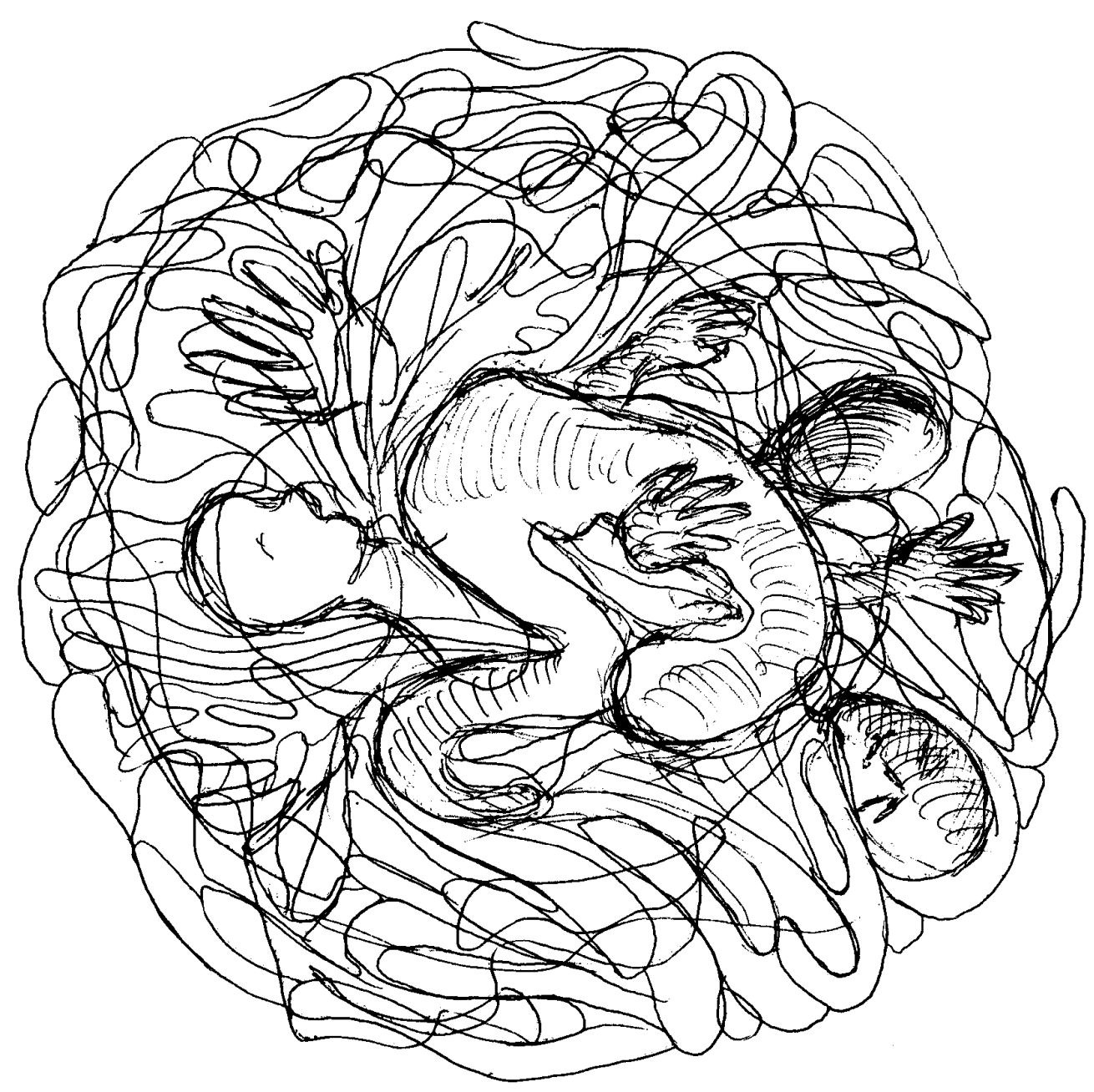

Figura 13. 05// Desenho emergente produzido por um interator imediatamente após a experiência em Instantes de Metamorfose 01.

Em alguns casos, os participantes restringiram a realização de filmagens que seriam um meio de captura das antenarrativas, contribuindo exclusivamente através de textos (escrita emergente), realizada logo após a experiência e, posteriormente, em dinâmicas realizadas via e-mail. Para ilustrar essas etapas posteriores à experiência, referimos aqui uma contribuição de um participante realizada 1 (um) mês após a experiência: 
Achei o som e a imagem um pouco dificeis de decifrar, mas achei que isso ficou interessante porque estimula a imaginação. Então, como estou lendo o livro Mil Platôs 4 de Delleuze e Guattari, vou escrever algumas relações que vi entre seu trabalho e algumas ideias desses autores, não sei se foram referência para você. Pensando na ideia de metamorfose, a pessoa que sobe a escada e vai dando vida, sofrendo uma espécie de "fusão" com outro ser, lembrei da definição de Deleuze e Guattari, para os quais cada indivíduo é uma multiplicidade infinita. Cada acidente, cada encontro o transforma em outro, outro que ao mesmo tempo é múltiplo de si mesmo. Assim, o indivíduo não é, mas ele está, pois se transforma a todo momento no encontro com pessoas ou situações. Ele não possui características eternas, mas as adquire e descarta ao longo do tempo. No contato com as coisas nos transformamos, e as coisas também se tornam outras coisas. [...] Não se trata de uma evolução como desenvolvimento linear, mas do que os autores chamam de "involução": uma evolução comunicativa e contagiosa entre heterogêneos, que não se dirige a um único ponto, mas lança inúmeras linhas de fuga. (SOLFA, 2011).

\title{
Esse mesmo participante continuou integrando a dinâmica de captura de narrativas e antenarrativas, tendo mencionado posteriormente, como referências que relacionou à instalação, a obra Very Nervous System, de David Rokeby, e um texto do mesmo artista Transforming Mirrors: Subjectivity and Control in Interactive Media. No texto, Rokeby fala de transformações nos papéis da audiência e do ator em trabalhos interativos de arte digital. Segundo Rokeby,
}

\begin{abstract}
Do mesmo modo que o papel do espectador é questionado e transformado, também o é o papel do artista. [...] O ato de realizar um trabalho é um processo de progressivamente estreitar o leque de possibilidades por uma série de escolhas criativas, até que uma das possíveis tenha se manifestado na obra acabada. Pode-se dizer que o artista interativo decide em algum ponto nesse processo não escolher de entre as possibilidades restantes, mas criar algum tipo de mecanismo de escolha atuado pela audiência. O precedente imediato para isso é encontrado em composições acaso de John Cage. Em cada uma dessas obras, Cage definiu um conjunto de regras e, em seguida jogou moedas para escolher uma composição específica a partir da gama de possibilidades permitidas por estas regras. A intenção de Cage em reduzir o controle que tinha sobre o resultado final pode ser inferida a partir de sua sugestão de que o maior objetivo é não ter nenhum propósito. Isso coloca a pessoa em acordo com a natureza em sua forma de operações. ${ }^{17}$ (ROKEBY, 2011, tradução nossa).
\end{abstract}

\footnotetext{
${ }^{17}$ Do original em inglês: "As the role of the spectator is questioned and transformed, so is the role of the artist. [...] The act of realizing a work is a process of progressively narrowing the range of possibilities by a series of creative choices until one of the possible has been manifested in the finished work. One might say that the interactive artist decides at some point in this process not to choose from among the remaining possibilities but to create some sort of audience-actuated choosing mechanism. The immediate precedent for this is found in John Cage's chance compositions. In each of these works, Cage defined a set of rules and then used the tossing of coins to choose a specific composition from the range of possibilities allowed by these rules. Cage's intent in reducing the control he had over the final result can be inferred from his suggestion that the highest purpose is to have no purpose at all. This puts one in accord with nature in her manner of operations." (ROKEBY, 2011)
} 
Durante a realização das dinâmicas de captura das narrativas e antenarrativas, vimos que cada participante construiu um universo particular de relações com a obra criando uma rede de significados emergentes, ligando o sistema ao contexto e o contexto ao sistema e abrindo a possibilidade futura de criação de conexões entre narrativas e antenarrativas, entre espaços estoricizados por afinidade.

A ideia é ampliar o Modelo Úmido em uma versão para ambientes 3D online, utilizando a plataforma Open Wonderland ${ }^{18}$ ou similares, criando em paralelo uma tag cloud que torne possível a visualização das conexões entre significados, inter-relacionando narrativas e antenarrativas. Esse poderá ser um dos objetivos a serem desenvolvidos em uma pesquisa de pós-doutorado, dando continuidade ao estudo do processo criativo coletivo como sistema, em diálogo com a experimentação prática, o que possibilitaria uma ampliação e rediscussão do modelo aqui proposto.

\subsection{Série Instantes de Metamorfose: versão 02}

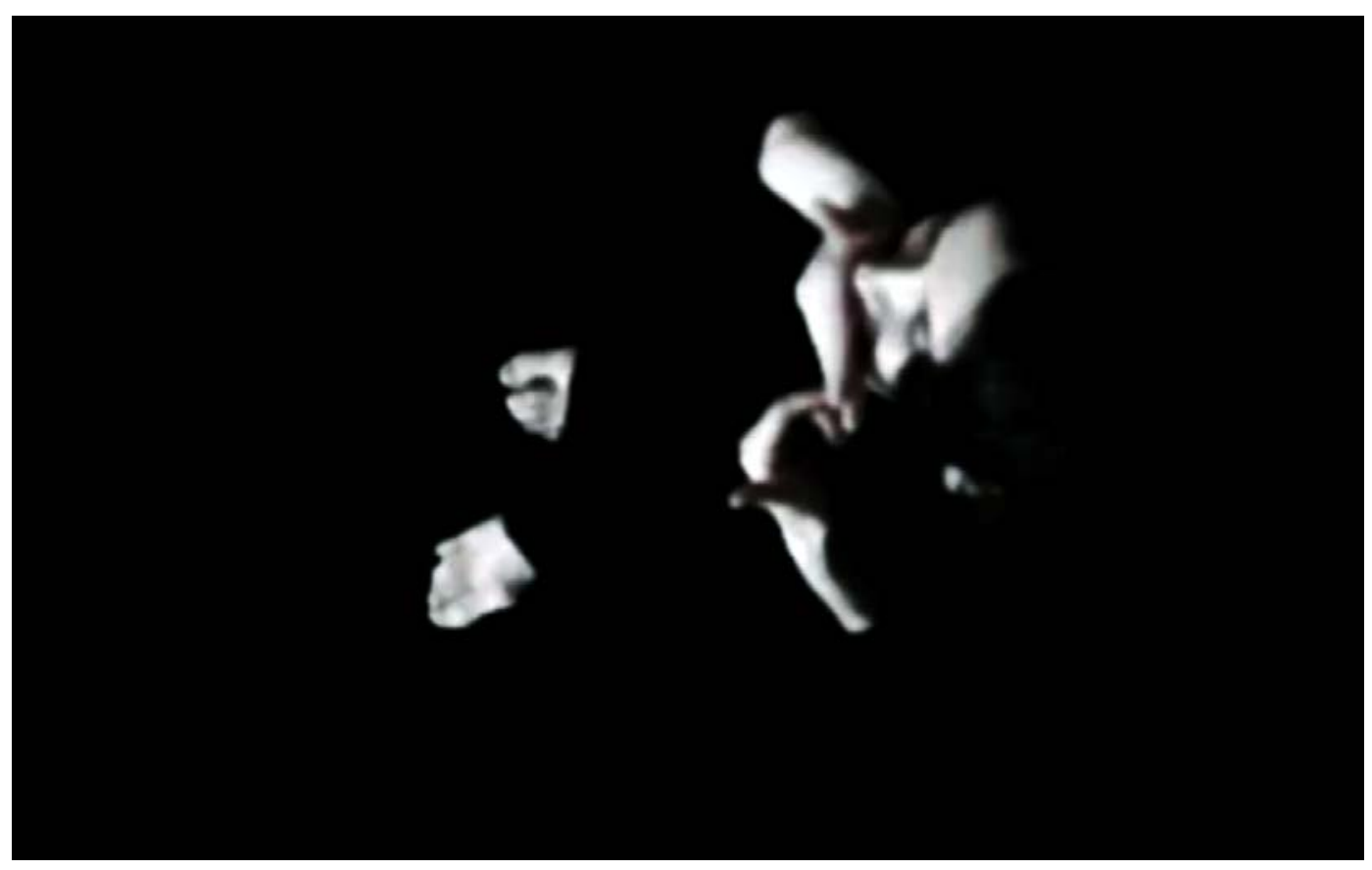

Figura 14.05// Instantes de Metamorfose versão 02, performance: Provando

\footnotetext{
${ }^{18}$ OPEN WONDERLAND. Java open source toolkit for creating collaborative 3D virtual worlds. Disponivel em: < http://openwonderland.org/>. Acesso em: 20 jan. 2011.
} 
Em paralelo à realização das dinâmicas relacionadas à construção dos espaços estoricizados relacionados à instalação Instantes de Metamorfose versão 01, as discussões em torno de uma segunda versão, segunda emergência no processo criativo coletivo do O Duplo, se intensificaram e deram origem a um trabalho que se encontra agora em sua versão preliminar de testes.

Explorando a leitura de Borges, no conto Dois Animais Metafísicos, das ideias de Condillac e de Lotze (BORGES, 2007, p.28-29), em torno do problema da origem das ideias, o trabalho tem a intenção de explorar os domínios da fenomenologia da percepção, da construção de realidades a partir da exploração do mundo dos fenômenos pelos sentidos, para além dos cinco sentidos, incorporando as ideias de sensações, intimidade, simulação.

No texto Virtual Environments, Personal Simulation and Telepresence, Scott Fischer, considera que um ponto de vista interativo em primeira pessoa adiciona dimensões de experiência. O pesquisador utiliza um fragmento do livro de Tom Bender, Environmental design primer (BENDER, 1973) onde ele afirma que,

\begin{abstract}
Nós obtemos informações diretas no processo de interagir com situações que encontramos. Raramente intensiva, a experiência direta tem a vantagem de vir com a totalidade de nossos processos internos - consciente, inconsciente, visceral e mental - e é amplamente testada e avaliada por nossa natureza. 0 conhecimento em segunda mão, processado, digerido, abstraído, é muitas vezes mais generalizado e concentrado, mas geralmente nos afeta apenas intelectualmente - sem o equilíbrio e a completude das situações vivenciadas."19 (BENDER, 1973 apud FISCHER, 1999, p.107, tradução nossa).
\end{abstract}

Assim como na versão 01 de Instantes de Metamorfose, há nessa segunda versão, a ideia de uma evolução criativa, diálogo entre processos conscientes e subconscientes do eu em busca de seu reflexo, do outro, da própria realidade que constrói. No referido conto (Dois Animais Metafísicos), Borges fala que Condillac, em certo ponto de sua alegoria no Tratado das Sensações, atribui "[...] a seu homem hipotético a audição, o paladar, a visão e por fim o tato. Este último sentido Ihe revelará que existe o espaço, e que no espaço

\footnotetext{
${ }^{19}$ Do original em ingles: We obtain raw direct information in the process of interactiong with situations we encounter. Rarely intensive, direct experience has the advantage of coming through the totality of our internal processes - conscious, unconscious, visceral, and mental - and is most completely tested and evaluated by our nature. Processed, digested, abstracted second-hand knowledge is often more generalized and concentrated, but usually affects us only intellectually - lacking the balance and completeness of experienced situations. (BENDER, 1973 apud FISCHER, 1999, p.107)
} 
ele está num corpo; os sons, os cheiros e as cores, antes dessa etapa, haviam Ihe parecido simples variações ou modificações de sua consciência." (BORGES, 2007, p.28)

Essa relação entre percepção e a construção do espaço, da experimentação do espaço, é noção que estrutura que influencia a concepção da instalação. Se referindo ao animal hipotético de Lotze, animal solitário que tem um único ponto sensível e móvel na pele, na extremidade de uma antena, Borges observa que, "sua conformação lhe proíbe, como se vê, as percepções simultâneas. Lotze pensa que a capacidade de retrair ou projetar sua antena sensível bastará para que o animal quase sem comunicação descubra o mundo externo [...] e distinga um objeto estacionário de um objeto móvel." (BORGES, 2007, p.29).

$\mathrm{Na}$ instalação, uma série de 4 (quatro) vídeo performances foi produzida, em torno da exploração do corpo e suas bordas, pelos sentidos - cheirando, olhando, provando, tocando. Os quatro vídeos são chamados em loop no código em Processing 1.0.9 simultaneamente, cada um rodando em uma posição inicial pré-definida na projeção.

Os vídeos são projetados sobre um tabuleiro metálico cheio de água até metade de sua altura que é de 10 (dez) centímetros. Uma webcam wide angle captura os movimentos dos participantes no espaço da instalação e faz convergir, simultaneamente todos os vídeos para a posição em que o participante se encontra. Este é convidado a estar descalço e imergir os pés na água durante a experiência.

O som ambiente é o som de mastigação de alimentos sólidos aerados pela performer na vídeo performance provando. A intenção é incentivar a reflexão sobre o diálogo interior/exterior, entre corpo e ambiente, nos processos auto-organizacionais dos seres vivos. No contexto das explorações, algumas perguntas começaram a se delinear como: O que é permeável aos sentidos? O que eles filtram? De que forma filtram? Como a abertura ao contexto, à realidade exterior através dos sentidos interfere nos processos organizacionais? Qual é, o que é, o ruído nesses processos? 


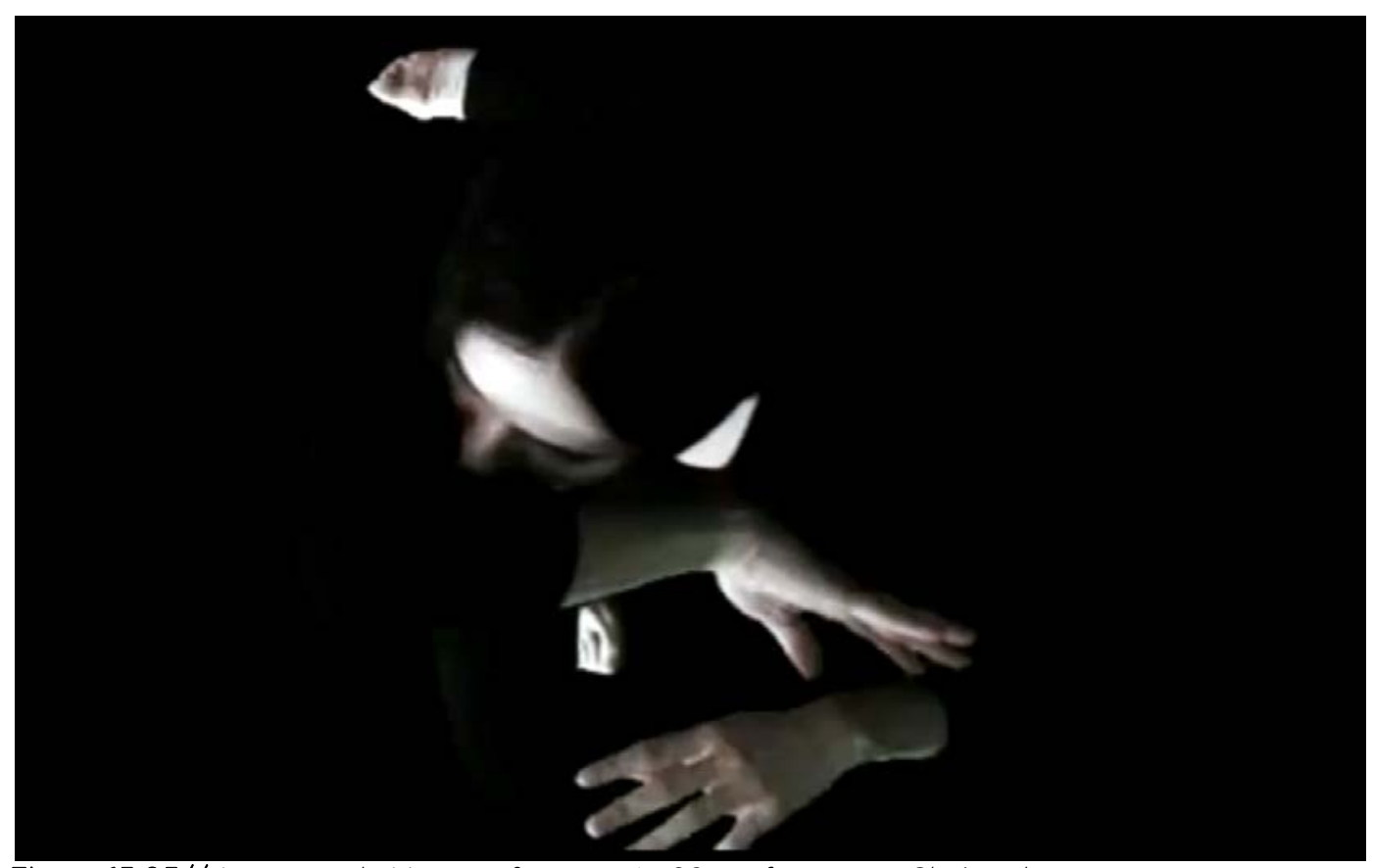

Figura 15.05// Instantes de Metamorfose versão 02, performance: Cheirando

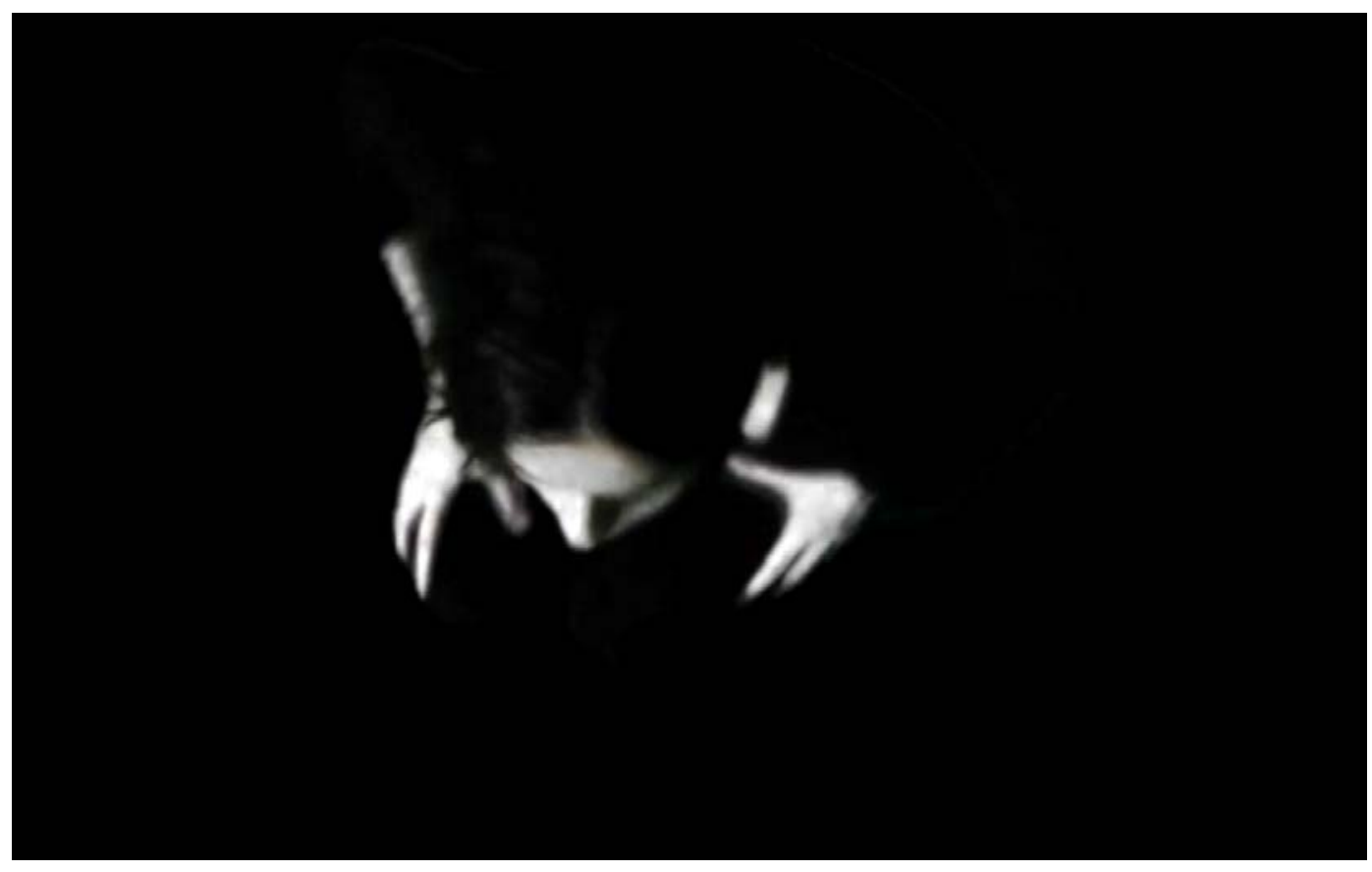

Figura 16.05// Instantes de Metamorfose versão 02, performance: O/hando 


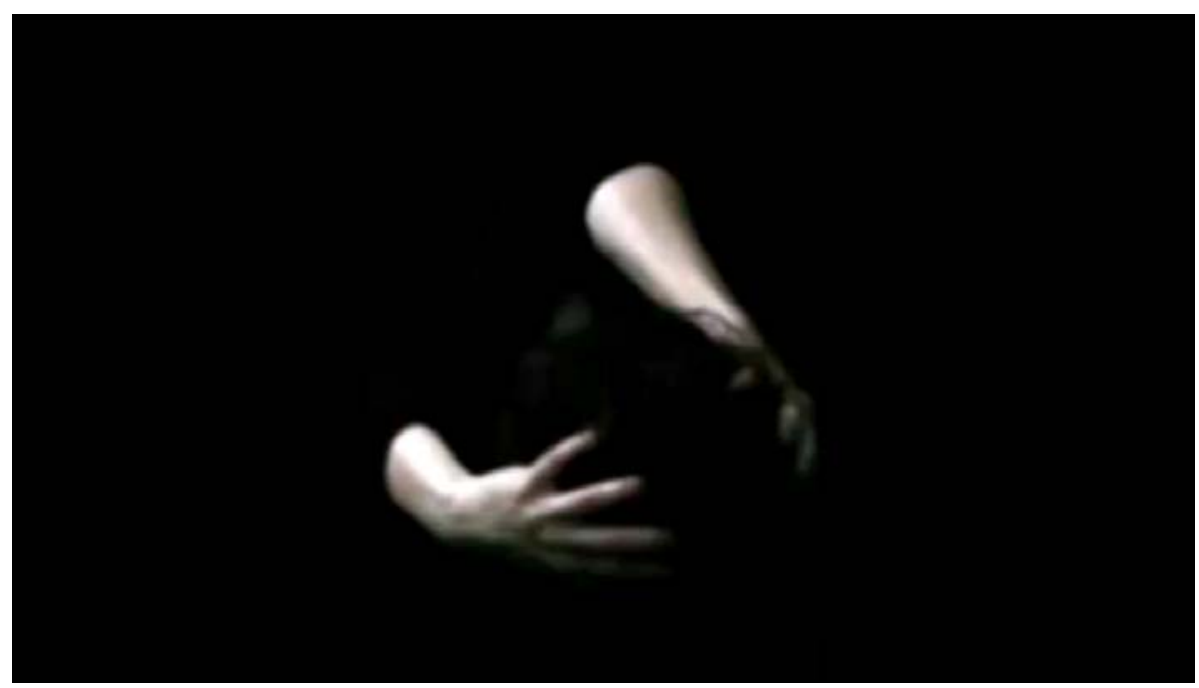

Figura 17.05// Instantes de Metamorfose versão 02, performance: Tocando

Todo o aparato tecnológico e os processos de familiarização e utilização de hardware e software da primeira instalação da série, delinearam a abordagem da utilização de tecnologias e mídias na presente proposta. O código em Processing 1.0.9, que foi ampliado e adaptado a partir do código desenvolvido para Instantes de Metamorfose 01, é a base para a construção dos mecanismos de interatividade via webcam.

A água na instalação, remete aos processos de reflexão, de emergência da consciência na descoberta do próprio Eu através da exploração do mundo pelos sentidos, da exploração e descoberta do corpo e das suas bordas permeáveis, das suas extensões. 0 participante é colocado na posição de observador desses seres que são projetados, mergulhados, através do espelho. Ao mesmo tempo, como um ser imaginário ele mesmo, descalço, interferindo na posição desses seres que vivem do outro lado da superfície, os sujeitos que participam da experiência causam distúrbio, desorganização, iniciando um processo de negociação do espaço que transcende a superfície da água.

Esse espelho d’água que não reflete o sujeito, cria uma descontinuidade na própria construção da realidade e do espaço na experiência na instalação. É nesse ponto que se evidencia a referência ao conto Animais dos Espelhos, de Borges (BORGES, 2007, p. 2627) que transcrevemos na integra: 


\begin{abstract}
Animais dos Espelhos
Em um dos volumes das Cartas edificantes e curiosas, publicadas em Paris durante a primeira metade do século XVIII, o padre Zallinger, da Companhia de Jesus, planejou um exame das ilusões e erros do povo de Cantão; num levantamento preliminar, anotou que o Peixe era um ser fugitivo e resplandecente que ninguém havia tocado, mas que muitos pretendiam ter visto no fundo dos espelhos. O padre Zallinger morreu em 1736, e o trabalho iniciado por sua pena permaneceu inconcluso; cento e cinquenta anos depois, Herbert Allen Giles retomou a tarefa interrompida. De acordo com Giles, a crença do Peixe faz parte de um mito mais amplo, que se refere à época legendária do Imperador Amarelo. Naquele tempo, o mundo dos espelhos e o mundo dos homens não eram, como hoje, incomunicantes. Além disso, eram muito diferentes um do outro; não coincidiam nem os seres nem as cores nem as formas. Os dois reinos, o especular e o humano, viviam em paz; entreva-se e saia-se pelos espelhos. Uma noite o povo do espelho invadiu a Terra. Sua força era grande, mas ao cabo de sangrentas batalhas as artes mágicas do Imperador Amarelo prevaleceram. Ele repeliu os invasores, encarcerou-os nos espelhos e Ihes impôs a tarefa de repetir, como numa espécie de sonho, todos os atos dos homens. Privou-os de sua força e de seu aspecto e reduziu-os a meros reflexos servis. Um dia, contudo, eles se livrarão desse letargia mágica.

O primeiro a despertar será o Peixe. No fundo do espelho perceberemos uma linha muito tênue, e a cor dessa linha será uma cor que não se parece com nenhuma outra. Depois, irão despertando as outras formas. Gradualmente diferirão de nós, gradualmente deixarão de imitar-nos. Romperão as barreiras de vidro ou de metal e desta vez não serão vencidas. Junto com as criaturas dos espelhos combaterão as criaturas da água. (BORGES, 2007, p.26-27).
\end{abstract}

\title{
5.7. Série Instantes de Metamorfose: complexidade e organização
}

Olhando a partir da complexidade para o processo criativo do coletivo O Dup/o, na série Instantes de Metamorfose, podemos considerar que esse processo é um sistema complexo na medida em que apresenta um aspecto de totalidade ou globalidade e um aspecto relacional, verificando-se evidente interrelação entre os integrantes do coletivo (elementos do sistema) e sendo o sistema constituido ele mesmo pelos elementos em inter-relação.

Esse sistema-processo/coletivo é um complexo organizado e adaptativo, na medida em que não responde passivamente aos eventos - a abertura em relação ao ambiente e a troca de informações num diálogo estabelecido, é o que constitui sua própria dinâmica auto-organizacional. A adaptabilidade se deve não só a um alto grau de interatividade entre as partes do sistema, mas à natureza não linear e à intensidade dessas interações. O Modelo Úmido funciona, aqui, como artifício que dá visibilidade à arquitetura sistêmica: 


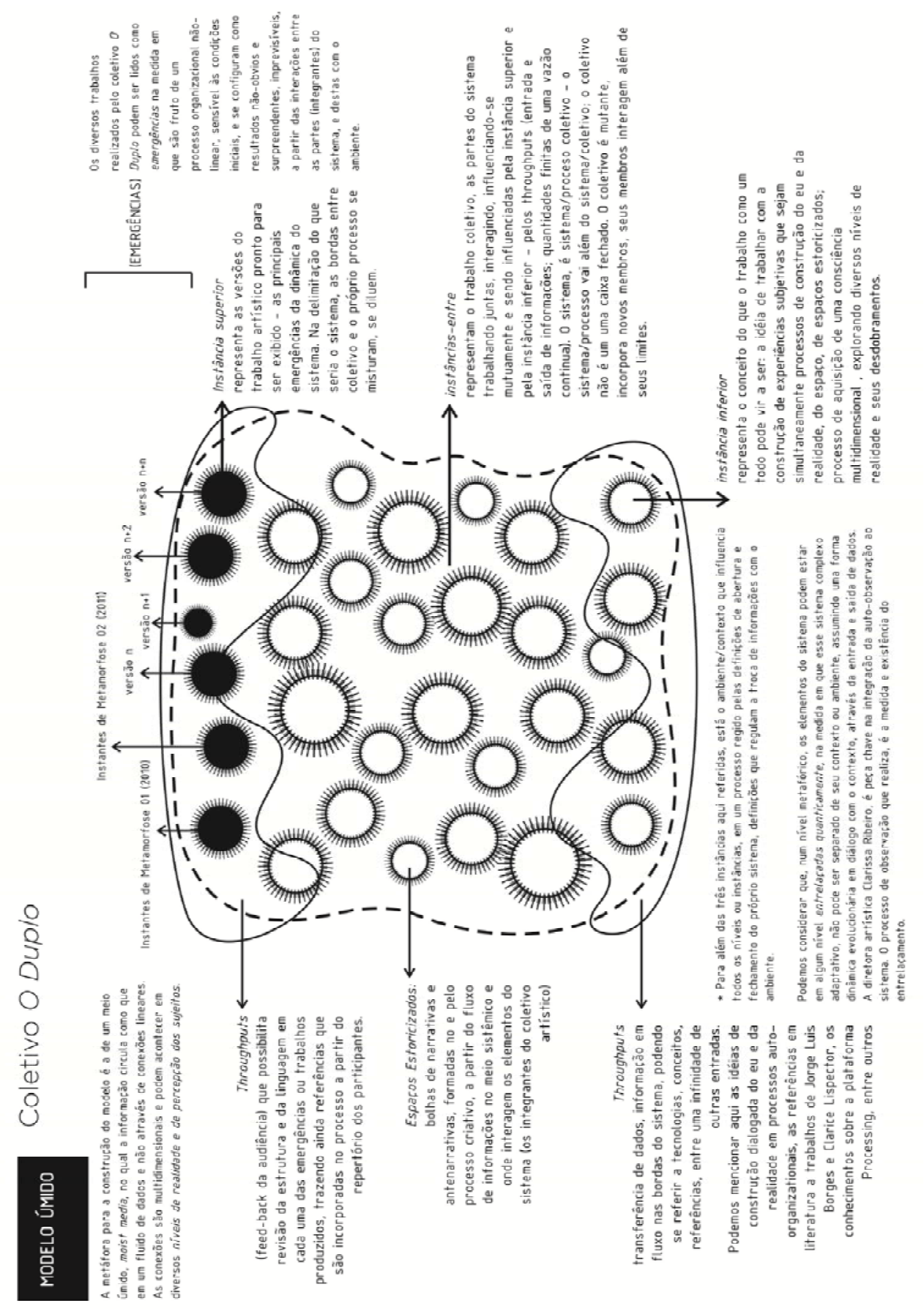

Figura 18.05// Modelo úmido Instantes de Metamorfose (vide anexo C)

200 
As diversas versões da série Instantes de Metamorfose podem ser consideradas emergências, na medida em que, sendo fruto de um processo organizacional não-linear, são resultados não-óbvios, imprevisíveis desse processo. Enquanto emergência, cada uma das versões ou trabalhos artísticos da série, não resulta das ligações entre as partes do todo sistêmico em si, mas da possibilidade de alcance de novos níveis ou instâncias organizacionais dentro do e pelo sistema.

As partes do sistema podem estar em algum nível entrelaçadas quanticamente, na medida em que esse sistema complexo adaptativo não pode ser separado de seu contexto ou ambiente, assumindo uma forma dinâmica evolucionária em diálogo com o contexto, através da entrada e saída de dados.

É a auto-observação integrada ao nosso sistema-processo criativo, na e pela construção de um metapontodevista, que pode definir os entrelaçamentos, as conexões entre as partes, de que forma se influenciam mutuamente em um meio úmido. É como forma de dar visibilidade a esse complexo organizacional que utilizamos o Modelo úmido, relacionando as principais características que caracterizam, segundo nossa análise, o processo criativo coletivo em arte digital um sistema complexo adaptativo. 


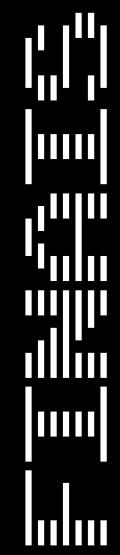

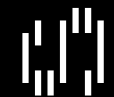

Int

I| ||l|'

$\left.\left.\right|_{I^{I I I}} ^{I}\right|^{I}$

IIIII

IIIIII

III)

IIIIII

Iulul

IIIII)

|피

In

IIII||

Ill III

|IIIII

| 


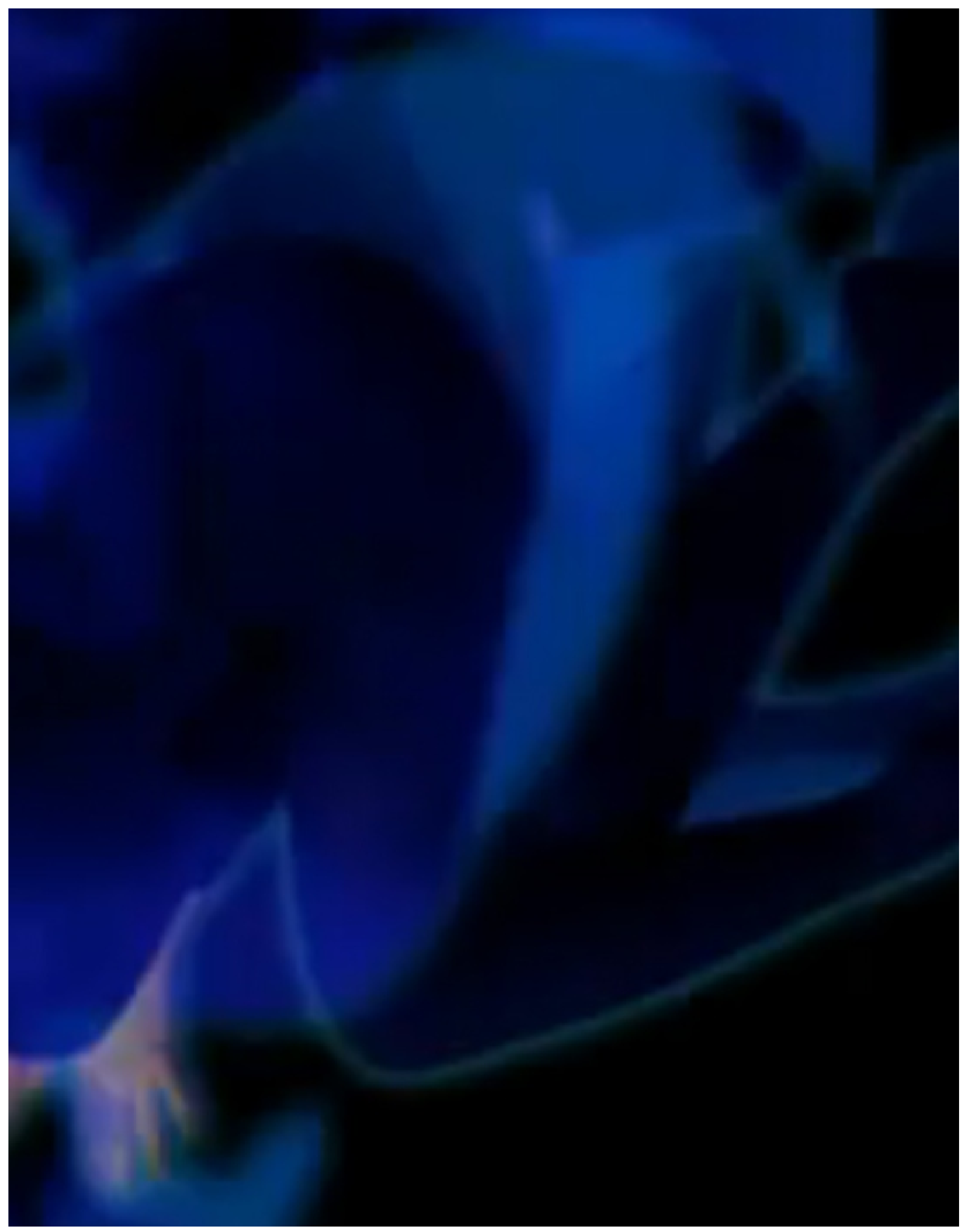


Estas considerações finais constituem uma reflexão sobre as potencialidades, trazidas por um pensar complexo, nos exercícios de teorizar e integrar práticas artísticas coletivas em artes digitais. Estas reflexões podem se apresentar como lentes para observar essas práticas. Simultaneamente, elas podem permitir aos sujeitos envolvidos em processos criativos, entenderem-se como elementos ativos em complexos organizacionais. Dessa forma, articulamos aqui, algumas ideias centrais que atravessam todas as instâncias da pesquisa realizada e que convergiram na abordagem da presente tese.

\section{Espaços Estoricizados}

A consideração da noção de espaços estoricizados ajudou a compreender que, a possibilidade de visualização da estrutura sistêmica em um modelo, poderia contribuir para dar ao sistema visibilidade de si, e influenciar o próprio processo organizacional. Um artifício que poderia interferir na emergência de uma espécie de consciência sistêmica, 
$\mathrm{Na}$ verdade, as coisas que acontecem raramente são as que queremos. Parece que não somos nós que as fazemos, muito embora saibamos que nós é que as fizemos. [...] As coisas se fazem através de nós. O querer se situa em todas as nossas células, no nível, muito precisamente, de suas interações com todos os fatores aleatórios do ambiente. É ai que o futuro se constrói.

Henri Atlan , 1992, p.118-119

dando ao complexo, possibilidade de entendimento de sua natureza auto-organizacional. A partir dessa perspectiva, pudemos entender ainda que, a percepção da estrutura sistêmica, pode ter caráter essencial nos processos de reprodução de eventos pelos eventos eles mesmos.

A partir das discussões levantadas em torno da ideia de espaços estoricizados, foi possível entender, além, que o estudo das interações nos processo criativos, entendidos a partir da perspectiva da complexidade, deve considerar o diálogo do sistema e dos elementos com o ambiente. Dentro dessa compreensão, se torna possível reconhecer que, os indivíduos que participam na interação, nos coletivos artísticos, desempenham outros papéis dentro de outros sistemas que integram. Quando há a aproximação de um novo possível integrante do coletivo, que começa a participar e a dialogar, ele tem que ser introduzido à dinâmica interna do sistema, precisa navegar pelos espaços estoricizados existentes e construídos anteriormente à sua participação. 
No contexto dessa abordagem, foi também possível entender a relação seminal entre ação e comunicação, e de que forma essa relação pode ser a base para a emergência, seja de uma consciência sistêmica ou dos trabalhos artísticos produzidos em processos criativos coletivos em artes digitais.

\section{Transcendendo as fronteiras disciplinares: da ordem a partir do ruído, ao entrelaçamento quântico}

Para que fosse possível estudar os processos criativos coletivos em artes digitais como sistemas complexos adaptativos, a construção de uma teia, relacionando conceitos das ciências -nomeadamente, a biologia, a físico-química, a física quântica - a conhecimentos no âmbito das ciências sociais, da filosofia e da metafísica, desempenhou função basilar. A partir de um cruzamento de referências dessas diversas áreas, numa perspectiva transdisciplinar, foi possível uma aproximação onde as práticas coletivas em artes digitais poderiam, potencialmente, ser consideradas como produtos das inter-relações entre os elementos de uma organização complexa.

A complexidade enquanto ciência de compreender como agentes interagem uns com os outros para se influenciarem mutuamente e ao todo que integram, permitiu entender como o processo criativo coletivo em artes digitais poderia ser considerado organizado e adaptativo. Vimos que isso só seria possível, se ficasse evidente que esse sistema se adaptava ao longo de um processo evolutivo, em diálogo com o meio, se organizando em um sistema ecológico, ajustado em função dessa dinâmica.

Ligando inter-relação e totalidade, a ideia de organização dá estabilidade às ligações entre as partes do sistema e assegura ao todo a possibilidade de duração e de adaptação diante do ruído, das perturbações aleatórias em sua relação com o ambiente. É a partir do momento em que podemos identificar no nosso objeto de estudos essas características, que elas permitem tratar o processo criativo coletivo como um sistema complexo - processo que se confunde com o próprio coletivo enquanto conjunto de elementos, sujeitos, em inter-relação num todo organizado.

No que se refere à questão da emergência, vimos que as definições do conceito, apesar da imensa variedade de abordagens, envolvem o comportamento de algum tipo de sistema complexo, estando, o estudo da emergência, historicamente atrelado ao estudo 
desses sistemas. O panorama em torno da ideia de emergência que procuramos construir na presente abordagem considera ambas as perspectivas filosóficas e científicas contemporâneas em torno do tema. O foco foi entender o que caracterizaria uma emergência aparente, que tem na vida uma fonte vasta de exemplos observáveis, e que podem contribuir para um entendimento primário do próprio conceito, como os fenômenos sociais e ecológicos. Desta forma, a perspectiva do conceito, que adotamos para ponderar sua ocorrência nos processos criativos coletivos em artes digitais, foi a de utilizá-lo para caracterizar certos fenômenos como novidade, não meramente no sentido de algo inesperado, mas no sentido teórico de ser imprevisível. Assim, a emergência se configura com base na informação relativa às partes espaciais ou outros constituintes dos sistemas nos quais esse fenômeno ocorre.

Numa ponte entre complexidade e quântica, descobrimos pesquisas que apontam para a possibilidade de uma caracterização filosófica do entrelaçamento quântico, a partir de uma moldura metafísica - uma metafísica das relações baseada na caracterização do entrelaçamento quântico em termos de não separabilidade, entendendo-o como uma espécie de holismo. A noção de entrelaçamento diz respeito à inseparabilidade dos elementos de um dado conjunto quântico. No contexto da pesquisa, foi importante constatar que pesquisadores, em diversas abordagens, têm expandido essa noção para os domínios macroscópicos, no estudo dos mais diversos sistemas. A partir dessa compreensão, foi possível observar, nos processos criativos, se o grau de inseparabilidade entre os elementos do sistema poderia afetar seus estados, mesmo após essa interação inicial ter cessado, quando esse elemento é submetido a uma observação. Através das dinâmicas de coletar ante-narrativas, na fase de envolvimento com a prática na presente pesquisa, foi possível perceber que era evidente a contaminação, o entrelaçamento, em diversos níveis, entre os elementos do sistema em questão. Em fragmentos de depoimentos dos integrantes do coletivo O Dup/o, como o de Graziele Lautenschlaeger, que citamos a seguir, fica evidente a possibilidade de existência de uma ligação pós-interação no coletivo, entre os integrantes/elementos.

Esse entrelaçamento pode acontecer, por exemplo, no nível das ideias, numa contaminação que se evidencia, no caso, a partir de referências compartilhadas. No fragmento abaixo, a artista integrante da primeira formação do coletivo, agradece aos outros integrantes por terem impulsionado a ler Borges e Clarice Lispector. Segundo 
Lautenschlaeger, "Ambas são referências muito inspiradoras para lidar com universos imateriais, abstratos no nível do pensamento, mas que de alguma forma são um exemplo potente para que artistas sejam tentados a tornar tangiveis através da sugestão de experiências." (LAUTENSCHLAEGER, 2011).

O outro conceito chave, a decoerência de sistemas quânticos abertos, se refere a uma espécie de entrelaçamento universal. Esse fenômeno é definido como consequência do entrelaçamento do sistema com o seu ambiente e remete ao fato de certos sistemas não poderem resistir ao entrelaçamento com seu ambiente, mesmo no caso de interações muito fracas entre seus elementos. O conceito traz a ideia de contaminação entre sistema e ambiente, num processo de influência mútuo. Se considerarmos que os processos criativos coletivos em artes digitais, enquanto sistemas complexos adaptativos, se estruturam em dinâmicas informacionais, em diálogo contínuo com o ambiente, transformando o contexto e sendo transformados por ele, podemos considerar a decoerência como uma perspectiva possível para descrever essas interconexões.

\section{O Modelo Úmido}

Nos exercícios realizados para a estruturação de um modelo e, a partir destes, foi possível identificar uma série de conexões, analisando desenhos e textos produzidos nas dinâmicas. A identificação dessas conexões, que remetia a níveis de percepção dos sujeitos envolvidos, contribuiu para desenhar as relações entre os espaços estoricizados, não a partir de conexões lineares, mas na perspectiva de um Modelo Úmido, onde as inter-relações existem em potência, numa dinâmica fluida, randômica, não-linear.

A intenção é que o modelo estruturado, possa contribuir para dar ao todo sistêmico, visibilidade de sua estrutura, das relações entre os integrantes de coletivos em artes digitais, das relações entre esses coletivos/processos entendidos como sistemas e o contexto, em seus processos auto-organizacionais. Na nossa proposta, os espaços estoricizados podem ser agrupados em 7 (sete) instâncias de organização e significado, em uma estrutura que é um sistema dentro do sistema-processo criativo. As instâncias foram definidas como: impressão, atenção, memória, comparação, julgamento, reflexão, e imaginação. 
É nesse movimento que vai da impressão à imaginação, que os níveis da alegoria de Condillac, em seu Tratado das Sensações, se transformam em sub-instâncias dentro de uma estrutura sistêmica. Essa estrutura se constitui na e pela dinâmica de conceberdesenvolver-exibir trabalhos artísticos, encerrando o próprio processo criativo. Dessa forma, as dinâmicas que envolvem desenho e escrita emergentes, se constituem como uma das bases do processo de construção dos espaços estoricizados. A coleção de espaços estoricizados, que pode crescer com os processos organizacionais em curso, torna visível a dinâmica sistêmica, reintegrando, enquanto informação com significado, o sistema e outros sistemas numa espécie de balé morfogenético.

\section{A construção do Metapontodevista}

A necessidade de envolvimento com a prática artística coletiva, no contexto da presente abordagem, assume caráter essencial na construção do olhar a partir da complexidade. O envolvimento nessas práticas é meio de integrar o sistema que se pretende observar. A noção de sistema em que não há objeto totalmente independente do sujeito, em que não há physis isolável do entendimento humano, de sua lógica, de sua cultura e de sua sociedade, conduz o sujeito, "[...] não apenas a verificar a observação, mas a integrar a auto-observação ao sistema." (MORIN, 2003, p.179). O objeto, seja ele real ou ideal, é um objeto que depende do sujeito.

Morin considera que, a própria relação entre observador e sistema, pode ser traduzida em termos sistêmicos, posto que todo sistema observado, está ligado a outros sistemas de sistemas e "[...] pouco a pouco se une à physis organizada ou Natureza, que é um polissistema de polissistemas" (MORIN, 2003, p.179). O sistema é observado por um sistema nervoso que faz parte de um organismo vivo - um sistema vivo do tipo homo que faz parte de um polissistema social e cultural, fazendo parte, em uma outra escala, do universo antropossocial.

Fazer parte do que se observa, integrando a auto-observação a um sistema que é o processo criativo em artes digitais, constituiu um exercício de construção do que seria, na definição de Edgar Morin (2003, p.180), um metapontodevista: um ponto de vista que permita observar o conjunto constituído pelo observador e sua observação. Para Morin, essa perspectiva simultaneamente proibida e impensável para a ciência clássica, "[...] exige não apenas que o observador se observe a si mesmo observando os sistemas, mas 
também que ele se esforce para conhecer o seu conhecimento." (MORIN, 2003, p.180). Assim, em um percurso que não pode se restringir à realização da pesquisa de doutorado que deu origem à tese, a compreensão das qualidades organizacionais e emergentes dos processos criativos, influencia as experimentações e é influenciada por elas. As referências se cruzam e se misturam; os atores do processo interagem numa rede complexa informacional - estrutura desse sistema que não pode ser definido, compreendido, fora do seu contexto, do seu ambiente.

Os estudos sobre sistemas complexos adaptativos e a realização de estudos de caso sobre o processo criativo de coletivos artísticos na área de artes digitais, se estendendo à participação em práticas artísticas como integrante do grupo Poéticas Digitais, constituíram momentos de construção de uma base a partir da qual observar. Em outro nível de realidade, integrar o coletivo O Duplo, como diretora artística, constituiu artifício para integrar a auto-observação ao sistema.

É a partir de um envolvimento visceral no desenvolvimento dos trabalhos da série Instantes de Metamorfose - na elaboração das ideias, na realização das performances que foi possivel compreender os aspectos de totalidade e o aspecto relacional, que poderiam fazer desse processo um sistema complexo. Somente assumindo essa posição de observador-sistema é que foi possível compreender que o complexo se constrói nas e pelas inter-relações entre os integrantes do coletivo (elementos do sistema), ou seja, o sistema é constituído pelos elementos em inter-relação em dinâmicas que podem ter características generativas. Os elementos podem estar entrelaçados assim como pode estar entrelaçado, numa perspectiva de decoerência, o sistema com o contexto no qual se insere.

A construção desse metapontodevista permitiu entender que, alguns processos criativos coletivos, podem ser considerados complexos organizados e adaptativos, na medida em que, não respondem passivamente a eventos. A adaptabilidade se deve, assim, não só a um alto grau de interatividade entre as partes, mas à natureza não linear e à intensidade das interações. Para ser considerado complexo, esse sistema deve apresentar abertura à troca de informações, o que caracteriza a dinâmica auto-organizacional do sistema. 
É compreendendo de uma forma internalizada essas noções, que pudemos entender os diversos trabalhos realizados pelo coletivo Transmute, relacionados ao desenvolvimento das duas versões da instalação Intimate Transactions, bem como as diversas versões da série Instantes de Metamorfose, desenvolvidas pelo coletivo O Duplo, como emergências da organização sistêmica. Esses trabalhos podem ser considerados emergências, na medida em que, sendo fruto de um processo organizacional não-linear, apresentam características que os revelam resultados não-óbvios, imprevisíveis, dos processos criativos. Enquanto emergência, cada uma das versões ou trabalhos artísticos aqui mencionados, não resulta diretamente das ligações entre as partes do todo sistêmico, mas da possibilidade de alcance de novos níveis ou instâncias organizacionais dentro do e pelo sistema.

Integrando o coletivo O Duplo, foi possível perceber que o processo não podia ser separado de seu ambiente, assumindo uma forma dinâmica evolucionária, em diálogo com o contexto, através da entrada e saída de dados, da incorporação temporária de colaboradores, do feedback da audiência. Assim, a noção de entrelaçamento quântico ajudou a entender a essencialidade dessa interdependência entre sistema e contexto. No entanto, é a partir do momento em que, internalizando conceitos pertencentes a diferentes níveis de realidade, vindos de universos disciplinares distintos dos referenciais teóricos da pesquisa, entendemos que é, no e pelo próprio metapontodevista construído, que esse entrelaçamento é definido. É no e pelo metapontodevista que podemos dizer que o processo criativo coletivo é um sistema complexo adaptativo.

\section{Desdobramentos Futuros}

O olhar construído a partir das ciências da complexidade, numa confluência de saberes que cruzam várias áreas do conhecimento, se construiu, na tese, com o objetivo de dar ao sistema visibilidade de si. Essa perspectiva deu visibilidade, além, aos processos que constituem o próprio sistema. De um modo geral, a construção desse olhar possibilitou um entendimento da fluidez e da aleatoriedade que permeiam os processos criativos coletivos em artes digitais - processos que podem apresentar características generativas e serem estudados como sistemas complexos adaptativos. Esperamos que o olhar que construímos aqui traga, em potência, muitos novos olhares, complexos, para os processos criativos coletivos em artes digitais. 


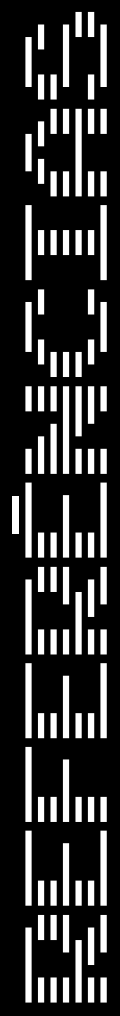




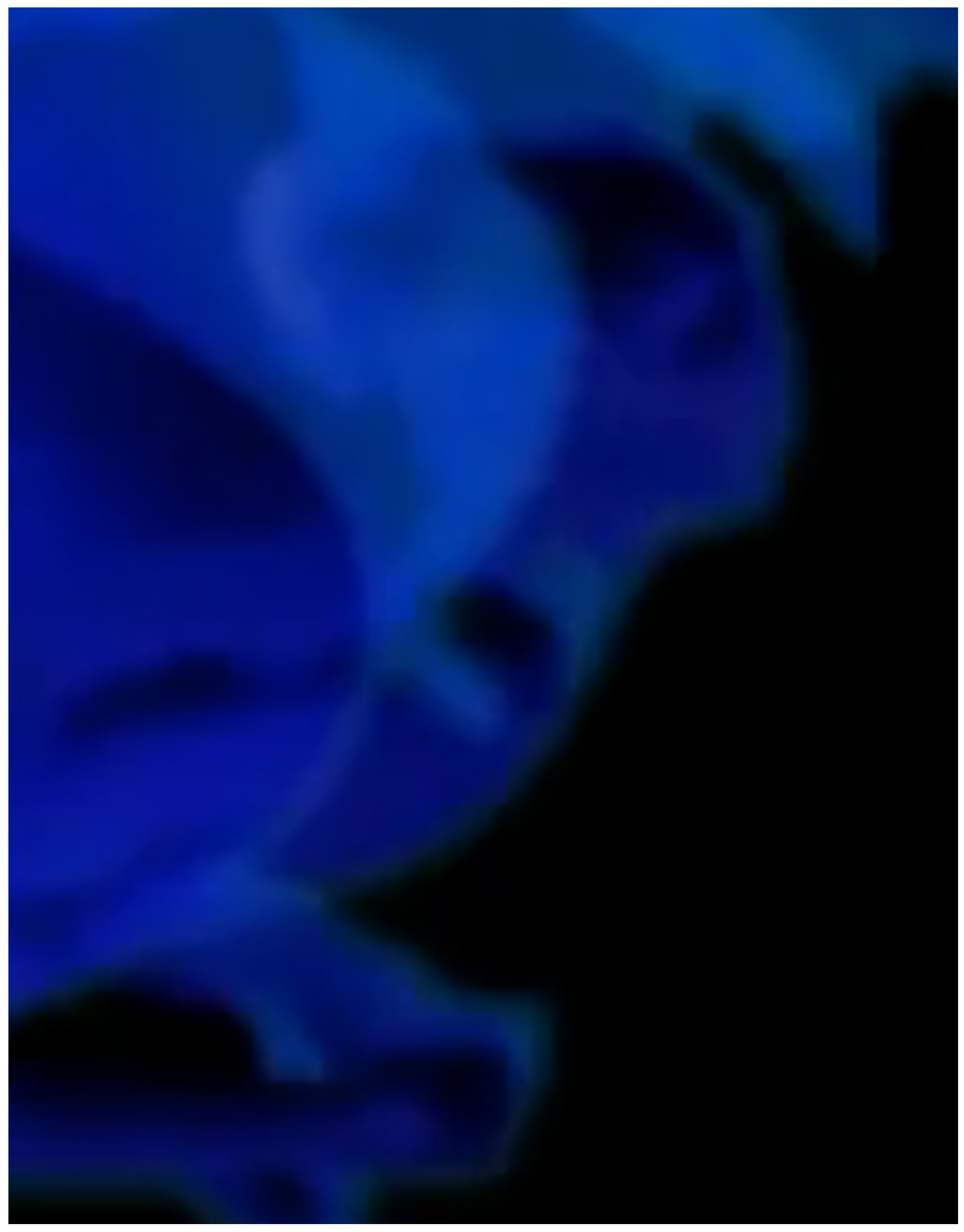




\section{Introdução}

ARMSTRONG, Keith. Towards a Connective and Ecosophical New Media Art Practice. In: JILLIAN, Hamilton (Ed) Intimate Transactions: Art, Exhibition and Interaction Within Distributed Network Environments. Brisbane, Australia: ACID Press, 2006, pp. 12-34.

BOLT, B. Art Beyond Representation: The Performative Power of The Image. New York: I.B. Tauris \& Co Ltda, 2004.

LIPPARD, Lucy R. Six years: the dematerialization of the art object from 1966 to 1972.../ edited and anoted by Lucy R. Lippard. Previously published: New York: Praeger, 1973. London: University of California Press, 1997.

SANTA FE Institute. Santa Fe Institute: complexity research expanding the boundaries of science. Disponível em: < http://www.santafe.edu/about/>. Acesso em: 20 jan. 2011. 
SHAW, Jeffrey. Points of View I: Computergraphic installation, 1983. Disponível em: < http://jeffrey-shaw.net/html_main/show_work.php?record_id=67>. Acesso em: 20 fev. 2011a.

Points of View II - Babel: Computergraphic installation, 1983. Disponível em: <http://jeffrey-shaw.net/html_main/show_work.php?record_id=68>. Acesso em: 20 fev. $2011 b$.

Points of View III - A Three-Dimensional Story: Computergraphic installation, 1984. Disponível em: <http://jeffrey-

shaw.net/html_main/show_work.php?record_id=69>. Acesso em: 20 fev. 2011c.

Reconstructed Points of View (1999). Disponível em:

<http://www.virtualart.at/database/general/work/-667ae3a68e.html>. Acesso em: 13 dez. 2010

UTTERBACK, C. Untitled 6, Camille Utterback, 2005. Disponível em:

<http://www.camilleutterback.com/untitled6.html>. Acesso em: 15 abr. 2010. 


\section{Capítulo 01}

BASKIN, K. Storied Spaces: The Human Equivalent of Complex Adaptive Systems. E:CO Issue, 10(2), 2008, p. 1-12. Disponivel em:

<http://business.nmsu.edu/ dboje/655/articles_655/Baskin_Storied_spaces_pdf.pdf>. Acesso em: 23 dez. 2010.

BATESON, Gregory. Steps to an ecology of mind. London: Chicago: The University of Chicago Press, 1972.

BOJE, David M. Narrative Methods for Organizational and Communication Research. London: Thousand Oaks, New Delhi: SAGE Publications, 2001.

COHEN, J. Why is negentropy, like Phlogiston, a privative? In: International Nonlinear Science Conference, Vienna, Austria 9 February, 2003.

DENNING, S. The Springboard: how storytelling ignites action in knowledge-era Organizations. Oxford: Butterworth Heineman, 2001.

DERRIDA, Jacques. Hospitality, justice and responsibility: A dialogue with Jacques Derrida. In: KEARNEY, Richard; DOOLEY, Mark. Questioning Ethics: Contemporary Debates in Philosophy. London/New York: Routledge, 1999, p. 65-83.

GELL-MANN, M. The Quark and the Jaguar: Adventures in the Simple and Complex. New York: Henry Holt and Company, 1994.

HAYS, Michael K. Foreword. In: BAUDRILLARD, Jean; NOUVEL, Jean. The singular objects of architecture. Translated by Robert Bononno. Foreword by K. Michael Hays. Minneapolis: University of Minnesota Press, 2002.

LEFEBVRE, Henri. The production of space. Translation of: La production de L'espace. Oxford: Blackwell Publishing, 2009.

LIPPARD, Lucy R. Six years: the dematerialization of the art object from 1966 to 1972.../ edited and anoted by Lucy R. Lippard. Previously published: New York: Praeger, 1973. London: University of California Press, 1997.

LUHMANN, N. Essays on Selfreference. New York: Columbia University Press, 1990.

The Autopoiesis of Social Systems. In: GEYER, F. ; ZOUWEN, J. van der. (eds.) Sociocybernetic Paradoxes. London: Sage, 1986, $172 \mathrm{f}$.

MATURANA, Humberto; VARELA, Francisco. A árvore do conhecimento: as bases biológicas da compreensão humana. São Paulo: Palas Athena, 2007. 
MATURANA, H. R. The Nature of the Laws of Nature. Systems Research and Behavioral Science, 17, 2000, p. 459-468.

RASMUSSEN, J. Textual interpretation and complexity: radical hermeneutics. In: The American Educational Research Conference - AERA SIG: Chaos \& Complexity, New Orleans, United States, 1-5 April, 2002.

TSCHUMI, Bernard. Questions of Space: The Pyramid and The Labyrinth (or The Architectural Paradox). Studio International, 190, n. 977, September/October 1975, p.137-142.

\section{Capítulo 02}

AKULIN, V. M.; KURIZKI, G.; LIDAR, D. A. How to control decoherence and entanglement in quantum complex systems? (Editorial) Journal of Physics B: Atomic, Molecular and Optical Physics, n.40, 2007. IOP - Institute of Physics Publishing, 2007. Disponível em: <http://iopscience.iop.org/0953-4075/40/9/EO1>. Acesso em: 03 jan. 2011.

ALMEIDA, Clarissa Ribeiro Pereira de. Entre e Através: Complexidade e Processos de Design em Arquitetura. 2006. 268 f. Dissertação (Mestrado em Arquitetura) Escola de Engenharia de São Carlos da Universidade de São Paulo, São Carlos, 2006.

ASHBY, W. R. Principles of the self -organizing systems. In: VON FOESTER, H.; ZOPF, J.; G. W. (org.). Principles of self-organization. Oxford: Pergamon, 1962, p.255-278.

ATLAN, Henri. Entre o cristal e a fumaça: ensaio sobre a organização do ser vivo Tradução de Vera Ribeiro. Rio de Janeiro: Jorge Zahar Editor Ltda, 1992.

Natural complexity and self-creation of meaning. In: AIDA, S. et al. The science and praxis of complexity. Tokyo: The United Nations University, 1985. Contributions to the Symposium Held at Montpelier, France, 9-11 May, 1984.

BEDAU, Mark; HUMPHREYS, Paul. Emergence: Contemporary Readings in Philosophy and Science. Cambridge, Massachusetts; London, England: The MIT Press, 2008.

BERTALANFFY, L. V. Teoria Geral dos Sistemas. Tradução de Francisco M. Guimarães. 3 ed. Petrópolis: Editora Vozes, 1977, 315p.

BRUZA, P.D.; KITTO, K.; NELSON, D.; MCEVOY, C. L. Entangling Words and Meaning. Proceedings of the Second Quantum Interaction Symposium, College Publications, 2008, p. 118-124

CHALMERS, David. Supervenience. In: BEDAU, Mark; HUMPHREYS, Paul. Emergence: Contemporary Readings in Philosophy and Science. Cambridge, Massachusetts; London, England: The MIT Press, 2008, p. 411-425. 
DUPLATIER, Bertrand; RAIMOND, Jean-Michel; RIVASSEAU, Vincent. (eds). Quantum decoherence: Poincaré Seminar 2005. Progress in Mathematical Physics, 48. Basel: Birkhäuser Verlag, 2005.

DUPlATIER, B.; RIVASSEAU, V. (eds.), Quantum Spaces, Poincaré Seminar 2007. Progress in Mathematical Physics, 53. Basel: Birkhäuser Verlag, 2007.

EINSTEIN, A.; PODOLSKY, B.; ROSEN, N. Can quantum-mechanical description of physical reality be considered complete? Physical Review, vol. 47, may 15, 1935. (A. Einstein, B. Podolsky and N. Rosen, Institute for Advanced Study, Princeton, New Jersey - received March 25, 1935). Disponível em:

<http://prola.aps.org/pdf/PR/v47/i10/p777_1>. Acesso em: 28 dez. 2010.

ESFELD, Michael. Quantum entanglement and a metaphysics of relations. Studies in the History and Philosophy of Modern Physics, 35B, Dec. 2004. Disponivel em: <http://philsci-archive.pitt.edu/1735/1/Entanglement.pdf>. Acesso em: O4 jan. 2011.

GALVE, Fernando; PACHÓN, Leonardo; ZUECO, David. Bringing Entanglement to the High Temperature Limit. Physical Review Letters, n.105, 29 October 2010.

HEMPEL, Carl; OPPENHEIM, Paul. On the idea of Emergence. In: BEDAU, Mark; HUMPHREYS, Paul. Emergence: Contemporary Readings in Philosophy and Science. Cambridge, Massachusetts; London, England: The MIT Press, 2008, p.62-67.

HOU, Yuexian; SONG, Dawei. Characterizing Pure High-order Entanglements in Lexical Semantic Spaces via Information Geometry. Disponível em: <http://www.comp.rgu.ac.uk/staff/ds/papers/17-Hou-Song-QI2009.pdf>. Acesso em: O2 jan. 2010.

KIM, Jaegwon. Supervenience and Mind: selected Philosophical Essays. Cambridge Studies on Philosophy. Cambridge: Cambridge University Press, 2002.

KITTO, Kirsty. Why quantum theory? Association for the Advancement of Artificial Intelligence (www.aaai.org), 2007. Disponível em:

<http://www.users.on.net/ kirsty.kitto/papers/why.pdf>. Acesso em 3 dez. 2011.

LANDSMAN, N.P. Lecture Notes on Hilbert Spaces and Quantum Mechanics. Draft: December 22, 2006. Disponível em:

<http://www.math.ru.nl/ landsman/HSQM2006.pdf>. Acesso em:03 jan. 2011.

MATURANA, Humberto; VARELA, Francisco. A árvore do conhecimento: as bases biológicas da compreensão humana. São Paulo: Palas Athena, 2007.

MCLAUGHLIN, Brian P. The Rise and Fall of British Emergenticism. In: BEDAU, Mark A.; HUMPHREYS, Paul. Emergence: Contemporary Readings in Philosophy and Science. London: The MIT Press, 2008, p. 19-59. 
Emergence and Supervenience. In: BEDAU, Mark; HUMPHREYS, Paul. Emergence: Contemporary Readings in Philosophy and Science. Cambridge, Massachusetts; London, England: The MIT Press, 2008, p. 81-97.

MCLUHAN, M. Os meios de comunicação como extensões do homem. Tradução de Décio Pignatari. São Paulo: Editora Cultrix, 1964. (copyright 1964).

MILL, John Stuart. A System of Logic, Ratiocinative and Inductive. Being a connected view of The Principles of Evidence and The Methods of Scientific Investigation. New York: Harper \& Brother Publishers, 1946.

MILLER, John H.; PAGE, Scott E. Complex Adaptive Systems. Princeton, New Jersey: Princeton University Press, 2007.

MORIN, E. A New Way of Thinking. The UNESCO Courier: February, 1996.

A inteligência da complexidade. São Paulo: Peirópolis, 2000.

- Método 1. A natureza da natureza. Tradução de llana Heineberg. Porto Alegre: Editora Sulina, 2003, $2^{\circ}$ Edição.

Natural History Museum. The Deep Sea exhibition, Waterhouse Gallery, Natural History Museum. London, 28 May - 5 September 2010. Disponível em:

<http://www.nhm.ac.uk/visit-us/whats-on/thedeep/>. Acesso em: 08 jan. 2011.

RAE, Alastair I. M. Quantum Mechanics. Bristol and Philadelphia: IOP Institute of Physics Publishing, 2002. (First edition 1980).

ROBERT GORDON UNIVERSITY. Fifth International Quantum Interaction Symposium 2011. Disponivel em: <http://www.rgu.ac.uk/areas-of-study/subjects/computing/newsand-events/events/quantum-interaction-2011/introduction>. Acesso em: O3 jan. 2011.

SCHRÖDINGER, Erwin. The present situation in quantum mechanics (1935). Tradução de John D. Trimmer. Translation originally published in Proceedings of the American Philosophical Society, 124, 323-38. [And then appeared as Section 1.11 of Part I of Quantum Theory and Measurement (J.A. Wheeler and W.H. Zurek, eds., Princeton university Press, New Jersey 1983).] Disponivel em: <http://www.tuharburg.de/rzt/rzt/it/QM/cat.html\#sect5>. Acesso em: 29 dez. 2010.

What is life? The Physical Aspect of the Living cell. (First published 1944 based on lectures delivered under the auspices of the Dublin Institute for Advanced Studies at Trinity College, Dublin, in February 1943). Disponível em:

<http://whatislife.stanford.edu/LoCo_files/What-is-Life.pdf>. Acesso em: 28 dez. 2010.

SHANNON, C. E. Recent Developments in Communication theory. In: Claude Elwood Shannon: collected Papers. New York: IEEE Press, 1993, p. 190-193.

. The Lattice Theory of Information. In: Claude Elwood Shannon: collected Papers. New York: IEEE Press, 1993. p. 180-183. 
SU, Meng; SLATYER, Tracy R.; FINKBEINER, Douglas P. GIANT GAMMA-RAY BUBBLES FROM Fermi -LAT: AGN ACTIVITY OR BIPOLAR GALACTIC WIND? Disponível em: <http://arxiv.org/PS_cache/arxiv/pdf/1005/1005.5480v3.pdf >. Acesso em: 20 jan. 2011

THOM, René. Structural Stability and Morphogenesis: An Outline of a General Theory of Models. (Translated from the French edition by D.H. Fowler). Massachusetts: Addison Wesley Publishing Company, 1989.

VAN CLEVE, J. Emergence vs. Panpsychism: Magic or Mind Dust? In: TOMBERLIN, J. E. (ed.) Philosophical Perspectives. Vol.4. Atascadero, Cal.: Ridgeview Publishing Company, 1990, p. 215-226.

WALDROP, M. Mitchell. Complexity: The Emerging Science at the Edge of Order and Chaos. New York, London, Toronto, Sidney: Simon \& Schuster Paperback, 1992.

WIENER, N. Cibernética e sociedade: o uso humano dos seres humanos. Tradução de José Paulo Paes. São Paulo: Editora Cultrix, 1954. (copyright, 1950, 1954)

Cibernética; ou contrôle e comunicação no animal e na máquina. Tradução de Gita K. Ghinzberg. São Paulo: Polígono e Universidade de São Paulo, 1970. (copyright, 1948)

YASMIN. Yasmin Discussions: a network of artists, scientists, engineers, theoreticians and institutions promoting collaboration in art, science and technology around the Mediterranean Rim and beyond. Disponível em: <http://www.media.uoa.gr/yasmin/>. Acesso em: 08 jan. 2011.

YATES, F. A. The Art of Memory. Chicago: The University of Chicago Press, 1984. (Orig. 1966)

ZEH, H. Dieter. Roots and Fruits of Decoherence. In: DUPLATIER, Bertrand; RAIMOND, Jean-Michel; RIVASSEAU, Vicent. (eds.) Quantum decoherence: Poincaré Seminar 2005. Progress in Mathematical Physics, 48. Basel: Birkhäuser Verlag, 2006, p.151-175.

\section{Capítulo 03}

ARMSTRONG, K. Towards a Connective and Ecosophical New Media Art Practice. Embodiedmedia: 2006. Disponível em:

<www.embodiedmedia.com/Resources/IntTransBook.pdf >. Acesso em O4 jan. 2011.

BASKIN, K. Storied Spaces: The Human Equivalent of Complex Adaptive Systems. E: CO Issue Vol. 10 No. 22008 pp. 1-12

BERGSON, Henri. Creative Evolution. Los Angeles: Indo-European Publishing, 2010.

Time and free will: an essay on the immediate data of consciousness.

Mineola, New York: Dover Publications Inc., 2001. 
BORGES, Jorge Luis. O Livro dos Seres Imaginários. São Paulo: Companhia das Letras, 2007.

BORGES, J. L. The Book of Imaginary Beings. New York: Penguim Group, 2005.

CARR, G. Preface. In: CONDILLAC, E. B. Treatise on the sensations. Translated by

Geraldine Carr. With a preface by Professor H. Wildon Carr. Lodon: The Favil Press, 1930.

CONDILLAC, E. B. Treatise on the sensations. Translated by Geraldine Carr. With a preface by Professor H. Wildon Carr. London: The Favil Press, 1930.

DESCARTES, René. Discourse on method and the meditations. Translated wich an introdution by F. E. Sutcliffe. Harmondsworth, Middle Sex, England: Penguin Books, 1971. (Penguin Classics)

DIDEROT, Denis. Cartas sobre os surdos-mudos para uso dos que ouvem e falam. São Paulo: Nova Alexandria, 1993.

GRIFFIN, Joanna. Joanna Griffin: Transtechnology Research. Disponivel em: <http://trans-techresearch.net/researchers/joanna-griffin>. Acesso em29 jan. 2011.

Re: No Doc's meeting // Two Metaphysical Animals [mensagem pessoal]. Mensagem recebida por <almeida.clarissa@gmail.com> em 09 abr. 2010.

HÜBLER, A. W. Predicting Complex Systems with a Holistic Approach: The "Throughput" Criterion. In: Complexity, vol.10, n.3. Wiley Periodical Inc., 2005.

INGOLD, Tim. Bringing Things to Life: Creative Entanglements in a World of Materials. Disponível em:

<http://eprints.ncrm.ac.uk/1306/1/0510_creative_entanglements.pdf>. Acesso em: 04 jan. 2011.

KITTO, Kirsty. Why quantum theory? Association for the Advancement of Artificial Intelligence (www.aaai.org), 2007. Disponivel em:

<http://www.users.on.net/ kirsty.kitto/papers/why.pdf>. Acesso em 3 dez. 2011.

LA ROCCA, Renata. Depoimentos: Instantes de Metamorfose. São Paulo, janeiro de 2011.

LISPECTOR, C. Água Viva. Rio de Janeiro: Rocco, 1998.

LOCKE, John. An Essay Concerning Human Understanding. John W. Yolton (ed.) London: Dent, 1972. Volume 1.

MATURANA, Humberto; VARELA, Francisco. A árvore do conhecimento: as bases biológicas da compreensão humana. São Paulo: Palas Athena, 2007.

MIHATA, K. The Persistence of Emergence. In: EVE, Raymond; HORSFALL, Sara; LEE, Mary (ed.). Chaos, Complexity and Sociology: myths, models, and theories. London: Sage, 1997. 
MORIN, E. O Método 1. A natureza da natureza. Tradução de llana Heineberg. Porto Alegre: Editora Sulina, 2003, $2^{\circ}$ Edição.

NICOLESCU, B. Manifest of Transdisciplinarity. New York: Suny Series, 2002.

RACCOON, L. B. S. The Chaos Model and The Chaos Life Cycle. In: ACM SIGSOFT, Software Engineering Notes, vol 20, n 1, January 1995, p. 55-66.

RIBEIRO, Clarissa; NIKOLOV(A), Jennifer Kanary. Bubbles. Initiated by Clarissa Ribeiro and Jennifer Kanary Nikolov(a) (based on a little document called 'ByChancel(12) or (13)'. Disponivel em: <http://www.facebook.com/pages/Bubbles/133809999992423?v=wall>. Acesso em: 07 jan. 2011.

"On Dematerialization: A Collaborative treatise on information, consciousness and imagination Or random conversations around information or a fairy tale". Emergent writing exercise via e-mail. The participants were base most of the time in Plymouth and Amsterdam, from 16 May to 01 August 2010.

SANTAELLA, Lucia; NOTH, Winfried. Imagem: Cognição, Semiótica, Mídia. São Paulo: Iluminuras, 1997.

STRATHERN, Paul. Locke in 90 minutes. London: Constable, 1996.

SUTHAMPTON UNIVERSITY. Wet' computing systems to boost processing power. Disponivel em:

<http://www.southampton.ac.uk/mediacentre/news/2010/jan/10_03.shtml>. Acesso em: 11 jan. 2011.

TRANSTECH. Transtechnology Research. Disponível em: <http://transtechresearch.net/>. Acesso em: 29 jan. 2011.

VARELA, F. J. Principles of Biological Autonomy. New York, NY: Elsevier North Holland, 1979.

VINES, John. John Vines, Transtechnology Research. Disponível em: <http://transtechresearch.net/researchers/john-vines>. Acesso em 29 jan. 2011.

Re: No Doc's meeting // Two Metaphysical Animals [mensagem pessoal]. Mensagem recebida por <almeida.clarissa@gmail.com> em 09 abr. 2010.

YOLTON, J. W. The Philosophy of the essay. In: LOCKE, John. An Essay Concerning Human Understanding. John W. Yolton (ed.) London: Dent, 1972. Volume 1.

\section{Capítulo 04}

ARMSTRONG, Keith. Intimate Transactions: The Evolution of an Ecosophical Networked Practice. Disponível em:

<http://journal.fibreculture.org/issue7/issue7_armstrong.html>. Acesso em: 21 jan. 2011. 
Grounded media: expanding the scope of ecological art practices within new media arts culture. Media-Space Journal (1 - New Media Art - Past, Present, Futures), 2008.

Towards a Connective and Ecosophical New Media Art Practice. In: JILLIAN, Hamilton (Ed) Intimate Transactions: Art, Exhibition and Interaction Within Distributed Network Environments. Brisbane, Australia: ACID Press, 2006, p. 12-35.

ARMSTRONG, K.; O'NEILL, L.; MARKS, B. Grounded Light. Promenade Performance and Installation on Mountain, Floating Land Festival, 2003, Mount Tinbeerwah, Noosa, 2003. Disponivel em:

<http://www.embodiedmedia.com/projects/groundlight/glightbase.html>. Acesso em: 7 jan. 2007.

ARMSTRONG, K.; VINCENT, C.; WEBSTER, G. Shifting Intimacies. Interactive, Sensed Space Installation With Dual Screens and Dust Covered Floor. London: Institute of Contemporary Art, 2006. Disponivel em:

<http://www.embodiedmedia.com/projects/groundlight/glightbase.html>. Acesso em: 7 jan. 2007.

ASCOTT, Roy. The Ambiguity of Self: living in a variable reality. In: IX Consciousness Reframed Conference Vienna 2008. Vienna: University of Applied Ars, July 3-5, 2008. New York: Springer, 2008, p.22-25.

Engineering Nature: Art \& Consciousness in the Post-Biological Era. Bristol: Intellect, 2006.

Telematic Embrace: Visionary Theories of Art, Technology, and Consciousness. Edited and with an essay by Edward A. Shanken. London: University of California Press, 2003.

Chapter 14 GESAMTDATENWERK: Connectivity, Transformation, and Transcendence. In: ASCOTT, Roy. Telematic Embrace: Visionary Theories of Art, Technology, and Consciousness. Edited and with an essay by Edward A. Shanken. London: University of California Press, 2003, p. 222-226.

ASCOTT, Roy; GANGVIK, Espen; JAHRMANN, Margarete. The 11 Annual International Research Conference, Consciousness Reframed: Art and Consciousness in the PostBiological Era, Making Reality Really Real, November 4-6, Trondheim, Norway., covered by TEKS - Trondheim Arts Centre. Trondheim: TEKS Publishing, 2010.

BAKER, Elizabeth. Ecological Being/Being Ecological: Self, Morality, and the Environmental Exigency. Queensland, Australia: 1997. (Unpublished Ph.D Thesis, Faculty of Science, Griffith University).

BUTLER, Judith. Bodies That Matter: On the Discursive Limits of Sex. New York: Routledge, 1993 
Como os corpos se tornam matéria: entrevista com Judith Butler. Estudos Feministas, v.1, n.163, janeiro de 2002, p. 155-167. Entrevista por: Irene Costera Meijer e Baukje Prins. Tradução de Susana Bornéo Funck. Publicado originalmente como How Bodies Come to Matter: An interview with Judith Butler em Signs: Journal of Women in Culture and Society, v. 23, n. 2, p. 275-286. The University of Chicago Press: 1998.

The Body You Want: Liz Kotz interviews Judith Butler. Artforum, v. 31, n. 3, November 1992. p. 82-89.

CALVINO, Ítalo. A nuvem de Smog. In: CALVINO, Ítalo. Os amores difíceis. São Paulo: Companhia das Letras, 1992, p.189-242.

CARROLI, Linda. Intimate Transactions: Transmute (2004). Disponível em: <http://www.fineartforum.org/Backissues/Vol_18/faf_v18_n02/faftext/faftext_index.htm I> Acesso em: 28 nov. 2007.

CARTER, P. The Lie of the Land. London \& Boston: Faber and Faber, 1996.

DOURISH, Paul. Where the Action Is. Massachusetts: MIT Press, December 2001.

EMBODIEDMEDIA. Knowmore (House of Commons). Disponível em: <http://www.embodiedmedia.com/\#/page/Knowmore-house-ofcommons>. Acesso em: 2 dez. 2008

FRY, Tony. Intimate Transactions: Close Encounters of Another Kind. Disponível em: <http://www.geoproject.org.au/geo/01_cms/details.asp?ID=401>. Acesso em: 09 jan. 2011.

GUATTARI, Felix. The ecosophic object. In: Chaosmosis: an ethico-aesthetic paradigm (trans Paul Bains and Julian Pefanis). Sydney: Power Publications, 1995, p 119.

Caosmose: um novo paradigma estético. Tradução de Ana Lúcia de Oliveira e Lúcia Cláudia Leão. São Paulo: Ed. 34, 1992. (Coleção TRANS)

GRAU, Oliver. Virtual Art: From Illusion to Immersion. Cambridge: The MIT Press, 2003.

HAMILTON, Jillian G. A reformation of space: intimate transactions in art and distributed communication. In: HAMILTON, Jillian G. (Ed) Intimate Transactions: Art, Exhibition and Interaction within Distributed Network Environments. ACID (Australasian CRC for Interaction Design). Brisbane Australia, 2006, p. 116-129.

KITTO, Kirsty. Why quantum theory? Association for the Advancement of Artificial Intelligence (www.aaai.org), 2007. Disponível em:

<http://www.users.on.net/ kirsty.kitto/papers/why.pdf>. Acesso em 3 dez. 2011.

NAESS, Arne. The Shallow and the Deep, Long-Range Ecology Movement. Inquiry 16: 95-100, 1973. Disponivel em:

<http://www.ecology.ethz.ch/education/Readings_stuff/Naess_1973.pdf>. Acesso em: 10 jan. 2011. 


\section{Capítulo 05}

ANSELL-PEARSON, Keith. Bergson and creative evolution/involution. In: MULLARKEY, John. (ed.) The New Bergson. Manchester, New York: Manchester University Press, 1999

ARDUINO. Open source prototype plataform. Disponível em: <http://www.arduino.cc/>. Acesso em 20 jan. 2011.

ASCOTT, Roy. Telematic Embrace: Visionary Theories of Art, Technology, and Consciousness. Edited and with an essay by Edward A. Shanken. London: University of California Press, 2003.

BEGOTTEN. Direção: Merhige, E. Elias. Produção: Theatre Of Material. Intérpretes: Brian Salzburg, Donna Dempsey and Stephen Charles Barry. Roteiro: Merhige, E. Elias. New York: Theatre Of Material, 1990. Uma bobina cinematográfica (78 min), son. Black and White, $35 \mathrm{~mm}$.

BENDER, Tom. Environmental design primer. Minneapolis: Rain Magazine, 1973.

BORGES, Jorge Luis. O Livro dos Seres Imaginários. Tradução de Heloisa Jahn. São Paulo: Companhia das Letras, 2007.

Animais dos Espelhos. In: BORGES, Jorge Luis. O Livro dos Seres Imaginários. Tradução de Heloisa Jahn. São Paulo: Companhia das Letras, 2007, p.26-27.

Dois animais metafísicos. In: BORGES, Jorge Luis. O Livro dos Seres

Imaginários. Tradução de Heloisa Jahn. São Paulo: Companhia das Letras, 2007, p.28-29.

The Book of Imaginary Beings. New York: Penguin Group, 2005.

O jardim das veredas que se bifurcam. In: BORGES, J. L. Ficções. Tradução de Carlos Nejar. São Paulo: Globo, 2001, p. 101-114.

/ CONDILLAC, E. B. Treatise on the sensations. Translated from French by Geraldine Carr. Preface by Professor H. Wildon Carr. London: The Favil Press, 1930. (Originally published in 1754).

FISCHER, Scott S. Virtual Environments, Personal Simulation \& Telepresence. In: DRUCKREY, Timothy (ed.) Ars Electronica: Facing the Future: A survey of two decades. Cambridge, Massachusetts, and London, England: The MIT Press, 1999.

FOUCAULT, M. Of Other Spaces. [online]. Translated from French by Jay Miskowiec. Foucault info project, 1967. Disponivel em: <http://foucault.info/documents/heteroTopia/foucault.heteroTopia.en.html>. Acesso em: 15 jan. 2011.

INSTANTS OF METAMORPHOSIS (Blog). Stories Spaces v.01. Disponível em: < http://instantsofmetamorphosis.blogspot.com/search/label/Storied\%20Spaces\%20v.01>. Acesso em: 15 jan. 2011. 
LADYGOGOGOCH (Blog). Instants of Metamorphosis. Disponível em:

<http://ladygogogoch.blogspot.com/search/label/Instants\%20of\%20Metamorphosis>. Acesso em 15 jan. 2011.

Let's Processing. Disponível em:

<http://ladygogogoch.blogspot.com/search/label/Let's\%2OProcessing\%2O//>. Acesso em 15 jan. 2011.

LA ROCCA, Renata. Arte da Memória e Arquitetura. 2007. 241f. Dissertação (Mestrado em Arquitetura) Escola de Engenharia de São Carlos da Universidade de São Paulo, São Carlos, 2007.

Instantes de Metamorfose: Depoimentos. 07 e 08 de Janeiro de 2011, Limeira, São Paulo, Brasil.

LAUTENSCHLAEGER, Graziele. Workshop. [mensagem pessoal]. Mensagem recebida por<almeida.clarissa@gmail.com>em 25 jun. 2009.

Don't Give Up! About a history that doesn't want to be told. Disponivel em: <http://www.youtube.com/videosdagra\#p/a/u/2/KbSQ8bVTV6k>. Acesso em: 14 jan. 2011

Depoimentos sobre a participação no coletivo O Duplo. Disponível em:

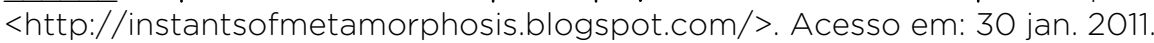

LAUTRÉAMONT, Conde de. Os Cantos de Maldoror. Tradução de Claudio Willer. São Paulo: Vertente Editora, 1970. (pseudônimo do poeta francês de origem uruguaia Isidore Ducasse)

INTERFACE CULTURE PROGRAM. Linz University of Arts. Disponível em: < <http://www.ufg.ac.at/index.php?id=1594\&L=1>. Acesso em: 14 jan. 2011.

LISPECTOR, C. The Stream of Life. Translated from Portuguese by Elizabeth Lowe and Earl Fitz. Foreword by Hélène Cixous translated by Verena Conley. Minnesota: University of Minnesota Press, 1995.

Água Viva. Rio de Janeiro: Rocco, 1998.

MORIN, E. O Método 1. A natureza da natureza. Tradução de llana Heineberg. Porto Alegre: Editora Sulina, 2003, $2^{\circ}$ Edição.

NASCIMENTO, Herbert. Antenarrativa: coletada através de transcrição de vídeo Dezembro de 2010, Limeira, São Paulo, Brasil.

NOMADS.USP. Linhas de Pesquisa. Disponível em:

<http://www.nomads.usp.br/site/mapa_astral/maO1/linhas_pesquisa.html>. Acesso em: 20 jan. 2011. 
OPEN WONDERLAND. Open Wonderland. Disponivel em:

<http://openwonderland.org/>. Acesso em: 20 jan. 2011.

\#8ART. $8^{\circ}$ Encontro Internacional de Arte e Tecnologia (\#8ART): arte, tecnologia e territórios ou a metamorfose das identidades, de 16 a 20 de Setembro de 2009, Brasília, DF. Coordenação Geral: Suzete Venturelli. Disponível em: <http://www.fav.ufg.br/8art/>. Acesso em: 15 jan. 2011.

PRADO, Gilbertto. RES: // LED RGB. [mensagem pessoal]. Mensagem recebida por <poeticas-digitais@googlegroups.com> em 10 mai. 2009.

Re: Reunião do Grupo Poéticas Digitais [mensagem pessoal]. Mensagem recebida por<laurentz@uol.com.br>; <assiralc1@yahoo.com>; <fabiofon@gmail.com>; <helia@actualis.com.br>; <rcecilio@usp.br>; <helia.vannucchi@gmail.com <andreithomaz@gmail.com>; <luisgbg@yahoo.com.br>; <mauriciotaveira@gmail.com>. em 05 mar. 2007.

Gilbertto Prado Projetos: Desertesejo. Disponível em:

<http://www.cap.eca.usp.br/gilbertto/desertesejo.html>. Acesso em: 13 jan. 2011.

Grupo Poéticas Digitais: Principais Trabalhos. Disponível em:

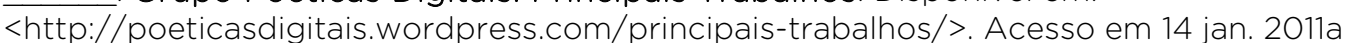

Re: Incognito [mensagem pessoal]. Mensagem recebida por <almeida.clarissa@gmail.com>em 04 fev. 2011b.

PROCESSING. Programming language. Disponível em: <http://processing.org/>. Acesso em 20 jan. 2011.

RIBEIRO, Clarissa; LA ROCCA, Renata. Instants of Metamorphosis. Disponível em: <http://instantsofmetamorphosis.blogspot.com/>. Acesso em: 14 jan. 2011

RIBEIRO, Clarissa. Ladygogogoch. Disponível em:

<http://ladygogogoch.blogspot.com/>. Acesso em: 14 jan. 2011.

ROKEBY, David. Very Nervous System. Disponível em:

<http://homepage.mac.com/davidrokeby/vns.html>. Acesso em: 15 jan. 2011.

Transforming Mirrors: Subjectivity and Control in Interactive Media

Disponível em: <http://homepage.mac.com/davidrokeby/mirrors.html>. Acesso em: 15 jan. 2011

SOLFA, Marilia. Instantes de Metamorfose (dinâmica). [mensagem pessoal]. Mensagem recebida por<almeida.clarissa@gmail.com>.em 4 jan. 2011.

TATE Modern. The Unilever Series: Rachel Whiteread: EMBANKMENT, 11 October 2005 - 1 May 2006. Disponível em:

<http://www.tate.org.uk/modern/exhibitions/whiteread/default.shtm>. Acesso em: 15 jan. 2011 
TATE Collection. Mary Martin, Spiral Movement, 1951 (Oil on board, object: $457 \times 457 \times$ $95 \mathrm{~mm}$, relief, Purchased 1963). Disponivel em:

<http://www.tate.org.uk/servlet/ViewWork? workid=9348\&roomid=6247>. Acesso em: 15 jan. 2011.

TONONI, Giulio. Consciousness as Integrated Information: a Provisional Manifesto. Disponível em: < http://www.biolbull.org/cgi/content/full/215/3/216> Acesso em: 15 jan. 2011.

VALBUENA, Pablo. Augmented Sculpture series. Disponível em: <http://www.pablovalbuena.com/>. Acesso em: 14 jan. 2011.

\section{Considerações Finais}

BORGES, Jorge Luis. O Livro dos Seres Imaginários. Tradução de Heloisa Jahn. São Paulo: Companhia das Letras, 2007.

LAUTENSCHLAEGER, Graziele. Depoimentos sobre a participação no coletivo O Duplo. Disponível em: <http://instantsofmetamorphosis.blogspot.com/>. Acesso em: 30 jan. 2011.

LISPECTOR, Clarice. Água Viva. Rio de Janeiro: Rocco, 1998.

MORIN, E. O Método 1. A natureza da natureza. Tradução de llana Heineberg. Porto Alegre: Editora Sulina, 2003, $2^{\circ}$ Edição. 


\section{ICONOGRAFIA}

\section{Capítulo 01}

Figura 1.01 // Fonte: LIPPARD, Lucy R. Six years: the dematerialization of the art object from 1966 to 1972 .../ edited and anoted by Lucy R. Lippard. Previously published: New York: Praeger, 1973. London: University of California Press, 1997, p. 167

\section{Capítulo 02}

Figura 1.02 // Fonte: GALVE, Fernando; PACHÓN, Leonardo; ZUECO, David. Bringing Entanglement to the High Temperature Limit. Physical Review Letters, n.105, 29 October 2010.

Figura 2.02 // Fonte: MORIN, E. O Método 1. A natureza da natureza. Tradução de llana Heineberg. Porto Alegre: Editora Sulina, 2003, $2^{\circ}$ Edição, p. 133

\section{Capítulo 03}

Figura 1.03 // Fonte: MORIN, E. O Método 1. A natureza da natureza. Tradução de llana Heineberg. Porto Alegre: Editora Sulina, 2003, $2^{\circ}$ Edição, p. 96

Figura 2.03 // Fonte: Imagem da autora.

Figura 3.03 // Fonte: SUTHAMPTON UNIVERSITY. Wet' computing systems to boost processing power. Disponível em: <http://www.southampton.ac.uk/mediacentre/news/2010/jan/10_03.shtml>. Acesso em: 11 jan. 2011.

Figura 4.03 // Fonte: Imagem da autora.

Figura 5.03 // I Fonte: magem da autora.

Figura 6. 03 // Fonte: Imagem da autora.

Figura 7. 03 // Fonte: Imagem da autora.

\section{Capítulo 04}

Figura 1.04 // Fonte: STERK. S. Intimate Transactions. Disponível em: <http://eprints.qut.edu.au/397/1/Armstrong_pixelraiders.PDF>. Acesso em30 jan. 2011.

Figura 2.04 // Fonte: HARGREAVES, P. Grounded Light. Disponível em: <http://eprints.qut.edu.au/8802/1/c8802.pdf>. Acesso em 30 jan. 2011.

Figura 3.04 // Fonte: HARGREAVES, P. Grounded Light. Disponivel em: <http://eprints.qut.edu.au/8802/1/c8802.pdf>. Acesso em 30 jan. 2011.

Figura 4.04 // Fonte: ARMSTRONG, K. Shifting Intimacies. Disponível em <http://eprints.qut.edu.au/8802/1/c8802.pdf >. Acesso em: 30 jan. 2011

Figura 5.04 // Fonte: ARMSTRONG, K. Shifting Intimacies. Disponível em: <http://eprints.qut.edu.au/8802/1/c8802.pdf>. Acesso em: 30 jan. 2011. 
Figura 6.04 // Fonte: ARMSTRONG, K. In_Step. Disponível em:

<http://eprints.qut.edu.au/8802/1/c8802.pdf>. Acesso em: 30 jan. 2011.

Figura 7.04 // Fonte: ARMSTRONG, K. Towards a Connective and Ecosophical New Media Art Practice. Embodiedmedia: 2006. Disponível em:

<www.embodiedmedia.com/Resources/IntTransBook.pdf >. Acesso em 04 jan. 2011

Figura 8.04 // Fonte: ARMSTRONG, K. Towards a Connective and Ecosophical New Media Art Practice. Embodiedmedia: 2006. Disponível em:

<www.embodiedmedia.com/Resources/IntTransBook.pdf >. Acesso em 04 jan. 2011

Figura 9.04 //. Fonte: ARMSTRONG, Keith. Intimate Transactions: The Evolution of an Ecosophical Networked Practice. Disponivel em:

<http://journal.fibreculture.org/issue7/issue7_armstrong.html>. Acesso em: 21 jun. 2008.

Figura 10.04 // Fonte: LAWSON, S. Intimate Transactions. Disponível em:

<http://www.geoproject.org.au/geo/01_cms/details.asp?ID=396>. Acesso em: 30 jan. 2011.

Figura 11.04 // Fonte: LAWSON, S. Intimate Transactions. Disponível em:

<http://www.geoproject.org.au/geo/01_cms/details.asp?ID=396>. Acesso em: 30 jan. 2011.

Figura 12.04 // Fonte: LAWSON, S. Intimate Transactions. Disponível em:

<http://www.geoproject.org.au/geo/01_cms/details.asp?ID=396>. Acesso em: 30 jan. 2011.

Figura 13.04 // Fonte: FISH, E. Intimate Transactions. Disponível em:

<http://www.geoproject.org.au/geo/01_cms/details.asp?ID=396>. Acesso em: 30 jan. 2011.

Figura 14.04 // Fonte: ARMSTRONG, K. Intimate Transactions. Disponível em:

<http://www.geoproject.org.au/geo/01_cms/details.asp?ID=396>. Acesso em: 30 jan. 2011.

Figura 15.04 // Fonte: ARMSTRONG, K. Intimate Transactions. Disponível em:

<http://www.geoproject.org.au/geo/01_cms/details.asp?ID=396>. Acesso em: 30 jan. 2011.

Figura 16.04 // Fonte: LAWSON, S. Intimate Transactions. Disponível em:

<http://www.geoproject.org.au/geo/01_cms/details.asp?ID=396>. Acesso em: 30 jan. 2011.

Figura 17.04 // Fonte: MCLEOD, D. Intimate Transactions. Disponível em:

<http://www.geoproject.org.au/geo/01_cms/details.asp?ID=396>. Acesso em: 30 jan. 2011.

Figura 18.04 // Fonte: ARMSTRONG, K. Intimate Transactions. Disponível em:

<http://www.geoproject.org.au/geo/01_cms/details.asp?ID=396>. Acesso em: 30 jan. 2011.

Figura 19.04 // Fonte: Imagem da autora.

\section{Capítulo 05}

Figura 1.05// Fonte: POÉTICAS DIGITAIS. Principais Trabalhos. Disponível em: <http://poeticasdigitais.wordpress.com/>. Acesso em: 30 jan. 2011.

Figura 2.05// Fonte: POÉTICAS DIGITAIS. Principais Trabalhos. Disponível em: <http://poeticasdigitais.wordpress.com/>. Acesso em: 30 jan. 2011

Figura 3.05// Fonte: POÉTICAS DIGITAIS. Principais Trabalhos. Disponível em: <http://poeticasdigitais.wordpress.com/>. Acesso em: 30 jan. 2011. 
Figura 4.05// Fonte: Imagem da autora.

Figura 5.05// Fonte: Imagem da autora.

Figura 6.05// Fonte: STUDIO AZZURRO. Ambientes Sensibles. Catálogo da Exposição Ambientes Sensibles, Sala Parapalló, 23 enero al 6 de abril de 2008. p.217

Figura 7.05// Fonte: Imagem da autora.

Figura 8.05// Fonte: TATE Collection. Mary Martin, Spiral Movement, 1951 (Oil on board, object: $457 \times 457 \times 95 \mathrm{~mm}$, relief, Purchased 1963). Disponível em:

<http://www.tate.org.uk/servlet/ViewWork? workid=9348\&roomid=6247>. Acesso em: 15 jan. 2011.

Figura 9.05// Fonte: VALBUENA, Pablo. Augmented Sculpture series. Disponível em: <http://www.pablovalbuena.com/>. Acesso em: 14 jan. 2011.

Figura 10.05// Fonte: TATE Modern. The Unilever Series: Rachel Whiteread: EMBANKMENT, 11 October 2005 - 1 May 2006. Disponível em:

<http://www.tate.org.uk/modern/exhibitions/whiteread/default.shtm>. Acesso em: 15 jan. 2011.

Figura 11.05// Fonte: Imagem da autora.

Figura 12.05// Fonte: Imagem da autora.

Figura 13. 05// Fonte: Imagem da autora.

Figura 14.05// Fonte: Imagem da autora.

Figura 15.05// Fonte: Imagem da autora.

Figura 16.05// Fonte: Imagem da autora.

Figura 17.05// Fonte: Imagem da autora.

Figura 18.05// Fonte: Imagem da autora. 


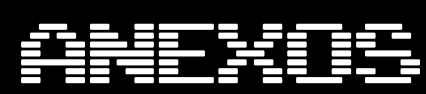




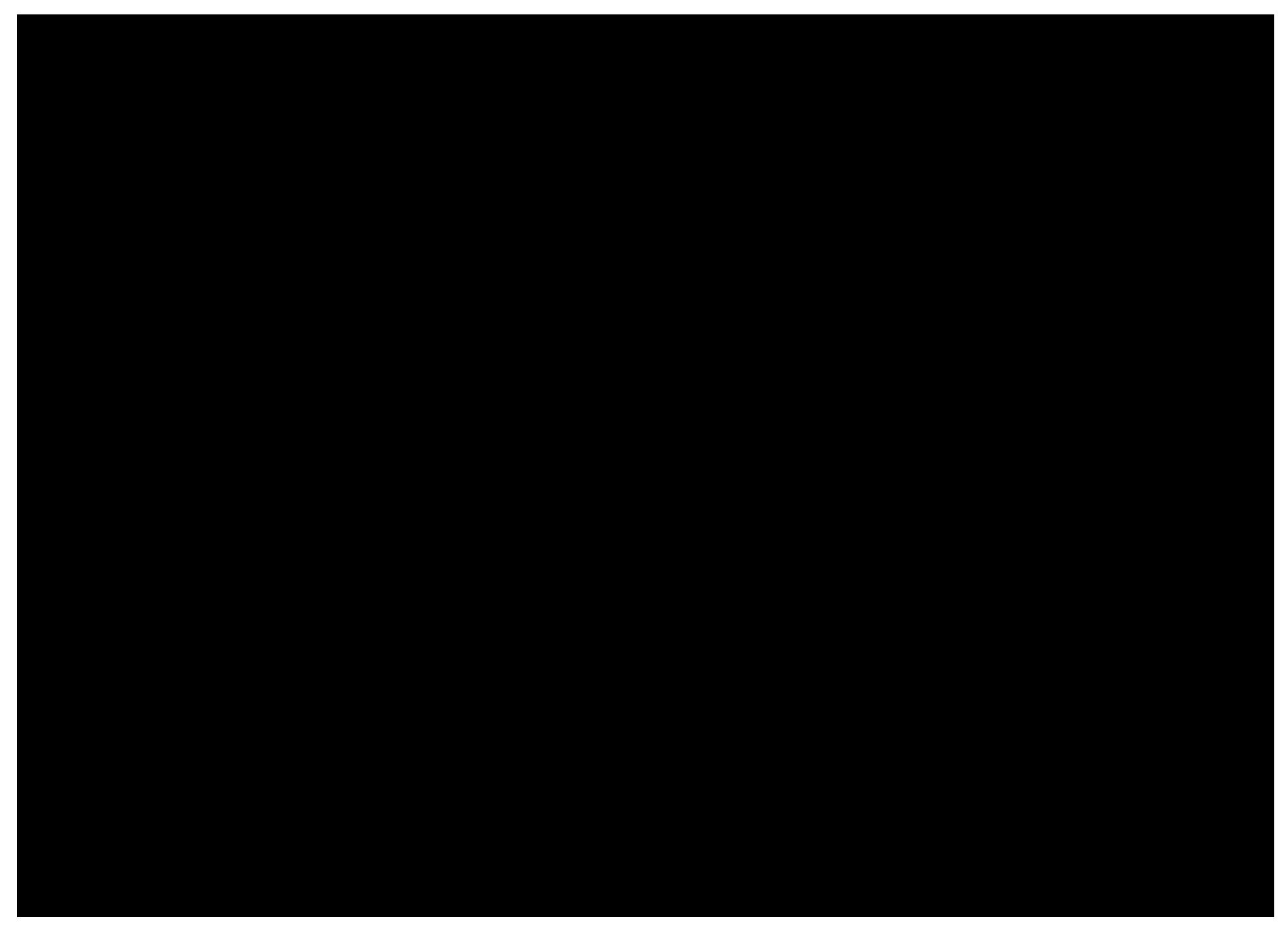





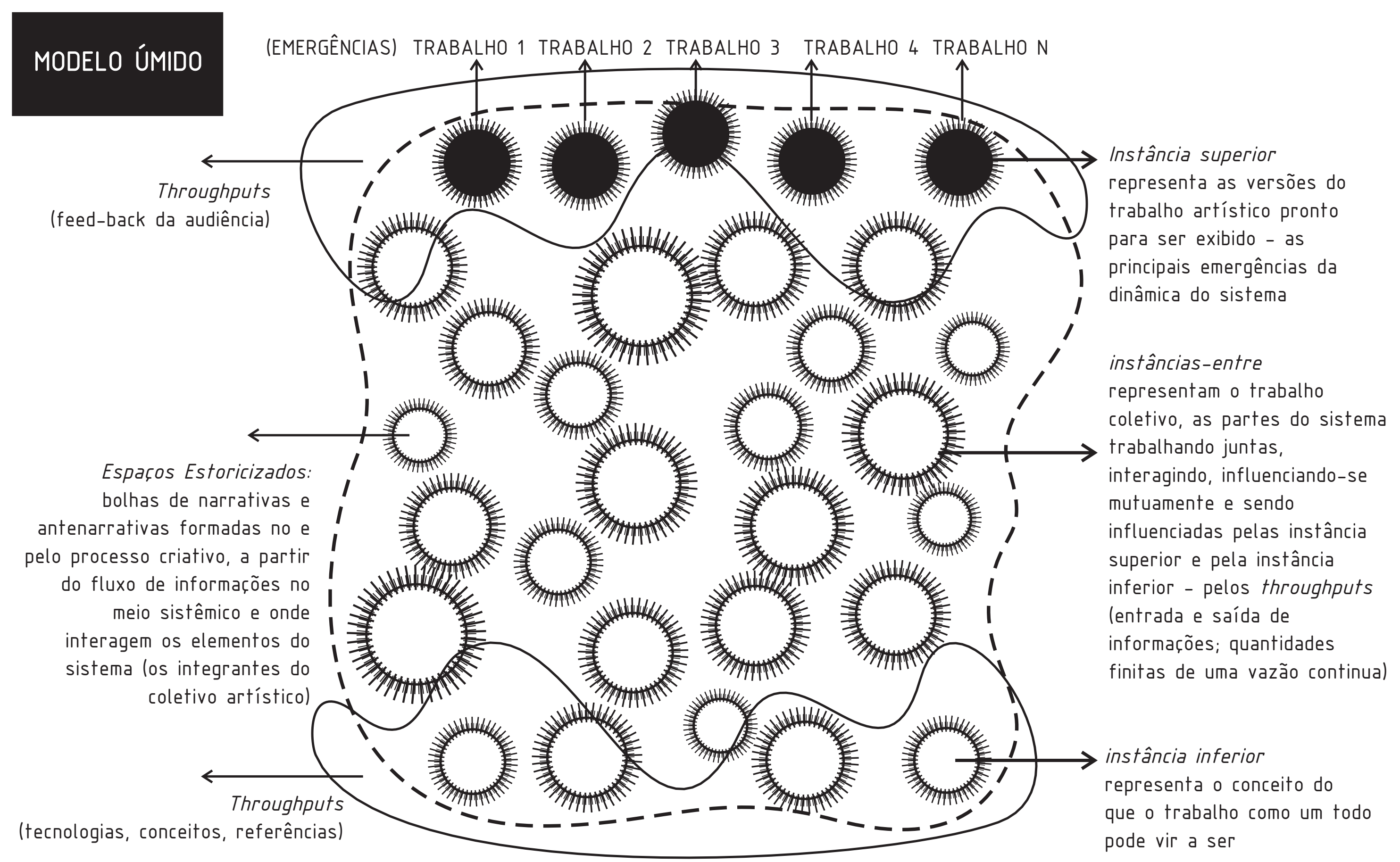

* Para além das três instâncias aqui referidas está o ambiente/contexto que influencia todos os níveis ou instâncias, em um processo regido pelas definições de abertura e fechamento do próprio sistema, definicões que regulam a troca de informações com o ambiente. 

A metáfora para a construção do modelo é a de um meio úmido, moist media, no qual a informação circula como que em um fluido de dados e não através de conexões lineares. As conexões são multidimensionais e podem acontecer em diversos niveis de realidade e de percep̧ão dos sujeitos.

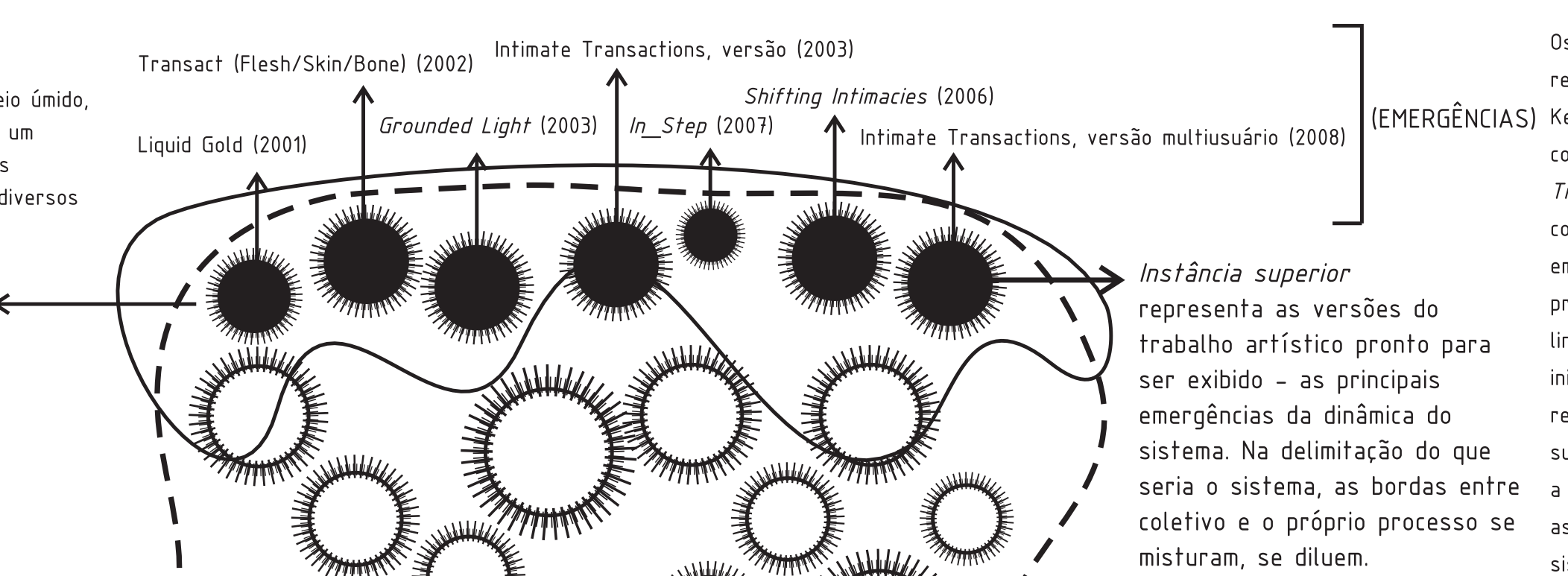
realizados sob a direção de Keith Armstron conjutamente com integrantes do coletivo Transmute, podem ser lidos como emergências na medida em que são fruto de um processo organizacional nãolinear, sensivel às condiçoes hiciais, e se configuram como resultados não-obvios e (feed-back da audiência) que da linguagem em cada uma das emergências ou trabalhos

produzidos, trazendo ainda referências que são incorporadas no processo a partir do repertório dos participantes.

Espaços Estoricizados: bolhas de narrativas e antenarrativas, formadas no e pelo processo criativo, a partir do fluxo de informações no meio sistêmico e onde interagem os elementos do sistema los integrantes do coletivo artísticol Throughputs
transferência de dados, informação em
fluxo nas bordas do sistema, podendo
se referir a tecnologias, conceitos,
referências, entre uma infinidade de
outras entradas.
Podemos mencionar aqui, ideias como a
de transferência de energia numa
prática performática, a partir de
influência de métodos e conceitos de
práticas Japonesas de performance;
ou as referências à questão da
subjetividade humana a partir de Tony Fry e Felix Guattari, para citar alguns.
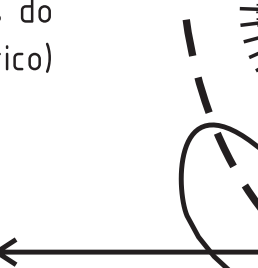
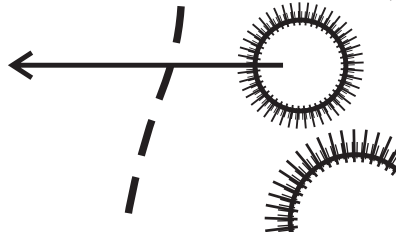

I 1

 1 (1) N iv

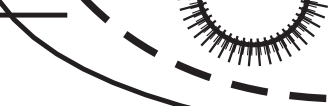<smiles>CCC1CCCC1CC</smiles>

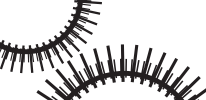

। misturam, se diluen. surpreendentes, imprevisíveis, partir das interações entre as partes (integrantes) do sistema e destas com ambiente.

\section{instâncias-entre}

representam o trabalho coletivo, as partes do sistema trabalhando juntas, interagindo, influenciando-se mutuamente e sendo influenciadas pelas instância superior e pela instância inferiore - pelos throughputs lentrada e saída de informações; quantidades finitas de uma vazão continua). 0 sistema, é sistema/proceso criativo coletivo o sistema/processo vai além do sistema/coletivo; o coletivo não é um uma caixa, um conjunto fechado. 0 coletivo é mutante, incorpora novos membros, seus membros interagem além de seus limites.

* Para além das três instâncias aqui referidas, está o ambiente/contexto que influencia todos os nivveis ou instâncias, em um processo regido pelas definicões de abertura e fechamento do próprio sistema, definiçōes que regulam a troca de informações com o ambiente.

Podemos considerar que, num nivel metafórico, os elementos do sistema podem estar en algum nivel entrelaçadas quanticamente na medida em que esse sistema complexo adaptativo, não pode ser separado de seu contexto ou anbiente, assumindo una forma dinâmica evolucionaria en diálogo com o contexto, através da entrada e saída de dados. 0 diretor artístico Keith Armstrong é peça chave na integração da auto-observação ao sistema. 0 processo de observação que realiza, é a medida e existêncía do entrelaçamento.

instância inferior

representa o conceito do que o trabalho como um todo pode vir a ser: a idéia de uma praxis ecosófica direciona e influencia os processos organizacionais do sistema, na medida em que se estrutura uma busca pelo papel que poderia desempenhar, a produção de arte

digital, nas possibilidades de engajamento com a questão ecológica. 



\section{MODELO UMIDO}

\section{Coletivo O Duplo}

A metáfora para a construção do modelo é a de um meio úmido, moist media, no qual a informą̧ão circula como que em um fluido de dados e não através de conexões lineares. As conexões são multidimensionais e podem acontecer em
diversos niveis de realidade e de percep̧ão dos sujeitos.

(feed-back da audiência) que possibilita revisão da estrutura e da linguagem em cada uma das emergências ou trabalhos produzidos, trazendo ainda referências que produzidos, trazendo ainda referências que
são incorporadas no processo a partir do repertório dos participantes.

Espaços Estoricizados: bolhas de narrativas e antenarrativas, formadas no e pelo processo criativo, a partir do fluxo de informações no meio sistêmico de informaçooes no meio sistêmico
onde interagem os elementos do sistema los integrantes do coletivo artísticol

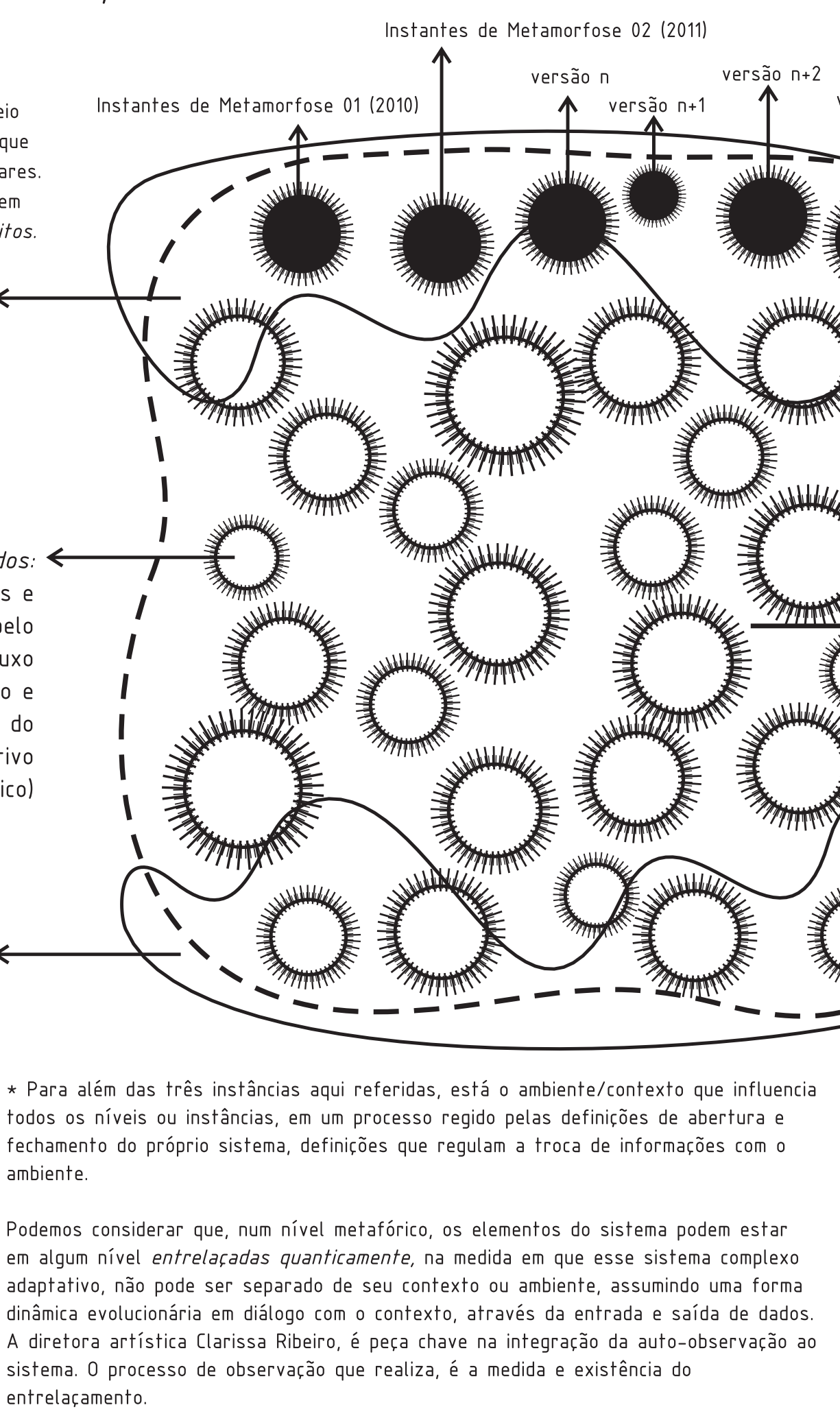

transferência de dados, informação en fluxo nas bordas do sistema, podendo se referir a tecnologias, conceitos, referências, entre uma infinidade de outras entradas.

Podemos mencionar aqui as idéias de construção dialogada do eu e da realidade em processos autoorganizationais, as referências em literatura a trabalhos de Jorge Luis

Borges e Clarice Lispector, os conhecimentos sobre a plataform Processing, entre outros sistema. 0 processo de observação que realiza, é a medida e existência do
Os diversos trabalhos realizados pelo coletivo 0 (EMERGÊNCIAS) Duplo podem ser lidos como emergências na medida em que são fruto de um processo organizacional nãolinear, sensivel às condiçoes iniciais, e se configuram como resultados não-obvios e surpreendentes, imprevisíveis, a partir das interaçōes entre as partes (integrantes) do

1 ser exibido - as principais

I emergências da dinâmica do seria o sistema, as bordas entre sistema, e destas com o misturam, se diluem. ambiente.

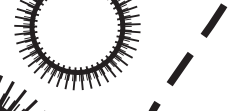

\section{instâncias-entre}

representam o trabalho coletivo, as partes do sistema trabalhando juntas, interagindo, influenciando-se mutuamente e sendo influenciadas pela instância superior e pela instância inferior - pelos throughputs (entrada e saída de informações; quantidades finitas de uma vazão continua). 0 sistema, é sistema/proceso coletivo - o sistema/processo vai além do sistema/coletivo; o coletivo não é um uma caixa fechado 0 coletivo é mutante, incorpora novos membros, seus membros interagem além de seus limites.

representa o conceito do que o trabalho como um

todo pode vir a ser: a idéia de trabalhar com a

construção de experiências subjetivas que sejam simultaneamente processos de construção do eu e da realidade, do espaço, de espaços estoricizados: processo de aquisição de uma consciência multidimensional, explorando diversos niveis de realidade e seus desdobramentos. 
